\title{
Community Gardens as Third Places
}

\author{
Joanne Elizabeth Dolley ${ }^{1}$
}

MSc Environmental Science; Griffith University, 2012

Grad Dip Ed; Canberra University, 1986

BSc Australian Environmental Studies; Griffith University, 1985

Griffith School of Environment \& Science, Griffith University

Submitted in fulfilment of the requirements of the degree of Doctor of Philosophy

Submitted 23 May 2019

${ }^{1}$ Formerly Joanne Pascoe 


\begin{abstract}
Third place ${ }^{2}$ is a concept which describes informal neighbourhood meeting places outside of home (first place) or work (second place). This thesis applies the concept to community gardens and in doing so, relates the findings to the social challenges associated with increased urbanisation and population mobility. Previous studies ${ }^{3}$ have made direct reference to community gardens being third places, however, this thesis is the first time the connection has been systematically investigated. In doing so, this thesis engages with theories of placemaking, social capital, neighbourhood resilience, and implications for the UN Sustainable Development Goal 11.7 on providing safe and inclusive green spaces. A qualitative case study approach is taken and a framework based on the eight characteristics of third place, has been applied to six case study community gardens (five in Australia, one in Denmark).

Third place is an ideal concept to understand community gardens because it is able to link research on social relations to research on placemaking. Community gardens are dynamic citizen-initiated places that have the potential to be responsive to the specific physical and social needs and preferences of the neighbourhood over time. This thesis contributes to placemaking research by providing insights into designing, building and supporting meaningful third places and in supporting the people who create and maintain community gardens. The thesis critically engages with social capital and placemaking theories by adding insights into how community gardens can function as third places with a communal purpose that is inclusive across socially diverse neighbourhoods, within and beyond the garden boundaries.
\end{abstract}

Thirty years on from Oldenburg's book on third places, "The Great Good Place", this thesis critically engages with the concept and adds insights in relation to gender in public spaces and the role of social media in third places. This thesis produces an original model that demonstrates how community gardens can operate simultaneously as a club and a third place, thereby encouraging the formation of both weak ties of association and strong ties of bonding social capital. These are important because they can foster both active and

\footnotetext{
${ }^{2}$ Oldenburg, 1989

${ }^{3}$ Firth, Maye \& Pearson, 2011; Glover, 2004; Thompson \& Maggin, 2012; Calderon, et al. 2014; Veen et al, 2015
} 
passive engagement, leading to improved neighbourhood resilience for individuals and local neighbourhoods. It was found that community gardens that act as third places ameliorate some urban challenges such as increased isolation and alienation experienced by many in cities. They improve the sense of community, as they offer opportunities for conversations within and outside the garden membership thereby assisting in introducing new people to the neighbourhood and increasing local social capital, which along with improved local food security, improves neighbourhood resilience.

Drawing together the placemaking and social capital findings, the thesis provides a number of suggestions that may inform the design of third place community gardens. The framework could be implemented as indicators for progress in achieving UN Sustainable Development Goal 11.7 to provide safe and inclusive green spaces. Given that community gardens which are third places can exhibit qualities that help improve wellbeing in urban communities, local councils can create social benefits from reducing barriers to community garden participation and increasing access to space and resources. This thesis is significant because it sheds light on the critical role that community gardens that are third places can play in an increasingly urbanised world where there is concern about social isolation and the lack of inclusive, safe and accessible public places. 
This work has not previously been submitted for a degree or diploma in any university. To the best of my knowledge and belief, the thesis contains no material previously published or written by another person except where due reference is made in the thesis itself.

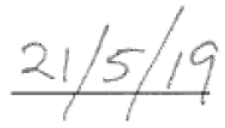




\section{Acknowledgements}

The first note of appreciation goes to the community garden participants who generously gave their time to be interviewed and invited me to their meetings.

Thanks Adrian for your interest, knowledge and wise words and for bringing me methodology books, appropriate portions of chocolate and timely cups of tea.

Thanks go to Jago Dodson for taking me on and starting me off on the $\mathrm{PhD}$. Thanks also to Neil Sipe for taking over the reins and introducing me to Ray Oldenburg.

Thanks Michael Howes for stepping in when supervisors departed and providing excellent guidance and resources and for giving me the opportunity to teach.

Special thanks go to Caryl Bosman who has been with me on the whole journey, including an actual journey to Copenhagen and Odense for our Griffith/Southern Denmark Uni grant. Caryl has been enthusiastic about the project and a good friend.

I'd like to thank Jens Troelson for collaborating on the USD project and Lars Breum Christiansen for kindly setting up three case study sites and interpreting.

I'd also like to thank all the authors on the third place book who were able to run with their topic to produce fascinating chapters. Thanks especially to Professor Ray Oldenburg, who at 83 years old, took an interest in my thesis and provided an insightful foreword for the book.

And my friends at the Cities Research Institute - Hadi, Anne, Pazit, Abraham, Matt, Shilpi, Ben, Mark, Greg, Tony, Ed, Kara, Cara, Sima, Claire, Prosper, Barbara, Bruno, Yulia, Xuna, Vik, Cheryl, Letitia, Diane and the rest of the gang...thanks for the fun. Thanks also to CRI Director, Paul Burton, for his encouragement and thanks School of Environment and Science staff for academic, administrative and financial support.

Plus thanks to GUPSA who provided writing support and fabulous parties.

I thank my friends, Katie, Kim, Christine, Clare and Crisia for their encouragement. Last but definitely not least, I thank my lovely daughter Rose Pascoe. 
TABLE OF CONTENTS

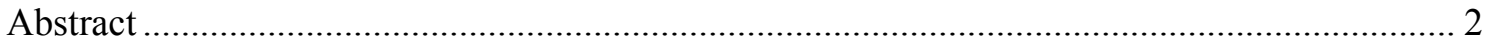

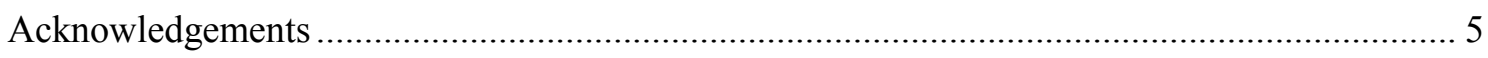

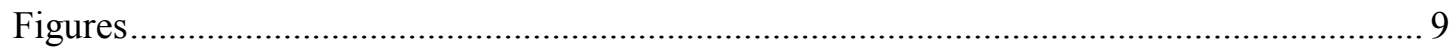

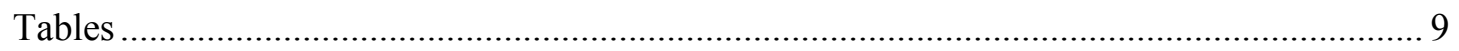

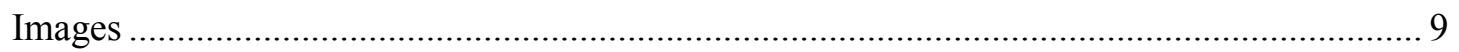

List of publications and media derived from this thesis to date .................................................. 11

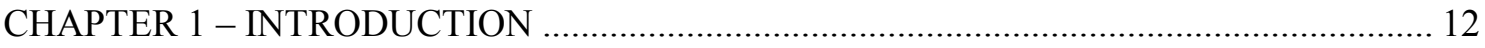

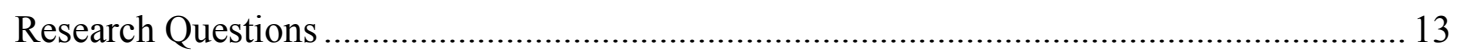

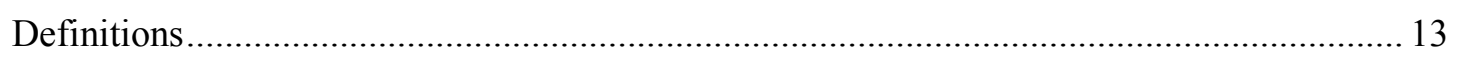

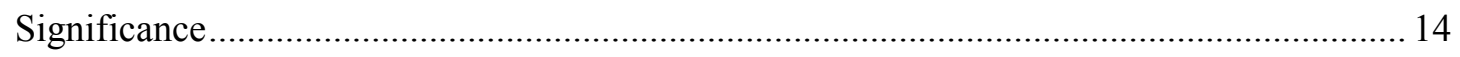

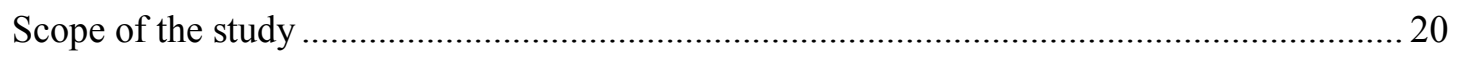

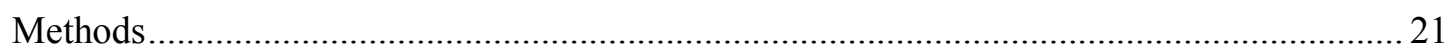

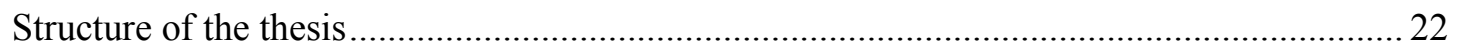

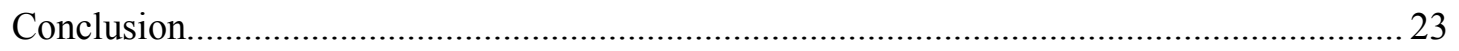

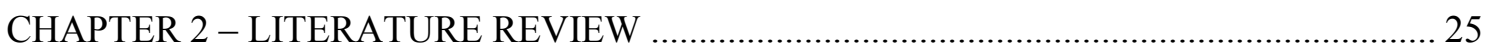

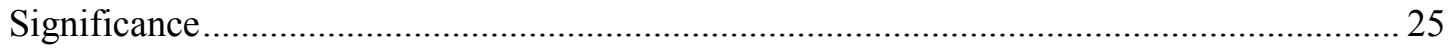

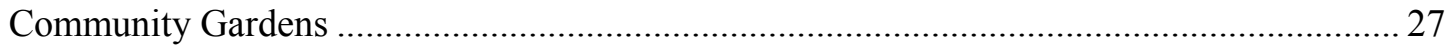

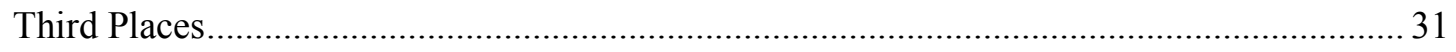

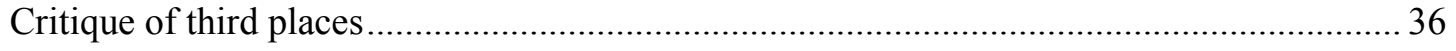

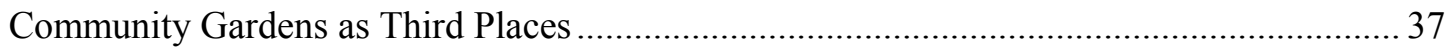

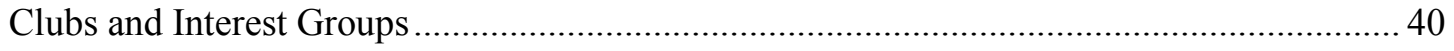

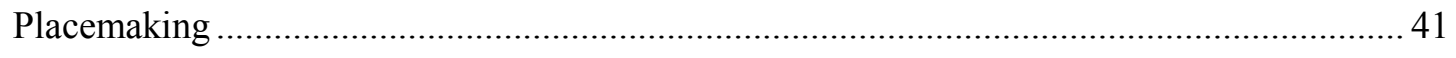

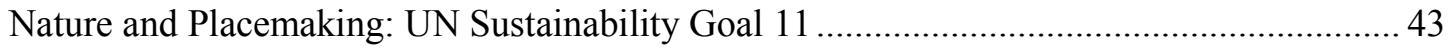

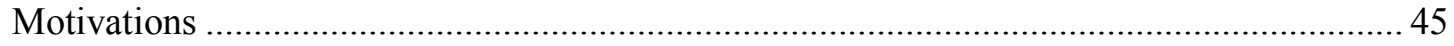

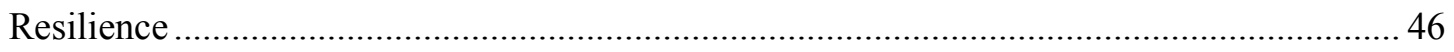

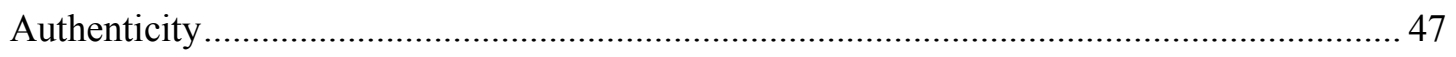

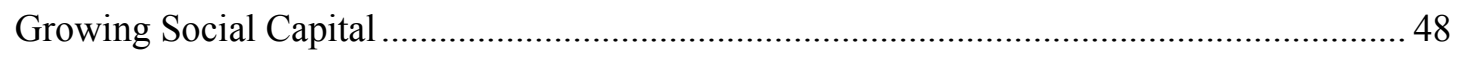

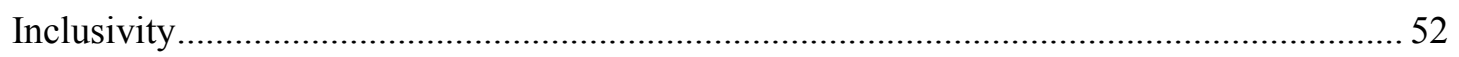

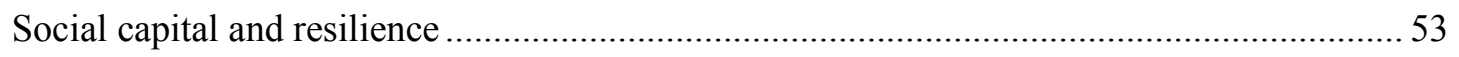

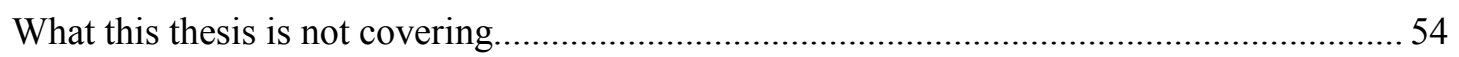

Community Garden Design and Planning Policy Implications............................................. 54

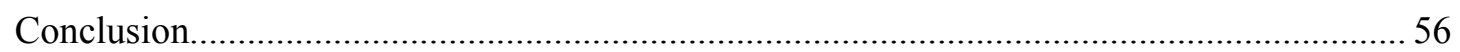

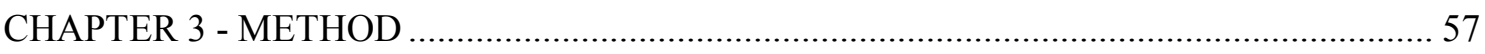

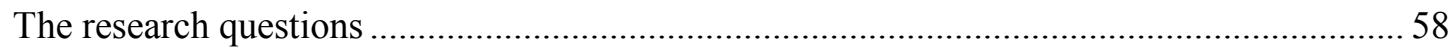




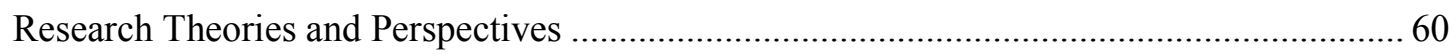

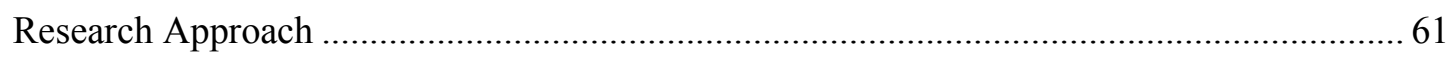

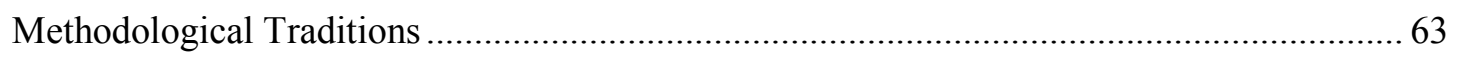

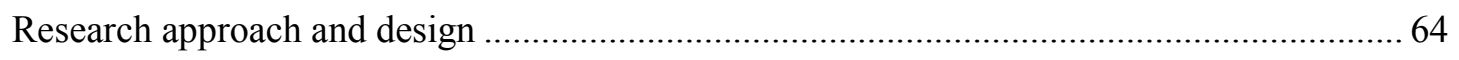

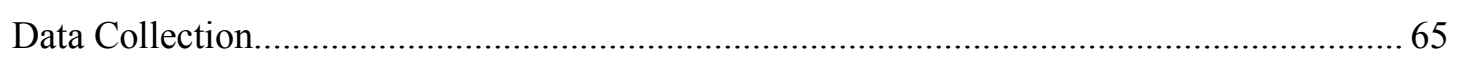

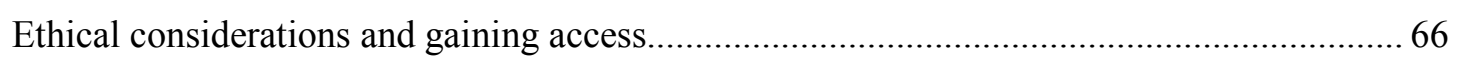

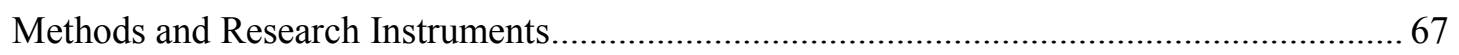

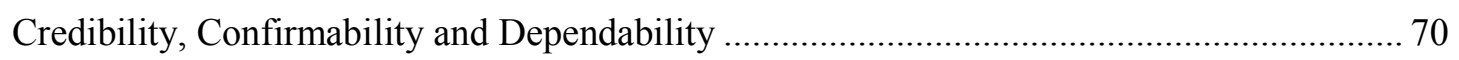

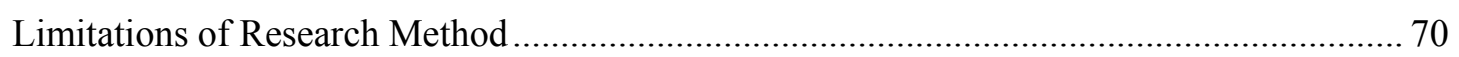

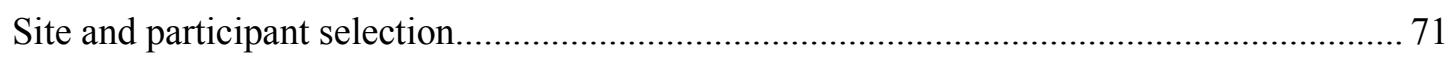

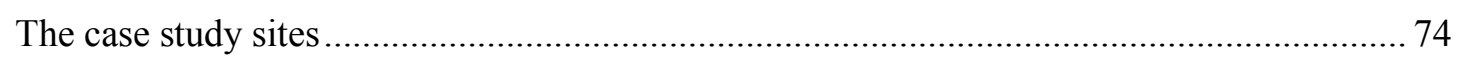

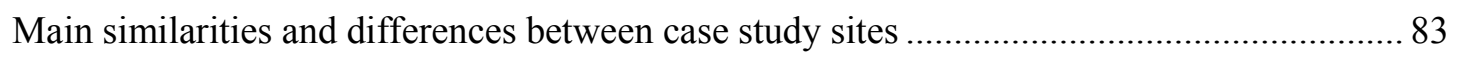

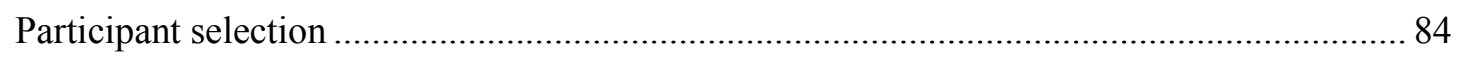

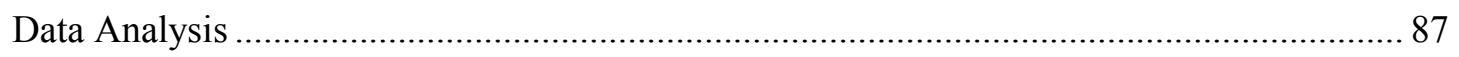

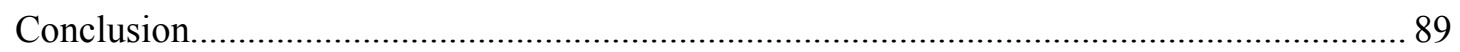

CHAPTER 4: FINDINGS - ARE COMMUNITY GARDENS A THIRD PLACE? .................. 90

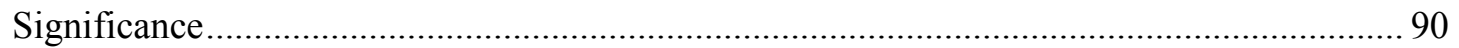

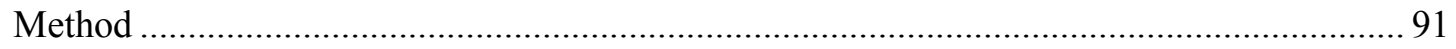

Results and analysis - Case Study Findings .......................................................................... 94

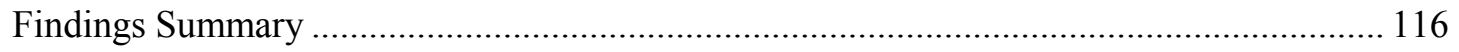

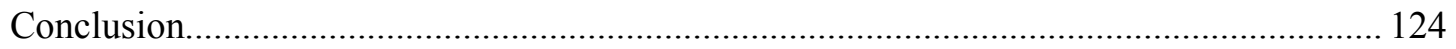

CHAPTER 5 - PLACEMAKING COMMUNITY GARDENS .............................................. 128

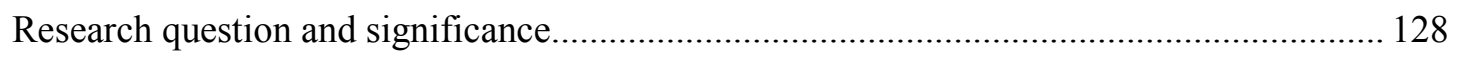

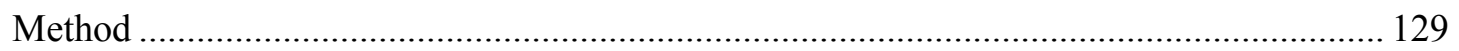

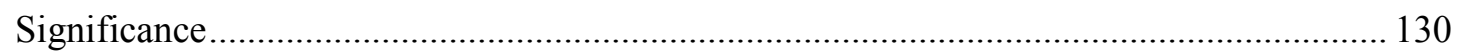

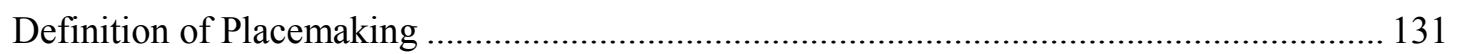

Placemaking characteristics of third place community gardens........................................... 132

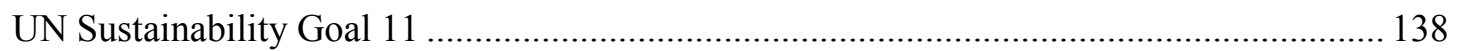

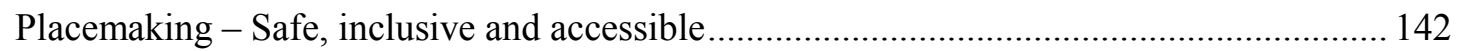

Placemaking in relation to population mobility ............................................................. 146

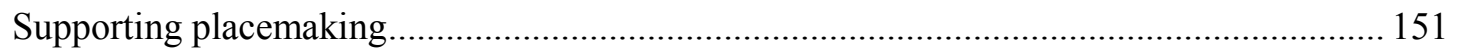

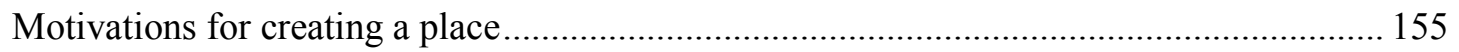

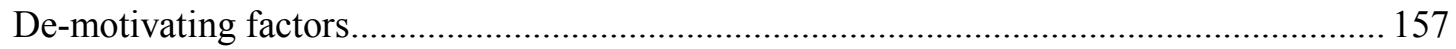

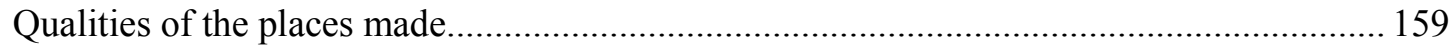

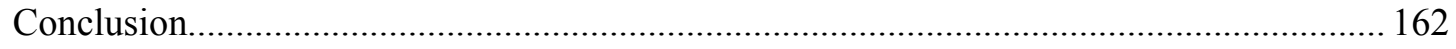

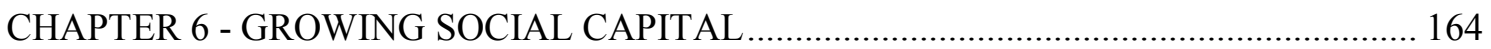




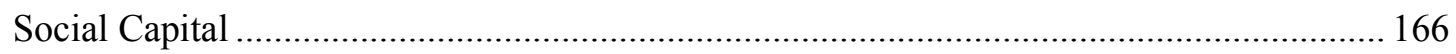

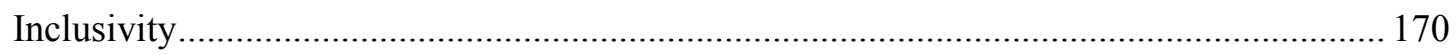

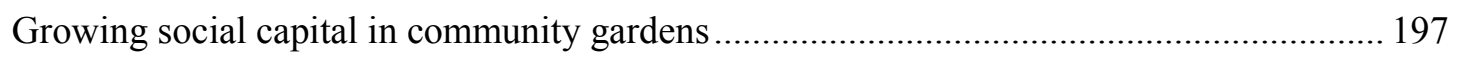

Third place model and social capital generation ................................................................ 203

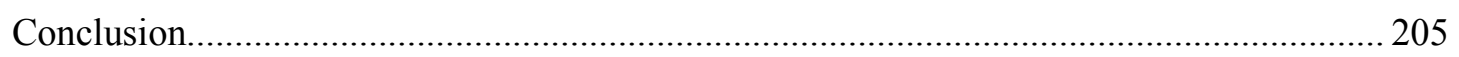

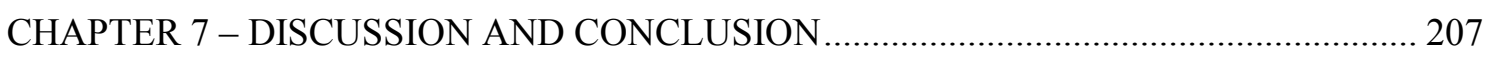

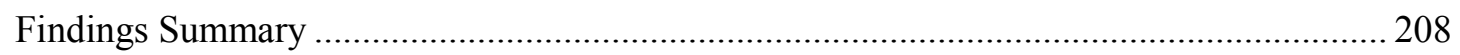

Question 1: To what extent are community gardens third places? ........................................ 208

Question 2: If a community garden is a third place, does it play a role in placemaking?.... 212

Question 3: Do third places which have a communal purpose (i.e. community gardening)

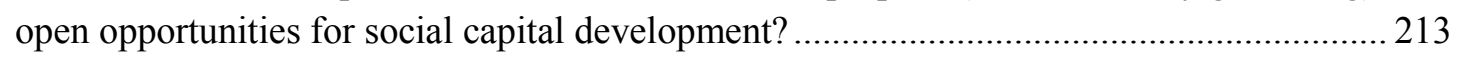

Integrating placemaking, social capital in the third place framework.................................. 216

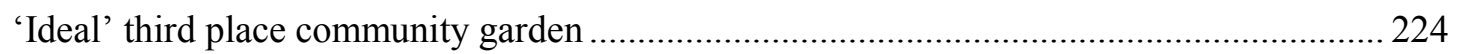

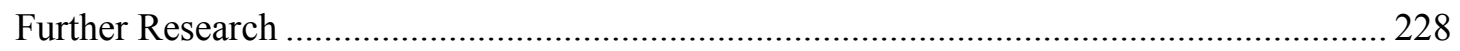

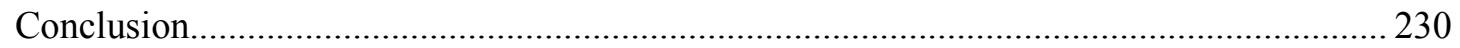

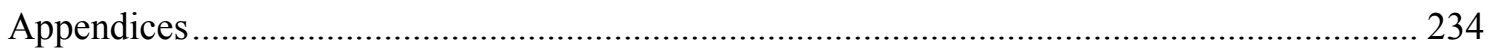

Appendix 1 Published conference paper - co-authored (open access).................................... 234

Appendix 2 Book chapter (Removed. Confidential due to copyright) ........................... 237

Appendix $3 \quad$ Book chapter - co-authored (open access) …………………................... 238

Appendix $4 \quad$ The Conversation Article - co-authored (open access)............................... 265

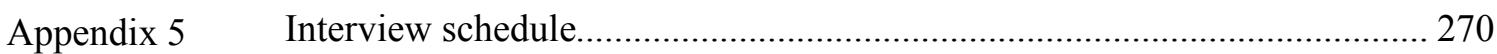

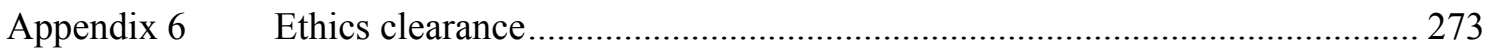

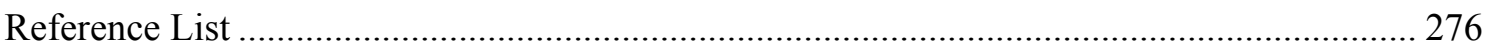




\section{Figures}

Figure 3.1 Research Questions...59

Figure 3.2 Research Questions in relation to third place characteristics...60

Figure 3.3 Semi-structured interview schedule checklist...68

Figure 4.1: Community gardens as a third place...119

Figure 4.2: Third place characteristics as they apply to the research questions...123

Figure 5.1: Situating the placemaking research question...129

Figure 6.1: Situating the social capital research question...165

Figure 6.2 Community garden third place model - Situating social capital...204

\section{Tables}

Table 1: Third Place in the Community Garden Literature...38

Table 3.1: Characteristics of the six case study sites...72

Table 3.2 Case study site participant details...87

Table 4.1: Summary of case study site features...91

Table 4.2: Community gardens data against third place framework...95

Table 4.3.1: Accessible and Accommodating...99

Table 4.3.2: Playful mood...101

Table 4.3.3: Low profile...103

Table 4.3.4: Home away from home...105

Table 4.3.5: Neutral...107

Table 4.3.6: Leveller...110

Table 4.3.7: Regulars/characters...113

Table 4.3.8: Conversation...116

Table 4.3.9 - Summary of that community gardens are third places...117

Table 7.1 Integrating placemaking, social capital in the third place framework: The case of community gardens...217

Table 7.2: Suggested Third Place Community Garden Features...227

\section{Images}

Image 3.1 Kookaburra Community Garden...75

Image 3.2: Kookaburra Community Garden - individual plots behind high fence...75

Image 3.3 Pine Park Community Garden...76

Image 3.4: Pine Park Community Garden - individual plots...77

Image 3.5: Marville Community Garden next to freeway...78

Image 3.6: Frank Street Community Garden...79

Image 3.7: Frank Street Community Garden- community composting...79

Image 3.8: Bluevale City Garden - children's play area...81

Image 3.9: Bluevale City Garden - Education and administration building...81 
Image 3.10: Library Community Garden...82

Image 5.1: Marville Community Garden (pseudonym) growth from 2016 to 2018...132

Image 6.1: Highrise garden plots at Kookaburra Community Garden at the Gold Coast...183 


\section{List of publications and media derived from this thesis to date}

\section{$\underline{\text { Published Conference Paper }}$}

Pascoe, J. \& Howes, M. (2017). A Growing Movement: Motivations for Joining

Community Gardens. Presented at the Sustainable Development and Planning 2017, Bristol, United Kingdom (2017). (Appendix 1)

\section{$\underline{\text { Edited Book }}$}

Rethinking Third Places: Informal Public Spaces and Community Building, (2019)

Edward Elgar Publishers, UK.

\section{Book Chapters}

Dolley, J. (2019) Third places and social capital: Case study community gardens, in Rethinking Third Places: Informal Public Spaces and Community Building, Edward Elgar (Appendix 2)

Bosman, C. \& Dolley, J. (2019) Rethinking Third Places and Community Building, in Rethinking Third Places: Informal Public Spaces and Community Building, Edward Elgar Publishers (Appendix 3)

\section{Journal article}

$\underline{\text { Under revise and resubmit }}$

Dolley, J. Community gardens as third places, Geographical Research

\section{$\underline{\text { Media }}$}

2018: The Conversation March 22, "Many people feel lonely in the city, but perhaps 'third places' can help with that" (Initiated by Joanne Dolley, co-authored with Dr Tony Matthews). 9,975 views in 4 weeks; 19,162 to date. (Appendix 4):

https://theconversation.com/many-people-feel-lonely-in-the-city-but-perhaps-thirdplaces-can-help-with-that-92847

8/7/19 - ABC Radio Australia Myf Warhurst's radio show discussing the book and third places.Link (audio no longer available): https://www.abc.net.au/radio/programs/myfwarhurst/myf-warhurst/11269438

29/7/19 - Life Matters (ABC Radio National) about third places and in particular her chapter on community gardens as third places. Podcast can be accessed at: https://www.abc.net.au/radionational/programs/lifematters/making-friends-in-yourneighbourhood-through-third-places/11355298

13/4/18: Newcastle Herald. “"Third places' where urban loneliness doesn't dwell” https:// www.newcastleherald.com.au/story/5340934/third-places-where-urban-loneliness-doesnt-dwell/ 


\section{CHAPTER 1 - INTRODUCTION}

"Life without community has produced, for many, a life style consisting mainly of a home-to-work-and-back-again shuttle. Social well-being and psychological health depend upon community" (Oldenburg, 1997, p. 7)

The purpose of this thesis is to explore the third place aspect of a range of community gardens and in doing so, relate the findings to social challenges associated with increased urbanisation and population mobility. The concept of third place, developed by Ray Oldenburg, can be summed up as, "informal public gathering spaces". Compared to the familiarity of home (first place) and the formality of work/school (second place), third places allow opportunities for a diverse population to interact informally in their neighbourhood (1997, p. 6). Community gardens have been described as third places in several studies, however, the concept has not, until now, been systematically investigated across a range of types of community gardens in a range of locations. In response to a perceived loss of informal gathering places in the USA, urban sociologist, Ray Oldenburg, developed the concept of 'third place' (1989). Third place is an ideal concept to apply to a community garden case study for its ability to link research on social connections to research relating to place. This study collected and analysed interview data from 29 participants across five Australian community gardens (one Gold Coast, one Sydney and three Brisbane) and one Danish community garden in a qualitative case study investigation to explore if they are third places. It builds upon the literature on community gardens, placemaking, social capital and neighbourhood resilience. In doing so this research significantly contributes to bodies of knowledge about the urban condition and concerns around resilience and sustainability.

A key concern of this thesis is to explore the relations that individuals and communities have with each other and the places they inhabit. The aim is to investigate community gardens to determine if they are places in which people connect in a meaningful way with each other and to their place in their local community. It seeks to determine the impact of these sites on modern urban challenges such as social isolation and population mobility. The research is focussed on the local scale and provides insights for people who design and build community gardens which are third places, as well as informing the design of other meaningful public spaces. 
Planners, architects and other design specialists may design public places intended to promote third place interactions, however, community gardens, are often designed and created by the local residents themselves for use by the local neighbourhood in response to local needs and conditions. This thesis posits community gardens as third places with a communal purpose, strengthen weak ties (bridging capital) within local place-based neighbourhoods. For members they also act as clubs where strong ties (bonding capital) of friendship are built. This thesis concentrates on the weak ties, which grow neighbourhood familiarity and build local social capital with potential to improve community wellbeing and neighbourhood resilience. This thesis also relates the role of third places in bringing together locals and newcomers, to the challenges of population mobility.

\section{Research Questions}

In order to determine if community gardens are third places, the first research question is:

1. To what extent are community gardens third places? Do community gardens fit the eight characteristics of a third place?

As will be discussed in the methods section, the eight characteristics of third place serve as a framework for analysing this question. Informed by the literature, a further two questions arose in relation to community gardens as third places.

2. If a community garden is a third place, does it play a role in placemaking?

3. Do third places that have a communal purpose (i.e. community gardening) open opportunities for social capital development?

The two broad themes of placemaking and social capital highlight the importance and relevance of the findings to challenges arising from population mobility and urbanisation, such as social isolation and alienation. In addition, questions 2 and 3 place the critical focus alternately on placemaking and then on social capital.

\section{Definitions}

As will be explored in the literature review (Chapter 2), the component topics of the three research questions are contested and justification for the chosen definitions is arrived at in Chapter 2. However, to make sense of the introduction, relevant definitions are 
presented below without debate in the first instance. The following definition of community gardens has been derived from the literature for this thesis:

Public gardens, including a food growing purpose, established and/or maintained by members of the community for the benefit of individuals and the community.

The concept of third place can be summed up as "informal public gathering spaces" (Oldenburg, 1997, p. 6). Third places provide opportunities for local people to meet and interact on neutral ground and get to know people in their neighbourhood (Oldenburg, 1999).

There is no definitive definition of placemaking that best suits discussion on community gardens which are third places, so the following definition of placemaking has been devised for this thesis from a combination of elements of the definitions discussed in Chapter 2:

Placemaking is a dynamic act of people collaboratively transforming public space into public places that increase the social life and sense of belonging to a local area.

For the purpose of this thesis, the following definition of social capital will be applied to this research:

"Social capital refers to connections among individuals - social networks and the norms of reciprocity and trustworthiness that arise from them." (Putnam, 2000, p. 19)

This thesis refers to 'neighbourhood resilience' as it links to the specific place of the neighbourhood, rather than 'community resilience' which implies an existing cohesive community of people (Stevenson and Petrescu, 2016). However, the following Black and Hughes' definition of community resilience is useful for describing resilience:

"...able to respond effectively and bounce back in the face of adverse circumstances, whether these be economic, environmental or social" (Black \& Hughes, 2001, p. 16).

\section{Significance}

The research is important for a number of reasons which cover context; the timing of the research; addressing a gap in the literature; and contributing to the literature and policy 
on a range of topics including placemaking, social capital and UN Sustainable Development Goal 11. Urbanisation has been associated with increasing levels of anxiety; loss of sense of community; anonymity and loneliness; and alienation from nature (Auge, 1995; Nursey-Bray et al., 2014; Putnam, 2000). The $21^{\text {st }}$ century has seen ongoing migration to urban environments worldwide with more than $50 \%$ of the world's human population living in cities and UN projections of $75 \%$ of the population living in cities by 2050 (Hollis, 2013). It is timely to consider how to address challenges associated with increasing urbanisation.

Research on community gardens is timely because community gardening is a growing trend in a number of countries including Australia, Singapore, Scotland, Italy, Taiwan, the USA and Canada (Australian Community Gardens Network, 2014; Celata \& Coletti, 2017; Cumbers et al., 2017; Hou, 2018; Tan and Neo, 2009; Walker, 2015). The number of community gardens can be difficult to determine as many are informal and not registered (Mintz \& McManus, 2014). The total number of community gardens registered with Australian City Farms \& Community Gardens Network (ACFCGN) ${ }^{4}$ is 604 in May, $2019 ; 18,000$ to 20,000 community gardens in the USA and Canada combined in 2007; and from first starting in Singapore in 2005 with 240 community gardens in 2019 there are 1,400 registered (Australian Community Gardens Network, 2019; Birky \& Strom, 2013; Communities in Bloom, 2019; Tan \& Neo, 2009). Given that there is limited open space within urban areas, community gardens are in some cases situated in contested public space, in competition for the use of the space against commercial or other community uses. If community gardens fulfil the role of third places, this positively impacts their value to urban neighbourhoods.

This thesis fills a lacuna in the study of community gardens, specifically, whether community gardens act as third places. It is apparent that across community gardens studies internationally that some third place characteristics are in evidence (Firth, Maye \& Pearson, 2011; Glover, 2004; Thompson \& Maggin, 2012; Calderon, Blackstock, Lea, \& Fels, 2014; Veen, Derkzen \& Visser., 2015). This thesis seeks to systematically test the connection.

\footnotetext{
${ }^{4}$ The Australian City Farms \& Community Gardens Network (ACFCGN) is conducting another survey in 2019 to update their audit of community gardens. 604 is the number of registered gardens in Australia with the https://communitygarden.org.au/ in May 2019. Note that two of the three case study Brisbane gardens are not registered here.
} 
Oldenburg's (1999) initial examples of third places include cafes, barbers, pubs and piazzas. The third place concept has been applied to place-based research to include other public places such as libraries (Houghton et al., 2013), market places (Mele, 2015), franchised food outlets (Jones, et al., 2015), pop up parks (McGlone, 2016) and virtual spaces (Steinkuehler \& Williams, 2006; Williams \& Kim, 2019). Community gardens have also been described as third places in a number of studies, however, the assertion has not been systematically and critically investigated (Calderon et al., 2014; Firth, Maye \& Pearson, 2011; Glover, 2004; Thompson \& Maggin, 2012; Veen 2015). This study uses data from six Australian community gardens in a qualitative case study to investigate if they are third places and what the implications of this may be for population wellbeing and planning policy.

This research is important for uniquely drawing together a range of social theories, as covered in the literature review. The community garden is a combination of a cultural landscape (community) and natural landscape (garden) in an urban landscape. The relationship between community and place as demonstrated through community gardens will draw on various concepts and theories of place and social capital. This research will also fill a gap in the literature by expanding on and critically engaging with the third place concept. The thesis will also expand the research on third place into the community garden literature.

Urban planners are largely concerned with understanding and finding solutions for urban constructs such as liveable cities, child-friendly cities, knowledge cities, walkable cities, healthy cities and active-aging cities (Alidoust, Holden and Bosman, 2014; Gleeson and Sipe, 2006; McGlone, 2016). The fact that there are so many kinds of re-imagined cities indicates that the experts perceive challenges in cities which need to be solved. Lefebvre discussed the "destructive social and environmental consequences" of an increasingly urbanised planet in his "dissolving city" concept (Wachsmuth \& Brenner, 2014). The utopian city has not been created. People's "receptivity" or tolerance of strangers in cities is low (Montgomery, 1998, p. 96). As citizen-led places, community gardens which act as third places increase the number of informal interactions between people in the neighbourhood therefore have potential to reduce the number of 'strangers' in the neighbourhood. 
The range and role of motivations of community gardeners will be included as part of the research design in order to examine the diversity of participants in community gardens and comment on the potential for community building. This thesis focuses on the "community" in community gardens. It investigates if community gardens as third places have potential to increase social capital via informal local connections. Social researchers have shown that increased alienation in cities in an increasingly globalised society lead to the demise of sense of community, which has implications for people's sense of place, their feelings of trust, safety, happiness and wellbeing (Jacobs, 1996; Frumkin, 2003; Son, 2010; Sennett, 2012; Easthorpe \& McNamara, 2013; Vic. Health, 2011). Jacobs (1996, p. 74) discussed the implications as: "When contact between social groups collapses, so people trust and care about one another less and there follows a widely felt loss of sense of 'community"'. Reduced interaction between social groups can lead to loss of trust, care and sense of community (Jacobs, 1996). Putnam (2000) lamented the demise of community in his book, "Bowling Alone", in which he described the decline of group participation in public recreational activities and corresponding isolation of individuals within neighbourhoods. He noted that leisure activities have become increasingly privatised and gave the example of the rise of home theatres. Add to that the reduction in the number of neighbourhood locales where people might have bumped into neighbours regularly. The local supermarket checkout has been automated; the video store has been replaced by vending machines and online movies; and self-serve fuel stations are tap and go. Increasing convenience and automation has reduced our opportunities for social interaction. When we are in the same place regularly with our neighbours, such as public transport, many of us are staring at our electronic devices, connected with friends through social media rather than interacting with fellow neighbours (O’Hare, 2019).

Third places allow local residents to socialise and as such, improve social capital through the development of weak ties. Community gardens are a place where gardeners, volunteers and visitors connect to the land and to each other. This research is concerned, in part, with how we meet people in the local neighbourhood and start to feel a part of the local community. In terms of social capital, community gardens which are third places, connect people together and connect across other groups, creating a multiplier effect. By being a third place, the goal or motivation of the community garden and its members, reaches out to more people in the community, which is of particular interest when they have a goal to educate about sustainability. Linking people across groups and connecting people to others who have different backgrounds and interests improves social cohesion 
and builds social capital which can improve a community's resilience to social, economic and environmental disturbances (Edwards, 2004; Aldrich, 2012, Black and Hughes, 2001). Social capital is a resource which can be called upon in order to "bounce back in the face of adverse circumstances" (Black \& Hughes, 2001, p.16).

This thesis critically comments on Oldenburg's assumptions that people in a third place will strike up conversations easily. Third places which are community gardens may prove more effective in their role of introducing new people to the local neighbourhood, as the activity of gardening and the number of topics of conversation around a garden help people to initiate a conversation. Conversation is a vital characteristic of third places in creating an enjoyable atmosphere and helping people to get to know each other (Oldenburg, 1999).

In addition, the third place concept was created in the late 1980s before social media was ubiquitous. The research will also briefly consider the role of social media in extending the placemaking opportunity of the community beyond physical confines of the community garden by providing information and contact details to potential participants. It will also consider the potential for social media to improve the networking capability and act as a resource for the community beyond physical confines of the community garden. This will be a critical addition to the third place concept, which focussed on faceto-face interactions.

This thesis will consider if community gardens which are third places can contribute to achieving UN Sustainable Development Goal 11 - Sustainable Cities and Communities and in particular, Goal 11.7, relating to provision of safe, inclusive and accessible, green and public spaces (UN, 2015). Community gardens promote social inclusion; aid in the conservation of green space; and can play a role in revitalising distressed neighbourhoods (Draper \& Freedman, 2010; Lyons, Richards, DesFours, \& Amati, 2013; Ohmer et al., 2009). Community gardens can combine culturally authentic use of green space as demonstrated in Latino Community Gardens in New York and Singapore community gardens (Saldivar-Tanaka \& Krasny, 2004, Tan \& Neo, 2009). This thesis provides qualitative discussion and examples of the role community gardens can play in relation to UN Goal 11.7 in terms of nature (green public spaces) and people (safe, inclusive and accessible). The author acknowledges that there are 17 United Nations' Sustainable 
Development Goals (UNSDGs) which are interrelated and this is particularly the case with community gardens which may relate to a number of goals, for example, UNSDG 2 (zero hunger), UNSDG 3 (good health and wellbeing), UNSDG 6 (water and sanitation) and UNSDG 13 (climate action) (Hall, Ross, Richards, Barrington, Dean, Head, Jagals, Reid and Hill, 2018; Lockie, 2016). However, the combination of community gardens and third place is particularly relevant to one target (11.7) of UNSDG 11 (sustainable cities and communities).

Community gardens are perceived to be worthwhile by many thousands of participants world-wide and their social and wellbeing benefits worth investigating. A community garden takes a great deal of time, resources and commitment to establish. There are many organisational hoops to jump through, starting with forming a group; convincing a landholder, either private or council, to allow access to valuable land; on occasion facing opposition from neighbourhood representatives; and fund raising and seeking sponsorship, all before one even gets to lift a shovel and turn the earth. Community gardens connect the social life and the environment and bring agriculture, albeit on a small scale, into the urban form.

This research has potential to inform land use policies that support the proliferation of community gardens. The development of a "third place with a communal purpose" framework also has potential value for investigating community aspects of other public infrastructure such as men's sheds, dog parks, skate bowls and council pools. Jivén and Larkham (2003, p. 79) argue that the, "values and views of the people occupying or using places are important" and designers, "should be informed to a much greater extent by the views of the people directly involved". The case study participant voices make a valuable contribution to community garden research and the findings provide insights for supporting designers and gardeners to better design third places and community gardens, where building social capital and sense of community is a goal.

The urban form affects population health and this thesis looks at the social and physical health impacts of community gardens which are third places. Particular to this thesis, facilities which attract visitors increase physical activity, encouraging walking or cycling, and have beneficial effects on the health of local people (Zapata-Diomedi, et al., 2019). Thompson and Maggin (2012, p. 398) discuss the lack of support and recognition of the health and social benefits of community gardens by decision makers and suggest that 
planners have a role in promoting the benefits of community gardens to local councils and providing facilities "to promote health and wellbeing". This thesis develops a model of community gardens which are third places. The findings potentially inform the design of third places and the design of community gardens, where building social capital and sense of community is a goal and where there is a goal to contribute to UN Sustainable Development Goal 11.7 to provide safe and inclusive nature-based public places.

\section{Scope of the study}

In seeking to determine if community gardens are third places, themes of placemaking and social capital development became evident and are explored in subsequent chapters. These two themes address several social challenges associated with urban living, namely population mobility; social isolation; making safe inclusive green spaces for people to enjoy; and increasing the resilience of local neighbourhoods.

Five articles specifically link the third place concept with community gardens, however third place is secondary to the topic of each of these papers. Third place is used to describe the community gardens as neighbourhood meeting places outside of home or work (Firth, Maye \& Pearson, 2011; Glover, 2004); places where local residents can get to know each other "in a healthy built environment" (Thompson \& Maggin, 2012, p. 398); and places where people can relax and get to know others in their neighbourhood (Calderon et al., 2014; Veen et al., 2015). Calderon et al. (2014, p. 190) went as far as mentioning several third place characteristics exhibited by community gardens, namely, "neutral nature, low profile and regulars". All five studies made the assumption that community gardens are third places, whereas this study is designed to examine the connection. The point of difference between this thesis and the aforementioned five studies claiming that community gardens are third places, is that those studies either applied a few of the characteristics of third places or the overarching essence of third place and claimed the said community garden/s to be third places, whereas this thesis systematically applies each characteristic of third place to each site. This study provides a thorough application of third place concept, and factors in a wide variety of community garden types and styles of operation.

This thesis cannot be all things to all researchers of community gardens or third place. The focus of the research on community gardens as third places was guided by the literature review on community gardens and third places. When studying community 
gardens as a case study, there are a multitude of directions one could take including: social justice (Lyons et al., 2013); alternative food movements (Cameron \& Wright, 2014); urban revitalisation (Thornton, Lyons \& Sharpe, 2018); gentrification (van Holstein, 2019); bio-diversity (Maller \& Farahani, 2018); addressing urban food deserts (Lewis, Galloway-Gilliam, Flynn, Nomachi, Keener and Sloane, 2011); food security (Singh-Peterson \& Lawrence, 2015); and sustainability (Houston, MacCallum, Steele \& Byrne, 2016). This thesis builds on an extensive body of literature on community gardens. It focuses on the social aspect of community gardens and their role in bringing people together as a third place. Third place is a suitable concept to apply for its ability to link research on social connections and place.

The thematic analysis of the data further clarified the range of the research. The findings provide insights which are applicable to the social science disciplines of human geography, including urban geography, and urban planning and covers topics of population mobility, placemaking and techniques of qualitative methods. The placemaking chapter also links to implications for UN Sustainable Development Goal 11.7. The UN Sustainable Development Goals are a global action, which require implementation at the local level (Holloway, 2017). The research focus of community gardens as a third place is at the local level, however the implications of the findings could be applied to global challenges.

\section{Methods}

The research method is detailed in Chapter 3 and includes justification of the choice of a qualitative case study. The characteristics of third place are used as a framework to determine if each case study community garden exhibits the characteristics of third place. The eight characteristics which make up a third place are described fully in the literature review and again as the framework of the research method. Twenty-nine interviews were conducted on site in six community gardens between 2014 to $2019^{5}$. The gardens were chosen in a range of ways including internet search, personal familiarity and through a research grant conducted in Denmark. They were selected to represent a range of types of community gardens within the definition provided, covering different designs; purposes; placement in relation to the members; openness to the public; and support from

\footnotetext{
${ }^{5}$ The length of time for data collection is due to the student being a part-time student.
} 
external bodies. As will be discussed in the methods chapter, the Denmark garden filled a particular type of garden (on commercial owned land and operated by a council authority) and provides an interesting international comparison.

This research aims to inform debate about wellbeing in cities and feed into planning policy on challenges of an ageing population; physical inactivity; social isolation; and environmentally sustainable urban development. The outcomes of the research are contextualised, but the findings and method are applicable to other community gardens and other public spaces which may be third places.

\section{Structure of the thesis}

This thesis begins with a review of the literature about third places and about community gardens in urban environments (Chapter 2). The literature review covers research on community gardens and third places, including describing each of the eight characteristics of third place and using the community garden literature as an example of that particular characteristic. The literature review also sets the global context of the research and covers concepts and theories of placemaking, social capital, resilience, population mobility and the UN Sustainable Development Goals.

The Methods chapter (3) presents the approach used to address the research questions of this thesis. It describes the characteristics of the six case study sites and participants and the rationale for choosing them. The methods chapter also explains how the interview data was collected and analysed. It also frames the researcher's methodological underpinnings which influence the choice of methods and where the topic is situated in relation to academic disciplines.

The findings (Chapter 4) details the analysis of the interview data against a framework of third place characteristics in order to determine if the six community gardens are third places. It shows how the case study sites measure up against the third place framework against each characteristic of third places. The thesis discusses how individual community gardens may fit on a continuum between a club and a third place and presents a model to illustrate the point. Themes which arose in the analysis make up two further data chapters, namely, placemaking (Chapter 5) and social capital (Chapter 6). 
Chapter 5 explores the placemaking qualities of community gardens which are third places and more specifically addresses placemaking in relation to motivations for involvement; UN Sustainable Development Goal 11.7 to create safe inclusive green spaces; and in relation to mobile populations.

Chapter 6 focuses on the opportunities for developing social capital in community gardens which are third places. In particular, data relating to promoting inclusivity; integrating new residents to the neighbourhood; and social capital and concomitant resilience of the neighbourhood are explored.

The thesis uses each case study to build a picture of community gardens as a third place and concludes (Chapter 7) by drawing together analysis and reflections to identify some key findings that may be of particular interest to researchers, planners, and community gardeners and communities looking for ways to improve social cohesion. It comments on the findings from the case study community gardens which are acting as third places in order to demonstrate how community garden participation can lead to increased social capital, through building social ties within and beyond the garden setting. The thesis concludes with the implications of community gardens as a third place in an urban context.

\section{Conclusion}

The overarching aim of this research is to explore if community gardens are third places and what the implications to urban populations may be. Some of the case study community gardens were particularly effective at acting as third places across all of the eight third place characteristics. While community gardens have been referred to as third places in several journal articles, this assertion had not, until now, been systematically tested. The framework of third place characteristics is very useful in determining whether the community gardens are third places. The third place framework developed in this thesis could be usefully applied to research on other public spaces and facilities to assess their inclusivity and effectiveness at reducing social isolation and building social capital.

Third place offers a useful conceptual stance for investigating the "community" aspect of community gardens. Third places act to build social capital, with weak ties (Granovetter, 1983 ) and bridging capital (Putnam, 2000). When people frequent a place, it functions to introduce the local community to each other. Regular characters play an important role 
as the people who provide the jovial atmosphere and homeliness of a third place. A community garden ensures regular contact (eg. working bees) as well as offering opportunities for chance encounters both within the membership and with the broader neighbourhood.

This thesis applies the concept of third place to the case study of community gardens to determine to what extent they are third places. It discusses the lessons which can be applied to other third places to increase their effectiveness in providing neighbourhoodbased informal public places which increase social capital. Community gardens which are not third places still have commendable roles to play in supporting the community, as do third places that are not simultaneously urban food projects. However, this thesis draws on the author's research and community garden literature to interrogate the benefits of community gardens which are third places. The research adds to the debates on how to approach the challenges of urbanisation and population mobility, as social cohesion becomes increasingly important to the creation and maintenance of healthy vibrant functioning cities. 


\section{CHAPTER 2 - LITERATURE REVIEW}

The concept of 'third place' - places outside of home (first place) and work (second place), where incidental neighbourhood interactions occur, has been applied to a range of public space research (Oldenburg, 1999). Community gardens have been identified as third places in several studies, however, this association has not been critically investigated (Calderon et al., 2014; Firth, Maye \& Pearson, 2011; Glover, 2004; Thompson \& Maggin, 2012; Veen et al., 2015). This thesis applies a framework based on the eight characteristics of third places to the qualitative case studies of community gardens, as later described in the methods chapter. The theoretical underpinning of the research is that of third place, social capital and placemaking. This chapter is a review of relevant literature to provide a background on community gardens; describe the third place concept; and underpin the research with themes of placemaking, social capital theory, population mobility, social alienation, inclusivity, authenticity, UN Sustainability Goal 11.7 and neighbourhood resilience.

\section{Significance}

This thesis looks at whether or not community gardens improve third places in that they have a communal purpose which provides opportunities for people to initiate conversations. It draws conclusions about the ability of third place community gardens to contribute to addressing challenges associated with population mobility and aspects of social isolation. The thesis also seeks to determine if community gardens are improved by being a third place, as the goal or motivation of the garden and its members, reaches out to more people in the community. In addition, the thesis investigates the role of third place community gardens in helping to address UN Sustainable development Goal 11.7 to provide safe green spaces to an inclusive population (UN, 2015). The findings will identify features of community gardens which best enhance their potential to be a third place.

As the world population becomes increasingly urbanised and mobile, third places take on greater importance for their role in incorporating new residents into the neighbourhood and reducing social isolation. The $21^{\text {st }}$ century has seen unprecedented migration to urban environments around the world with more than $50 \%$ of the world's human population living in cities since 2007 (Hollis, 2013). Every day 180,000 people move to cities and 
the UN projects that $75 \%$ of the population will be living in cities by 2050 (Hollis, 2013, p. 5). Australian capital cities housed more than two thirds of the population at the time of the 2016 census (ABS, 2017). Urbanisation has been associated with increasing levels of increasing levels of anxiety (Auge, 1995; Jacobs, 1996; Nursey-Bray et al., 2014), loneliness, anonymity and loss of sense of community (Hollis, 2013; Putnam, 2000) and alienation from nature (Gaynor, 2006; Turner, 2010; Firth, Maye \& Pearson, 2011). It is timely to consider addressing social challenges associated with increased urbanisation and population mobility.

In modern society much of the population is highly mobile which affects urban social cohesion. In 1997, Oldenburg indicated that every year nearly a fifth of the population changed residence in the USA. In Australia, $81 \%$ of rental tenants and $26 \%$ of home owners had moved location within the five years previous to 2014 (ABS, 2015). Of the sample population $8 \%$ had moved twice in 5 years and $15 \%$ had moved three or more times. Coleman (1988, p. 113) investigated the impact of mobility on the family in relation to school achievement and found that: "for families that have moved often, the social relations that constitute social capital are broken at each move" (Coleman, 1988, p. 115). His particular example found that dropout rates of high school students are demonstrably higher when the family has less access to social capital (Coleman, 1988). Lefebvre (2014, p. 205) comments on population mobility as the, "city dweller is in perpetual movement - constantly circulating and settling again". Tuan (2014) associated population mobility with weakening people's attachment to place. Third places provide opportunities for local people to informally meet each other, which provides a valuable contribution to introducing new residents to a neighbourhood and potentially improving urban social cohesion. Oldenburg suggested that:

"One might have thought that the high rate of residential mobility in our society would have inspired planners to make provision for new residents to get acquainted quickly and easily.” (Oldenburg, 1997, p. 7).

Population mobility is one of several factors which exacerbate social isolation. Another factor leading to social isolation is a reduction in group-based leisure activities. Both Oldenburg (1999) and Putnam (2000) argue that in the USA, leisure and socialising occurs almost entirely within private homes. Hemingway (1999, p. 164) highlights the role of leisure in: "the formation of trust, cooperation, and social connectedness". 
Oldenburg (1999, p. 81) discusses how the, "sociological individualism of industrial societies" reduces opportunities for ritual as different patterns of work shifts and holidays can leave people celebrating holidays alone rather than collectively. This individualistic lifestyle does not "serve the functions of unifying and integrating community and society, nor does it reinforce normative behaviour" (Oldenburg, 1999, p. 81). In addition, the design of public space is not always conducive to social cohesion. Auge (1995) criticised many popular public places in the USA, such as airports and large shopping malls, as impersonal "non-spaces" where neighbourly personal interactions do not occur. These socially isolating trends apply to many highly urbanised societies including Australia (Kingsley \& Townsend, 2006). With people hooked into personal devices and fewer local characters seeing the same people, it is difficult to initiate or be part of public place social interactions.Thompson and Maggin argue that regular incidental interaction between people increases feelings of caring and safety (2012, p. 260). Forrest and Kearns (2001) argue that the local neighbourhood takes on greater significance in providing opportunities to develop social cohesion for an increasingly globalised society.

The research is timely because community gardening is a growing trend in a number of countries. Firth, Maye \& Pearson (2011, p. 555) indicate that there is an upsurge of interest in community gardens in the UK, USA and Australia. The total number of community gardens registered with Australian Community Gardens Network was 604 in May, 2019, however, this figure does not capture the total number in Australia (ACGN, 2019). Singapore community gardens numbered 240 in 2008 to over 1,400 in 2019 (Tan \& Neo; Community in Bloom, 2019). In 2007, the American Community Garden Association estimated that there were 18,000 to 20,000 community gardens in the USA and Canada combined (Birky \& Strom, 2013).

\section{Community Gardens}

There are many different types of community gardens in practice today including Indigenous gardens, kitchen gardens, garden clubs, re-vegetation projects, crime diversion projects, work and training, leisure, healing and therapy, environmental/restoration, neighbourhood pocket parks and permaculture gardens (Ferris et al., 2001). The literature indicates that community gardens are generally inclusive and 
informal, based around broadly common interests, attracting people with a range of ages and demographics.

A comprehensive systematic study of community garden literature conducted in 2012 found that very few studies defined the term "community garden" (Guilart et al., 2012). Ferris et al. (2001, p. 562) in defining community garden in their research, found the common factor was "that specific communities actively support them". Glover (2003) notes three important factors in defining a community garden, namely: 1) they are located in an urban environment; 2) they produce food and/or flowers; and, 3) there are benefits for both individuals and communities. The American Community Garden Association include in their definition that it is 'urban agriculture' gardened by a group (Birky \& Strom, 2013). Holland's broad definition of community gardens is: "Community gardens are open spaces managed and operated by members of the local community for a variety of purposes" (2004, p. 302). Drawing together common characteristics of community garden definitions, this thesis defines community gardens as:

Public gardens, including a food growing purpose, established and/or maintained by members of the community for the benefit of individuals and the community.

Community gardens bring people together with nature in a public garden setting (Hensley, 2015). Urban community gardens have been found to promote wellbeing including positive mental health benefits of increased relaxation and reduced anxiety and provide physical health through active living and access to fresh food (Easthorpe \& McNamara, 2013). A popular governance and design across community gardens in Australia is the part communal areas and part individual garden plots. Communal areas can include fruit trees, native plants and charity gardens as well as shared paths and boundaries and communal activities such as worm farms and compost making (Glover, 2004). Community gardens which are situated in publicly owned space in Australia, require a committee, fundraising, public liability insurance and rosters of membership activities. The 'Brisbane Community Garden Guide', which borrows from the similar City of Sydney guide suggests that the management committee should become an incorporated association $^{6}$ (BCC, accessed 2/10/17). Such rules are important when considering if

\footnotetext{
6 The Brisbane Community Garden Guide indicates that a community garden needs to become an incorporated association with a constitution in order to be eligible for Council grants. They define incorporated association as: "A legal entity with certain rights and responsibilities under Australian law. It
} 
community gardens are club-like places or open to informal public engagement with the community, as a third place.

In Australia, community gardens are generally created to address people's desire to grow organic food, enjoy nature, enact environmental sustainability and interact socially with the local community (Pascoe \& Howes ${ }^{7}, 2017$ ). In an international context, community gardens vary in goals and support. Firth, Maye and Pearson (2011, p. 555) describe an upsurge of interest in community gardens in the UK, USA and Australia due to people's desires to "reconnect with food, nature and community". "Community gardens are one among many food movement strands in civil society, alongside farmers markets, organic farms, slow food, window farming, local food, fair trade and food cooperatives" (Walter, 2013, p. 523). Celata and Coletti's (2017, p. 4) study of Rome's approximately 170 community gardens in 2016 found varying purposes including "producing healthy food, but more often by the aim of providing a public collective space, promoting social inclusion and citizens' participation". In Canada, Vancouver's approximately 80 community gardens are encouraged by the city's sustainability plan to make Vancouver "the greenest city in the world by 2020" (Walker 2015, p7). Singapore community gardens show a tension between the government's program to green the city and their desire to limit civic actions (Tan \& Neo). Unlike Singapore, community gardens in the USA, are often sites of civil rights and environmental and ethnic movements and many seek practical outcomes of urban food production for poor residents (Guitart et al., 2012; McClintock, 2013; Walker, 2015). Glasgow community gardens are growing in number, often as a practical form of recovering derelict space for use by the community (Cumbers et al., 2017). In the UK and the Netherlands community gardens are less common, but there is a growing demand for allotments (ETRA, 1998; Veen et al., 2014). It should be noted that allotments differ from community gardens in that they are individual garden plots with security of tenure for the gardeners involved. In the UK, the Federation of City Farms and Community Gardens counted 1000 community gardens compared to 330,000 allotments, where allotments are individual plots leased to individuals by the local authority for growing food (Miller, 2015).

\footnotetext{
allows an organisation to do such things as sign a lease or obtain insurance without risk to individual members." (BCC, P.28, accessed 2/10/2017)
}

\footnotetext{
${ }^{7}$ See Appendix A - Pascoe \& Howes conference paper.
} 
A community garden takes a great deal of effort and commitment to establish. The goals of community gardens include enabling food security for political, economic and health reasons; crime prevention; beautifying an area; environmental activism; conservation of natural space; and an alternative to modern industrialised food production and distribution (Draper \& Freedman, 2010; Hogan \& Thorpe, 2009; Gaynor, 2006; Walter, 2013; Veen, 2014). In the literature, purposes of community gardens are grouped in a variety of ways. For example, the study conducted by Zoellner et al. (2012), found that community gardens promoted health, economic, and community benefits which could be investigated at the individual, social, and environmental levels of influences. Latino Community Gardens in New York were categorised as performing many functions which the researchers grouped as community development, open space, and civic agriculture (Saldivar-Tanaka \& Krasny, 2004). Lyons et al. (2013) viewed community gardens as part of a larger ethical food movement with social, political, economic and ecological dimensions.

There is a great deal of literature on the benefits which individuals and society receive from community gardens, which includes providing food to impoverished residents; crime prevention; beautifying an area; enacting Local Agenda 21 (LA21); exercise; civic engagement; enjoyment; access to fresh organic food; increased social capital; improved nutrition and wellbeing; and financial and community building (Ferris et al., 2001; Guitart et al., 2012, Draper \& Freedman, 2010; Firth \& Maye \& Pearson, 2011). For example, in Singapore, elderley members of community gardens benefitted from the connection with nature and the nostaligic aspect of the gardens reminding them of their farming days in pre-urbanised Singapore (Tan \& Neo, 2009). In Melbourne, Australia, community gardening reduced social isolation by providing an opportunity for neighbours to meet (Kingsley \& Townsend, 2006). West Hollywood, USA community garden participants increased physical activity by $6 \%$ and increased fruit and vegetable consumption by $10 \%$ (Twiss et al., 2003). Ohmer et al. (2009) determined that community gardens improve distressed neighbourhoods, particularly those with limited green space. School gardens draw in the community by encouraging parents, relatives and neighbours to be involved and volunteer (Ferris et al., 2001; Pascoe \& Wyatt-Smith, 2013). In summary, the community garden literature generally shows positive benefits to individuals and communities. Participants' motivations, goals and the benefits of community gardens provides a useful background to investigating if they also operate as third places and their impact on the local neighbourhood. 


\section{Third Places}

The concept of third place, developed by Ray Oldenburg, can be summed up as, "informal public gathering spaces" (1997, p. 6). Oldenburg (1999) generalises that compared to home (first place) and work (second place), third places allow opportunities for a diverse population to interact informally. Oldenburg's (1999) third places include commercial venues, such as cafes and municipal authority run venues such as parks. They provide opportunities for people to meet and interact on neutral ground and to develop a sense of belonging to place (Oldenburg, 1999).

Numerous social researchers suggest that the everyday incidental interactions of third places improve relationships between neighbours; decrease loneliness and isolation; improve the perception of safety; build social capital and create a sense of place (Oldenburg, 1999; Thompson \& Maggin, 2012; Vincent et al., 2016). Third places are inclusive across age, class and cultural backgrounds. For example, Mele et al. (2015) found that wet markets in Singapore acted as effective third places facilitating regular casual social interactions between local residents across gender, ethnicities and socioeconomic status. Thompson and Maggin (2012, p. 260) argue that: "incidental interaction on a day-to-day basis enhances the possibilities for human connection and caring". They indicate that it leads to improved perception of safety and decreases loneliness and isolation. As people identify with an area more, they take more responsibility for it and maintain the norms of the place rather than leave everything to the authorities (Oldenburg, 1999, p. 83). The third place is an informal, inclusive gathering place where one can bump into local people in a convivial manner as "part of a citizen's daily life" where familiar faces can be seen (Oldenburg 1999, p. xxix). The place may not be recognised as particularly "special" by its patrons as the activity which occurs there may be quite ordinary (Oldenburg, 1999).

The demise of community as a social construct is explored through the lens of Ray Oldenburg's concept of third place to view contemporary issues of alienation, loss, safety, mobility and sense of place - frequently cited causes for the demise of community and the decline in social health and well-being. Third places are an essential component of urban life because without them people are more likely to experience social isolation. The concept of third place provides a geographical understanding of the relations between place and community. This thesis employs third place as a framework to investigate how 
a particular site, the community garden, may exhibit characteristics which promote informal neighbourhood interactions. The findings can be incorporated into planning and urban design to offer localised places of interaction that promote togetherness in an urbanised world of mobility and rapid change.

\section{Eight characteristics of third place}

For the purpose of this thesis, the eight criteria used in Oldenburg's 1999 book are used to define a third place. This section will describe each of the eight characteristics of a third place to frame the critique of community garden literature. The characteristics of third place make an appearance in various forms across community garden research internationally. An example from the community garden literature will be given for each of the eight third place characteristics in this section.

\section{Easy to access and accommodating}

Oldenburg (1997, p. 6) describes third places as: "nothing more than informal public gathering places". "Accessible" relates to the location and "accommodating" relates to the place and time of third places. "The nature and frequency of routine encounters and shared experiences depend a great deal on attributes of these spaces and places" (Knox, 2005, p.8). Oldenburg's (1999) third place concept is place-based, as he argued that third places should be accessible by walking and they are open to everyone. They are places where you see the familiar neighbourhood faces. Kingsley \& Townsend's research (2006) found that by being situated in the local park, Portside's community garden in Melbourne provided opportunities for the gardeners to reach out and speak to others in the neighbourhood. Third places are accommodating in that they are open at times which suit the locals between their duties.

"The third place accommodates people only when they are released from their responsibilities elsewhere. The basic institutions - home, work, school - make prior claims that cannot be ignored. Third places must stand ready to serve people's needs for sociability and relaxation in the intervals before, between, and after their mandatory appearances elsewhere" (Oldenburg, 1999, p. 32). 


\section{Playful}

The concept of third place is associated with incidental interactions. Third places are fun and, "the entertainment is provided by the people themselves", through lively conversation (Oldenburg, 1997, p. 9). Bonow and Normark (2017, p. 8) found that of 48 community garden interviewees in Stockholm, Sweden: "Almost all of the gardeners answered that they were engaged in a community garden because it was fun". Members voluntarily work together for enjoyment and satisfaction and they celebrate their harvests. Pascoe and Howes (2017) described that community gardeners in their case study sites found the social aspect of community gardens as unexpected benefit and enjoyed this aspect more than they anticipated. Ohmer et al. (2009, p. 390) reported that interviewees said that it was, "really fun to get together with neighbours" in a community garden and it evokes a "sense of pride". Oldenburg and Brissett (1982, p. 274) say that in informal public places frequented by locals, "One can never be certain exactly who will be there; can never 'predict' what the chemistry of a particular 'mix' of people will create".

\section{Low profile}

Oldenburg (1999) describes third places as homely, plain and tending to being wholesome. The community garden literature refers to community gardens as bringing "authenticity" to urban environments (Zukin, 2010, p. 197). They are place-based specific to weather, seasons, soil type and choice of plants relating to local diet. "People are generally not bothered by the fact that we do most work by hand and need to use bucket lids as cake plates" (Veen et al., 2014, p. 270). Bende-Nagy (2016) described the homely fixtures made by the community gardeners in Szeged in Hungary, including scarecrows, outdoor furniture and barbeques. Third places are low key rather than showy. As one participant indicated, it brings together people who might not participate in meetings, but would get together "and get their hands dirty" (Ohmer et al., 2009, p. 390).

\section{Homes away from home}

Third places are comfortable and people feel at home while they are there, but without the obligations which might come along with actual "home" or "work". Oldenburg and Brissett (1982, p. 276) agree with Mihaly Csikszentmihalyi's 1975 observation that when people concentrate on a task that they enjoy they forget time and their problems and gain a "sense of harmony" with their surroundings. Hondagneu-Sotelo state that, "gardens evoke Eden" and act, "as a sanctuary from the frenetic pace of public life, work, and competition" (2010, p. 499). "Often it's sociable in the evenings, when you are in the 
canteen and you are with everyone else, you play cards and you talk but you also exchange experiences" (Veen et al., 2014, p.270). Numerous community garden studies report the members saying that the act of gardening was relaxing compared to their regular daily stresses (Bonow \& Normark 2017; Pascoe \& Howes, 2017). Bende-Nagy’s (2016, p. 101) study of community gardens in Szeged, Hungary found that community gardens help people who are new to the area integrate into the community through forming connections with the neighbourhood social network.

\section{Neutral ground}

Oldenburg (1999) described third places as open to all - places where everyone is free to come and go without obligations. "Third places, especially those which are not insulated by formal membership requirements, often uniquely provide a common meeting ground for people with diverse backgrounds and experiences" (Oldenburg \& Brissett, 1982, p. 275). Although reporting on allotments rather than community gardens, a 1998 UK Parliamentary report reported that the public gardens involved people from many cultures and a range of ages and they cooperated and shared their knowledge and resources in a harmonious manner (ETRA, 1998). In principal, membership in most community gardens is open to everyone, though minimum requirements may be set such as involvement in a regular working bee or a small charge to cover necessities such as insurance. In many cases this might only amount to a brief monthly involvement and fees are often discounted for low income members. These minor obligations would not exclude community gardens from being 'neutral' and may in fact increase the opportunity for members to get to know each other. By contrast, community gardens in housing blocks that are restricted to residents only, do not exhibit the neutral characteristic, though may act somewhat as third places amongst the residents themselves. Community gardens that have expensive membership fees; compulsory committee membership obligations; and/or locked gates with key entry only, might be considered to not exhibit the neutral characteristic. However, restricted community gardens can become more neutral by encouraging visitors and holding open days to encourage the people of the neighbourhood to visit.

\section{Levellers}

Third places are not dependant on participants' social or economic status as everyone is free to be there regardless of rank and status. "One of the good feelings they experience is that stemming from the realization that they are accepted and liked by people from many different walks of life" (Oldenburg, 1999, p. 45). Community gardens create a mix 
of people interacting. Saldivar-Tanaka and Krasny's (2004, p. 399) study of 20 Latino community gardens in New York City describes them as, "unique participatory landscapes" where the gardens are the location for numerous social, educational, and cultural events. Third places bring together people of different ages, classes, ethnicity, and skill levels. Community gardens bring together people who might not participate in meetings, but would get together to garden, work cooperatively and share produce (Gaynor, 2006; Ohmer et al., 2009).

\section{Regulars/characters}

Third places have a core group of influential regulars or characters who contribute to the friendly atmosphere and play a role in bringing together regulars and newcomers. The regulars are familiar with many visitors and play a role in introducing people to each other. The regulars know people and keep an eye on the neighbourhood (Oldenburg, 1999, p. xix). Community garden regulars include organisers, plot holders and passersby. Chitov's New York study found that community gardens such as the East New York gardens exist because of the work of particular characters. "It is primarily because of characters like Juanita that the East New York gardens exist. Bridging social capital is also reinforced by these characters" (Chitov, 2006, p. 454). These characters are often the ones who provide a homely, friendly atmosphere amongst organisers, plot holders and passers-by. However, Bonow and Normark (2017) cautioned that in their observations of community gardens in Stockholm, Sweden, that gardens may rely heavily on only one or two organisers. When the regulars are burdened with too much responsibility as it affects the longevity of the community garden.

\section{Conversation}

Oldenburg observed the lost skill of conversation and refers to the "uncomfortable quiet" of many US bars (1999, p. 48). Perhaps in this fragmented modern age and city design, successful third places need a particular emphasis on conversation. In the third place literature, opportunities for conversation are enhanced when there is a reason for people to speak with each other. Oldenburg (1997) gives the examples of games such as boules in a park, or pool in a pub which help promote conversation. Third places enable routine social encounters and conversation is the main activity. Third places: "should facilitate casual encounters as well as settings for sustained conversations" (Knox, 2005, p. 8). Community gardens promote conversation by having a communal purpose because they 
encourage involvement of everyone and provide ample reasons for initiating conversations on broad topics of common interest (weather, plants, activities) requiring no specialist knowledge. Studies in Sweden, Denmark and Australia noted the importance or benefits of the social aspect of community gardens as a motivation either to join, or to remain involved (Bonow \& Normark, 2017; Pascoe \& Howes, 2017; Turner, 2011).

\section{Critique of third places}

This research takes a fresh look at third place theory, in particular the assumption that strangers in public places will speak to each other. In some cases Oldenburg's examples of third places are very masculine places, such as a bar, where it would be unlikely that a female would feel comfortable striking up a conversation with a stranger. Oldenburg $(1999$, p. 180) referred to advice in the early 1980s that the rise of singles bars led women to meet "unsavoury" men. Gender relations in public spaces and rights to safe public spaces for women is a rich literature which could be further explored in relation to third places (Drucker \& Gumpert, 1997; Fullagar, O’Brien and Lloyd, 2019; Patel, 2006).

This research will add to the third place literature by focussing on informal place which provides a communal purpose to interactions. The term 'communal purpose' has been produced for this thesis to mean that activity associated with the place is open to all the people in the community, whether actively involved or not. It differs slightly from Oldenburg's suggestions of more individualistic third place activities for example, games such as chess in the park or pool in the pub (1999). The "key ingredients" of third place: "seem to remain elusive and emergent and these no doubt change with the shifting patterns of lifestyles. It is possible, therefore, only to describe a few of the necessary, but certainly not all of the sufficient, characteristics of third places" (Oldenburg, \& Brissett, 1982, p. 270). The research will take a closer examination of the role of third places in building social capital.

Oldenburg (1999) in his later writings, argued that the internet was not and could not be a third place and stressed the importance of third places being physical spaces. Crick, however, in her 2011 study criticised third place as a western and old fashioned concept and sought the opinions of Generation Y in a developing country (Crick, 2011). The participants responded to the characteristics of third place as not accounting for exclusion by wealth and social strata and they found the internet provided them with more freedom to mix with different people and to relax and be themselves. Kavanaugh, Reese, Carroll 
and Rosson (2005, p. 119) note, the use of social media as a: "tool for maintaining social relations, information exchange, and increasing face-to-face interaction, all of which help to build both bonding and bridging social capital in communities". Social media plays a role in the formation of community gardens and recruitment of members. The public nature of the social media means that the cyberspace version of the community garden can be visited by anyone who has access to the internet thereby extending the boundaries.

\section{Community Gardens as Third Places}

Community gardens have been described as third places in several studies, however, the attribution of third place to community gardens has not been systematically investigated. This study was designed to investigate this claim across a range of types of community gardens in a range of locations. Five articles specifically link the third place concept with community gardens. Firth, Maye and Pearson (2011) briefly describe community gardens' role as a neighbourhood meeting place which acts as a third place outside home and work. Glover (2004, p.143) refers to community gardens as being third places outside of work and home where: "people can gather, network, and identify together as residents of a neighbourhood". Thompson and Maggin (2012, p. 398) describe community gardens as a: "good example of a 'third place' in a healthy built environment" as they "provide opportunities for local residents to socialise and develop vital ties". Veen et al. (2015, p. 1) said that community gardens had potential to act as third places: "in which people can relax in good company on a regular basis". However, their research found that interestbased community gardens were not as much like third places as place-based community gardens because they connections did not: "trickle down through the wider community" (Veen et al., 2015, p. 15,). Calderon et al. (2014, p. 190) state that community gardens: "promote many of the characteristics of third places: neutral nature, low profile and regulars come together to cultivate both the land and their social connections". All five studies made the assumption that community gardens are third places.

In order to show that third place relates to community gardens, the following table compares examples in the Oldenburg literature and how they might relate to community garden research findings. 
Table 1: Third Place in the Community Garden Literature

\begin{tabular}{|c|c|c|c|}
\hline & $\begin{array}{l}\text { Third Place } \\
\text { Characteristic }\end{array}$ & Description and Example & Community Garden \\
\hline 1. & Neutral ground & $\begin{array}{l}\text { Open to all. (Piazza, pub, } \\
\text { barber) }\end{array}$ & $\begin{array}{l}\text { Public space. "In a world where people often don't co- } \\
\text { operate and are divisive or bigoted, it is truly inspiring } \\
\text { to see the way that plot-holders co-exist. Every age } \\
\text { and every culture is there and everyone helps each } \\
\text { other - with advice and with gifts of seeds, offsets, } \\
\text { divisions, spare produce etc."(ETRA, 1998). }\end{array}$ \\
\hline 2. & Leveller & $\begin{array}{l}\text { All people are equal. Rank } \\
\text { and status don't matter. }\end{array}$ & $\begin{array}{l}\text { Everyone is welcome. Once a member, however, } \\
\text { some obligations apply. As one participant indicated, } \\
\text { it brings together people who might not participate in } \\
\text { meetings, but would get together "and get their hands } \\
\text { dirty" (Ohmer et al., 2009, p.390). }\end{array}$ \\
\hline 3. & $\begin{array}{l}\text { Accessible and } \\
\text { accommodating }\end{array}$ & $\begin{array}{l}\text { Everyone free to come and } \\
\text { go. (Local pub - England) }\end{array}$ & $\begin{array}{l}\text { Walking distance. "Gardens evoke Eden" and act "as } \\
\text { a sanctuary from the frenetic pace of public life, } \\
\text { work, and competition" (Hondagneu-Sotelo, 2010, } \\
\text { p.499). }\end{array}$ \\
\hline 4 & $\begin{array}{l}\text { Conversation (is the } \\
\text { main activity) }\end{array}$ & $\begin{array}{l}\text { Games such as boules in a } \\
\text { park, or pool in a pub help } \\
\text { promote conversation and } \\
\text { give a reason for people to } \\
\text { speak with each other. }\end{array}$ & $\begin{array}{l}\text { Gardening activity helps promote conversation and } \\
\text { give a reason for people to speak with each other. } \\
\text { Allotments are, "a place where people can indulge in } \\
\text { two of life's passions - gardening and talking - and } \\
\text { can do them in the peace and quiet of the allotment } \\
\text { site" (ETRA, 1998). }\end{array}$ \\
\hline 5 & $\begin{array}{l}\text { Regulars (a core } \\
\text { group of influential } \\
\text { regulars) }\end{array}$ & $\begin{array}{l}\text { The regulars provide the } \\
\text { character. "public } \\
\text { characters" (Jacobs) know } \\
\text { people and keep an eye on } \\
\text { the neighbourhood } \\
\text { (Oldenburg, 1999, p. xix) }\end{array}$ & $\begin{array}{l}\text { Regulars: organisers, plot holders and passers-by. "It } \\
\text { is primarily because of characters like Juanita that the } \\
\text { East New York gardens exist. Bridging social capital } \\
\text { is also reinforced by these characters" (Chitov, 2006, } \\
\text { p.454). }\end{array}$ \\
\hline 6 & Low profile & $\begin{array}{l}\text { Not a grand place; not } \\
\text { showy. Casual passers-by } \\
\text { not attracted. Unlike } \\
\text { franchise which discourages } \\
\text { lingering. }\end{array}$ & $\begin{array}{l}\text { Can look messy. Rudimentary (but safe) materials. } \\
\text { Focus on dirt. Authentic activity. "People are } \\
\text { generally not bothered by the fact that we do most } \\
\text { work by hand and need to use bucket lids as cake } \\
\text { plates" (Veen et al., 2014, p.270). }\end{array}$ \\
\hline 7 & Playful mood & $\begin{array}{l}\text { Wit exchanged. Not too } \\
\text { serious. }\end{array}$ & $\begin{array}{l}\text { Voluntarily working together for } \\
\text { enjoyment/satisfaction. Celebrations/harvests. "It is } \\
\text { really fun to get together with neighbours" in a } \\
\text { community garden and it evokes a "sense of pride" } \\
\text { (Ohmer et al., 2009, p.390). }\end{array}$ \\
\hline 8 & $\begin{array}{l}\text { Home away from } \\
\text { home }\end{array}$ & $\begin{array}{l}\text { A "congenial environment", } \\
\text { at ease. }\end{array}$ & $\begin{array}{l}\text { "Often it's sociable in the evenings, when you are in } \\
\text { the canteen and you are with everyone else, you play } \\
\text { cards and you talk but you also exchange } \\
\text { experiences" (Veen et al., 2014, p.270). }\end{array}$ \\
\hline
\end{tabular}

While all five aforementioned studies referred to community gardens as third places, they did not critically investigate if this is the case. Table 1 shows that community gardens can exhibit qualities of a third place, but without the original data, it is not possible to analyse community garden studies in the literature against all third place characteristics. This study applies a framework of third places characteristics to six case study community gardens, as described in the Methods chapter (3). 


\section{Community}

The definitions of 'community' have changed over time. The normative ideal of community has different conceptions in different times and societies according to ideologies. For example, socialism, communism, liberalism, fascism, conservatism cover extreme ideals of community from Marxism (pure community) to liberalism (individualism) (Day, 2006, p. x). Community involves boundaries which means some people are in and some are out (Day, 2006, p. 2). "Community can be exclusive or inclusive" and exhibit, "bonds of commonality and sociality" (Delanty, 2010, p. 5 \& p. 2). The definition of community which is applied in this thesis is Day's definition:

"Those things which people have in common which bind them together, and give them a sense of belonging with one another" (Day, 2006, p. 2).

This definition is used in relation to determining how community gardens can in some ways be considered clubs with a sense of community based on commonality and belonging. Third place offers a useful theoretical stance for investigating the "community" aspect of community gardens. Third place is place-based as it relies on being accessible by walking. Third place also acts to build social capital (Putnam, 2000). If people are frequenting a place, the place is functioning to introduce the local community to each other and allows for development of a regular characters (Jacobs, 1961), who often are the people who provide the jovial atmosphere and homeliness of a third place. A community garden ensures regular contact (eg. working bees) as well as offering the opportunity for chance encounters. In the post-modern society, friendship becomes more important for support as families are fractured by distance and fragmentation (Delanty, 2010).

Liminal community is considered by some to be a valid form of community and this includes, for example, communities of commuters, in places such as trains or airport lounges (Delanty, 2010; O’Hare, 2019). By contrast, Auge (1995) would say these are "non-places".

Putnam (2000) lamented the demise of community in "Bowling Alone", which described the decline of group participation activities and corresponding isolation of individuals within neighbourhoods. There is evidence that unstructured social activity is declining in the U.S., a trend confirmed by Oldenburg (1997), who noted the disappearance of opportunities for informal social gatherings in what he labels "the great good place" or "the third place". However, in two decades, there has been a growth in community 
gardening. Members and visitors meet like-minded people and others, so it will be interesting to investigate if these meetings lead to increased social capital, civic engagement and social ties beyond the garden setting. It should be emphasized that although Putnam is particularly concerned with associational activity, this is not the only source of social capital formation. Social interaction generally, whether structured or unstructured, plays a significant role.

\section{Clubs and Interest Groups}

Community gardens are places where people gather to grow food, socialise and interact with the neighbourhood. Community gardens tend to exhibit a multitude of purposes, whereas third places are: "a forum for 'play' in a society interfused with stubborn commitment to work and purposiveness" (Oldenburg \& Brissett, 1982, p. 282). In some regards, community gardens act as a club or society, with membership rules and obligations, whereas, the concept of third place is associated with incidental interactions. Some community gardens may fit the model of a club with membership, but some act as a hybrid third place/club with volunteers and passers-by gathering in a place. Many of the eight criteria of third place suit community gardens and some more so than others depending on the characteristics of individual community gardens.

Clubs and societies are organisations with membership criteria, rules and obligations, which exhibit elements of exclusivity and common interests (Putnam, 2000). While clubs and societies may have a narrow focus, community gardens attract members motivated by a broad range of motivations around community, environmental action and food growing (Gaynor, 2006; Guilart et al., 2012; Pascoe \& Howes, 2017).

Oldenburg and Brissett (1982) highlighted the unique opportunities that the openness of third places bring for meaningful interactions between people of diverse backgrounds on common ground, unhindered by membership requirements. Some community gardens are place-based, created and maintained by local residents who live within walking distance of the garden (Pascoe \& Howes, 2017). While community gardens are firmly rooted in a physical place, they may attract participants from beyond the neighbourhood to form an interest-based community garden. Interest-based gardens draw people from beyond the local area for such activities as training, sustainability education and market days (Firth, Maye \& Pearson, 2011; Easthorpe \& McNamara, 2013; Turner, 2011). Interest-based community gardens may be less third place-like. It will be interesting to investigate if 
place-based versus interest-based affects how third place-like a community garden and if interest-based community gardens only draw in like-minded people leading to bonding capital (Firth, Maye \& Pearson, 2011).

\section{Placemaking}

Oldenburg's third place concept is place-based and this thesis utilises the third place characteristics as a way to investigate the placemaking aspect of community gardens. Community Gardens are created and re-created by the participants and as such provide potential to instil a sense of place. A sense of place is: "always socially constructed" (Knox, 2005, p. 1). Saldivar-Tanaka and Krasny's (2004, p. 399) study of Latino community gardens in New York demonstrated the production of a sense of place through a wide variety of community activities occurring in the community garden including: "numerous social, educational, and cultural events, including neighbourhood and church gatherings, holiday parties, children's activities, school tours, concerts, health fairs, and voter registration drives" and "to promote community activism". Jiven and Larkham (2003, p. 70) discuss Yi-Fu Tuan's interpretation of space as embodying: "feelings, images and thoughts of those who live, work or otherwise deal with that space". Ingredients for "sense of place" include: "respect for seasonality and traditional rhythms of community life" (Knox, 2005, p. 8).

The term 'placemaking' is being used in this thesis as a verb describing the act of making a space into a place, whereby the resultant 'place' is somewhere that people can identify with and possibly feel some connection to. Schneekloth and Shibley (1995, p .1) define placemaking as: "The way in which all human beings transform the places they find themselves into the places where they live". Friedmann (2010) refers to qualities of placemaking as occurring on different scales from the local urban scale by the people transforming their own 'place', to large scale placemaking such as global branding of cities. Much of the literature on placemaking refers to the Project for Public Places (PPS) definition of placemaking. The Project for Public Places is a not for profit organisation which supports people to "create and sustain public spaces". Their definition of placemaking is: "Placemaking refers to a collaborative process by which we can shape our public realm in order to maximize shared value" (PPS, 2007). Placemaking Chicago, part of the PPS group, refer to placemaking as a "people-centered approach to the planning, design and management of public spaces" (Placemaking Chicago, 2008). 
Placemaking has been variously referred to as 'place-construction' (Cresswell, 2004) and 'place-shaping' (Carmona, 2014), amongst other names and similar concepts. Cresswell (2004, p. 84) discusses research on placemaking strategies of a mobile population ranging from micro-placemaking of moving into a new room and placing up a favourite picture, to the a globalised view of placemaking in which largescale displacement of populations and subsequent development erase character and "appear to flatten out difference". Carmona (2014, p. 3) describes 'place-shaping' of public space as created, generated, regenerated, managed and owned in a range of rights and processes. Place-shaping is the mix of design and development processes in the creation and management of places.

In defining placemaking, first one must decide on what a 'place' is. It should be noted that Oldenburg's concept of third place differs from Edward Soja's (1996) theory of 'thirdspace' which reimagines space as not only a physical place, nor only a conceptual construct, but as an integrated way of thinking about spatiality. Soja's (1996, p. 11) concept of thirdspace is a mode of thinking about spaces as a combination of "real-andimagined" spaces. Soja comments that Lefebvre rarely wrote about 'place', instead referring to "lived space" where everyday life takes place (Soja, 1996, p. 40). Soja (1996) does not agree with the separation of the concepts of space and place as espoused by cultural geographers.

For the purpose of this chapter, 'space' and 'place' are used as distinctive concepts, where space can be made into place through the act of placemaking. There is no definitive definition of placemaking which best suits discussion on community gardens which are third places, so through a combination of elements of the definitions discussed above, the following definition of placemaking has been constructed:

Placemaking is a dynamic act of people collaboratively transforming public space into public places that increase the social life and sense of belonging to a local area.

The definition stated above accounts for the collective neighbourhood activity and dynamic nature of creating and maintaining community gardens and third places. Placemaking is a dynamic process and this is no more evident than in a community garden where the purpose, design, seasons and participants change over time. 


\section{Nature and Placemaking: UN Sustainability Goal 11}

Placemaking is enhanced by people connecting to nature in community gardens. Community garden members connect with the soil and through planting, they put down roots. Community gardens can play a role in forming an attachment to place as they are broadly place-specific to weather, seasons, soil type and choice of plants relating to local diet. Gaynor (2006) discusses community gardening as a response to people's alienation from nature. Edward Wilson described human beings' natural affinity with nature as "Biophillia" (Hensley, 2015). Natural spaces in urban environments help promote wellbeing in the community through positive mental and physical health benefits of urban green spaces become increasingly important as cities expand (Shanahan et al, 2015).

Community gardens have potential to contribute to achieving UN Sustainable Development Goal (UNSDG) 11 - "Sustainable Cities and Communities" and in particular, Goal 11.7:

By 2030, provide universal access to safe, inclusive and accessible, green and public spaces, in particular for women and children, older persons and persons with disabilities. (UN, 2015)

The UNSDG were adopted by Australia in 2016 and: "their goals and targets cannot be achieved at the global and national level, without aligning local processes for integrated special planning and investment" (Holloway, 2017, p. 181). Australia reports on the State of the Environment to the UN every 5 years under the terms of Agenda 21 (Holloway, 2017). Community gardens which are third places, can play a pivotal role in achieving the UN Sustainability Goal 11.7. Community gardens have demonstrated that they can be a community space that promotes social inclusion across age, gender, social class, ethnicity and disability (Lyons et al., 2013). Not only do community gardens aid in the conservation of green space, but they are a green space which helps revitalise distressed neighbourhoods (Draper \& Freedman, 2010; Ohmer et al., 2009). Community gardens can provide an element of culturally authentic use of green space as demonstrated in Latino Community Gardens in New York and Singapore community gardens (SaldivarTanaka \& Krasny, 2004; Tan \& Neo, 2009). Latino Community Gardens in New York were multi-functional community developments combining open space, civic agriculture, cultural festivities and a sense of community (Saldivar-Tanaka \& Krasny, 2004). Tan 
and Neo (2009) found that Singapore community gardens benefitted elderley members through a nostaligic connection with nature and gardening. Third places, particularly those that combine social interaction with physical activity, such as gardening, have beneficial health and wellbeing outcomes for the community (Frumkin, 2003).

Planners recognise a need for public green space (Ferris et al., 2001). Yokohari and Amati $(2005$, p. 53) note increasing demands for planners to restore nature in cities through parks and open spaces in urban areas to achieve a "city in nature". Access to nature in urban environments helps promote wellbeing in the community through generating positive feelings, sustained attention, relaxed wakefulness, and reduced anxiety (Shi et al., 2014; Shanahan et al., 2015; Yokohari \& Amati, 2005). Community gardens provide valuable green space for community activity in distressed neighbourhoods (Ohmer et al., 2009). In Berkeley, civic initiatives have achieved pocket parks reclaimed from the car parking and conservation restoration projects restoring waterways from concrete culverts (Ferris et al., 2001). Celata and Coletti's (2017, p. 4) study in Rome, found that community gardens are a public "collective space" which promote social inclusion and "citizens" participation".

Active community gardens contribute to achieving the UN Sustainability Goal 11.7, as they are open to the public and they encourage regular attendance of members, which taps into Janes Jacobs' theme of 'eyes on the street', which improves the safety of the area (1961). Third places affect the perceived safety of a local area, though "fear of crime is often not a reflection of actual risk and may vary across gender, age, ethnicity and socioeconomic status", but the perception of fear can be influenced by the environment business, signs of rubbish and neglect (Holden, 2019, p. 96). Where greenspaces are viewed as sites of either natural danger (eg. snakes) or human danger (eg. crime), local residents are less likely to use them (Maller \& Farahani, 2018). Holden concludes that the effect of third places improving the eyes on the street may not necessarily reduce the amount of crime (more highly correlated with artificial lighting), but it improves the perceived safety of the area, which in turn encourages more people to feel comfortable in public. Therefore, third places can contribute to providing UN Sustainability Goal 11.7's "safe, inclusive and accessible, green and public spaces".

There is still work to be completed to develop methods to define, measure and track progress towards reaching the UNSDGs (Arfvidsson et al., 2017; Holloway, 2017). 
Chapter 5 relates the case study data to UNSDG 11.7 and Chapter 7 integrates the placemaking data and social capital data to provide a framework which could be applied as an indicator of progress towards reaching the UNSDG 11.7 goal.

\section{Motivations}

The act of placemaking will be explored as a way for a mobile population to become part of a place, developing ties to the local community. Placemaking will be discussed in depth in Chapter 5. Placemaking addresses a human need to have a sense of belonging somewhere as features in the five "Hierarchy of Needs" from Maslow's Theory of Motivation (Maslow, 1943). The five needs start with those required for basic survival: physiological; and safety; and progress to higher needs of: belonging and love; esteem; and self-actualization (Maslow, 1943). The theory argues that human beings are motivated by unsatisfied needs and one of those needs is "love and belonging", which includes a "sense of connection". Love and belonging can be seen in reference to a desire for a sense of "community" and in seeking out friendship and belonging to a group. The social aspect is evidenced in those community gardeners who are motivated to get to know people in the neighbourhood, learn together and share resources and make friends. The self-actualization motivation is related to a sense of purpose. "Purpose in life, often viewed as a central component of well-being, refers to the extent to which people see their lives as having meaning, a sense of direction, and goals" (Kim et al., 2017, p. 1040).

This research will be looking at the community aspect of community gardens, however, not in isolation from the mix of motivations of community gardeners. There are some commonalities in motivations for participation in community gardens across countries. In a study of USA found that participation in community-supported agriculture schemes were driven by "diverse impulses" and found that members' motivations changed over time during participation (Cox et al., 2008, p. 204). Individual's motivations include a simple desire to grow organic, locally grown, seasonally appropriate food (Firth et al., 2011; Twiss et al., 2003); a need for cheap food, or to find an alternative to modern food production and distribution (Hogan \& Thorpe, 2009; Gaynor, 2006); to connect with nature (Turner, 2010); to promote and enact environmental sustainability (Ferris et al., 2001); and to be part of a community, sharing produce and working cooperatively (Gaynor, 2006). Community gardeners cite a variety of motivating factors beyond the food growing aspect, including social justice, charity, self-help, exercise, environmental action, education, socialising, civic engagement and skill building (Lyons et al., 2013; 
Ohmer et al., 2009; Pascoe \& Howes, 2017; Turner, 2011). Ferris et al., (2001) acknowledge the complex mix of motivations behind the development of community gardens and the strength of effort and "altruism" involved in starting one.

Pascoe and Howes (2017) [Appendix 1] found that motivations for community garden involvement was grouped as community (social cohesion), gardens (food growing, nature) and individual (health, satisfaction). They determined that the social aspect of community gardens is not usually the primary reason for joining, however, it is stated as a benefit, or an unexpected bonus, often over taking the initial motivation of growing food. Turner found that the communal aspect of community gardens was not the main motivation for any of the participants in the Canberra case study, citing that: "for all but one interviewee, it was an added benefit, but it did not encourage participation" (Turner, 2011, p. 514). Veen et al. (2014) group the motivations of urban food growing initiatives, including community gardens, as about health, social connections and an alternative to industrialised food. Ferris et al. (2001) noted a broad range and mix of motivations for creating and being involved in community gardens. Community gardens which grow from a broad range of interests, may contribute to the diversity of participants in community gardens and to their potential for third place interactions and building of weak ties. A diversity of participants is a characteristic of third place which broadens their community building potential.

\section{Resilience}

Neighbourhoods with high social capital have been shown to exhibit greater resilience to disaster through improved recovery time (Aldrich, 2012). In the case of community gardens, disaster resilience is uniquely enhanced by their potential for residents working cooperatively and improving food security (Chana, et al., 2015; Nursey-Bray, et al., 2014; Singh-Peterson \& Lawrence, 2015). "Resilience" is a term describing a system's ability to "bounce back" to its original state after some kind of change is imposed upon it (Davidson et al., 2016). Adapted for use in the social sciences, resilience has been defined by Davidson et al. as:

"Fostering development of those elements that will enable social-ecological systems to absorb and/or adapt to unforeseen change and deal with uncertainties - learning to live with change, maintaining diversity (natural, cultural, social, economic, institutional) to increase options, combining different types of 
knowledge for learning, and providing opportunities for self-organization" (Davidson et al., 2016, p. 27).

The types of disturbances which call for neighbourhood resilience include natural forces, economic shocks, and political and social events which impact the particular community (Davidson et al., 2016). This thesis will use Black and Hughes definition of a resilience and apply it to the neighbourhood:

"...able to respond effectively and bounce back in the face of adverse circumstances, whether these be economic, environmental or social" (Black \& Hughes, 2001, p. 16).

Chana, DuBois and Tidball (2015) discuss the role of community gardens in neighbourhood recovery from 'superstorm' Sandy which was approximately 1000 miles wide and impacted New York City. It is difficult to imagine the impact of a community garden on recovery from a disaster of such an immense scale, however, Chana, DuBois and Tidball (2015) were able to document how community gardens helped the locals to recover from the superstorm. Some examples include that: community garden members checked on each other after the storm; initially used the site as a meeting space for postdisaster distribution of goods; provided signs of recovery to the neighbourhood, by restoring the children's art; they collaborated with other groups and agencies to help where possible and shared information; held workshops; supported emotional recovery and memorials; a site to share disaster and recovery stories; and were a place to start resuming normal activities. The community gardens acted as sites of post-disaster recovery, which indicates the adaptive capacity inherent in the community garden community.

\section{Authenticity}

In relation to placemaking, the civic engagement of local people in creating and maintaining community gardens gives them an element of authenticity. Zukin (2010, p. 197) refers to community gardens as bringing "authenticity" to urban environments. Authenticity refers to a combination of uniqueness, rituals and a real quality to a place, though Zukin cautions that authenticity can be used as a tool of gentrification (Zukin, 2010). Jane Jacobs (1961) talks about the variety of design of an older section of Park Avenue, New York, which includes a multitude of buildings of different sizes, styles and 
uses, yet which hangs together aesthetically. Jacobs (1961, p. 228) contrasts this with a modern section of Park Avenue purposefully designed to include variety and refers to their 'exhibitionism' and 'phoneyness' leading to a kind of monotony. Despite both streets being filled with variety of building designs, one is perceived by Jacobs to be authentic and one phoney or inauthentic. Gaynor (2006, p. 167) discusses ecological lifestyles as: "an attempt to reclaim an authenticity of experience seen as lacking in modern consumer society, in which people were alienated from nature, and from each other". The cooperative interactions of the community gardens participants as they create and re-created their place could be considered to be authentic.

\section{Growing Social Capital}

Social capital is a term used to describe the value or measure of social networks between groups of people. Easley and Kleinberg (Easley \& Kleinberg, 2010, p. 69) refer to James Coleman's distinction between social capital and other forms of capital such as physical capital: "the implements and technologies that help perform work", and human capital: "the skills and talents that individual people bring to a job or goal". Pierre Bourdieu related social capital to economic capital: "consisting of monetary and physical resources", and cultural capital: "the accumulated resources of a culture that exist at a level beyond any one individual's social circle, conveyed through education and other broad social institutions" (Easley \& Kleinberg, 2010, p. 69). Bourdieu's theory of social capital is more individualistic than the community based social capital definition of Putnam (2000).

Alexis de Tocqueville's (1899) study of the US republic in the late 1800s discussed the need for citizens to be active in working together to create functioning communities. Jane Jacobs (1961) discussed the value of social networks. Coleman (1988, p. 98) sees social capital as a "resource for persons" which "is not lodged either in the actors themselves or in physical implements of production". Coleman identifies the function of social capital as a resource which can be applied by an individual to achieve his/her own an interests and advancement. This thesis is looking more generally at the values of social capital between networks of people and in creating a sense of community, rather than measuring any particular personal benefits (Coleman, 1988). For the purpose of this thesis, Putnam's (2000, p. 19) definition of social capital will be applied:

\footnotetext{
"Social capital refers to connections among individuals - social networks and the norms of reciprocity and trustworthiness that arise from them."
} 
Putnam (2000) describes communities with 'bridging' social capital (weak ties across groups) and 'bonding' social capital (strong ties within groups). Drawing on Putnam's writings on social capital, Easley and Kleinberg explain that bonding capital corresponds to the kinds of social capital arising from "connections within a tightly-knit group" and bridging capital is from "connections between such groups" (Easley \& Kleinberg, 2010, p.69). They say that the, "notion of social capital thus provides a framework for thinking about social structures as facilitators of effective action by individuals and groups" (Easley \& Kleinberg, 2010, p. 69). Putnam describes clubs and societies, with their membership rules and obligations as generating strong ties of social capital, or bonding capital (2000).

Putnam (2000) applies the social capital concept in a broadly positive sense for depicting social connections which produce positive benefits for not just the individual, but the collective. Putnam does, however, acknowledge that social capital can be enacted in ways that produce negative results for the broader community. For example, Putnam cites the social capital enlisted to carry out the 1995 USA domestic terrorist incident, the Oklahoma City bombing (Putnam, 2000). However, for the communal purpose of a collective neighbourhood activity, such as creating and maintaining a community garden, the community based social capital definition of Putnam is suitable. In addition, the Putnam definition closely mirrors the Australian Bureau of Statistics (ABS) social capital definition, which is also used by the OECD, which is: "Networks, together with shared norms, values and understandings which facilitate cooperation within or among groups" (ABS, 2015). Social capital is an important indicator of the social wellbeing of individuals and the community, which can be utilised to inform discussion ranging from education, economic wellbeing, community renewal, and health issues for the "development of sustainable local communities"; "active engagement of the local people" in planning their community future (ABS, 2004, p. vii \& p. 1). As the thesis utilises ABS data now and in future publications from this research, it is strategically advantageous to align the definition of social capital applied in this thesis to that of the ABS.

Third places exhibit openness, inclusivity and incidental social interactions (Oldenburg, 1997). Building on Mark Granovetter's 1960s work on strong and weak ties, Easley and Kleinberg (2010) determine that the informal interactions of third places are likely to generate 'weak ties' of association, which play an important role in creating broad social 
networks. The incidental social interactions of third place which Oldenburg (1999) defined are more likely to generate weak ties of association which play an important role in linking people, leading to, for example, broadening of opportunities for finding employment (Granovetter, 1983). Third place interactions provide an opportunity for the formation of weak ties, some of which may lead to strong ties of friendship and all of which contribute to building local social capital and forming of a sense of community (Granovetter, 1983). Third place acts to build social capital, particularly bridging capital (Putnam, 2000). While bonding capital is an expression of ties between people who are somewhat alike in identity and/or interests and have a strong group identity, bridging capital links people across groups and connects people to others who have different backgrounds and interests. "Social cohesion in part depends on a balance of bonding, bridging, and linking ties" (Edwards, 2004, p. 103).

Firth, Maye \& Pearson (2011) found the theory of social capital useful for investigating how social ties between neighbours are increased through involvement in community gardens. Community gardens are usually open to the public and many people not involved in the gardens still show an interest. "Community gardens create social capital in that they create a meeting place, which enables people to interact and contribute to the creation of community. This helps to build bonding social capital through increasing ties between neighbours and like-minded individuals" (Firth, Maye \& Pearson, 2011, p. 565). An example of this kind of social capital building can be found in Kingsley and Townsend's (2006) research example of a community gardener in Portside, Melbourne, Australia who said that she had not met any neighbours in 15 years until she joined the community garden.

When people frequent a place, it functions as an introduction point to introduce the local community to each other and allows for development of a regular characters. Social capital can be built by neighbours spending time together improving their neighbourhood (Alaimo et al., 2010). Involvement in community gardening was found to increase residents' perception of bonding and bridging social capital in Flint, Michigan, USA (Alaimo et al., 2010). Bende-Nagy's (2016, p. 101) study of community gardens in Szeged, Hungary, found that community gardens help people who are new to the area integrate into the community through forming connections with the neighbourhood social network. Draper and Freedman (2001, p. 484) found that: "The collective nature that differentiates community gardens from private gardens means that a social interaction is inevitable and the cultivation of meaningful relationships are likely to occur". This 
chapter demonstrates how community gardens create opportunities for social capital development within the garden and the wider community.

Community Gardens require members to work cooperatively and often produce is shared (Gaynor, 2006). Membership rules downloadable from many community garden websites specify that membership is dependent on participation in regular working bees and social media sites show pictures of members celebrating their harvests. Community gardens in the USA were found to improve interpersonal development, team work and commitment (Draper \& Freedman, 2010). Community gardens help to build a sense of community as they are a collective activity, which means that social interactions between members are inevitable (Draper \& Freedman, 2010). Regular contact occurs in community gardens between members and volunteers at meetings and working bees, as well as informal encounters. The potential for over the fence conversations is enormous with opportunities to talk about the weather; enquiring about particular types of plants; asking to take cuttings, etc. In addition, interactions with the community can take place beyond the community garden, where the community garden features as a point of conversation between gardeners and non-gardeners.

Community gardens are community-based initiatives in which neighbours work cooperatively. They have been found to contribute to the creation of community through strengthened social capital between neighbours, member and visitors (Dolley, 2019; Ferris et al., 2001; Firth, Maye \& Pearson, 2011). This is particularly important where traditional links between neighbours are weak due to population mobility and isolation (Frumkin, 2003). Several studies have commented on the potential of community gardens to build social capital within and beyond the garden into the wider community (Chitov, 2006; Draper \& Freedman 2010; Firth, Maye \& Pearson, 2011).

The Draper and Freedman's (2010, p. 485) review of community garden research found that $25 \%$ of the papers discussed the community garden members mobilising themselves and other community members to: "address further community needs". School-based community gardens draw in the community by encouraging parents, relatives and neighbours to volunteer and be involved (Ferris et al., 2001; Pascoe \& Wyatt-Smith, 2013). Ohmer et al. (2009, p. 390) found that $41 \%$ of interviewees in a Pennsylvanian study indicated that volunteering in community gardens lead to volunteering in other community activities and all of the volunteers and community partners in that study indicated that the sense of community had increased due to the community garden. 
As third places, community gardens introduce new neighbours to the community, building local social capital, potentially leading to greater neighbourhood resilience. Oldenburg refers to third places as "ports of entry" for newcomers into the life of the neighbourhood by helping newcomers to learn about people in their community (Oldenburg, 1999, p. xviii). Thompson and Maggin argue that incidental interaction on a day-to-day basis enhances the possibilities for human connection and caring" (2012, p. 260). They indicate that it leads to improved perception of safety and decreases loneliness and isolation. Third places act as a: "mediation between the individual and the larger society" (Oldenburg, 1999, p. xxix). Montgomery discussed the importance of "receptivity" or tolerance of strangers relating to a feeling of belonging (1998, p. 96). It is not contested that third places help to improve community spirit. Gardening in a community setting adds value to the third place notion, as gardening provides a common reason to initiate a conversation to share information and participate in activities together or chat with non-members about the garden.

\section{Inclusivity}

Community gardens are inclusive third places, which encourage placemaking through connecting people with each other and with the land. Despite the opportunity for community gardens to unite people across diversity, Australian research indicates that they are overwhelmingly a monocultural, middle class concern (Turner, 2011; Firth, Maye \& Pearson, 2011). Unlike Australia, social inclusion was found to be both a motivation behind and benefit of community gardens in the USA (Draper \& Freedman, 2010, p. 488). In the USA, community gardens tend to focus on social inclusion where people of different ethnic groups and socioeconomic backgrounds come together, and they provide the opportunity for food growing to the poor and disenfranchised. van Holstein (2019) cautions on the gentrification of community gardens as the incoming demographics change and the new residents gain control of the community garden, disenfranchising the former members.

The term 'third place' is applied loosely to many venues, but the essence of a third place is that one will by chance meet someone in their neighbourhood and have a friendly chat, perhaps facilitated by a local character. The growing familiarity with people in the neighbourhood can help to make people feel like they belong in that location. These third place interactions are the formation of weak ties, some of which may lead to strong ties 
of friendship and all of which contribute to building social capital and forming of a sense of community.

This chapter utilises Granovetter's theory of Weak ties (1983), which are the loose ties between acquaintances and people who socialise together occasionally. The theory of weak ties was developed in the 1960s by Granovetter when he investigated how people came to know about job opportunities (Easley \& Kleinberg, 2010). Granovetter's interview data showed that people were more likely to find out about a job opportunity from people they described an "acquaintance" rather than a close friend. He developed views of friendship across networks and described ties between friends as either weak or strong ties. Weak ties play an important role in creating feelings of safety, connection and wellbeing in communities (Chitov, 2006). Gomez, Baur and Malega (2018, p. 349) investigated users of neighbourhood dog parks in the USA in terms of bridging and bonding social capital and found that the regular social interaction of dog parks build both weak and strong ties improving perceived social cohesion in a "stepwise manner".

Weak ties act as bridges between "clumps of close friends" (Granovetter, 1983, p. 209). Social systems are strengthened through weak ties as they "provide people with access to people and resources beyond those available in their own social circle" (Granovetter, 1983, p. 209). A mix of weak and strong ties is present in community garden interactions, as the weak ties of third places develop into strong ties of friendship. Third places increase neighbourhood sense of belonging and social capital generally (Oldenburg, 1999, p. xxix). Numerous social researchers suggest that everyday incidental interactions of third places improve relationships between neighbours; decrease loneliness and isolation; improve the perception of safety; build social capital and create a sense of place (Oldenburg, 1999; Thompson \& Maggin, 2012; Vincent et al., 2016).

\section{Social capital and resilience}

With increasing need for citizens to be resilient through rapid changes in the Anthropocene, supporting people to be active and engaged citizens is important, for example, in playing a role in both climate change mitigation and adaptation (Crowley, \& Nakamura, 2018; Nursey-Bray et al., 2014). Neighbourhoods with high social capital have been shown to exhibit greater resilience and in the case of community gardens, disaster resilience is uniquely enhanced by their potential for residents working cooperatively and improving food security (Aldrich, 2012; Nursey-Bray et al., 2014; 
Chana et al., 2015). Nursey-Bray et al. (2014, p. 15) conducted a pilot study in South Australia to determine if community gardens could provide a bottom up way of building neighbourhood resilience by strengthening ability for the community to self-organise and strengthen adaptive capacity in order to provide "community-driven responses to change" rather than external 'fixes'. They found that: "community gardens do have the potential to build local adaptive responses to climate change and food security" (Nursey-Bray et al., 2014, p. 15). Houston, MacCallum, Steele and Byrne (2016) discuss the importance of mobilizing grassroots action to respond to climate change. Berkes and Ross (2013, p. 5) discuss: "building resilience through agency and self-organization, with attention to people-place connections". Thornton, Lyons and Sharpe (2018, p. 228) note that planning departments of the inner city and Sydney metropolitan area have developed criteria to assess "the use value of urban agriculture" but have undervalued "many of the important values and contributions that advocates of social movements champion". The importance of the connections between people to place and to other people are of interest to this research study about community gardens and third place and their relationship to placemaking and social capital.

\section{What this thesis is not covering}

Discussions about community gardens, access to green spaces and growing social capital in third places might inevitably veer towards theories of sustainability. In interdisciplinary sustainability research studies, there are four interlinked foci, namely, economy, ecology, politics and culture (James \& Magee, 2016). With a case study of community gardens, it might be expected that this thesis could enter the territory of urban ecology and urban agriculture. It is acknowledged that community gardens are nature-based and can contribute to provision of food at the local level site of consumption and provide resilience in times of disaster given the 'just-in-time' provision of food in cities (Morgan, 2009). Growing food will be considered as part of the motivations of community gardens, however, urban agriculture, food deserts, and food justice will not be a focus of this investigation.

\section{Community Garden Design and Planning Policy Implications}

Public space usage is hotly contested, drawing competing demands and limited budgets for infrastructure. 
"Although some city officials appear sympathetic, and in some cases supportive of neighbourhood efforts to start up community gardens on public lands, the general approach demonstrates one of ad hoc, and case by case, consideration of urban agriculture proposals to assess their merits, rather than broad-scale support and valuing of such initiatives" (Thornton, Lyons \& Sharpe, 2018, p. 228).

Mintz and McManus (2014) suggest that research findings and policy evaluation frameworks can improve policy and decision making to support community gardens.

Third places are accessible by walking and open at times which suit the visitors, they are places where neighbourhood faces become familiar (Oldenburg, 1999). In terms of health and wellbeing, the number of people who walk somewhere is affected by the amenity, density and the variety of destinations, therefore providing places which are worth visiting on a walk has implications for improving the wellbeing of the neighbourhood (Zapata-Diomedi, et al., 2019). Zapata-Diomedi et al. (2019) note that in Australia there is increasing attention being paid to designing communities which are walkable, sustainable and encourage physical activity. One such plan they refer to is the document, "A Plan for Growing Sydney" in which Goal Three to promote thriving communities includes:

"Access to locally grown fresh food also supports healthy communities and broader sustainability objectives. There should be increased access to food production in urban areas and in adjoining spaces through community gardens, which provide home-grown produce, and through better access to produce grown in surrounding agricultural areas.” (NSW Planning and Environment, 2018)

There is a duel benefit to the combination of walkability (including being a 'destination' which adds to the reasons to walk) and fresh food that community gardens produce. These benefits are enhanced if the community gardens are also third places, as this adds to their social value.

As with van Holstein study of community gardens in Sydney, the gardeners express resistance to assistance (or interference) from the local council (2019). In van Holstein's (2019, p. 11) study the community gardeners reportedly express that the council would like more control over the look and operation of the community garden and express that "resisted efforts by government to enact discursive ownership over the space". 
People's actions are shaped by their environment and they in turn shape their environment by their actions. A community garden is often an untidy place in a world of straight lines and hard surfaces. Community Gardens are a place where the people make the rules. Wright Mills (1959, p. 12) writes of the sociological imagination that: "By the fact of his (sic) living, he contributes, however minutely, to the shaping of this society and to the course of its history, even as he is made by society and by its historical push and shove". The community gardeners, by gardening in an urban public space, contribute to the shaping of their city and society, to the course of its history and direction of its future. What is really interesting as a research problem is that many people in the city have access to food growing opportunities at their residence albeit in some cases just a windowsill or balcony, however community gardeners choose to garden together.

\section{Conclusion}

This literature review identified a gap in the literature in determining whether or not community gardens are third places and what the implications of community gardens as third places would be on neighbourhood wellbeing. This chapter explored the literature on community gardens and on third places and then drew the two together as a background to the research problem to investigate community gardens against third place characteristics in a range of locations. This chapter critically revisited the third place literature through the theoretical lens of placemaking and social capital.

To date, the research on community gardens has extensively investigated their goals and benefits. The literature on community gardens indicates that they are, on balance, a positive force for those involved and the surrounding urban community, though the factors which influence the success and longevity of community gardens vary. The literature illustrates community gardens as third places with examples from community garden literature, however notes that they are assertions applied loosely. Community gardens combine nature with community, bringing the combined health outcomes of a cultural landscape (community) and natural landscape (garden) in an urban landscape. Planning policy might alleviate some urbanisation challenges by offering space for community gardens and advice on designs which best facilitate third place interactions. 


\section{CHAPTER 3 - METHOD}

This chapter provides the context and details of the case study sites and the stages of the research processes that inform the findings discussed in the three thematic results chapters (4, 5 and 6). Reviewing the literature on community gardens showed that they had not been specifically studied in relation to the urban sociological concept of 'third place'. While there are several articles describing community gardens as third places, the term has been applied as a description to indicate qualities of informal meeting places in a neighbourhood. The findings on community gardens that have been described as third places have been presented in the previous chapter. The literature on community gardens does not include data in a format which is appropriate or sufficient enough to demonstrate if community gardens of different locations and characteristics all equally act as third places. Therefore, in order to investigate if community gardens are third places, the research design of this study applies a purposeful framework of the third place concept to a selection of community garden case study sites.

As already stated, there are a number of reasons to consider this topic sufficiently significant to research, including the effect on urban challenges such as social isolation and challenges associated with population mobility. The research links into placemaking, social capital and resilience-building research. The research problem also relates to UN Sustainable Development Goal 11.7, to provide safe and inclusive green spaces to the community. As with sustainable development goals, the goal may be global, but the action is taken at the local level. Community gardens are symptomatic of a desire for change in the face of the pressures of a complex urban environment. It is worth investigating the motivations and benefits behind the growing interest in community gardens and the additional value they may bring to society if found to act as third places.

In this chapter, the research questions, method and design of this dissertation are described and justified. It covers the choice of a qualitative research study and the use of case studies as the chosen research method. Data was collected and analysed with the intention of determining if community gardens are third places. The data collection and analysis techniques and questions of confirmability, dependability, credibility and ethics are addressed. 


\section{The research questions}

The findings in the literature review informed the formation of the research questions posed in this thesis (Abrahamson, 1983). The first research question explores where community gardens fit in relation to Oldenburg's concept of "third place" as described by eight signature characteristics (1999). The overarching research question and the subquestion is:

1. To what extent are community gardens third places? Do community gardens fit the eight characteristics of a third place?

Given the previously discussed community garden literature which loosely associates the third place concept with community gardens, it is not presumptuous to start from a position that in all likelihood there are at least some elements of third place in some community gardens. This is why the research question is not a simple, "Are community gardens third places?', but asks a detailed question of the extent to which they may be third places. The sub-question denotes the problem solving framework employed to determine the extent to which community gardens are third places. The eight characteristics of third places act as a framework to answer the research question.

The question is broad, allowing the exploratory nature of the case study. While an exploratory case study is "broad and open ended", the research questions need to be focussed around several "how and why" questions on issues which arose in the literature review (Hartley, 2005, p. 328). In order to address the research significance of the answer to the first question, a further two questions are posed, derived from the basic question Are community gardens third places? (See Figure 3.1) 


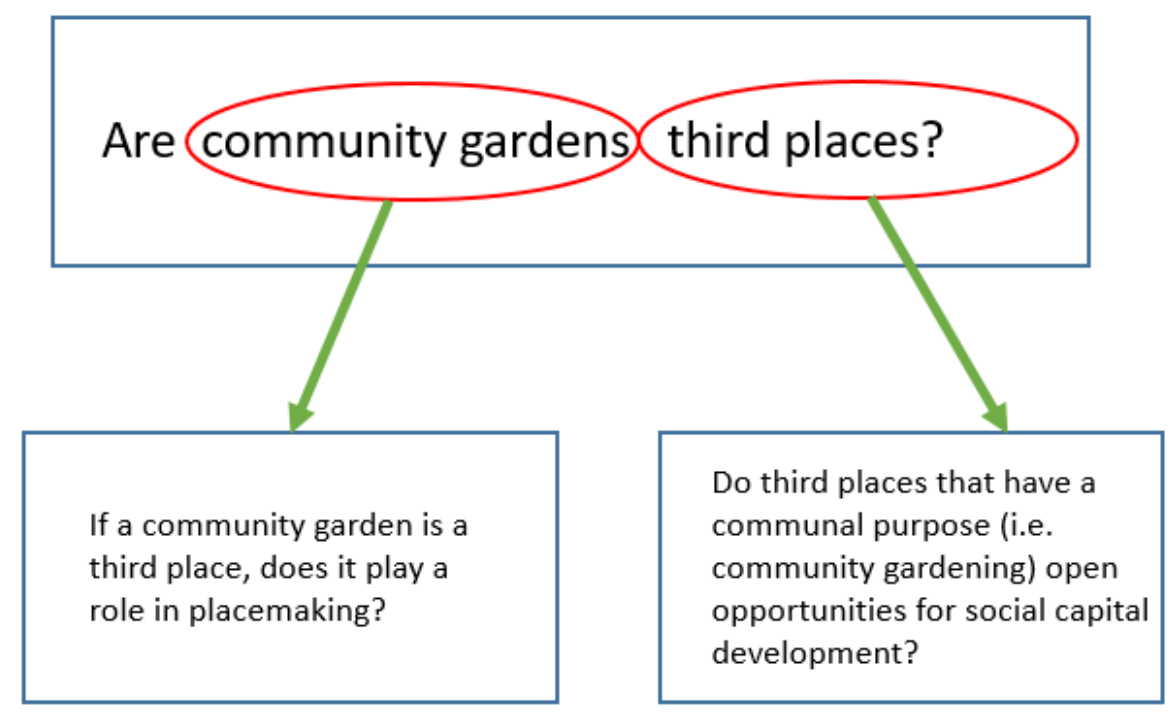

Each of these three questions in Figure 3.1 forms the basis of the three thematic data chapters which follow. The first question is the focus of Chapter 4 with the aim to address the gap in the literature on community gardens as third places. The literature review and first data chapter inform the research question on placemaking (Chapter 5) and social capital (Chapter 6).

As Figure 3.2 illustrates below, the framework of the eight characteristics which is applied to determine third place can be divided approximately evenly to inform the themes which arise from the data analysis. Chapter 5 responds to Question 2 - If a community garden is a third place, does it play a role in placemaking? It explores the placemaking attributes of community gardens which are third places and has implications for addressing population mobility and sense of place. Chapter 6 responds to Question 3 - Do third places that have a communal purpose (i.e. community gardening) open opportunities for social capital development? It determines effects on social capital development of community gardens which are third places and has implications for addressing social isolation and building neighbourhood resilience. The research questions and the approach to answering them are informed by the researcher's theoretical approach which is described in the following section. 


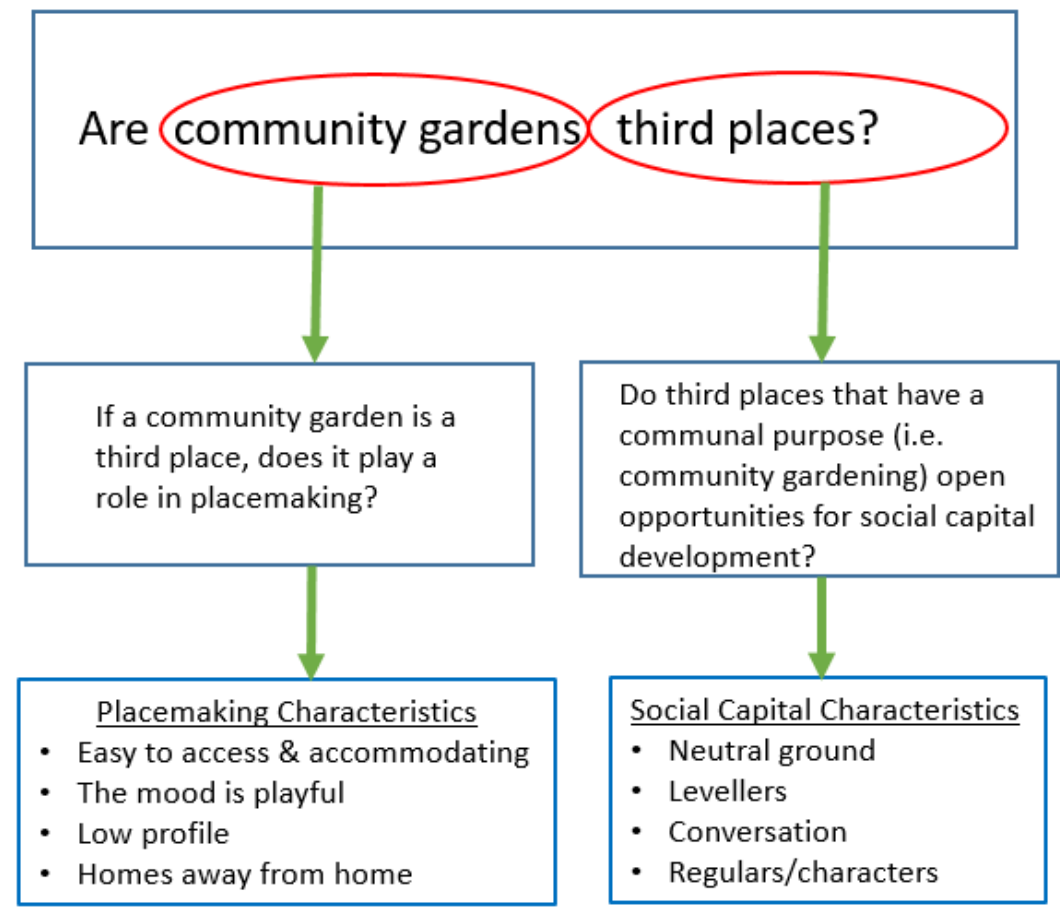

\section{Research Theories and Perspectives}

This research will use a qualitative research methodology involving the method of case studies. Research methodology refers to the approach taken to a research project, while the research method is the set of tools used to achieve the research goals (Pacho, 2015). The research questions will be addressed by an exploratory case study across six sites which cover different characteristics of community gardens.

A qualitative approach to the research problem is useful when complexities such as people in urban environments are the subject, as the approach can tell a rich story. Draper and Freedman's comprehensive literature review of 55 USA papers on community gardens from 1999 to 2010 found that $49 \%$ of studies on the topic were qualitative (2010). "The advantage of a purely qualitative, hermeneutic analysis of the evidence lies in its ability to provide insights that are difficult to achieve using quantitative, statistically oriented methods" (Fiss, 2009, p. 433). A qualitative research approach allows the researcher to draw insights into multiple facets of people in community gardens and third places and the intersection of both, with caveats that different times, mixes of people and urban designs may yield different results.

A quantitative approach would require a representative sample of a large number of participants in order to make statistically significant assertions (ie. through a survey), but 
would not have been suitable for this topic because it would have lacked the thick description associated with qualitative research (Silverman, 1993). The researcher did not approach the research from a positivist's view to seek to 'know' the truth sufficiently to judge all community gardens and gardeners. However, by using a qualitative approach seeking a range of types of gardens and a range of types of members (explained in Tables 3.1 and 3.2), the interview data provides thick description in order to find relationships between the data, theory and existing bodies of literature. The aim is to derive useful insights into how community gardens can act as third places and what the benefits, challenges and implications of this would be. The size and selection of the data sample aims to be sufficient to capture the 'black swan' of the case study community gardens, where a single exception can provide a wealth of information for interpreting the findings (Taleb, 2007). It is intended that the epistemological framework in these methods would be applicable to research on other types of public spaces.

\section{Research Approach}

The research paradigm is a way of thinking about the underlying assumptions which contribute to how we perceive and understand attributes and characteristics of the world around us (Kuhn, 1970). Research about human behaviour within society presents difficulties in attempting to determine or know the accuracy of the situation as there may be numerous interpretations of "truth" depending on the perspective of the research subject - in this case, community gardeners and the researcher (Halfpenny, 1982). In this study I will attempt to explain how community gardens work in relation to the third place concept, but I acknowledge this will be my interpretation, not an objective finding on the matter. When investigating such complexities as communities, a social science approach to research is useful as it can tell a rich story. In questioning if community gardens act as third places, the research will investigate the reasons why people want to work together; what they hope to achieve by working for their community; and how they go about working together. It can be impossible to prove a theory in such an urban research question, however a case can be formed. The case made can be asserted partly through disproving alternative explanations.

I am motivated to seek answers to some of the challenges affecting the happiness and wellbeing of people who live in cities. Michael Jacob (1996, p. 18) describes the "overdeveloped megalopolis" as causing an "experience of uneasiness". I am in part 
spurred on by what Eagleton (2008, p. 13) refers to an "ontological anxiety" which leads people to seek meaning, rather than despair of a "crash" or "collapse", which Slaughter (2010) describes as "do nothing" words of giving up passively. As Cameron and Wright (2014) suggest, by conducting research into alternative food movements, such as community gardens, the research findings have potential to support to their goals. Coupling the case study site with third place research links the relevance of community gardening to the wider community neighbourhood.

The epistemological approach explains the relationship between knowledge and the researcher. I acknowledge that 'knowledge' in urban research struggles to be objective, however, confirmability will be sought through including the context of the research in the telling of the findings (Byrne, 2012). The epistemological approach used is interpretivism, namely to "understand what it is to be human and what meanings people attach to the events in their lives" (Grant and Giddings, 2002, p. 16). This thesis will involve interpreting the data in relation to the situational context and constructing meaning from it in relation to the other case study participants and sites and to the other research literature on community gardens and third places.

While positivists seek an objective finding, the interpretivists acknowledge their role in interpreting their research (Halfpenny, 1982). As an interpretivist researcher in a case study research method, the researcher is somewhat immersed in the context of the site. At varying levels at the six community gardens, I pulled out some weeds alongside the gardeners, attended some meetings and shared lunch and afternoon tea (and on the downside was accidently hosed and picked some stinging nettle with bare hands). This was not intentional participant observation embedded as a fellow gardener, and clearly my gardening skills were not in evidence. However, the observations were recorded as notes and add to the richness of the data.

The interpretivist approach requires reflexivity on the part of the researcher in the collection, analysis and interpretation of the data (Grant and Giddings, 2002). Delving into participants' personal motivations for joining a community garden, consideration may involve "the epistemological importance of emotions in mediating identities, relationships and place" (Pini, Mayes \& MacDonald, 2010, p. 559). While the interviews were not emotive, it was possible to detect emotions when some participants reflected on conflict, setbacks, effort and enjoyable times. Considering my own positionality and the fluidity of the researcher/participant relationship, I acknowledge that I am well disposed 
towards community gardens and impressed by the time and effort that community gardeners put into their establishment and maintenance. Though never having been a community gardener, my time visiting and interviewing active participants has introduced me to their concerns, motivations and community spirit. Over the course of data collection I may have developed a supportive attitude, but I attempt to counteract any element of researcher bias at play in this qualitative research by reflecting on my research practice and systematically adhering to the research method. I acknowledge that I have developed an interest in third places (refer to the edited book in production in parallel with this research thesis). By presenting the research findings with thick descriptions from the participants own voices, the reader also has the opportunity to be actively involved in the researcher's interpretation of the interview data, which therefore strengthens the research confirmability. The study participants were friendly and on occasion in the semistructured interview format, we meandered beyond the topic of community gardens and motivations onto other topics, some of which appear in the "future research" section in Chapter Seven.

\section{Methodological Traditions}

Methodology refers to systematic ways to discover knowledge, and every discipline has its own methodological traditions and precedents. This research will use a number of sociological theories and concepts which have been discussed more fully in the literature review (Chapter 2), namely, third place, placemaking, social capital and to a lesser extent, population mobility, social alienation, inclusivity, resilience and authenticity. Like most areas of sociology, urban sociologists employ a range of methods including case studies, statistical analysis, observation, social theory, interviews, amongst other methods, to study a range of topics, including migration and demographic trends, economics, poverty, race relations and economic trends (Gans, 2017; Flanagan, 1993). As an example of methodologies which have been successfully applied to food-related social and community learning contexts, Firth, Maye and Pearson (2011) discuss the approaches of "communities of practice" and "diverse economies" to assist researchers to further investigate the value and social capital building capacity of community gardens. As an example of research on a site which could be called a third place, Gomez, Baur and Malega's (2018) case study of local dog parks examined social cohesion using theoretical frameworks of bridging and bonding social capital in a small site where regular 
neighbourhood interactions occur. Urban planning research often centres on comparative analysis to investigate best practice planning (Dodson, 2014).

My research is situated in the research paradigm of human geography and refining this further is the field of urban geography. Urban geography research questions always relate in some way to a spatial dimension (Chakravarti \& Tiwari, 1990). In the case of this research, the spacial dimension is a crossover of community gardens and third places. Chakravarti and Tiwari describe four types of research problem in geography and arrange them in a hierarchy of quality, starting with the more basic form of 'descriptive', to 'problem solving' to 'developing methodology' to 'law giving' (1990, p. 53). This research project evolves from descriptive to problem solving in that it seeks to answer a research question through "systematic analysis" (Chakravarti \& Tiwari. 1990, p. 53). Research in Human Geography and Urban Geography can fit quantitative methods or mixed methods, however, my investigation into the specific social world of community gardens and third places is best suited to the qualitative approach (Grant \& Giddings, 2002). The intent is for this research thesis not only to answer the research questions, but to discuss it in relation to a number of theories and to develop a method of applying a third place framework to a site which can be replicated for other place-based research.

\section{Research approach and design}

Conceptualising the problem or research question to be addressed is the first step in designing a research project. The research method chosen for this dissertation was the case study. Case studies are a popular method of investigating research problems in social sciences as they provide an in-depth sample of societal phenomenon (Silverman, 1993). Yin's definition of the case study research method is an empirical inquiry that investigates a contemporary phenomenon within its real-life context; when the boundaries between phenomenon and context are not clearly evident; and in which multiple sources of evidence are used (Yin, 1993). As Yin (2009, p. 71) points out, the case study method requires "adaptiveness and flexibility" and the researcher should acknowledge if the case study leads to a change in emphasis of the research, maintaining "rigor - but not rigidity". Criticisms of case studies centres on the generalizability of the research, however the research design minimises this by using multiple cases in different locations including an international site. Dietz (2002) warns that although the characteristics of neighbourhoods 
may influence social and/or economic outcomes for the residents, in many cases the causative effects may be overestimated in the research outcomes.

The method employed in this study was an exploratory case study based on broad questions about community gardens, third place and social capital. Exploratory case studies allow for broad questions, resulting in a more general picture which in turn might point to areas for further research (Yin, 2009). It is a useful research method where there is a need to find out what is happening and determine if there are problems to explore or to "seek new insights" about a topic (Saunders, Lewis, \& Thornhill, 2009, p. 139). The exploratory case study is appropriate when there is limited academic literature specific to the topic, in this case, filling a gap in the literature on community gardens as third places.

The reason for choosing a multiple case study over a single case study is that "the research may be strengthened" by additional cases as this allows for exploration of contrasts and similarities (Hartley, 2005, p. 326). A number of potential case study sites were researched in person while at an AFRN (Alternative Food Research Network) conference in Sydney; personal local knowledge in Brisbane; Facebook searches; and sites provided by the international grant collaborative team in Denmark. Purposive sampling guided the choice of case study sites (Silverman, 2006). They were chosen in order to represent a range of characteristics of community gardens as informed by the literature review. Purposive sampling covered a range of case study sites and range of participant types in order to best come to understand the participants and the meaning they attach to the place (community garden) and the people they interact with. Investigating across community gardens which cover a range of locations and characteristics presents a range of contextualised outcomes.

\section{Data Collection}

To investigate the research questions, this study uses interviews, observations and reviewing secondary data including reports and social media as data collection methods. Interviews and observations take place in community gardens. Secondary data source material includes publicly available information such as the Australian Bureau of Statistics data; community garden reports retrieved from websites; and Facebook information.

The stages of data collection and analysis used to help to address the research questions are: 
- Stage 1 - Semi-structured interviews with community garden key stakeholders from six types of community gardens

- Stage 2-Observations noted while spending time in the case study sites.

- $\quad$ Stage 3 - Transcription and analysis of data using NVIVO.

- $\quad$ Stage 4 - Feedback will be provided to participants.

\section{Ethical considerations and gaining access}

As with all Australian university-based research, contact with research participants requires Ethics Committee approval. The approval letter is provided in Appendix 7. The ethics approval from Griffith University was expedited because of low risk. There were only minor ethical issues to consider in this project despite enlisting human subjects. As the participants were adults, they could provide their own consent to participate in the project. An informed consent form for signature and accompanying information sheet was supplied to each potential participant. Recording the interviews required signed consent forms. The audio recorded data was transcribed and de-identified and safeguarded on a password protected Griffith University computer in the de-identified form. Observation of activities and meetings in the community garden did not present ethical difficulties because there was no direct questioning of gardeners.

Steps were taken to preserve confidentiality and anonymity. The ethics approval required that the community gardens and individual participants were assured anonymity, therefore all gardens and participants have been given pseudonyms. Individual names cannot be released, however, it is not documented that the community garden itself needs to remain anonymous. However, just to ensure that no participant is recognisable, pseudonyms for the case study sites have also been provided. The city in which the community garden is situated is stated, as several municipal documents have been referred to with regard to support for community gardens in that city. A pseudonym was provided for the town in Denmark as it was the only library in the area, therefore would be easily identifiable.

Obtaining further information was made possible through information placed on community garden websites and Facebook pages. However, as the ethics approval applied for did not include permission to present these as a source of information, they have only provided background information about dates of events, contact persons, and historical information about the garden. A gift of two packets of organic or heirloom seeds were 
given to participants as a token of appreciation. Feedback has been given to the participants in the form of links to papers published and a "The Conversation" article (see Appendix 4). At the conclusion of the $\mathrm{PhD}$, a summary of the report will be posted to each community garden with a note of appreciation for their involvement.

\section{Methods and Research Instruments}

The research techniques employed in carrying out this research include interviews, observation and secondary data collection. These three techniques are regularly used in social science research for providing a rich account of phenomenon from a representative sample of a particular population subset (Abrahamson, 1983; Patton, 2002; Yin, 1984). The research questions are addressed by interviewing participants from community gardens in different locations covering a variety of different community garden characteristics (Silverman, 1993; Yin, 2009).

The semi-structured interview questions were designed then discussed with the supervisors of this thesis and were approved by the University Ethics Committee (Appendix 6). Data was collected through semi-structured interviews with key stakeholders (Hartley, 2005). Semi-structured interviews require an element of rapport with the interviewees based on their gaining an awareness of the broad aims of the research project (Noaks \& Wincup, 2014). The semi-structured format was chosen over structured interviews or surveys because it allows freedom to explore topics as they arise, yet provides enough structure to ensure the basic questions are covered. Rapport with the interviewees developed by starting with an interview schedule which included a number of initial set questions asking about the participant's role in the community garden; how long they had been a member; and about their motivation for joining the community garden. In most cases, the rapport was also achieved by interviewing them in the garden.

The interviews were conducted in a semi-structured technique, using the questions as guidelines, but allowing the interviewer to pursue interesting lines of inquiry. The introductory questions were the same for all participants: "How would you describe your role in the garden?"; "How long have you been a member/visitor/staff?". The following interview questions were semi-structured, based on a simple checklist of the eight characteristics of a third place that were used as cue notes to ensure that the topics arose, but without being fed to the interviewees. For example, for the characteristics of 'conversation' and 'playful mood' the questions might include: 
- What sort of activities do you participate in when you visit here?

- What do you like most about being a member of a community garden?

- What are some of the enjoyable aspects of being part of this community garden?

- Is there something about what you grow that others are interested in?

The semi-structured interview technique suited the exploratory case study method as it allowed the interviewees the opportunity to elaborate on broader points of interest about the community garden and their role and relationship to it. The semi-structured nature of the interviews allowed flexibility to respond to interesting information which the interviewee was imparting.

The interview schedule (see Appendix 6) included a checklist of the eight characteristics of third place, but it is important to note that the words of the third place characteristics and the concept of third place were not explained to the participants. This may be why the participant quotes do not exactly match the wording of the characteristics, but were reached obliquely through presenting simple, open questions to allow the participant to explain rather than supply words relating to the topic. There were questions relating to each characteristic as prompts, but being semi-structured interviews, the simple list at the end of the interview schedule served as a checklist (see Figure 3.3 below).

Figure 3.3 Semi-structured interview schedule checklist

\section{Third place checklist}

\begin{tabular}{|l|}
\hline Neutral ground \\
\hline Leveller \\
\hline Accessibility and accommodation \\
\hline Conversation \\
\hline Regulars \\
\hline Low profile \\
\hline Playful mood \\
\hline Home away from home \\
\hline
\end{tabular}

The semi-structured interview method allowed the freedom for new themes to emerge beyond each characteristics of third places. The data from participants was digitally recorded interviews, field notes relating to observations and photos. Semi-structured interviews were the primary source of data collection. Key informants provided 
interviews ranging from 10 minutes to 60 minutes, averaging 25 minutes and all but three were recorded on site (one was via a phone call due to being interstate; one was conducted at a participant's house; and one took place at the participant's workplace). As most of the interviews were conducted on site (and occasionally in action) this was an authentic context to obtain rich data.

In addition, the opportunity to observe meetings, group activities such as working bees and informal interactions amongst members and between members and the wider community provided rich data. These were recorded as notes during and after leaving the site visits. Photographs of the sites were taken for reference in recalling the design. These cannot be reproduced in any numbers or the anonymity of the sites may be compromised. The purpose of observations was to investigate several of the characteristics of third place, eg. 'conversation' and 'playful mood', and the interactions with people in the neighbourhood. There are precedents for this type of research method. For example, Saldivar-Tanaka and Krasny conducted interviews with key stakeholders and collected observations in 20 New York community gardens, coding the data for themes (2004).

Observations of activities occurring on the case study sites are included in the analysis. The notes from the observations were taken in hard copy then scanned and stored with each case study site folder, for reference when required. They were not coded in NVIVO, as is the case in some research projects, but along with the photos, served to remind the researcher of the context and reflect on how the design and placement and activities relate to the findings.

The sources of data include secondary data such as Australian Bureau of Statistics information about the case study areas. Characteristics of the sites are detailed in the case study section as part of the background data, because socio-economic status and other location-related data informs the research outcomes.

The research methodology also involves reviewing the role of social media in community gardens, including Facebook and websites, in facilitating recruitment, information dissemination and in strengthening connections in the community. Wilson, Gosling and Graham's (2012, p. 203) extensive literature review on the use of Facebook as a source of data for research concluded that it has the advantages of being able to, "observe behaviour in a naturalistic setting". They did note, however, that it is a relatively new forum in which to collect data, therefore the most effective ways to conduct research from social media sources are still being investigated for future research opportunities. The 
semi-structured interviews are the primary source of data for this research thesis. Observations and secondary data including social media provide supplementary evidence to enrich the data analysis.

\section{Credibility, Confirmability and Dependability}

Triangulation of multiple data sources was carried out in order to increase the rigour of the findings (Yin, 2009). Credibility in qualitative research relates to how trustworthy or valid the findings are (Byrne, 2012). Credibility is strengthened through data triangulation of information collected through different methods and sources (Byrne, 2012; Denscombe, 2010). In this case, the main method is interviews, but observations, social media and secondary data such as council reports provide multiple sources of information for triangulation (Abrahamson, 1983). The interviews were recorded and fully transcribed. The observational data provides context such as a description of the physical setting of the garden and a list of activities which occur there.

Confirmability parallels objectivity in relation to the likelihood of other researchers drawing similar findings from the same sample of research participants (Byrne, 2012). Reflecting on my positionality, my background in environmental science and Masters research on the use of school gardens for teaching the school curriculum does give me a positive outlook towards community-based gardening. However, I consider this has provided the interest in the topic rather than a bias which will affect the confirmability of the analysis towards seeking unsubstantiated positive findings.

Dependability was achieved through using the same procedures for each interview (Byrne, 2012; Yin, 1993). The collection of interview data demonstrated consistency in interview technique because only one researcher conducted the interviews and a semistructured schedule of questions was used. Only one researcher coded the data, which limited the "inter-rater reliability" (Silverman, 1993, p. 149). However, dependability in coding for themes emerging from the open-ended questions was achieved by the researcher's co-authoring with one supervisor on a conference paper (Pascoe \& Howes, 2017 - Appendix 1) and peer review of an accepted book chapter by my second supervisor (Dolley, 2019 - Appendix 2), as well as their review of the findings of this thesis.

\section{Limitations of Research Method}

The fact that the gardens are in different cities is not to say that they are representative of all community gardens in those cities. In addition, the study would have benefitted by also capturing directly the voices of some people who interact with the community garden 
without being members. In drawing conclusions from the data it was important to be cautious about making generalisations from a sample of the population and about assessing that what the interviewees say as representative of how they actually behave (Silverman, 1993, p. 150). As there is only one of each type of community garden in each category and only six in total, there are limitations on the generalizability of the findings. However, by covering a range of garden types, the thesis is able to provide valid insights into community gardens as third places and their impacts on neighbourhood social capital.

\section{Site and participant selection}

The rationale for this participant selection method is to cover a broad range of community garden types and participant types. Table 3.1 is a table of characteristics of community gardens derived from the literature in order to inform the selection of case study sites. The six chosen case study community gardens cover various combinations of characteristics including: garden design; garden purposes; garden placement; characteristics of the area (housing density and socioeconomic status); type of participant membership; security of tenure; infrastructure; land ownership; operational matters; infrastructure provision; support (official support, land, advice); and governance style. Each garden has at least one unique characteristic (highlighted). The fact that the gardens are in different cities is not to say that they are representative of community gardens in those cities, but rather each is part of the larger study and represents certain characteristics of current community gardens as represented in Table 3.1. Nor is one case study site which uniquely represents a particular characteristic, intended to represent that characteristic across all community gardens. By systematically selecting case study sites which exhibit a range of community garden characteristics the data offers the potential to test the rigor of the findings and explore alternative explanations. Covering a range of characteristics of community gardens is intended to provide the opportunity for a broad exploration of community gardens of various characteristics. 
Table 3.1: Characteristics of the six case study sites

\begin{tabular}{|c|c|c|c|c|c|c|c|}
\hline TYPE & Characteristics & $\begin{array}{l}\text { Case Study } 1 \\
\text { Kookaburra }\end{array}$ & $\begin{array}{l}\text { Case Study } 2 \\
\text { Pine Park }\end{array}$ & $\begin{array}{c}\text { Case Study } 3 \\
\text { Marville }\end{array}$ & $\begin{array}{l}\text { Case Study } 4 \\
\text { Frank Street }\end{array}$ & $\begin{array}{l}\text { Case Study } 5 \\
\text { Bluevale }\end{array}$ & $\begin{array}{l}\text { Case Study } 6 \\
\text { Hagenlund }\end{array}$ \\
\hline \multirow[t]{3}{*}{ Garden design } & Communal only & & & $\mathrm{X}$ & $\mathrm{X}$ & & \\
\hline & Individual plots only & & & & & & $\mathbf{X}$ \\
\hline & Both communal and individual & $\mathrm{X}$ & $\mathrm{X}$ & & & $\mathrm{X}$ & \\
\hline \multirow[t]{3}{*}{ Garden purposes } & $\begin{array}{l}\text { Education focussed (Sustainability, skill } \\
\text { development, etc) }\end{array}$ & & & & & $X$ & \\
\hline & Growing Food Purpose & $\mathrm{X}$ & & & $\mathrm{X}$ & & $\mathrm{X}$ \\
\hline & Mixed Purpose & & $\mathrm{X}$ & $\mathrm{X}$ & & & \\
\hline \multirow[t]{2}{*}{ Garden placement } & $\begin{array}{l}\text { Place-based (mainly locals - walking distance - the } \\
\text { closest) }\end{array}$ & $\mathrm{X}$ & $\mathrm{X}$ & $\mathrm{X}$ & $\mathrm{X}$ & & $\mathrm{X}$ \\
\hline & Interest-based (people from afar) & & & & & $\mathrm{X}$ & \\
\hline \multirow[t]{3}{*}{ Housing density } & High Density & & $\mathrm{X}$ & & & & $\mathrm{X}$ \\
\hline & Mixed density & $\mathrm{X}$ & & $\mathrm{X}$ & & $\mathrm{X}$ & \\
\hline & Low density suburban & & & & $\mathrm{X}$ & & \\
\hline \multirow[t]{2}{*}{ Socioeconomic status } & Low SES & & & & & & $\mathrm{X}$ \\
\hline & Mixed SES (and gentrification) & $\mathrm{X}$ & $\mathrm{X}$ & $\mathrm{X}$ & $\mathrm{X}$ & $\mathrm{X}$ & \\
\hline \multirow[t]{2}{*}{ Membership type } & Membership only/mainly & $\mathrm{X}$ & & & & & \\
\hline & $\begin{array}{l}\text { Low membership requirements/Volunteers and } \\
\text { visitors welcome }\end{array}$ & & $\mathrm{X}$ & $\mathrm{X}$ & $\mathrm{X}$ & $\mathrm{X}$ & $\mathrm{X}$ \\
\hline \multirow[t]{4}{*}{ Land ownership } & Private or commercial land & & & & & & $\mathrm{X}$ \\
\hline & Public land/ park & $\mathrm{X}$ & $\mathrm{X}$ & & $\mathrm{X}$ & & \\
\hline & Reclaimed or contested land & & & $\mathrm{X}$ & & & \\
\hline & Marginal land & & & & & $\mathrm{X}$ & \\
\hline \multirow[t]{2}{*}{ Operational } & Organised/operated by the members & $\mathrm{X}$ & $\mathrm{X}$ & $\mathrm{X}$ & $\mathrm{X}$ & $\bar{X}$ & \\
\hline & Organised/operated by an authority & & & & & & $\mathrm{X}$ \\
\hline \multirow[t]{2}{*}{ Infrastructure } & Provided by authority & & $\mathrm{X}$ & & $\mathrm{X}$ & & $\mathrm{X}$ \\
\hline & Provided by members/grants/ fundraising & $\mathrm{X}$ & & $\mathrm{X}$ & & $\mathrm{X}$ & \\
\hline \multirow[t]{2}{*}{ Support/ Adisor } & Official support & & $\mathrm{X}$ & & $\mathrm{X}$ & & $\mathrm{X}$ \\
\hline & Self-supporting (largely) & $\mathrm{X}$ & & $\mathrm{X}$ & & $\mathrm{X}$ & \\
\hline \multirow[t]{2}{*}{ Openness } & Open $24 / 7$ & & $\mathrm{X}$ & $\mathrm{X}$ & $\mathrm{X}$ & $\mathrm{X}$ & $\mathrm{X}$ \\
\hline & Fenced/ limited opening times & $\mathrm{X}$ & & & & & \\
\hline \multirow[t]{2}{*}{ Governance style } & Committee roles/ formal/ a leader & $\mathrm{X}$ & & $\mathrm{X}$ & $\mathrm{X}$ & $\mathrm{X}$ & $\mathrm{X}$ \\
\hline & Laisser-faire, consensus, no formal rules & & $\mathrm{X}$ & & & & \\
\hline
\end{tabular}

Highlighted cells indicate a feature unique to that case study site. 


\section{Declined participation and problems encountered with case studies}

It should be noted that one of the proposed Brisbane case study community gardens declined the invitation to participate in the project due to operational reasons offered by the management. The garden had a specific characteristic of being funded and run by an organisation, thereby avoiding the need for organisational obligations on the part of the community garden members. It was pivotal to the case study selection process, as the methodology included a garden where most of the organisational work and cost is undertaken by an authority of some kind. It fitted within the definition of a community garden (as applied in this thesis), as it is, 'maintained by members of the community' through involvement of volunteers and is of "benefit of individuals and/or the community", as an educative food garden visited by locals and tourists. Through a research grant awarded during my candidature, the University of Southern Denmark collaborators were able to arrange interviews with two community gardens and an allotment in Denmark. It was fortuitous that the Hagenlund Library Garden (Denmark) was available to participate, as it exhibited the desired characteristics. While it was excellent to find a replacement garden for the study, there are limitations of the particular case study site which perhaps make the data less representative. The number of interviewees and the length of time of observation limit the depth of the data. Because the garden is in a location where English is not the local language, only one community garden organiser was available to interview. Also, because of the limited time available to visit the garden, observations of the garden over time were not possible. However, the Hagenlund Library Garden website has been visited to follow the progress of the garden. There may be limitations to comparing case study sites when all but one are in Australia. This case study site is a point of comparison between types of community gardens rather than a review of differences between countries. The other two garden visits arranged by Southern Denmark University were both in Odense and included a school garden and an allotment, which upon reflection did not fit the community garden definition set out by the case study design. On the positive side, it is interesting to include a community garden from another country as a point of comparison and it is beneficial to be able to replace the community garden type which was otherwise unavailable due to permission issues. 


\section{The case study sites}

The data collection includes 29 interviews conducted across six case study sites including five community gardens in Australia (one Sydney, three Brisbane, one Gold Coast) and one in Denmark. The quality of the case study is enhanced when data is collected from multiple sources of evidence (Yin, 1993). It was fortunate that in the approach to the community gardens, all but one potential case study site agreed to participate, however, this was replaced. The inclusion of one Denmark case study is explained in the section on 'declined participation'. Criteria for inclusion as case study sites was within this thesis definition community gardens:

Public gardens, including a food growing purpose, established and/or maintained by members of the community for the benefit of individuals and/or the community.

To follow is a description of each case study site and the research participants and a summary of the main similarities and differences between sites.

\section{Kookaburra}

The Kookaburra community garden at the Gold Coast (Queensland, Australia) is in the middle of a mixed socioeconomic status suburb at the northern end of the city with a mix of detached houses, townhouses and multi-story units. It was established in 1998. The Kookaburra garden is hidden below the street level and behind two metre high security fences, with members having key access to the premises. Many of the members drive to the garden, though for most it is their closest community garden. The design is a mixture of individual and common charity plots for local schools and for providing food to charities. The Kookaburra garden has a structured committee and the committee is vigilant of active membership and well maintained plots. They have a social membership class for those who are unable to or don't want to garden. Interviews were conducted with eight members across the three participant categories of committee member, long term and new members. 


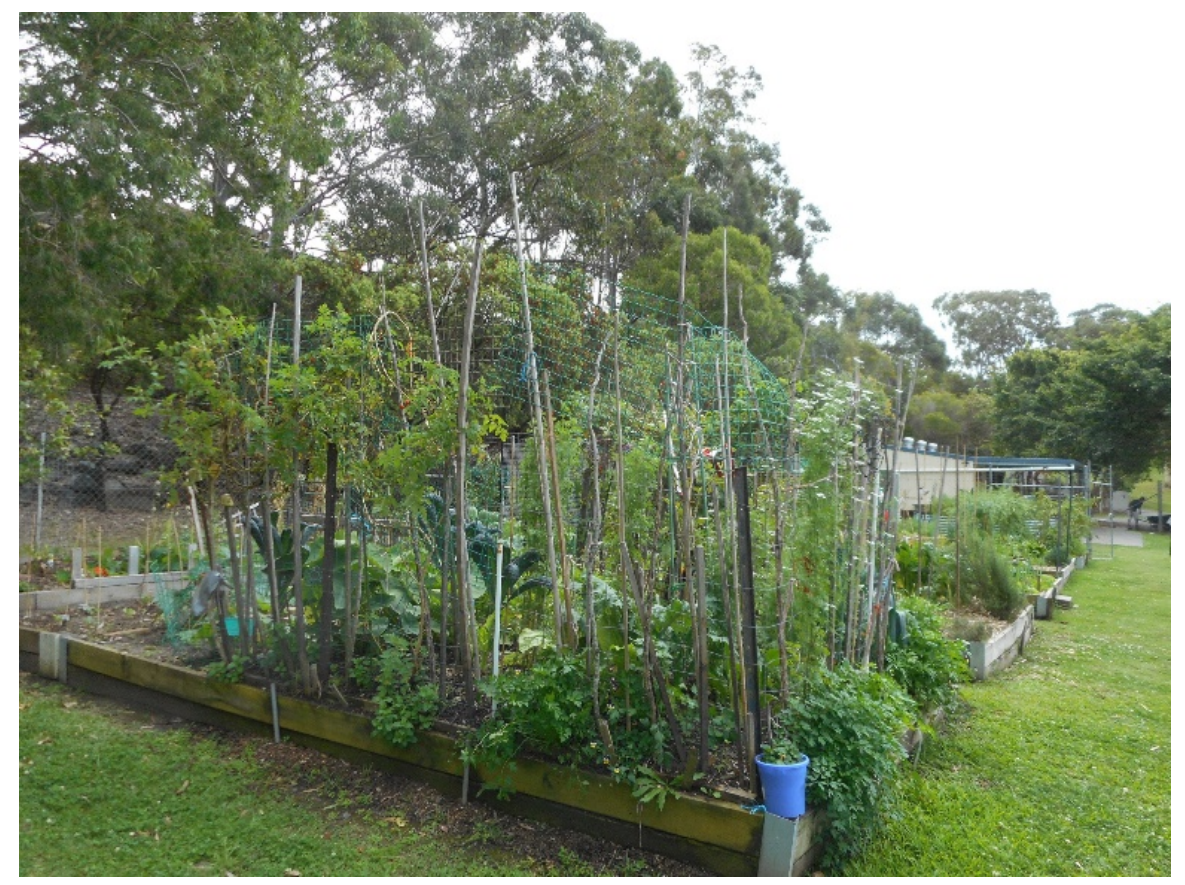

Image 3.1: Kookaburra Community Garden - individual plots behind high fence. Source - The author, September, 2015.

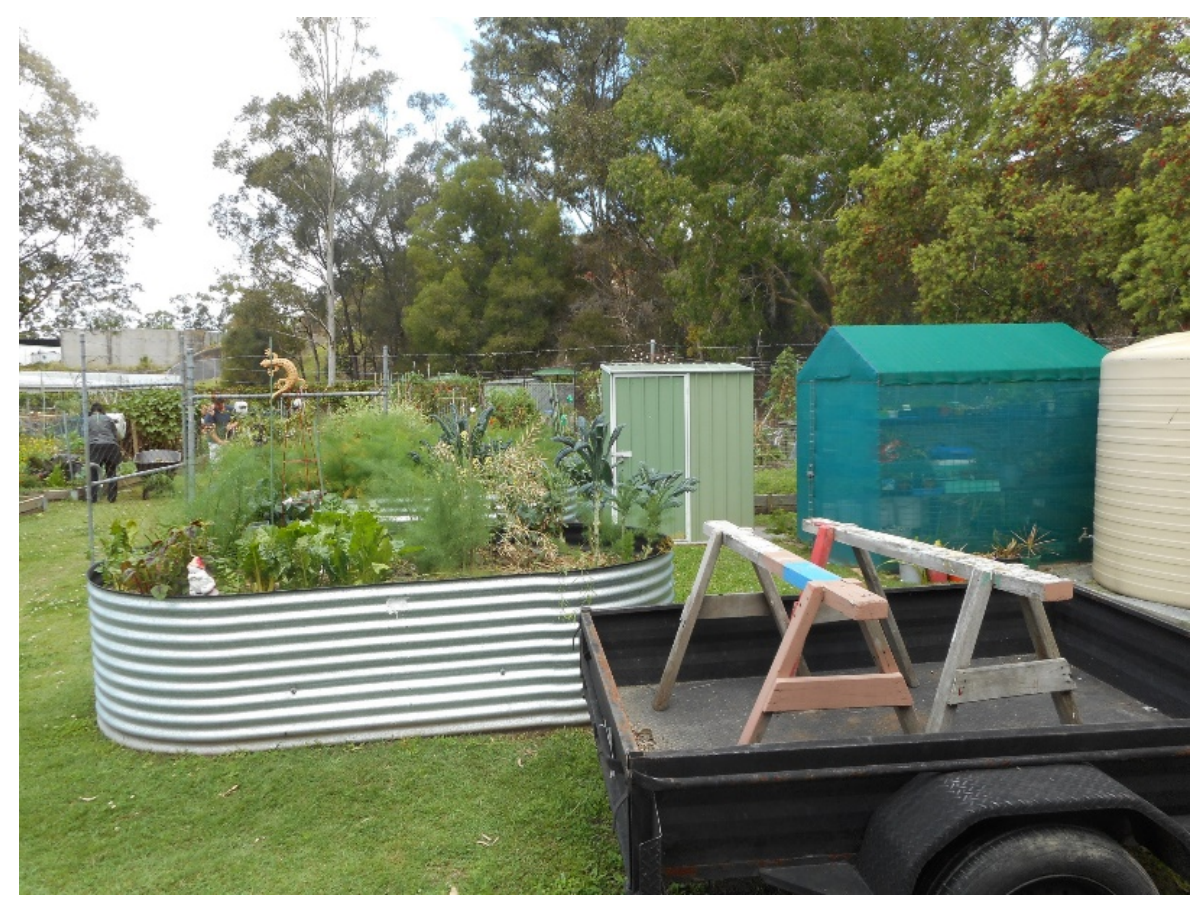

Image 3.2: Kookaburra Community Garden - Raised garden beds. Source - The author, September, 2015.

\section{Pine Park Community Garden}

Pine Park community garden (Sydney, New South Wales, Australia) is situated in the centre of an inner city social housing area, 1.5KM from the CBD. From participant estimates, it was established in approximately 2001 at its current site. The community 
garden is situated in a public park which also includes a tennis court, a children's playground and basketball courts. All members reportedly live within walking distance of the garden. The garden is enclosed by a short fence and is open all hours to the public. The design includes a mix of individual and common plots. To join, Pine Park gardeners are asked to attend two Sunday meetings. Attendance is checked annually through collection of minimal membership fees (discounted for those on welfare or age pensions). Some members are also involved with the neighbouring primary school food garden. Six members across the three participant categories were interviewed.

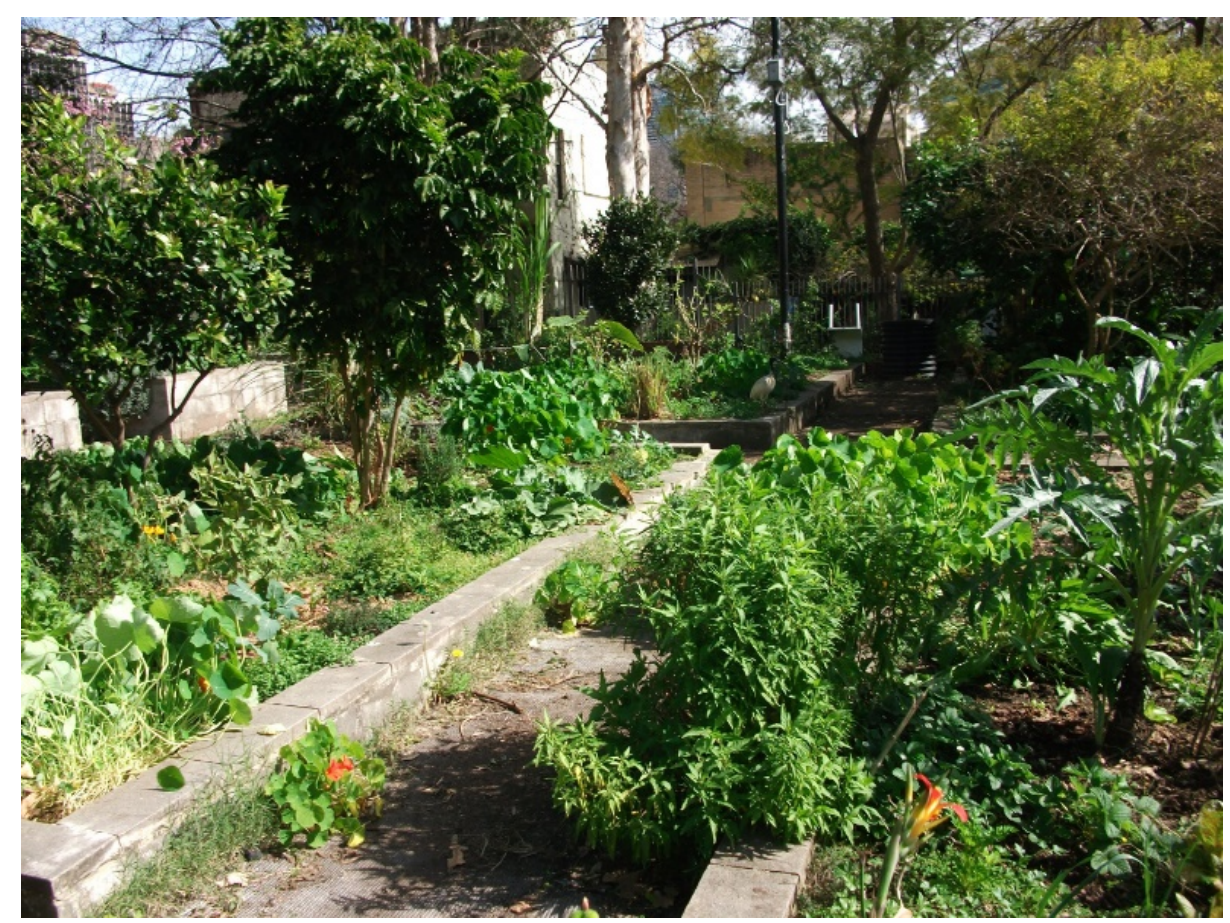

Image 3.3: Pine Park community garden - individual plots. Source - The author February, 2016. 


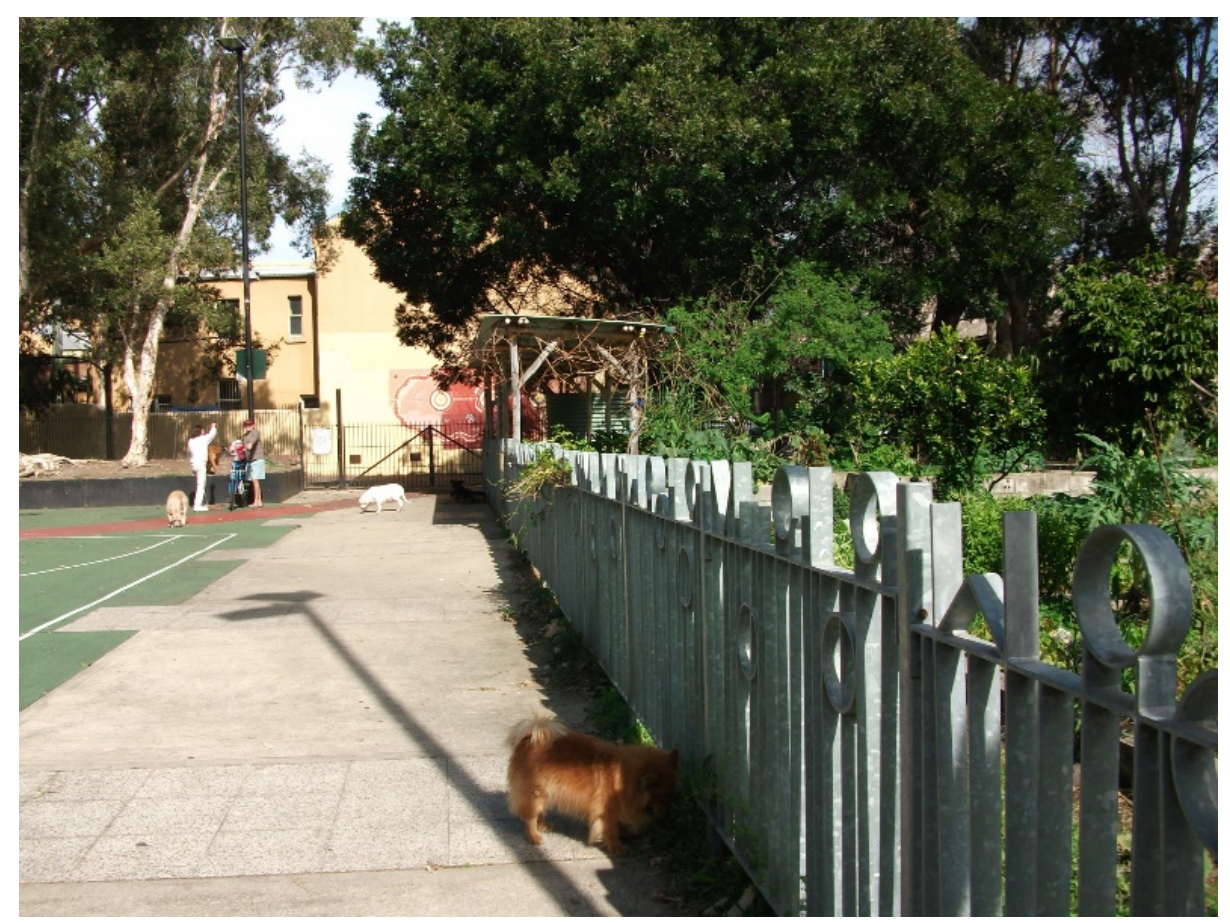

Image 3.4: Pine Park community garden - Placement of the garden. Source - The author February, 2016.

\section{Marville Community Garden}

The Marville Community Garden in Brisbane (Queensland, Australia) was created on a small (similar to one house sized block) poorly maintained state government land which was left over from a freeway subdivision, three KM from the CBD. At the time of interviews, the garden was less than one year old. Gaining the use of the site took two years of substantial lobbying of the State Government by the neighbourhood. It is situated amongst detached housing in a mixed socioeconomic status suburb which has no other park in the vicinity. Almost everyone walks to the garden. The community garden has a low fence which is not locked. There are no individual plots. The mix of plantings are herb gardens, native shrubs, fruit trees and vines and ornamental plants. There is an organising committee and a minimal fee for membership, although use of the garden is not contingent on being a member. Food which is harvested is left on a table for passersby to share. Five members across the three participant categories were interviewed. 


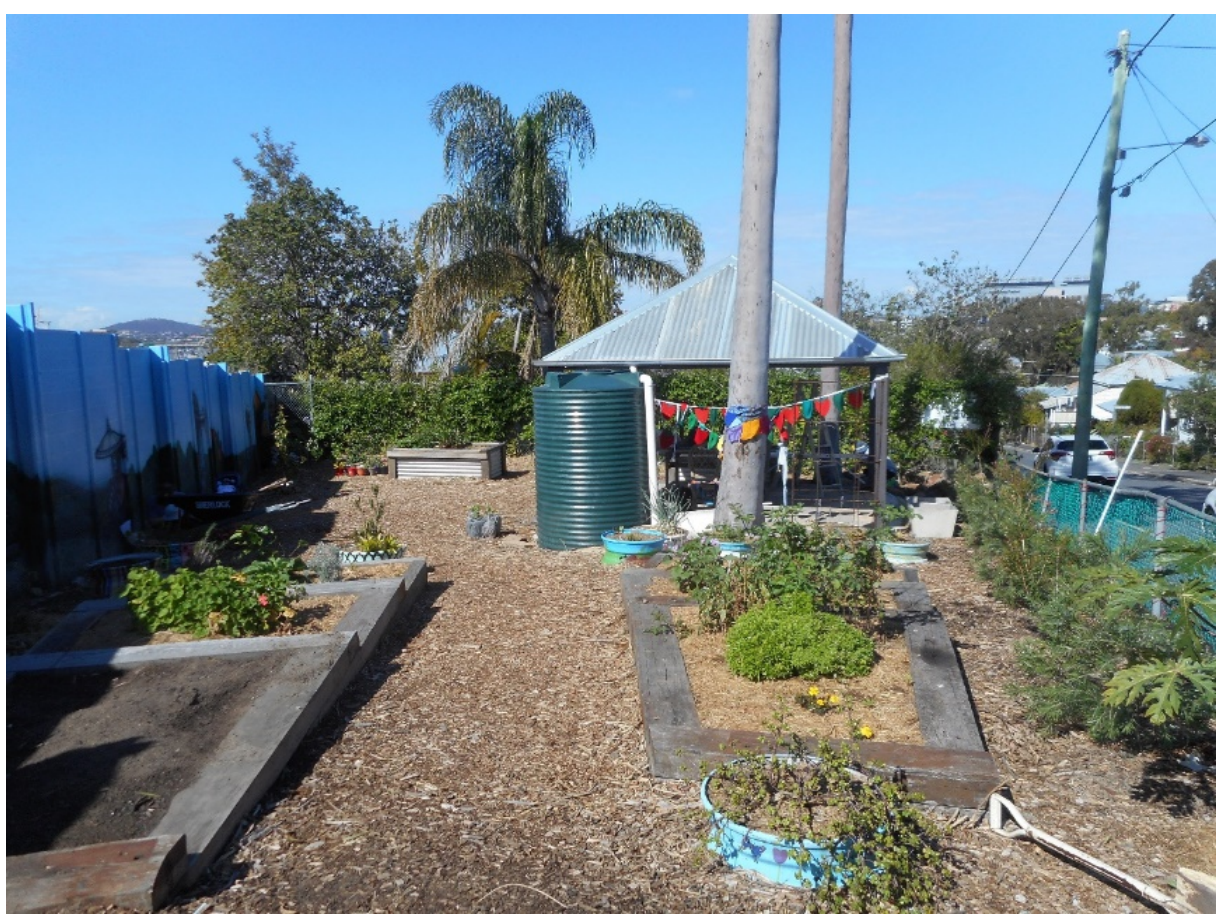

Image 3.5: Marville Community Garden next to freeway. Source - The author, August 2016.

\section{Frank Street Community Garden}

The Frank Street community garden is in a public park in the middle of a mixed socioeconomic suburb, $9 \mathrm{~km}$ from the Brisbane CBD. The garden was founded in 2012. The housing mix is predominantly detached suburban housing and some two or three story unit blocks. The community garden is located in a park neighbouring a lawn bowls club and backs onto by a single row of detached housing. All gardeners reportedly walk or cycle to the garden. There is a bike path past the garden, but otherwise it is not connected to the surrounding suburb. It is not fenced and is open all hours to the public. The design has no individual plots. Membership is particularly easy in the Frank Street community garden - just turn up. There are no membership fees. Meetings and working bees are advertised on their Facebook page. The Brisbane City Council paid for the infrastructure which includes raised garden beds, a water tank, and a picnic shelter. Five participants representing different lengths of involvement were interviewed. 


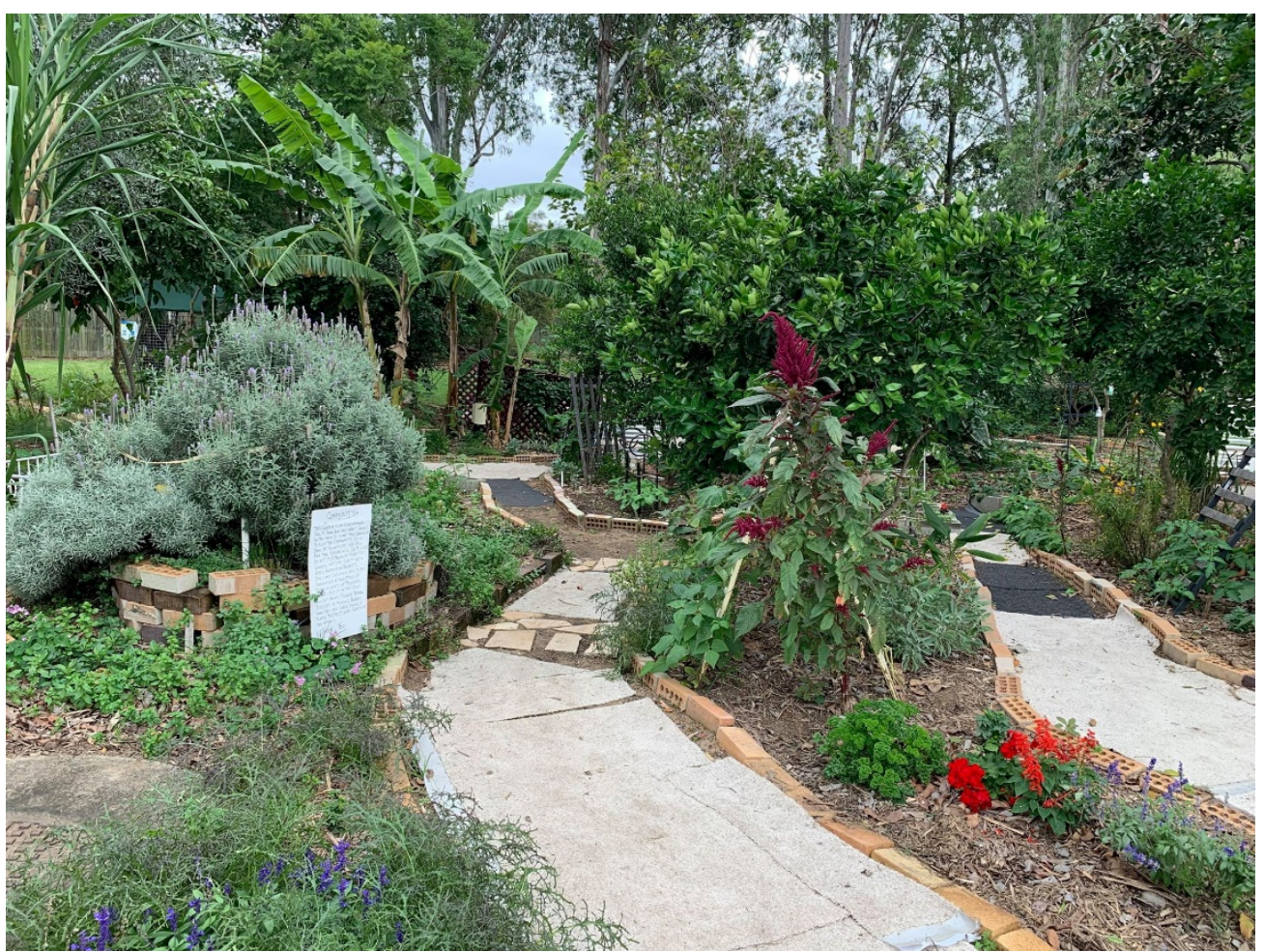

Image 3.6: Frank Street Community Garden. Source - Rose Pascoe 20/5/19.

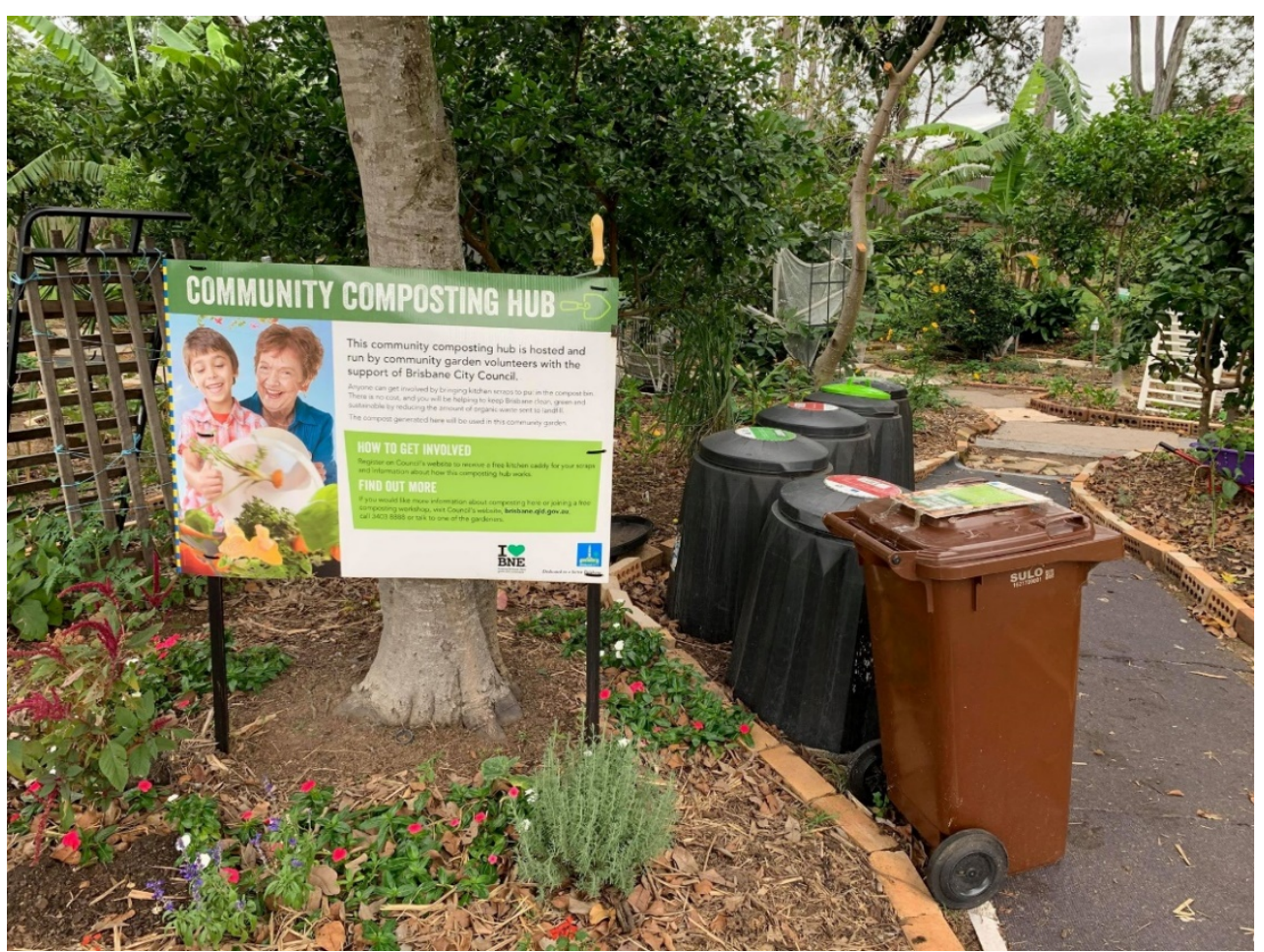

Image 3.7: Frank Street community composting. Source - Rose Pascoe 20/5/19. 


\section{Bluevale City Garden}

The Bluevale City Garden is a community garden situated on marginal flood prone public land owned by the Brisbane City Council. The garden was founded in 1994. It is in a mixed socio-economic suburb, four $\mathrm{km}$ from the Brisbane CBD. The housing mix is predominantly detached suburban housing and some two or three story unit blocks. The community garden is located near a major hospital and some hospital staff park in the large carpark which is used for weekend organic markets. Public transport and a bike path are other ways of accessing the garden. Many gardeners reportedly walk or cycle to the garden, however it is an interest-based community garden which attracts visitors from afar. The design has demonstration gardens, communal plots and 41 individual allotment plots, plus a community composting facility. There is a communal outdoor kitchen which is used to provide lunch to the staff, volunteers and work-for-the-dole participants. All of it except the plant nursery is open all hours to the public. Membership is by annual fee, but anyone is free to visit or can pay to take part in their regular workshops or events. There are discounts on membership fees for some low income categories. The garden has several part-time paid positions in farm and nursery management and administration, including being a provider for the government's work-for-the-dole (WEX) program. Education is a major focus of the organisation, providing permaculture training and community workshops on topics such as how to grow mushrooms, keep bees and design for child-friendly gardens. All plans are made through meetings and all decisions made by consensus. The Brisbane City Council has jurisdiction over the land. 


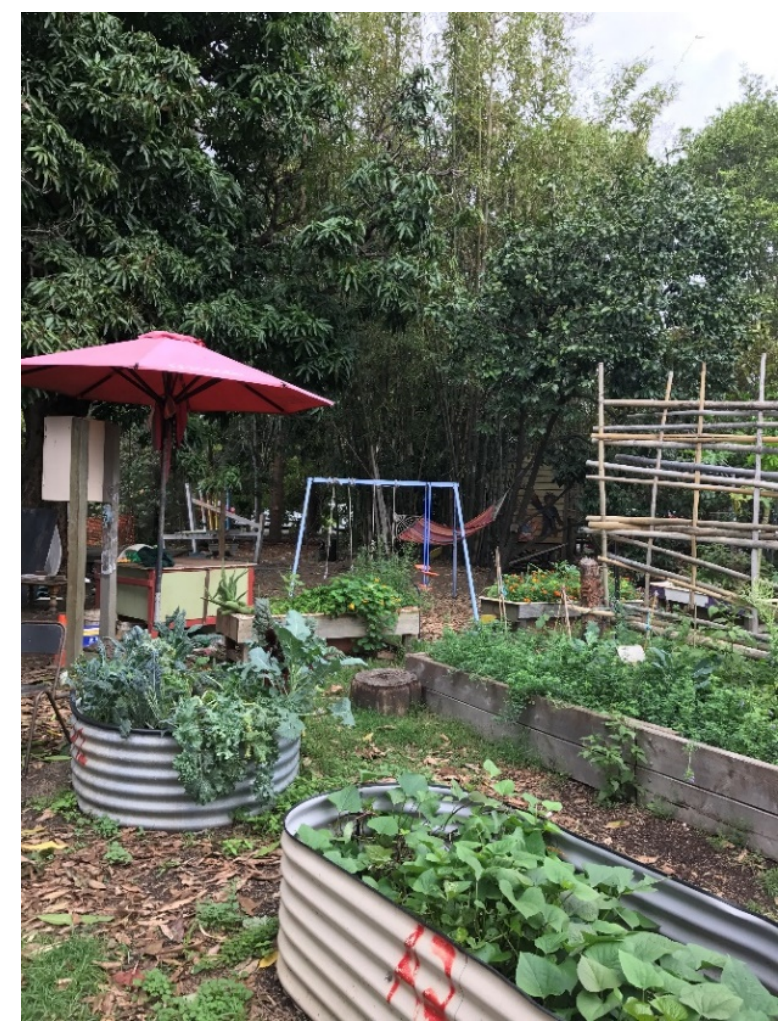

Image 3.8: Bluevale City Garden - Children's play area. Source - The author, August, 2018.

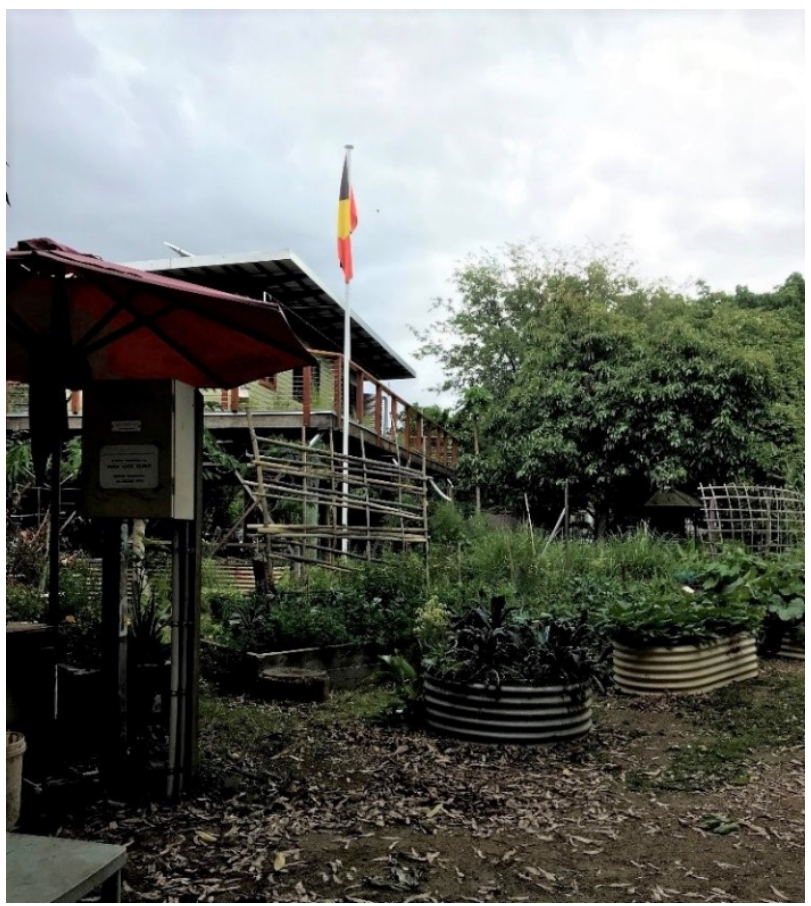

Image 3.9: Bluevale City Garden - Education and administration building. Source - The author, August, 2018. 


\section{Hagenlund Library Community Garden, Denmark}

The Hagenlund library community garden is situated in a planned community $17 \mathrm{~km}$ west of Copenhagen in Denmark. The garden was founded three years prior to the time of the interview which took place in 2015. The library community garden is situated on land owned by a private organisation which rents apartments to people and families and rents buildings to the municipality, including the library, youth club, and a kindergarten. The housing area, although connected to other housing areas via paths, is a bit hidden. The Librarian indicated that the neighbourhood local population is comprised of approximately $50 \%$ ethnic minorities from numerous language groups. All members live within walking distance, though some librarians may travel from further afield. The garden is a number of raised garden beds in boxes, as the open spaces are concrete. The housing company provided all the equipment, garden beds and numerous well developed apple trees and provide the seeds and seedlings for the participants. Approximately 15 families are involved and each family can have 2 boxes; the youth club has a handful of boxes, as do the local school the kindergarten. The librarians try to gather the participants every second week so that they help take care of the rest of the garden, though it is difficult to find a time which suits the library hours and participants who work during the day. The community garden was developed as a joint venture between the private housing organisation and the municipal library. Due to constraints of time and language, only one organiser was interviewed (35 minutes).

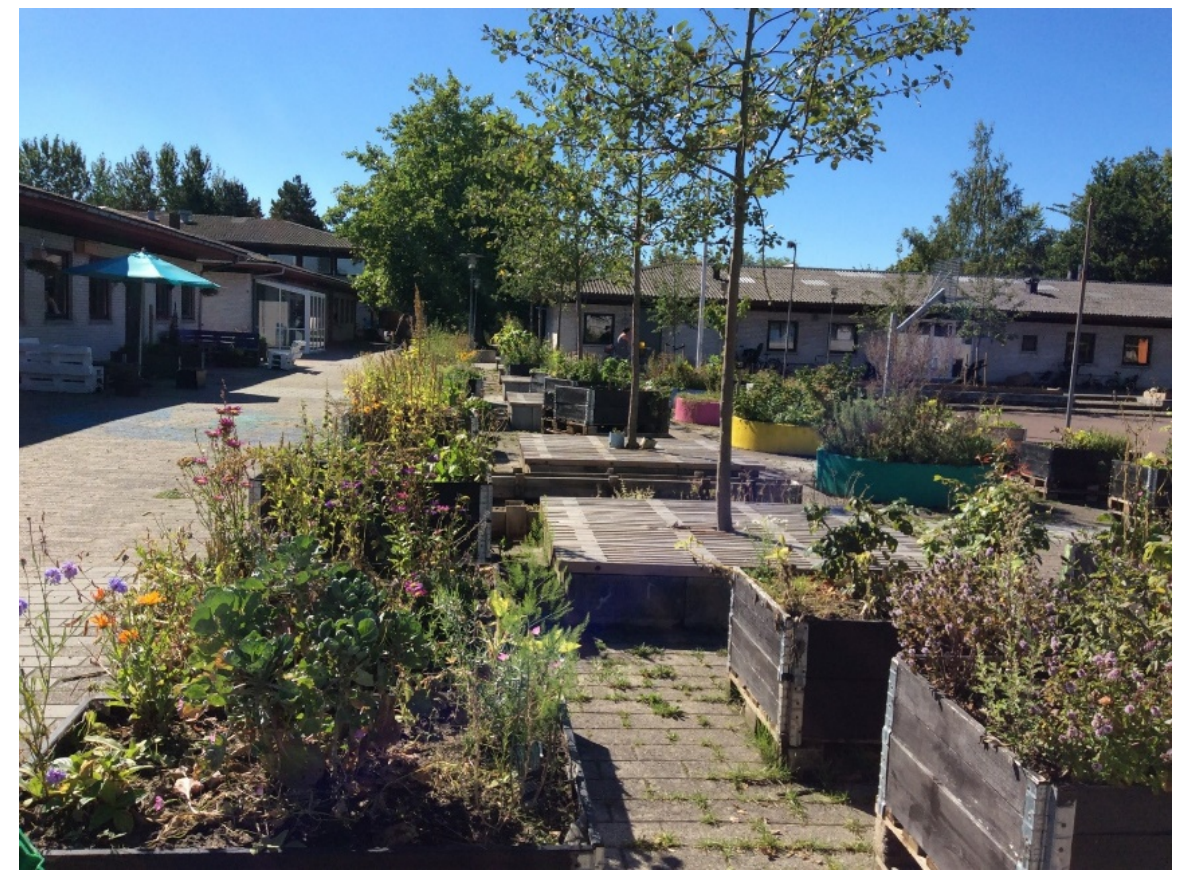

Image 3.10: Hagenlund Library Garden. Source - The author, September, 2016. 


\section{Main similarities and differences between case study sites}

All five Australian case study sites are citizen-led initiatives on government owned land. All six gardens employed sustainable practices as evidenced by organic growing, mulching, harvesting rainwater, seed-saving and composting and two also included native bee keeping. The Pine Park, Kookaburra and Hagenlund Library Gardens have involvement with local schools.

Each of the six sites has at least one unique feature as described below.

Kookaburra access is mainly by membership as the garden is fenced with limited opening times. The Kookaburra garden is hidden below the street level and behind two metre high fences, with members having key access to the premises. The Kookaburra community garden committee is well organised and attentive to active membership and well maintained plots.

Pine Park has many similarities to the other community gardens, however, they state (and this was verified by observation) they have no formal membership titles and operate on consensus at meetings. While they are the only Australian case study garden situated in a housing commission residential area, they draw members from the greater neighbourhood of private dwellings. While Pine Park, Frank Street and Kookaburra had supportive local authorities, Pine Park was the only one with access to a paid community garden advisor.

Marville community garden is situated on land which was hard fought for, contested abandoned land left over from a freeway construction.

Frank Street is the only community garden situated in low density suburban area $(9 \mathrm{kms}$ from the CBD). It should be noted that membership is particularly easy in this garden (just turn up).

Bluevale City Garden has a number of unique features. It has several paid positions in managing the garden and administration. It is education focussed and has various programs such as the government's work-for-the-dole (WEX) program; permaculture training; and community workshops. It is interest-based, drawing visitors and members from afar. It holds weekly markets and has a nursery and annual events which attract people from outside the local area. Also, some gardeners feel the land is not of secure tenure as the city council has on occasion shut down its operation due to issues such as 
land contamination. This is also marginal land which experiences flooding more frequently than the major city-wide (100 year) floods.

Hagenlund Library is the only garden which has individual plots only, although some of those plots are for groups such as the local kindergarten. It is the only case study site which is on privately owned land (a housing development) and the only one run by an external person (the librarians).

\section{Participant selection}

The research participants were all members of the community gardens. In all the Australian case study sites, the initial contact person was the named person on the community garden website or Facebook page. The contact person at each site emailed the project information to members to inform them and check if there were any objections to participating. Most participants were therefore aware of the project by the time of the interviews. Potential participants were invited to take part by email through a community garden representative and additional participants were recruited on site through snowball sampling that occurred at several community gardens due to opportunities which arose at their working bees (Abrahamson, 1983). The Community Gardens and participant names have been de-identified for reporting. In Denmark, due to limited time and connections, a research collaborator found contacts for two community gardens and an allotment garden and arranged interview times. Only one of those sites fitted the community garden definition applied in this thesis.

Purposive sampling was carried out in order to inform the research objective, namely the three different types of community gardeners who represent differing stages of participation and knowledge of the site (Patton, 2002). Key stakeholders were interviewed at each site. Through the literature review, three key stakeholder categories were identified in community gardens and they included:

- a member of the organising committee (in order to describe the governance and membership);

- a long term member (because it has been shown that motivations for membership in community gardens change over time (Cox et al., 2008);

- a new member $<1$ year (to provide first impressions of the community garden and integration into the membership). 
The informants are key in that they are in a position or specialist role to provide particularly important understandings to the researcher (Bloor \& Wood, 2006). The perceptions of the key participants provide rich data from which several themes are developed.

The key stakeholders were all members of the community gardens and, with the exception of Hagenlund Library, included representatives from the organising committees, experienced long term-members, and relatively new members. At each site, at least one member on the organising committee or founding member of the community garden is included, as the literature shows that they often claim to be aware of the variety of motivations within the garden membership. Long term members were chosen because it has been shown that motivations for membership in alternative food networks (including community gardens) change over time (Cox, 2008). This relates to the importance of social aspects of membership over time. The reason for including new members is to provide first impressions of the community garden and the relative ease of integration into the membership. Members include people who have joined as members; may be hiring a plot; live in a residence associated with the community garden; and/or regularly take part in working bees.

The number of case study interviews was 29 , which included multiple interviewees at all but one site. Unlike quantitative research which has a tradition of recommended interviews/surveys in order to provide statistical generalizability with confidence, qualitative research is not as clear cut on guidelines on participant numbers. The goal of qualitative research is to interview enough participants to feel confident of reaching theoretical saturation, where no further sampling is required as no new opinions or variation in data are appearing, and/or enough data has been collected to be able to theorise on findings (Guest, Bunce \& Johnson, 2016). Guest, Bunce and Johnson (2016) determined that 12 participants yielded $90 \%$ of the codes used to analyse their interview data. However, they noted that their sample was relatively homogeneous and their interview questions were fairly consistent between interviewees. All but three opportunities for data collection arose on site, which on numerous occasions included interviewing while the participant actively gardened. As previously mentioned, only one gardener was interviewed at Hagenlund Library Garden due to constraints of time and language, though the interviewee was an organiser who had played a pivotal role in setting up the garden, so was very knowledgeable and reflective about the garden. Data saturation 
accounting for variability was achieved through treating the sample of 29 interviews as one sample which covers variability across member types and community garden designs and situations.

The interview data was collected from the following participants: 
Table 3.2 Case study site participant details

\begin{tabular}{|c|c|c|c|c|c|c|}
\hline Characteristic & $\begin{array}{c}\text { Case Study } \\
1 \\
\text { Kookaburra }\end{array}$ & $\begin{array}{c}\text { Case Study } \\
2 \\
\text { Pine Park }\end{array}$ & $\begin{array}{c}\text { Case Study } \\
\mathbf{3} \\
\text { Marville }\end{array}$ & $\begin{array}{c}\text { Case Study } \\
4 \\
\text { Frank } \\
\text { Street }\end{array}$ & $\begin{array}{c}\text { Case Study } \\
5 \\
\text { Bluevale }\end{array}$ & $\begin{array}{c}\text { Case Study } \\
6 \\
\text { Hagenlund } \\
\text { Library }\end{array}$ \\
\hline $\mathrm{M} / \mathrm{F}$ & $4 \mathrm{M} 4 \mathrm{~F}$ & $5 \mathrm{~F} 2 \mathrm{M}$ & $3 \mathrm{~F} 2 \mathrm{M}$ & $3 \mathrm{~F}, 2 \mathrm{M}$ & $2 \mathrm{~F}, 2 \mathrm{M}$ & $1 \mathrm{~F}$ \\
\hline AGE & $\begin{array}{l}1 \text { young, } 4 \\
\text { middle, } 3 \\
\text { retired }\end{array}$ & $\begin{array}{l}2 \text { young, } 2 \\
\text { middle, } 3 \\
\text { older }\end{array}$ & $\begin{array}{l}\text { All young } \\
\text { (parents) }\end{array}$ & $\begin{array}{l}\text { All young } \\
\text { (parents) }\end{array}$ & $\begin{array}{l}1 \text { young, } 1 \\
\text { retired/semi } \\
\text {-retired }\end{array}$ & 1 young \\
\hline Committee & $\begin{array}{l}3 \text { com, } 5 \\
\text { gardeners }\end{array}$ & $\begin{array}{c}2 \text { roles } \\
\text { committee, } \\
5 \text { gardeners }\end{array}$ & $\begin{array}{c}3 \\
\text { committee, } \\
2 \text { gardeners }\end{array}$ & $\begin{array}{l}3 \text { com, } 2 \\
\text { gardeners }\end{array}$ & $\begin{array}{c}2 \\
\text { committee, } \\
1 \text { employee/ } \\
\text { committee, } \\
1 \text { former } \\
\text { employee } \\
\text { (now } \\
\text { visitor) }\end{array}$ & 1 role \\
\hline $\begin{array}{c}\text { Meetings/ } \\
\text { working bees } \\
\text { attended }\end{array}$ & 1 & 1 & 1 & 1 & 2 & 0 \\
\hline Total visits & 2 & 4 & 3 & 2 & 6 & 1 \\
\hline $\begin{array}{c}\text { Total } \\
\text { interviewees }\end{array}$ & 8 & 7 & 5 & 5 & 4 & 1 \\
\hline
\end{tabular}

\section{Data Analysis}

Interview data from the community garden case study sites were analysed against a framework of the third place characteristics in order to determine if community gardens are third places. The interview data was transcribed then analysed using NVIVO starting with the previously described eight characteristics of third places as theme nodes, and developing further themes nodes during analysis. NVIVO is a popular program amongst the qualitative data analysis software for managing interview data and subsequent qualitative analysis (Woods et al., 2016). Precedents in the literature include Lyons et al. (2013, p. 159) who conducted semi-structured interviews with 25 "key actors", then coding the data for emerging themes in their study of ethical food movements in Melbourne. In applying an inductive approach informed by human geography and an interdisciplinary approach linking placemaking, social capital and resilience literature, research themes began to emerge while still conducting the interviews, as recurring themes were brought up by different participants. Apart from the eight third place characteristics, the emerging ideas from the field served as initial themes for coding the 
interview data. Deriving themes from the data is an iterative process where numerous themes are grouped and merged into different levels of abstraction. Using the qualitative data analysis package, NVIVO is a systematic way to code the themes and allows the transcripts to be recoded and regrouped as more interviews are added and higher order themes emerge. The set of themes started with those derived from the literature and then were modified as the research progressed in a reflexive process. The codes were sorted into overarching themes which respond to the substantive research questions and relate to the literature. Overarching themes of inclusivity; introduction to neighbourhood; and placemaking emerged during analysis. These themes contribute to discussion on the implications of community gardens as third places. This kind of theme coding is an inductive approach to the research questions, common in qualitative research.

Table 4.2 in the next chapter shows examples of coding quotes from the interview data of half of the case sites on a matrix of the eight third place characteristics. The table provides a sample of the way the quotes were coded. The full quotes are referred to in full in the discussion section. These are not statistical calculations, but rather a visual representation of the third place qualities of each of the three selected example case sites.

Thematic analysis was carried out on the interview data in order to:

1. Investigate the extent to which community gardens are third places.

2. Determine where each of the six types of community gardens sit on a third place continuum, showing which characteristics are more or less prevalent in each type of community garden.

3. Illustrate if community gardens add additional characteristics to the third place criteria - are an improvement on third place; or extend the third place definition (ie. third place with a communal purpose).

4. Develop a model of third place using community gardens as the case study.

The researcher interpreted the interview data by noting emerging themes guided by the focus questions (Appendix 6) and by the checklist of third place characteristics detailed in Figure 3.3 (Silverman, 1993). In writing up the findings, illustrative quotes and examples are used. The use of quotes from interview data adds richness and credibility to the findings (Byrne, 2012; Yin, 2009). The findings are related back to the focus questions and literature review. The data analysis is written thematically rather than presented as 
separate case studies. Key themes which emerged from the data form a framework for the data synthesis.

The data shows that all six case study sites exhibit a majority of third place characteristics, but each one differs from the others. The characteristic which limits the third place qualities of both is "access", as defined by everyone free to come and go. The membership requirement of the case studies exhibit access characteristic to differing degrees. The case study community gardens sit in different places on a continuum between a club and third place. The results chapter (4) compares the interview data of each case study site to the eight characteristics of third places.

\section{Conclusion}

In this chapter, the choice of a qualitative research study and the use of case studies as the chosen research method was described and justified, with the goal to determine if community gardens are third places. Each site is described in detail along with the research questions, method and design. The data collection and analysis techniques and questions of confirmability, dependability, credibility and ethics are also addressed. The data analysis relates to the goal of the research which is to document previously undocumented ways in which community gardens are or are not third places. The sites cover a range of community garden designs, governance and urban environments. A framework of the eight characteristics of third place was applied to case study data. The author interviewed 29 community gardeners across six case study sites including five community gardens in Australia (one Sydney, three Brisbane, one the Gold Coast) and one in Denmark (Hagenlund). Key stakeholders were interviewed, which included members and volunteers including at least one committee member at each site. Responses were analysed by coding the data into themes using NVIVO. The themes included each characteristic of third places, however a number of additional and overarching themes emerged, namely placemaking and social capital. The findings are discussed in the following three chapters. 


\section{CHAPTER 4: FINDINGS - ARE COMMUNITY GARDENS A THIRD PLACE?}

Community gardens have been referred to as third places in several articles, however, this is the first time that the concept has been systematically investigated against case study sites (Firth, Maye \& Pearson, 2011; Glover, 2004; Thompson \& Maggin, 2012; Veen et al., 2015). This chapter seeks to answer the research question: "To what extent are community gardens third places?", by applying a framework of the eight characteristics of third places. The findings from six case studies that cover a range of types and locations are then drawn together and related to the literature. The chapter concludes with a summary of the implications that this may have for the challenges arising from urbanisation and population mobility. Subsequent chapters apply the findings to concepts of placemaking (Chapter 5) and the theory of social capital (Chapter 6).

\section{Significance}

“The social and physical environment shapes our behaviour in ways we've failed to recognise; it helps make us who we are and determines how we live." (Klinenberg, 2018, p. 13)

Investigating community gardens through a third place lens allows an opportunity to analyse how physical space and human activity interact to make places that have the potential to reduce social isolation, increase social capital, and improve neighbourhood resilience. As Oldenburg (1999) suggested, third places play a role in addressing issues of social isolation that, in part, arise from high rates of residential mobility in urban environments. Celata \& Coletti's (2017, p. 4) study in Rome, found that community gardens are a public "collective space" that promote social inclusion and "citizens' participation". Community gardens are sites of civic engagement that have been found to increase social capital and as with third places, are sites of enjoyment and community building (Draper \& Freedman, 2010; Ferris et al., 2001; Firth, Maye \& Pearson, 2011; Guitart et al., 2012).

In addition to providing urban food to the participants, community gardens that are third places have potential to contribute to achieving the UN Sustainability Goal 11.7 to: "provide universal access to safe, inclusive and accessible, green and public spaces, in 
particular for women and children, older persons and persons with disabilities" (UN, 2015). Community gardens aid in the provision and conservation of green space and may help to revive distressed neighbourhoods (Draper \& Freedman, 2010; Ohmer et al., 2009). Community gardens function as a community space that promotes social inclusion as part of a larger ethical food movement with social, political, economic and ecological dimensions (Lyons et al., 2013). In Chapter 2, examples were given of community gardens in New York, Singapore, Scotland, and Rome amongst others, that are multifunctional community developments combining open space and civic agriculture and promoting a sense of community across a range of social class and ethnicity, lifestyles and ages of the participants (Celata \& Coletti, 2017; Cumbers et al., 2017; SaldivarTanaka \& Krasny, 2004; Tan \& Neo, 2009). This chapter is significant because it proposes a model showing how a community garden, as a community-led and maintained facility in a public space, can operate as a third place. The significance of the findings of this chapter are explored in more depth in Chapters 5 and 6, as this chapter focusses on determining if community gardens are third places.

\section{Method}

As discussed in the previous chapter, this study analysed interview data from 29 participants across one Danish and five Australian community gardens in a qualitative case study investigation. The research question being addressed in this chapter is: "To what extent are community gardens third places?" A third places framework was applied in order to answer the sub-question: Do community gardens fit the eight characteristics of a third place? The third place characteristics described in Oldenburg's (1999) book, "The Great Good Place", were discussed more fully in the literature review (Chapter 2), but to recap, the characteristics are:

1. Easy to access and accommodating: Informal public space, generally accessible by walking;

2. The mood is playful: Enjoyable and lively atmosphere;

3. Low profile: Plain, comfortable and not showy;

4. Homes away from home: The place and activity that occurs there may be considered as quite ordinary and 'homely' by its visitors;

5. Neutral ground: The general public are free to come and go without obligations;

6. Levellers: Inclusive places that are not dependant on participants' social or economic rank or status; 
7. Regulars/characters: A core group of regulars frequent the place;

8. Conversation: Conversation is the main activity of third places.

Each of the eight characteristics of third places are analysed separately against the data from all six case study sites and examples of participant quotes are provided with discussion on the characteristic. The description of and rationale for choosing the case study sites and the research participants are detailed more fully in the methods chapter (3). Table 4.1 recaps some basic details about each case study site as a guide to analysing the results of each of the eight characteristics in turn. 
Table 4.1: Summary of case study site features

\begin{tabular}{|c|c|c|c|}
\hline Case Study Site & Main Characteristics & Distinctive Feature & Visits/Interviews \\
\hline $\begin{array}{l}\text { Kookaburra, } \\
\text { Gold Coast }\end{array}$ & $\begin{array}{l}\text { - In the middle of a mixed socioeconomic status suburb - a mix of detached houses and multi-story units. } \\
\text { - } \quad \text { Hidden below the street level; behind } 2 \text { metre high security fences; members have key access } \\
\text { - } \quad \text { Structured committee and vigilant of and common 'charity' plots. High rise gardens beds for those who cannot bend. } \\
\text { - } \quad \text { Includes social membership class for those who are unable to or don't want to garden. } \\
\text { - Some members drive to the garden. }\end{array}$ & $\begin{array}{ll}- & \text { Key entry, high fences } \\
- & \text { Many drive to the CG } \\
\text { Emphasis on charity } \\
\text { contributions/involvement } \\
\text { - } \\
\text { gormal committee structure } \\
\text { governance }\end{array}$ & $\begin{array}{l}\mathrm{N}=8 \text { interviews } \\
1 \text { Working bee attended }\end{array}$ \\
\hline $\begin{array}{ll}\text { Pine } & \text { Park, } \\
\text { Sydney } & \end{array}$ & $\begin{array}{ll} & 1.5 \mathrm{kms} \text { from the Sydney CBD; Located in a public park that includes swings, basketball, tennis courts. } 15+\text { years established } \\
\text { - } & \text { Surrounded by apartments and terrace houses, many owned by the government for public housing } \\
\text { - } & \text { Mix individual \& communal plots } \\
\text { - } & \text { Minimal joining requirements \& discount for pensioners and welfare recipients. } \\
\text { - } & \text { A low fence that is not locked. Open } 24 / 7 \\
\end{array}$ & $\begin{array}{ll}- & \text { Non-hierarchical governance } \\
- & \text { Supported by local council } \\
\text { - } & \text { Inner city in housing estate area } \\
\text { in a gentrifying area }\end{array}$ & $\begin{array}{l}\mathrm{N}=7 \text { interviews } \\
3 \text { visits, } 1 \text { meeting } \\
\text { attended }\end{array}$ \\
\hline $\begin{array}{l}\text { Marville, } \\
\text { Brisbane }\end{array}$ & $\begin{array}{ll}\text { - } & \text { Less than } 1 \text { year old (at time of interview) } \\
\text { - } & \text { Small (house sized); previously poorly maintained state government land that was left over from a freeway subdivision. } \\
\text { - } & \text { Gaining the use of the } \text { CBD. took } 2 \text { years of substantial lobbying by the neighbourhood. } \\
\text { - } & \text { Situated amongst detached housing in a mixed SES suburb that has no other park in the vicinity. } \\
\text { - } \quad \text { low fence that is not locked. Open } 24 / 7 \\
\quad \text { An organising committee and a minimal fee for membership. Use of the garden is not contingent on being a member. } \\
\text { - } \quad \text { Almost everyone walks to the garden. }\end{array}$ & $\begin{array}{l}\text { - } \quad \text { Situated on unused land } \\
\text { - } \quad \text { No parks in the area } \\
\text { - Communal only by locals } \\
\text { - Open } 24 / 7\end{array}$ & $\begin{array}{l}\mathrm{N}=5 \text { interview } \\
3 \text { visits }\end{array}$ \\
\hline $\begin{array}{ll}\text { Frank } & \text { Street, } \\
\text { Brisbane } & \end{array}$ & $\begin{array}{l}\text { - } \quad \text { Set in a public park in the middle of a mixed socio economic status (SES) suburb. 9km from the Brisbane CBD. } \\
\text { The housing mix is predominantly detached housing. } \\
\text { - } \quad \text { No fence. Open } 24 / 7 \text {. } \\
\text { - } \quad \text { All mership - just turn up. No fees. } \\
\text { - The design has no individual plots. } \\
\quad \text { The Brisbane City Council paid for the infrastructure (raised garden beds, a water tank, picnic shelter). }\end{array}$ & 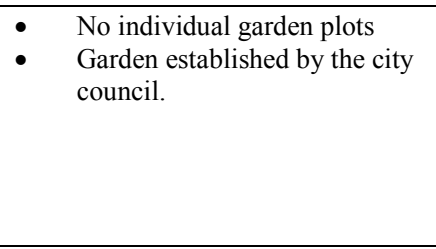 & $\begin{array}{l}\mathrm{N}=5 \text { interviews } \\
1 \text { working bee attended }\end{array}$ \\
\hline $\begin{array}{l}\text { Bluevale, } \\
\text { Brisbane }\end{array}$ & $\begin{array}{ll} & \text { Founded in 1994. A non-profit community organisation. } \\
\text { - } & \text { Paid positions \& non-profit nursery \& weekly farmers markets + WEX (employment) program } \\
\text { - } \quad \text { Education focussed (permaculture, food growing and cooking) } \\
\text { - } \quad \text { Four hectare a farm site on marginal (flooding) land owned by the city council, situated on the banks of a creek in Brisbane. }\end{array}$ & $\begin{array}{ll}- & \text { Interest-based } \\
- & \text { Consensus governance } \\
- & \text { Vision of all living sustainably }\end{array}$ & $\begin{array}{l}\mathrm{N}=4 \text { interviews } \\
7 \text { visits ( } 4 \text { meetings, } 3 \\
\text { observations) }\end{array}$ \\
\hline $\begin{array}{l}\text { Hagenlund, } \\
\text { Denmark }\end{array}$ & $\begin{array}{l}\text { - } \quad 17 \mathrm{~km} \text { west of Copenhagen in Denmark. } \\
\text { - } \quad \text { Local population approximately } 50 \% \text { ethnic minority residents from numerous language groups. } \\
\text { - } \quad \text { No growing season in winter. }\end{array}$ & $\begin{array}{l}\text { Established, organised and } \\
\text { funded by a local authority }\end{array}$ & $\begin{array}{l}\mathrm{N}=1 \text { interview } \\
\text { Organiser was } \\
\text { interviewed ( } 35 \text { minutes) }\end{array}$ \\
\hline
\end{tabular}




\section{Results and analysis - Case Study Findings}

A thematic analysis of the data from the semi-structured interviews provides the foundation of this results chapter. As discussed in the methods chapter (3), the interview data was analysed using NVIVO, with the eight characteristics of third places as the initial key themes for the data analysis. Table 4.2 illustrates a sample of data from three of the case study sites: Kookaburra (at the Gold Coast); Marville (in Brisbane); and Pine Park (in Sydney), to demonstrate how participant quotes were coded in the data analysis process. The contents of the table illustrate representative participant quotes that determine the fit of each garden to each third place characteristic. Note that more than one quote was used to determine third place for each case study site and Table 4.2 is illustrative only. Table 4.3.9 in the 'findings summary' shows the outcome of the analysis for every case study site. 
Table 4.2: Community gardens data against third place framework

\begin{tabular}{|c|c|c|c|c|}
\hline Third Place Characteristic & $\begin{array}{l}\text { None } \\
\text { to } \\
\text { Low }\end{array}$ & Med. & High & $\begin{array}{l}\text { Illustrative quotes from: } \\
\text { Kookaburra; Marville; Bluevale }\end{array}$ \\
\hline \multirow[t]{4}{*}{$\begin{array}{l}\text { Accessible (easy to visit } \\
\text { location) } \\
+ \\
\text { Accommodating } \\
\text { (Open at accessible times) }\end{array}$} & $\checkmark$ & & $\checkmark$ & $\begin{array}{l}\text { I do have to drive, but you know it's ten minutes' drive, it's okay. } \\
\text { (Jane, Kookaburra) } \\
\text { We have some social members for people that used to perhaps be } \\
\text { part of the garden and they've given up their plot because they } \\
\text { haven't been able to keep up. (Janet, Kookaburra) }\end{array}$ \\
\hline & & & $\checkmark$ & $\begin{array}{l}\text { We get a lot people just walking past and seeing what's going on, } \\
\text {... stop off and then say, "Oh I love what you're doing," or "I've } \\
\text { been watching it grow", that aren't probably actively involved } \\
\text { but, you know, are grateful for the space, but I've seen just up } \\
\text { here eating their lunch. (Mandy, Marville) }\end{array}$ \\
\hline & & & $\checkmark$ & $\begin{array}{l}\text { At the moment (I visit) every day because my child goes to school } \\
\text { just there so I check on it every day. (Tina, Pine Park) }\end{array}$ \\
\hline & & & $\checkmark$ & \\
\hline \multirow{3}{*}{$\begin{array}{l}\text { Playful mood (Enjoyable. } \\
\text { Entertainment by the } \\
\text { participants themselves) }\end{array}$} & & & $\checkmark$ & $\begin{array}{l}\text { Some people are in units and they just enjoy to be outside in this } \\
\text { kind of environment and out of the four walls. (Janet, Kookaburra) }\end{array}$ \\
\hline & & & $\checkmark$ & $\begin{array}{l}\text { It's a nice area where people can hang out and like the actual } \\
\text { gardening part of it, it's sort of-it's nice. The actual gardening } \\
\text { part is secondary. (David, Marville) }\end{array}$ \\
\hline & & & $\checkmark$ & $\begin{array}{l}\text { I just find it interesting... my life's not about this, but it's just that } \\
\text { segment of my life which I enjoy and I get a lot of pleasure in. } \\
\text { (Edward, Pine Park) }\end{array}$ \\
\hline \multirow[t]{3}{*}{$\begin{array}{l}\text { Low profile } \\
\text { (Homely and comfortable) }\end{array}$} & & & $\checkmark$ & $\begin{array}{l}\text { I like to get my hands in the soil and I love to grow things. (Jane, } \\
\text { Kookaburra) }\end{array}$ \\
\hline & & & $\checkmark$ & $\begin{array}{l}\text { We had the community playgroup here, which is I think is making } \\
\text { the kids feel really comfortable in this space at a time when } \\
\text { there's not a working bee, so then when there is a working [bee], } \\
\text { often there's a lot of kids running around the dirt pile. (Violet, } \\
\text { Marville) }\end{array}$ \\
\hline & & & $\checkmark$ & $\begin{array}{l}\text { It is by no means a beautiful community garden I mean there are } \\
\text { others around that are gorgeous things to look at. Ours is a bit } \\
\text { more ramshackle than that. (Matthew, Pine Park) }\end{array}$ \\
\hline \multirow{3}{*}{$\begin{array}{l}\text { Home away from home } \\
\text { (Well integrated into daily } \\
\text { life) }\end{array}$} & & & $\checkmark$ & $\begin{array}{l}\text { My wife thinks I live here, but I don't really! I do come home, } \\
\text { when I'm hungry. (Fred, Kookaburra) }\end{array}$ \\
\hline & & & $\checkmark$ & $\begin{array}{l}\text { People feel like they can come in and do what they like. So, I } \\
\text { think that's important...to have a little bit of space where you can } \\
\text { come in and have a sit or whatever. (Brenda, Marville) }\end{array}$ \\
\hline & & & $\checkmark$ & $\begin{array}{l}\text { I find it's quite relaxing and it's not too much to like upkeep. } \\
\text { (Claire, Pine Park) }\end{array}$ \\
\hline \multirow[t]{3}{*}{$\begin{array}{l}\text { Neutral } \\
\text { (Everyone free to come and } \\
\text { go) }\end{array}$} & $\checkmark$ & & & $\begin{array}{l}\text { We think homeless people come in... and so, we're replacing } \\
\text { padlocks. ...(They) pushed the barbed wire down and get over } \\
\text { on top of the shed. (Janet, Kookaburra) }\end{array}$ \\
\hline & & & $\checkmark$ & $\begin{array}{l}\text { I always have a look in, and often as not, I see somebody doing } \\
\text { something in here and I don't always recognise them. So I think } \\
\text { it is - people feel like they can come in and do what they like. So, } \\
\text { I think that's important. That was the goal. (Brenda, Marville) }\end{array}$ \\
\hline & & & $\checkmark$ & $\begin{array}{l}\text { I think the second go around, rather than have someone take over } \\
\text { as the king of the castle, we were very keen that we were much } \\
\text { more an egalitarian mob. So what we do, some people take on I } \\
\text { suppose particular responsibilities. (Matthew, Pine Park) }\end{array}$ \\
\hline
\end{tabular}




\begin{tabular}{|c|c|c|}
\hline \multirow{3}{*}{$\begin{array}{l}\text { Levellers } \\
\text { (No importance on an } \\
\text { individual's status in a } \\
\text { society) }\end{array}$} & $\checkmark$ & $\begin{array}{l}\text { Fred helps a lot with the charity plot and we give it to an } \\
\text { organization ... and they put on a feed for people every Sunday no } \\
\text { questions asked. (Daisy, Kookaburra) }\end{array}$ \\
\hline & $\checkmark$ & $\begin{array}{l}\text { It's nice to get out with your neighbours and work together for - } \\
\text { towards a common goal and it's nice to see a transformation take } \\
\text { place. (Stefan, Marville) }\end{array}$ \\
\hline & $\checkmark$ & $\begin{array}{l}\text { It ebbs and flows...there would only be about } 3 \text { or } 4 \text { (members } \\
\text { from social housing) of the } 20 \text { odd. (Matthew, Pine Park) }\end{array}$ \\
\hline \multirow{3}{*}{$\begin{array}{l}\text { Regulars } \\
\text { ('Characters'. Play a role in } \\
\text { integrating new visitors) }\end{array}$} & $\checkmark$ & $\begin{array}{l}\text { There's some people, like Fred who are here all the time. (Jane, } \\
\text { Kookaburra) }\end{array}$ \\
\hline & $\checkmark$ & $\begin{array}{l}\text { Mandy's really been the leader and she's great. She's really } \\
\text { friendly. (Brenda, Marville) }\end{array}$ \\
\hline & $\checkmark$ & $\begin{array}{l}\text { There are a lot of people who walk through the garden every day. } \\
\text { (Edward, Pine Park) }\end{array}$ \\
\hline \multirow[t]{3}{*}{$\begin{array}{l}\text { Conversation } \\
\text { (The main activity) }\end{array}$} & $\checkmark$ & $\begin{array}{l}\text { You get to know the people so if they've got something extra they } \\
\text { can offer you, we swap. (Samuel, Kookaburra) }\end{array}$ \\
\hline & $\checkmark$ & $\begin{array}{l}\text { I feel like most of us are novice gardeners. Like, we're all kind of } \\
\text { doing Google research and finding out information .... We're all } \\
\text { kind of sharing information about - 'Oh, I found this plant,' or 'I } \\
\text { heard an interview about this type of thing.' (Violet, Marville) }\end{array}$ \\
\hline & $\checkmark$ & $\begin{array}{l}\text { My partner ..., she liked the idea of gardening. I think I like the } \\
\text { idea of getting the local gossip. (Matthew, Pine Park) }\end{array}$ \\
\hline
\end{tabular}

Table 4.2 shows that each community garden can exhibit different third place characteristics. For example, Kookaburra is not completely at third place due to the characteristics 'access', which relates to whether or not the garden is in a walkable location to its participants, and 'neutral', as defined by everyone is free to come and go. The next section details each third place characteristic and examples are given from a number of the case study sites to illustrate how the characteristic is or is not present.

\section{Easy to access and accommodating}

The 'easy to access and accommodating' characteristic is the 'where and when' of third places.

"Third places must stand ready to serve people's needs for sociability and relaxation in the intervals before, between, and after their mandatory appearances elsewhere" (Oldenburg, 1999, p. 32).

'Accessibility' relates to the location of the third place. Oldenburg's (1999) third place concept is place-based, and he argues that third places should be accessible by walking and open to everyone. For the purpose of this thesis, riding a bike along local streets to the garden, as at Hagenlund and Frank Street, is considered accessible because this does 
not interfere with them being places where you see familiar neighbourhood faces. Two community gardens, Kookaburra and Bluevale, were not accessible to all members, as they were not 'walkable' (or local bike ride) distance from all members' place of home or work. At Kookaburra, Jane describes how her internet search for a community garden in the area came up with this as her closest.

I live in that pink building, see the pink building there? [Jane points to a high rise building in the distance] It's a bit of a walk. It's sort of forty minutes and I don't like riding a bike here because there isn't a bike path so, I do have to drive, but you know it's ten minutes' drive, it's okay. (Jane, Kookaburra)

In the case of Kookaburra, it is situated in a city with high car dependency ${ }^{8}$. It is also situated in a subtropical climate, in which heat can impact on decisions to walk or drive. The “ten minutes' drive, it's okay" may well fit within Jane's idea of local. Leanne of Kookaburra 'Googled' to find her closest community garden and found it is easy to stop at when driving between her workplace and picking up her children from school. Another factor to consider at this site is the physical placement of the garden. Although on a map it is situated next door to a retirement village, it is a steep walk between the two facilities. Jim indicated that some retirement village residents had been involved in the garden, but due to ill health no longer attend, though he said of one past member at the retirement village:

I think he keeps a bit of an eye on the place through the trees. (Jim, Kookaburra) In this case, it is not the distance from home to the garden, but the ability to access it which affects its accessibility. Jane Jacobs (1961) talks about the importance of the placement of public spaces and the need for them to be interconnected in order to increase the traffic and increase the likelihood that the place will be frequented.

The Pine Park garden is easy to access as all of the members live within walking distance of it. The garden occasionally receives publicity, which attracts potential members from outside the local area, but members encourage them to find (or start) a community garden closer to their home.

\footnotetext{
${ }^{8}$ The Gold Coast has a "high dependence on motor vehicles" according to the Gold Coast City Council "Sustainable Transport" plan. "Gold Coast City Transport Strategy 2031" accessed 21/3/19
} 
We've been on the tele a couple of times and a thing in 'The Herald' that we got to feature in, so people with that sort of publicity they get excited about it and they sort of come from miles and sometime they come from quite a distance away and they want to be part of it and we say this works better if you are a short walk of where it is and if you're a kilometre away, probably better finding some like-minded people and a patch, and get into council and say there is a group of us here and we'd like to start a community garden in our little patch. (Matthew, Pine Park)

This emphasis on walkability is echoed throughout the Pine Park garden membership as it promotes the usability of the produce and the neighbourhood composting facility. Barbara lives close enough to the garden that she adds her food scraps to the community compost and picks some of her plants to add to her meals.

I think if you had to drive, or if you lived more than 10 minutes ' walk, you wouldn't bother, whereas for me it's always been around the corner. (Barbara, Pine Park)

By being in close proximity, the garden works as a third place because gardeners are able to frequent the garden and get to know other local residents. The Marville community garden is easy to access as all members live within walking distance of it and visit it at all different times. Similarly, the members and volunteers at Frank Street live close by and some enjoy socialising together in the garden using the facilities such as the barbeque and shelter and there is a big emphasis on the children playing and having fun in the garden. At Hagenlund library community garden, all members of the garden live within walking or bike riding distance, making it very easy to access.

Accommodating refers to a feeling that the place is available to visit at convenient times (Oldenburg, 1999). Pine Park is accommodating, as it is open 24 hours a day to the public, however, the openness came at a cost with some instances of theft and vandalism. The current members expressed that such acts had discouraged the gardeners, but their talk demonstrated a level of tolerance for such negative events. Harriet explained that, "It is an open garden. We don't lock it." Barbara at Pine Park explained that, "If they take 1 or 2 leaves it is fine", but to prevent greater loss, she keeps some weeds in her plot in order to hide her plants from theft and vandals. The same gardener explained that despite the thefts and vandalism, she appreciated the sense of community brought about by the garden, which to her is a greater benefit than just growing produce. 
If it was a locked garden, it would be a lot easier, but then if it is locked, it is a lot more exclusive. Not so community minded. (Barbara, Pine Park)

As with the other case study sites, the openness of the Hagenlund Library Garden 24 hours a day leaves it vulnerable to theft and vandalism. This was in evidence on a sign posted on the garden beds that said (translated):

"Please don't take the kid's vegetables" because they are supposed to be having a harvest party for the kids next week. Everything was just about ready for the harvest and then it was gone one morning. It is a sad little crying child on the poster there. (Yvonne, Hagenlund)

Pine Park and Bluevale also experiences a number of homeless people using the garden. While Kookaburra locks vandals and homeless people out of their garden, their garden has one communal garden bed dedicated to growing food to contribute to a local charity that supports homeless people. The role of community gardens in the provision of food and shelter for the homeless is a topic which merits future investigation.

One other comment on the accommodating characteristic relates to the nature of gardening. Most activity occurs during daylight hours and is limited by seasonal variation. Unlike any of the Australian case study sites, Hagenlund experiences snowy winters and is dormant during that season. Dormancy in winter will not be considered as ruling out Hagenlund as a third place, however, it shows how third places can be characteristically specific to their locations. Certainly Oldenburg's examples of third places mostly do operate in winter, as one may conjure up the image of a cosy local English pub - one of Oldenburg's favourite examples of a third place (1999).

Table 4.3.1: Accessible and Accommodating

\begin{tabular}{|l|c|c|c|c|c|c|}
\hline Third Place Characteristic & Kookaburra & Pine Park & Marville & Frank Street & Bluevale & Hagenlund \\
\hline $\begin{array}{l}\text { Accessible (easy to visit } \\
\text { location) } \\
+\end{array}$ & X & $\checkmark$ & $\checkmark$ & $\checkmark$ & X & $\checkmark$ \\
$\begin{array}{l}\text { Accommodating } \\
\text { (Open at accessible times) }\end{array}$ & $\checkmark$ & $\checkmark$ & $\checkmark$ & $\checkmark$ & $\checkmark$ & $\checkmark$ \\
\hline
\end{tabular}

Table 4.3.1 summarises the findings of the third place characteristic, 'accessible and accommodating'. In coding the data, this study has found that this characteristic is more useful in the analysis framework if applied as separate characteristics. Using Oldenburg's meaning of accessible, Kookaburra and Bluevale were not situated within walking distance for many members. The discussion section will consider if the scale of the 
definition of local could be expanded. In the case of Kookaburra, the car is a part of getting around for many residents and a short drive is not necessarily considered beyond the scope of 'local'. Bluevale City Garden is a place-based community garden that attracts members and visitors from all over Brisbane city. This could lead to a revised version of what a third place is when the scale of local extends beyond the micro-level walkable neighbourhood.

The community gardens were found to be accommodating within the limitation of most activity taking place in daylight hours, with the exception of case of Kookaburra's keyed access and Hagenlund in winter. Accessibility has implications for a third place, as it is the familiarity that grows from frequenting a place and bumping into the same regulars and other locals that makes it a third place (Oldenburg, 1997).

\section{Mood is relaxed and playful}

Oldenburg (1997, p. 9) described the concept of third place as associated with incidental interactions and fun and: "the entertainment is provided by the people themselves" through lively conversation. Samuel at Kookaburra mentions the garden as a place to relax after a stressful week at work. He describes the main benefit of joining the garden as:

Relaxation. I'm a teacher just down the road, so I can get quite stressed out at times. It is nice to come here on my way home to have a water or weed something out. (Samuel, Kookaburra)

At Pine Park, the mood is relaxed and social with meetings taking place over a morning tea break. In the observation of the meeting which followed their Sunday working bee, it was apparent that passing around the cake was a pleasant act of sharing which the members seemed to enjoy. The mood at Pine Park garden is relaxed and social activities occasionally extend to activities beyond the garden.

We recently all went out to dinner together because there's a chef ... who opened a restaurant in Potts Point ... and asked us if we could set aside part of one of our plots so she could grow some Vietnamese mint, right? And we said yes, and she did, and then at the end of the year she invited us all up to come and have a meal at the restaurant. (Edward, Pine Park) 
This is an example of how community garden activity can extend beyond the garden boundaries into the wider community. Edward describes the garden as one of his interests which he enjoys.

I just find it interesting, you know. ... My life's not about this, but it's just that segment of my life which I enjoy and I get a lot of pleasure in. (Edward, Pine Park)

At Marville the mood is relaxed and the children enjoy playing in the dirt and toys are left out for all to play with. As discussed later in home away from home, the community garden is utilised by many of different local people for a wide range of purposes. It is seen by members as much needed local green space. Similarly at Frank Street a lot of the sentiment is about the children and enjoying the outdoors.

It's nice to do something, especially with the kids outside. They really like it. It's great for their sort of friendships as well and-yeah, it's just nice doing something outside. (Kat, Frank Street)

Most Frank Street interviewees mentioned bringing the children to the garden to get them playing outdoors. Grant at Frank Street said: "It's very relaxing”. Grant was originally from the country and is a self-confessed "green thumb". He said that he has a large yard with a vegetable garden at home, but he explained that as well as the relaxing solitary time gardening:

I like the people that hang out here, so it's nice to come and hang around with people who are interested in gardening and cultivating. (Grant, Frank Street)

This garden acts as a third place for Grant, as it provides relaxation and social time where he can 'hang around' with local people.

Table 4.3.2: Playful Mood

\begin{tabular}{|l|c|c|c|c|c|c|}
\hline $\begin{array}{l}\text { Third Place } \\
\text { Characteristic }\end{array}$ & Kookaburra & Pine Park & Marville & Frank Street & Bluevale & Hagenlund \\
\hline $\begin{array}{l}\text { Playful mood (Enjoyable. } \\
\text { Entertainment by the } \\
\text { participants themselves) }\end{array}$ & $\checkmark$ & $\checkmark$ & $\checkmark$ & $\checkmark$ & $\checkmark$ & $\checkmark$ \\
\hline
\end{tabular}

Words such as 'party', 'relax' and 'enjoy' crop up throughout the interviews and indicate a playful and pleasant mood in the community gardens, as described by Oldenburg's third place characteristic of 'playful'. Conversations help facilitate the social interactions 
between the community garden participants, as will be discussed in that forthcoming section.

\section{Low profile}

Oldenburg (1999) describes third places as homely, plain and tending to being wholesome. Kookaburra provides opportunities for the physical exertion of gardening activities.

Probably the most enjoyable (activity) is when I do get my hands dirty because you can't just pull vegetables out and then throw new ones in. You have to dig and prepare the soil, and do the weeding so I'm trying to get better at it, but ... get your hands dirty - good fun <laughs> (Harry, Kookaburra)

It should be noted that a keenness to get the hands in the soil was mentioned by both males and females at a number of the gardens.

The Pine Park garden cover of weeds strategy mentioned earlier by Barbara, protects the produce and contributes to the low profile atmosphere of the garden, with one member describing it as: "by no means a beautiful community garden" (Matthew, Pine Park).

Marville is low profile with toys scattered around the garden. Spare produce such as passionfruit are left in a box for anyone in the neighbourhood to take for free.

The Frank Street garden is low profile as the priority for many at Frank Street is about being together enjoying the outdoors with their children.

It's good for the kids. It's a nice community activity as well, and also the idea of there being fresh produce growing nearby, that's good. (Kat, Frank Street)

As April points out, they don't mind if the food they grow is not of a great standard.

It's something nice to teach the kids and they don't care if the tomatoes that they pick are sour and yucky. They will always eat them and be happy that they've picked something that they've grown and harvested themselves. (April, Frank Street)

Clarissa from Bluevale City Garden noticed people in the neighbourhood visit the garden enjoying the natural surroundings. 
Yeah they walk their dogs through and say hi to the chickens and that sort of stuff. It's kind of near the hospital. A lot of people park there and walk in to the hospital, but often they'll take a little walk through the gardens on their way and sometimes just sort of take their time. You see people just walking through. They don't always stop and chat and get involved in a more organised way but they enjoy the space. (Clarissa, Bluevale)

The Hagenlund library garden is also low profile and not showy. Casual seating and outdoor umbrellas have been provided for locals to enjoy the garden area. The low profile design of community gardens provides a relaxing environment in a natural setting.

Table 4.3.3: Low profile

\begin{tabular}{|l|c|c|c|c|c|c|}
\hline Third Place Characteristic & Kookaburra & Pine Park & Marville & Frank Street & Bluevale & Hagenlund \\
\hline Low profile & $\checkmark$ & $\checkmark$ & $\checkmark$ & $\checkmark$ & $\checkmark$ & $\checkmark$ \\
(Homely and comfortable) & & & & & & \\
\hline
\end{tabular}

\section{Home away from home}

Third places are comfortable and people feel at home while they are there. They are free from the obligations that might come along with home or work (Oldenburg, 1999). The Kookaburra community garden can feel like a home away from home and include alone times for the enjoyment of gardening. At Kookaburra, Fred visits three or four times a week.

My wife thinks I live here, but I don't really! I do come home, when I'm hungry. (Fred, Kookaburra)

Fred looks after his own garden plot and the charity plot and helps to keep the place tidy by mowing the grass. Social membership is available for anyone at a very low cost of $\$ 10$ per year.

Sometimes people, if they like, they can be a social member whilst they're waiting to get a plot, so they can still come down because some people are in units and they just enjoy to be outside in this kind of environment and out of the four walls. (Janet, Kookaburra)

These examples show how the Kookaburra can become like an extension of the home where people can spend some relaxing time outdoors, particularly where people have 
moved to housing without a garden. Claire at Pine Park describes how the garden activity is relaxing and she is happy to be there regularly.

I'm not that chatty a person, so I'm quite happy to come down and pull weeds out for a while and it's cathartic and then I go away. Yeah, I find it's quite relaxing and it's not too much to, like, upkeep. (Claire, Pine Park)

The Frank Street community garden facilities, including a shelter, seating and a barbecue provided by the council, help to make it a welcoming place that facilitates feeling like a home away from home.

We have a barbecue in the park. Yeah, we're very lucky we all live sort of around the next block down and we can congregate, yeah, which is nice. (Kat, Pine Park)

The Marville gardeners talk about lots of different homely activities which take place in the community garden by numerous different local people, including local workers having lunch, playgroups, and someone whose house was being renovated used the space to conduct their music lessons. Brenda says that when she is passing and looks in she doesn't always recognise the people and that: "people feel like they can come in and do what they like. So, I think that's important".

Mandy mentioned another homely use of Marville:

Another lady in the neighbourhood asked if she could have her daughter's seventh birthday party here, just a space to have it so she'd have maybe a half dozen people up here. (Mandy, Marville)

These examples show how the Marville garden has become an extension of the home where people can relax outdoors. Marville is made homely in that the design includes a sheltered meeting space and bamboo cave (for the children). Their outdoor pizza oven was donated by a local businesswoman who had come to appreciate the garden as a pleasant place to visit away from her office. Brenda described Marville, which had only been established for one year at the time of the interviews, as a transition from a neglected unused space to a 'positive' place. Making and watching the change over time is an example of local residents' act of placemaking - a place for their own use. This concept is explored in the next chapter. The group at Marville have made a useful green space for the whole community to use, which is an example of the UN Sustainable development 
goal 11.7 to create safe and inclusive green spaces, which will also be discussed in Chapter 5.

Martin at Bluevale explained how the garden feels homely to him.

I feel at home there, but I have a niche, things I do, and that creates the at-home feeling for me. If I didn't have activities that I was involved in there, I'd have to find something, so that I'm making a positive contribution to the place. (Martin, Bluevale)

Martin describes having a "niche" and a role at the garden as important to his sense of home at the garden.

There is evidence at the Hagenlund library garden that it feels like home away from home, with the librarian noting that locals are enjoying the seating at library closing time. All gardening materials are supplied for free and shaded seating areas are provided for all to use. The interviewee noted that it has vastly improved what was a "very boring, very bland" concrete area, to a place that adults now congregate and socialise in.

Table 4.3.4: Home away from home

\begin{tabular}{|l|c|c|c|c|c|c|}
\hline Third Place Characteristic & Kookaburra & Pine Park & Marville & Frank Street & Bluevale & Hagenlund \\
\hline Home away from home & & $\checkmark$ & $\checkmark$ & $\checkmark$ & $\checkmark$ & $\checkmark$ \\
$\begin{array}{l}\text { (Well integrated into daily } \\
\text { life) }\end{array}$ & & & & & $\checkmark$ \\
\hline
\end{tabular}

The four third place characteristics of easy to access, playful, low profile and home away from home are evident to varying degrees in the case study community gardens and all contribute to the placemaking connections of the local people (community) to the local land and nature (garden). These four characteristics are thematically grouped as placemaking characteristics. Many interviewees appreciate the knowledge they acquire about gardening and access to 'dirt', but also appreciate the sense of community they developed with fellow gardeners and local residents. The placemaking aspect of the community gardens will explored more fully in the next chapter (5) in relation to how they can contribute to achieving UN Sustainable Development Goal 11.7 by providing inclusive green spaces for the community. Chapters 5 will also discuss how the act of placemaking works to address some social challenges arising from population mobility as people work together to create and maintain their community garden, or watch the 
garden's progress and interact with members. The experience of cooperative effort will be discussed in relation to the neighbourhood's adaptive capacity and subsequent neighbourhood resilience. This thesis relates the findings to neighbourhood resilience as it is specific to the diversity within a location rather than community resilience which implies an existing cohesive community of people. Stevenson and Petrescu (2016) discuss how resilience is often researched at the building, city or regional level, often the missing level of neighbourhood resilience.

\section{Neutral Ground}

Oldenburg (1999) described third places as open to all and places where everyone is free to come and go without obligations. Five of the community gardens were open 24/7 to the public, as discussed in the 'accommodating' characteristic section. The Kookaburra community garden committee had chosen to enclose the area with high fence (barbed wire on top) and have key entry, which does not fit with the third place characteristic of neutral.

We've all got our own keys for the gates here and for the gate up the top. (Harry, Kookaburra)

Jim at Kookaburra explained that the group had decided to lock the place because of evidence that people were possibly using the area for sleeping. In his role as president of the committee, he also advised the members to lock themselves in if they are gardening alone. However, the membership was inclusive and as stated earlier did not require a gardening role.

Being open at all hours, Pine Park acts as neutral ground where people of the neighbourhood join in. Some found out about the garden through neighbours while most came across it while walking through the neighbourhood. They have a notice board which explains the membership requirements and when the meetings are scheduled. The garden is open to use as a third place and there are local people who show interest in the garden without being members or actively involved in it. Barbara at Pine Park said, "We do get a fair few (passers-by) stop and chat" and she and other members try to encourage those visitors to join. 
Marville is neutral ground, as membership in the garden is free and is not necessary in order to participate or enjoy the garden. Everyone is welcome to use the space. It is used by locals, business people, grandparents, playgroups, etc. It is open all hours every day.

Because the Frank Street community garden is open and has no membership obligations, it is neutral ground where members and visitors are welcome to come and go. Albert, whose house backs onto the community garden, had been a regular for a year helping to keep the garden tidy and was unaware if there were membership fees. The garden is open to anyone to participate, as described by one young neighbour:

We've got a house with a large backyard, so we do a bit of vegetable gardening there. ... I'm not really a formal member or anything. I just turn up here and do some gardening and hang out with some people that I like. (Grant, Frank Street)

The Hagenlund library garden acts as a neutral ground, started in order to 'engage' with the adults who live in the area by providing an attractive green place where they can get to know the library staff and each other.

Table 4.3.5: Neutral

\begin{tabular}{|l|c|c|c|c|c|c|}
\hline Third Place Characteristic & Kookaburra & Pine Park & Marville & Frank Street & Bluevale & Hagenlund \\
\hline $\begin{array}{l}\text { Neutral } \\
\begin{array}{l}\text { (Everyone free to come and } \\
\text { go) }\end{array}\end{array}$ & X & $\checkmark$ & $\checkmark$ & $\checkmark$ & $\checkmark$ & $\checkmark$ \\
\hline
\end{tabular}

\section{Leveller}

Third places are not dependant on participants' social or economic status as everyone is free to be there regardless of rank and status (Oldenburg, 1997). At Kookaburra there are mixed ages involved, including children and a few teenagers. Parents indicated that their children like the gardening experience. Samuel at Kookaburra said his seven year old child is actively involved in the gardening and that his wife enjoys having the garden as a project while she is on maternity leave with their baby. At Kookaburra, Leanne noted the benefits of taking her teens to the community garden:

"My teenagers - will eat more vegetables. I think it's the taste factor. And you know that it's organic - it's something you've grown yourself." (Leanne, Kookaburra) 
Third places reduce social isolation of older residents and community gardens have the bonus of providing fresh food and promoting active living. Fred, a retired member of the Kookaburra garden said that: "It's giving me an outlet for something to do". Kookaburra gardeners interacted with community groups and local schools, including having certain growing plots put aside for charity work and different schools. Through their charity work and external fund raising activities, Kookaburra acts as a third place extending beyond the boundaries and beyond the membership. Cultural diversity and inclusivity was noted by the President of Kookaburra which included members who were originally from Thailand, Greece and Bosnia. Kookaburra also provides high rise garden beds for people with physical limitations and their chickens are looked after by clients of an organisation for people with multiple handicaps.

Pine Park acts as a leveller where age, occupation and other defining factors are irrelevant to visiting or participation. Members who were interviewed were involved in a variety of occupations including retirees, professionals, a university student and her small children and a (formerly) unemployed person. People of all ages, including children, join in.

It's made up of, seems to be mostly university educated people in there, some in their 20s, 30s. I'm probably the oldest person in the group. But there is another set, there's about maybe four or five of us who are 60 plus. And then there's some people in their $50 \mathrm{~s}$, and then there's the rest of them. And I think there's about 20 members, 20 financial members. (Edward, Pine Park)

While the quote refers to the mix of adult ages, members also mention the children who participated currently or in the past. The community garden actively encourages interactions with the broader neighbourhood. For example, three of the members help out with the neighbouring primary school garden. The local coffee supplier took an interest in the garden's coffee trees and showed the members how to care for the trees and helped them to harvest and roast the coffee beans. One member noted there is a local pride in the garden even amongst non-members. Members recounted use the garden by locals for a variety of activities. One member described a few examples of people who are not members but still spend time in the garden.

It is surprising the number of people who are aware that it's there and some people just sit in it in the mornings and read the paper in it, wander around and see how it's doing. 
There are a lot of people who walk through the garden every day. There's another person who comes and grabs weeds, they've got a rabbit. (Edward, Pine Park)

Marville was a leveller in that there were mixed ages and gender balance present. Oldenburg (1999) and Jane Jacobs (1961) point out the need for safe public places for teenagers to hang out. The Marville local teens use the garden as a place to hang out. While members of the Marville struggled to attract older locals to join their community garden, the interactions with older people occurred in a third place manner.

[Older people are] Not quite actively involved but they often stop for a chat and they'll give us plants and things. (David, Marville)

The interactions between members and non-members, who are regular visitors, are third place interactions. At Marville, one female member noted opportunities for community garden roles beyond gardening activities:

Because I was either pregnant or with the baby,... I haven't done any heavy lifting or anything. Most of my involvement has been on the record-keeping side of things. I haven't really been onsite as much. (Brenda, Marville)

At Marville, only established one year at the time of interviews, some members lament that the cultural diversity of their neighbourhood is not yet represented in their membership. Members indicated that they would like to encourage diversity of cultural background for example, to learn together and: "to encourage people to grow what they know, wherever it's from, and teach others about it too" (Brenda, Marville). Oldenburg (1999) generalises that third places allow people opportunities to interact with a more diverse population compared to work and home. In an ethnically and socioeconomically diverse suburb such as the one Marville is situated in, diversity of membership may develop over time.

Mandy at Marville community garden explained that it is not only gardening that draws people to the garden. In an area of 500 houses, 200 people attended the opening of the garden and 60 people attended their winter woollies workshop. Mandy said that: "people are wanting to engage, they're wanting to get to know their neighbours". As one Marville gardener described his community garden:

I think it's in the title. It's community and it's a garden. So I mean, it's nice to sort of see community being developed near where you live, get to know your 
neighbours and people who live around you, and also it's a public garden, so it's a nice use of green space. (Stefan, Marville)

This is a leveller in that getting to, "know your neighbours", as Stefan and Mandy said, is based on those people living in close proximity to each other, not on any other socially distinguishing features.

The Frank Street community garden members who were interviewed included young parents who had children in tow. All the ingredients were there for the garden to act as a leveller with everyone welcome. Kat at Frank Street described the garden as, “We've got a very nice strong community." Mixed ages are present at the Frank Street community garden and children are a focus for many of the interviewees.

I reckon there's a bit of family connection, community connection. Yeah. Just catching up with people and doing something together, having a sense of just being productive together on a weekend and hanging out and having the kids - a bit part of it is probably the kids actually, for me. (Emma, Frank Street)

A diversity of participants was described by Clarissa at Bluevale City Garden, including: "people in remission, people long-term unemployed, struggling with mental health or social isolation, or just strong personalities". Bluevale is an open site which combines volunteers, national and international visitors, locals, WEX participants (work for the dole program), plot holders and people who work at the local hospital who walk through the garden.

The Hagenlund library garden encourages the participation of anyone who wants to join in and therefore acts as a leveller across ages, languages and ethnicity. The librarian organising the garden says that the membership is: "actually representing this neighbourhood quite well", as it includes Danish residents and immigrants from Pakistan, Turkey, Somalia and Thailand. Involvement in the garden is free and all supplies are provided, therefore income is no barrier to participation.

Table 4.3.6: Leveller

\begin{tabular}{|l|c|c|c|c|c|c|}
\hline Third Place Characteristic & Kookaburra & Pine Park & Marville & Frank Street & Bluevale & Hagenlund \\
\hline Levellers & $\checkmark$ & $\checkmark$ & $\checkmark$ & $\checkmark$ & $\checkmark$ & $\checkmark$ \\
$\begin{array}{l}\text { (No importance on an } \\
\text { individual's status in a } \\
\text { society) }\end{array}$ & & & & & & \\
\hline
\end{tabular}




\section{Regulars}

Third places have a core group of influential 'regulars' who contribute to the friendly atmosphere and play a role in introducing people to each other, "bringing together newcomers as well as routine patrons" (Knox 2005, p. 8). Jane Jacobs referred to neighbourhood regulars as 'public characters' $(1961$, p. 8$)$. Every case study site had people who acted as regulars.

It's very pleasant to come and talk to people and Daisy is a real sweetie she holds everybody together. (Jane, Kookaburra)

At the Pine Park community garden the regulars help to introduce new or potential members to each other and these connections are consolidated through the occasional social event.

Once or twice a year there will be some sort of meeting with food and everybody will bring some food and have a lunch. So there is a bit of social activity around it. (Claire, Pine Park)

The organisers act as regulars at Marville. Similarly at Frank Street there is a core group of regulars and as Greg explains, the participants like gardening together.

I think that's mostly what it's about and strengthening community connection and people who are interested in knowing other people in the community. (Grant, Frank Street)

Although the Frank Street community garden gets visitors as a third place, the design of this garden being communal only creates some issues with attracting members. According to the group's own research, some local potential members would prefer to have their own garden plot. Having a low number of members affects the third place characteristic of regulars, as there are less regular faces on site at any given time to play the role of introducing new people to each other and to the place.

They usually come once and then that's it. Yeah. It's rare that other than that immediate circle, we get people who stay for longer than one session. (April, Frank Street) 
The organiser had two potential explanations. One was that, having conducted a survey of her local neighbourhood, the coordinator noted that the communal-only design was seen as a negative amongst potential members.

At the moment, it's all communal, but I think we'll move to individual plots because people seem to want that.... I did a survey on Survey Monkey earlier in the year and that was one of the questions. (April, Frank Street)

The second potential explanation for people not returning as members was described as thinking there were existing friendships which might be difficult to break into.

I mean all of the people who come regularly-we're all friends. We all go to the same school. They were an existing community. ... I don't know whether it makes it harder for other people to come in because of that, but-yeah. We like hanging out anyway. (April, Frank Street)

However, Albert, a volunteer gardener whose house backs onto Frank Street community garden, attends regularly, but was only meeting the other members for the first time that day. He was a regular volunteer at the garden without joining. He said the members, "seem friendly". It is possible that the Frank Street community garden might benefit from being a little more club-like to add structure so that individual plots can be organised and members can understand their role. The perceived difficulty attracting members to the Frank Street runs counter to many of the other community gardens which did not claim to struggle to attract members or visitors. From the interviews and looking at Facebook posts, it seems this garden has a strong focus on children and the structure and purpose of the community garden is not altogether clear, which may make joining confusing.

Clarissa at Bluevale described how the regular contact with familiar faces at her community garden means that, "you do make friends". At the Hagenlund library garden, the librarians act as the core group of influential regulars.

It is part of our (library) portfolio now. You can say we have to be careful how many hours but it makes sense. It gives us great connection to the school and the kindergarten and the youth club and it makes sense with these partnerships because a lot of the kids who come here we know and we know them from very young and they come back and have their families. (Yvonne, Hagenlund) 
As well as the librarians, the children from the school and kindergarten are also regulars, but the garden was initiated as a way to draw in more adults from the neighbourhood into the library.

Table 4.3.7: Regulars/characters

\begin{tabular}{|l|c|c|c|c|c|c|}
\hline Third Place Characteristic & Kookaburra & Pine Park & Marville & Frank Street & Bluevale & Hagenlund \\
\hline Regulars & $\checkmark$ & $\checkmark$ & $\checkmark$ & $\checkmark$ & $\checkmark$ & $\checkmark$ \\
$\begin{array}{l}\text { ('Characters'. Play a role in } \\
\text { integrating new visitors) }\end{array}$ & & & & & \\
\hline
\end{tabular}

In all six case study sites, the regulars help newcomers to feel part of the neighbourhood by introducing them to the place and the people. This will be discussed in subsequent chapters in relation to building social capital and reducing social isolation.

\section{Conversation}

Oldenburg (1999) notes the importance of 'conversation' in third places and describes how the opportunities for conversation are enhanced when there is a reason for people to speak with each other, such as a game. At Kookaburra community garden, the gardening activities give rise to exchanges of information and cooperative action and the gardens promote conversation beyond the garden, with locals who are not involved with it.

We've met some really nice people [who are] willing to share knowledge as well... And it generates a lot of discussion in the wider community. (Leanne, Kookaburra)

Conversation is a main activity at Pine Park, both between members and with visitors in and outside the garden, where the garden can be a topic of conversation.

Quite often if I'm down here I'll get people walking through and asking about it and whether they can join and you tell them about it and they might come or they might not. It tends to be word of mouth and the blackboard that spreads information, so sometimes people chat. (Claire, Pine Park)

Gardening is a good conversation starter. The community garden actively encourages interactions with the broader neighbourhood, for example, three of the members help out with the neighbouring school community primary school, which has their own school 
garden. In addition, people from outside the garden take an interest in the garden as a topic of conversation at the local pub, or coffee shop. For example, the local coffee supplier took an interest in the garden's coffee trees. The Pine Park garden promotes conversation beyond the garden, with local business patrons who are not involved with gardening.

Even though they're not involved, you know, when I go to the local pub, there are people there in the pub who will say you know, 'How is the garden going?', and they'll know those of us in the pub who are from the garden. (Matthew, Pine Park)

The Pine Park garden is well known and a point of conversation with non-gardening locals, therefore acts as a third place where gardeners experience valued interactions with passers-by and the local neighbourhood community.

One member suggested that the Marville Community Garden gives people reasons to initiate a conversation.

I mean, it's always awkward meeting new people, but at least here there's something to do. Like you're not just standing around. Sometimes in a party, it's more awkward 'cause you're put in a space to socialise, whereas here, you've kind of got something to do and then you end up talking anyway. (Violet, Marville)

Oldenburg (1999) makes an assumption that people (strangers) will easily strike up a conversation in a third place. However, Oldenburg (1999) adds that an activity, such as a game of boules in the park or snooker in the bar, enhances opportunities for conversation. Conversation plays an important role in all of the case study sites and interactions go beyond conversation to cooperative actions such as swapping ideas and surplus produce.

Gardening and conversation go hand in hand as the main activities in the Frank Street community garden.

People are running around here and kids are running around, say, 'Hi' and some people have a bit of a conversation about the garden or whatever. (Grant, Frank Street) 
Community gardens offer a myriad of opportunities to initiate a conversation. Penny at Bluevale coordinates the volunteers who look after the chickens and through that role she meets and converses with a number of people.

I coordinate the chook team just do the rostering and fill in for people and talk to people who look after the garden. (Penny, Bluevale)

Yvonne considers that the Hagenlund library garden provides an authentic reason for initiating a conversation between strangers. She discusses the library's attempts to host cultural meetings with the purpose of bringing together people in the neighbourhood who are migrants from many different countries. By comparison, the activity of gardening provides a purpose for initiating a conversation.

It is an opportunity to make people meet across age and cultures and languages and its one of the principals we have developed through the last six years that making people meet just because they are different is not really working. I mean what makes people come together is if they share a common interest. That is an incentive to do something. It is not like, 'Ok I can go and meet people from Pakistan and Turkey but what is the point? But we can go and garden together. I would like to do that.' It gives you a common purpose. (Yvonne, Hagenlund)

The act of working cooperatively potentially extends the idea of conversation beyond language barriers. The Hagenlund library garden reaches beyond the members who have garden boxes and for people beyond the immediate neighbourhood by holding workshops about growing edible plants.

We also have workshops where people can learn about edible plants and when we have these workshops people from outside the community come to participate. (Yvonne, Hagenlund)

Almost everyone interviewed at the case study community gardens noted conversations with other members, in exchanging knowledge and garden produce, sharing tools and produce, noting the weather, or general non-gardening topics. The garden provides an authentic topic of conversation and the act of gardening provides an authentic common purpose to start a conversation. The findings show that third places with a communal purpose, in this case community gardening, promote inclusivity because they give people reasons to initiate a conversation. This was reflected in a comment made at Marville that meeting new people can be "awkward", whereas at the community garden there is 
"something to do", so people "end up talking" to each other. The purposeful activity of gardening created opportunities for people to initiate conversations across a broad range of gardening and non-gardening topics. This research adds to the third place literature by focussing on informal place that provides a communal purpose to interactions.

Table 4.3.8: Conversation

\begin{tabular}{|l|c|c|c|c|c|c|}
\hline $\begin{array}{l}\text { Third Place } \\
\text { Characteristic }\end{array}$ & Kookaburra & Pine Park & Marville & $\begin{array}{l}\text { Frank } \\
\text { Street }\end{array}$ & Bluevale & Hagenlund \\
\hline $\begin{array}{l}\text { Conversation } \\
\text { (The main activity) }\end{array}$ & $\checkmark$ & $\checkmark$ & $\checkmark$ & $\checkmark$ & $\checkmark$ & $\checkmark$ \\
\hline
\end{tabular}

The analysis of the characteristics 'neutral', 'levellers', 'regulars' and 'conversation' group together under the theme of social capital. Social capital is enhanced through the third place community garden's inclusive nature and their role in introducing people to the place. In particular, the characteristics 'neutral', and 'levellers' contribute to the concept of 'inclusivity' and the characteristics 'regulars' and 'conversation' contribute to the idea of 'introduction to place'. Chapter 6 will investigate how community gardens that are third places can play a role in producing and distributing social capital, thereby reducing the impacts of population mobility and social isolation and increasing the resilience of a neighbourhood.

\section{Findings Summary}

The findings show that community gardens can be third places. Four of the community gardens studied meet all eight characteristics of third places. Six characteristics were present across every case study site, namely: low profile, levellers, regulars, playful mood, home away from home, and conversation. The results are summarised in Table 4.3.9. 
Table 4.3.9 - Summary of that community gardens are third places

\begin{tabular}{|l|c|c|c|c|c|c|}
\hline Third Place Characteristic & Kookaburra & Pine Park & Marville & Frank Street & Bluevale & Hagenlund \\
\hline $\begin{array}{l}\text { Accessible (Easy to access) } \\
\text { and }\end{array}$ & X & $\checkmark$ & $\checkmark$ & $\checkmark$ & X & $\checkmark$ \\
$\begin{array}{l}\text { Accommodating } \\
\text { (Comfortable to be in.) }\end{array}$ & $\checkmark$ & $\checkmark$ & $\checkmark$ & $\checkmark$ & $\checkmark$ \\
\hline $\begin{array}{l}\text { Playful mood (Enjoyable. } \\
\text { Entertainment by the participants } \\
\text { themselves) }\end{array}$ & $\checkmark$ & $\checkmark$ & $\checkmark$ & $\checkmark$ & $\checkmark$ \\
\hline $\begin{array}{l}\text { Low profile } \\
\text { (Homely and comfortable) }\end{array}$ & $\checkmark$ & $\checkmark$ & $\checkmark$ & $\checkmark$ & $\checkmark$ & $\checkmark$ \\
\hline $\begin{array}{l}\text { Home away from home } \\
\text { (Well integrated into daily life) }\end{array}$ & $\checkmark$ & $\checkmark$ & $\checkmark$ & $\checkmark$ & $\checkmark$ & $\checkmark$ \\
\hline $\begin{array}{l}\text { Neutral } \\
\text { (Everyone free to come and go) }\end{array}$ & $\checkmark$ & $\checkmark$ & $\checkmark$ & $\checkmark$ & $\checkmark$ & $\checkmark$ \\
\hline $\begin{array}{l}\text { Levellers } \\
\text { (No importance on an individual's } \\
\text { status in a society) }\end{array}$ & & & $\checkmark$ & $\checkmark$ & $\checkmark$ \\
\hline $\begin{array}{l}\text { Regulars } \\
\text { ('Characters'. Play a role in } \\
\text { integrating new visitors) }\end{array}$ & & $\checkmark$ & $\checkmark$ & $\checkmark$ & $\checkmark$ & $\checkmark$ \\
\hline $\begin{array}{l}\text { Conversation } \\
\text { (The main activity) }\end{array}$ & $\checkmark$ & $\checkmark$ & $\checkmark$ & $\checkmark$ & $\checkmark$ & $\checkmark$ \\
\hline
\end{tabular}

Pine Park, Marville, Frank Street and Hagenlund are third places across the eight third place characteristics. Kookaburra exhibited 6.5/8 characteristics and Bluevale 7.5/8 characteristics when treating accessible and accommodating as two halves of one characteristic. Kookaburra community garden is lower on accessibility due to the number of people driving to the garden, however this garden was the closest to the members who had to drive there. Kookaburra leans towards being somewhat club-like with its key entry, however they are accommodating and levellers as anyone is allowed to join, even if not actively gardening. The key entry is discussed again in Chapter 6 in relation to safety at the garden. The context of individual community gardens is considered when applying the third place characteristic framework to each site and Kookaburra overall exhibited a number of third place outcomes. For example, members engaged with the community in many ways, both on and off site (charity work, schools, fund raising).

Blueville City Garden is a third place to the many local people who visit and volunteer. It would be considered a third place on the framework if the idea of 'local' was interpreted on a larger scale to include, in this case, the whole city. As an interest-based community garden rather than place-based, it draws in members from all over Brisbane and beyond for various sustainability education workshops, playgroups, or work-for-the-dole and volunteer activities. Interest-based community gardens draw members and visitors from beyond the local area (Easthorpe \& McNamara, 2013; Firth, Maye \& Pearson, 2011). As Clarissa noted, the garden introduced her to people in Brisbane with whom she remained 
friends. In this instance a revised version of 'local' would be the city of Brisbane ${ }^{9}$. This could lead to a revised version of what a third place is when the scale of local extends beyond the micro-level walkable neighbourhood. The role of community gardens as third places in introducing new residents to locals will be discussed in Chapter 6 .

The findings also show that even when all eight of the third place characteristics are not present across all members, the overarching benefits of third places can be achieved by community gardens, which may explain why they have been assumed to be third places in previous studies. In particular, all six case study community gardens act as informal local public places where the local neighbourhood have the opportunity to meet each other, as facilitated through the regulars (members, volunteers).

Third places differ from club or community organisations as they exhibit openness, inclusivity and incidental social interactions (Oldenburg, 1997). By comparison, clubs and community organisations are organisations with membership criteria, rules and obligations that exhibit elements of exclusivity and/or common interests (Putnam, 2000). Community gardens that are situated in publicly owned space in Australia, by their nature need to operate somewhat like a club or community organisation because many are incorporated with committee membership, fundraising activities, public liability insurance and rosters of membership activities. However, this does not exclude them from being able to act as third places, remembering that many of Oldenburg's examples are privately owned establishments, such as coffee shops and public bars that conform to government regulations and have the right to exclude certain patronage (dress code, unruly behaviour, etc). Community gardens can be described as urban commons and the theory debates exclusionary practices versus unrestricted access by the public in relation to encouraging diversity of nature and people (Huron, 2017; Rogge \& Theesfeld, 2018). A community garden has a management structure and rules, just as a (third place) commercial café does. Community gardens fit somewhere along a continuum between club-like organisation and third place, often juggling the two roles simultaneously. Figure 4.1 illustrates how a community garden can simultaneously operate as a club or community organisation and act as a third place within the neighbourhood.

\footnotetext{
9 "The size of Brisbane is $15,826 \mathrm{~km}^{2}$. Brisbane population will reach 2.562 million by the end of June 2019." http://www.population.net.au/brisbane-population/
} 


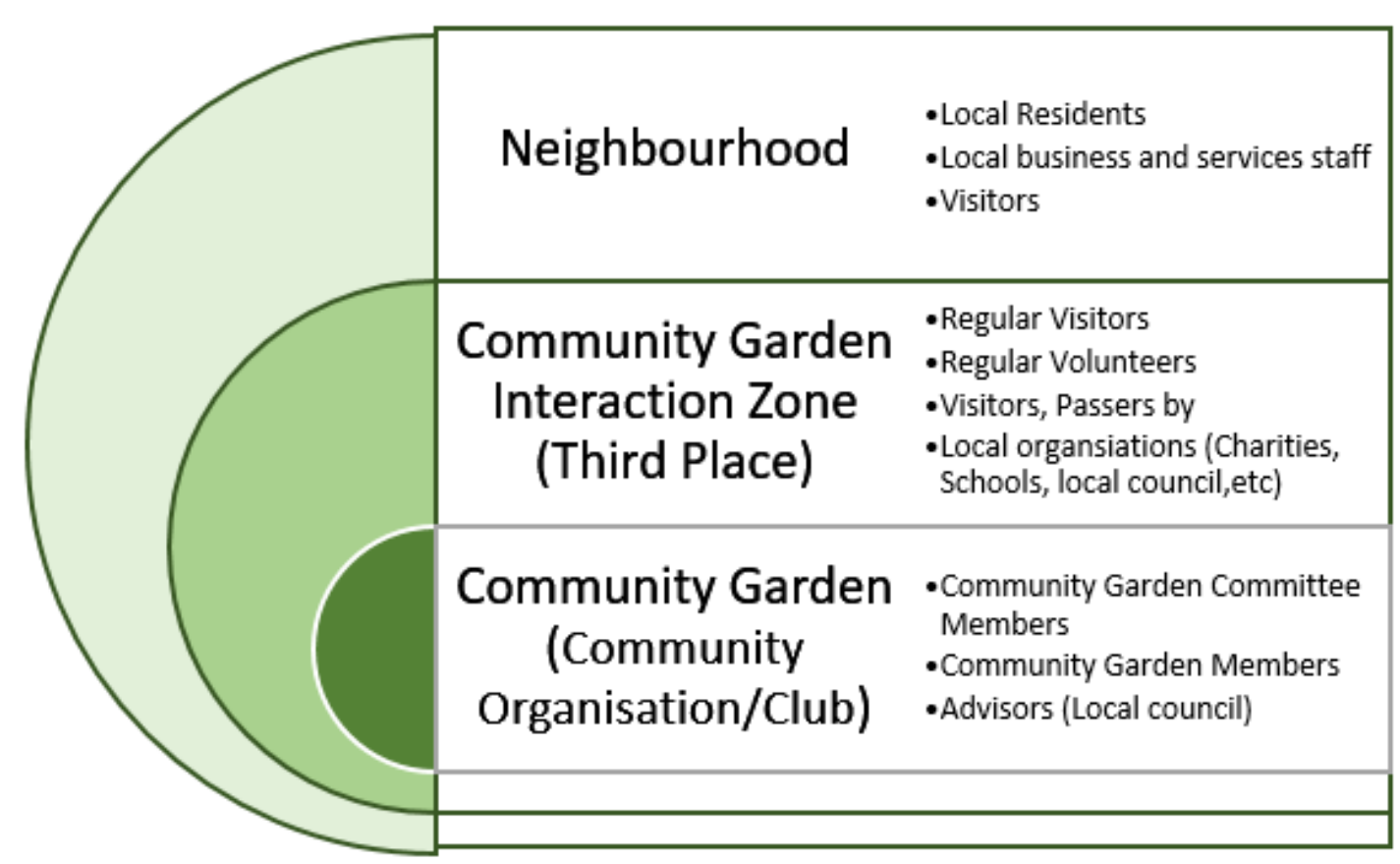

The diagram locates the community garden within a neighbourhood of local residents, workforce and visitors. The core of the community garden is club-like including the membership and organising committee and advisors. Interactions that occur between the core 'club' and the setting (local neighbourhood) are an interaction zone or third place. The third place interaction zone occurs within the garden and outside the garden in the local neighbourhood. The diagram illustrates how a community garden is not necessarily a dichotomy between a club or community organisation and a third place, but can co-exist where conditions of accessibility, inclusivity and neutrality still occur. The interaction zone can occur on or off site. For example, Pine Park is a point of conversation at the local pub and coffee shop.

Of the six case study sites, Kookaburra community garden could be considered the most club-like due to: the use of keys and tall fences topped with barbed wire; stringent membership obligations on the high quality of maintenance of individual plots (weed control, attending working bees); formal committee roles and succession planning; and, the payment of council water fees that necessitated fund raising. The characteristic of neutral ground, where everyone is free to come and go, could not be applied to Kookaburra due key entry for members and high fences used to protect the garden. The 
benefits of the restricted access to Kookaburra community garden is that it suffers no vandalism and minimal theft, therefore produces a good quantity of organic food for associated charities and individual members. Kookaburra acts as the 'black swan' of the case study sites, where one single exception can invalidate previous observations and assumptions (Taleb, 2007), which in this case is that not all community gardens are third places across all eight characteristics. It should be noted, however, that this garden performs several third place functions as it: acts well as a leveller as anyone is able to join the garden; and introduces new residents to the local neighbourhood. Kookaburra, while not strictly a third place across every characteristic, will be explored further for its third place qualities, providing an interesting case representing a different place on the continuum between and club and a third place.

Not all examples of third places act as such across all sites. Oldenburg (1999) gave the example of bars that are friendly, local and inviting, compared to bars in which nobody speaks to anyone. Similarly, some community gardens do not entirely fit the third place definitions. This was the case with two of the six case study sites, namely Kookaburra and Bluevale. However, it should be noted that these two community gardens exhibited most of the third place characteristics and the associated neighbourhood benefits. However, if adjusting the characteristics to take into account specific contexts, for example by broadening the definition of "local", more community gardens may fit into the definition. All six community gardens achieve the same aspirations as Oldenburg's spirit of third places, namely to be informal, inclusive local places where regular characters and locals get to meet and interact frequently enough to become familiar with each other. This is exemplified by Jane's comment below that describes how the community garden became more to her than somewhere to grow food.

Well the benefit of it that I wanted was to be able to grow things and so that's been good. And another thing is feeling a part of a community at the Gold Coast. So that's been very good. ... I didn't realise I would talk to people so much, but it's really nice and, and I didn't realise we would help one another so much. (Jane, Kookaburra)

Despite not strictly fitting the third place definitions, Kookaburra achieves many of the outcomes and benefits of third places, extending personal interactions beyond the boundaries and beyond the membership. 
The case study community gardens sit in different places on a continuum between a club or community organisation and third place. Marville members spoke about how they formed a committee in order to lobby the state government for access to the land that took two years. However, now established, the committee roles seem less onerous and more informal and the community garden has matured into a third place, with relaxed membership requirements and use of the garden is not contingent on membership. Marville shows how dynamic community gardens are over time as they adjust to circumstances in the neighbourhood. The dynamic placemaking nature of community gardens will be discussed in Chapter 5.

The Bluevale City Garden has some aspects that are more like a club or community organisation rather than a third place, which can be traced back to being interest-based rather for many members rather than place-based, as it draws members from further afield, for example to educate about sustainability. Community gardens that are open to the public and walkable distance from members' homes, are likely to act as third places, even if by organisational necessity they need to have some club-like characteristics. In this case there is a club-like structure at the centre with rules and commitments in order to function in a public space, however most of them simultaneously act as a third place to the broader community.

Pine Park community garden is an exemplar of a third place. It is walking distance to members and open 24/7; is easy to join as members, with the requirement being merely managing to turn up to two Sunday meetings in a row; obligations are low; conversation with regulars and non-members is common; and the quality of gardening is less monitored or judged in the Pine Park garden. Pine Park Community Garden is well integrated into the immediate neighbourhood as a third place. The third place interaction zone (Figure 4.1) is demonstrated in the Pine Park garden, which is utilised by a variety of nonmembers. Third place interactions also occur outside the garden. The community garden draws in more people than those just interested in gardening, therefore it acts as a third place for the neighbourhood. Matthew at Pine Park notes that interest in the garden extends beyond the members and mentioned civic pride brought about by the community garden. 
There are people who take an interest in it without being actively involved in it. ...There are some people who are not members of it or who have previously been members of it who have some sort of you know there is a community pride that it is there I think. (Matthew, Pine Park)

Matthew described how the community garden acts as a talking point with local residents who may not be involved with the garden. The garden acts as a conversation starter in another third place - the pub.

At no point in the interviews, nor the ethics information document was the third place concept discussed or explained to the participants, yet in a few cases the comparison between the community garden and home and work came up. Grant at Frank Street mentions first place ('family life') and second place ('work') as a contrast to the relaxing activity of gardening at the community garden.

The work and family life and things like that is quite hectic, so spending a bit of solitary time just doing gardening work. It's very relaxing. (Grant, Frank Street)

Similarly Samuel at Kookaburra stops in at his garden plot on his way home from a stressful day at work.

I'm a teacher just down the road, so I can get quite stressed out at times. It is nice to come here on my way home to have a water or weed something out. (Samuel, Kookaburra)

Mandy at Marville discussed her cooking inspired motivation to be involved in the community garden in which she hoped to grow herbs for the use of the neighbourhood. She describes it as a place to visit between work and home to pick up herbs for dinner and a place to chat with local people.

I enjoy cooking and it was like it'd be really nice just, you know, to spend time with other people and learn about different spices and herbs. ... I thought it'll be really nice to have somewhere where you could grow a lot of these herbs, ... On your way home from work, you could stop off and go, 'I'm going to make this' or 'I need a bit of [that]'. (Mandy, Marville)

The findings demonstrate that community gardens can be inclusive third places that present opportunities for purposeful interactions across neighbourhood diversity both within and beyond the garden boundaries. The case studies exhibited inclusivity across 
age, gender, cultural background, socio-economic status and disability. Gardening in a community setting adds value to the third place notion, as gardening provides a purpose to initiate a conversation, which is the mechanism for new and existing residents to get to know each other and get to know the place. This relates to Oldenburg's (1999) suggestion that town planners should take account of residential mobility in society by designing places that encourage people to meet informally and get to know each other. Involvement of regulars aids in the introduction of newcomers to the neighbourhood, which has potential to help ameliorate some of the challenges of isolation and alienation associated with an increasingly urbanised and mobile population. Placemaking is enhanced in community gardens through connecting people to nature and to other local residents in their neighbourhood. Many interviewees noted the sense of community they developed with fellow gardeners and local residents.

Having determined that community gardens can be third places across the eight third place characteristics, there are two main impacts of community gardens as third places in urban environments, namely: placemaking and building social capital, as illustrated in Figure 4.2.

Figure 4.2: Third place characteristics as they apply to the research questions

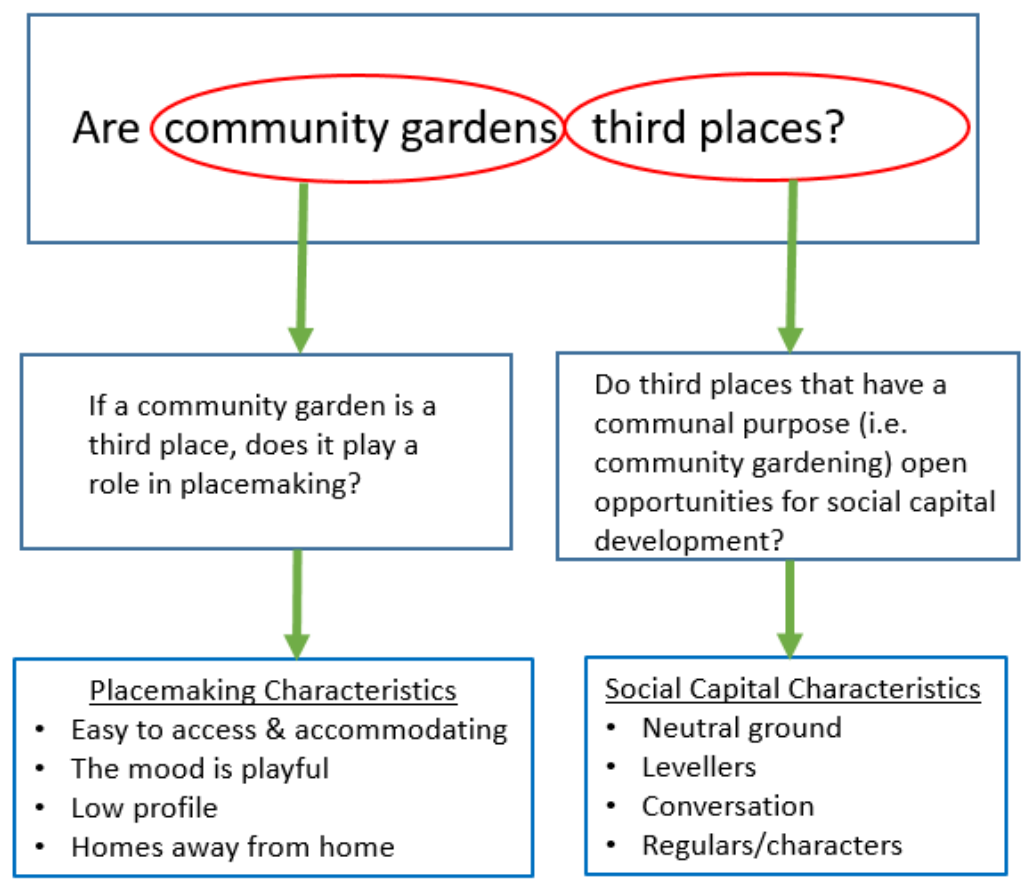

Analysis of the data found that four of the eight third place characteristics related dominantly, though not exclusively, to placemaking qualities of community gardens that are third places, namely: Easy to access and accommodating; the mood is playful; Low 
profile; and Homes away from home. The other four third place characteristics related dominantly, though not exclusively, to social capital making qualities of community gardens that are third places, namely: Neutral ground; Levellers; Regulars/characters; and Conversation. Figure 4.2 illustrates the analytic division of the eight third place characteristics across research questions 2 and 3 which will be explored further in the next two thematic chapters.

\section{Conclusion}

This chapter has demonstrated that most of the community gardens studied are third places across all eight third place characteristics. While community gardens have been referred to as third places in several journal articles, this assertion had not, until now, been intentionally studied. The research applied a framework of the eight characteristics of third place to six community garden case studies in order to determine if they are third places.

All six case study sites acted as levellers (no importance on an individual's status in a society) as anyone was free to become a member. All sites were inclusive to varying degrees across age, gender, ethnicity and disability. All six sites acted as relaxing homes away from home and were low profile in their comfortable atmosphere. Members at all the case study sites reported enjoying their time gardening with company, thereby fitting the characteristic that the mood is playful. Participants at all sites mentioned various committee members or gardeners as regulars who helped to introduce them and make them feel welcome at the garden. The regulars played a role in facilitating conversations, which is the main activity of third places, and the mechanism for casual interactions. The characteristic of conversation was found at all sites, due to the act of working cooperatively and opportunities to chat about common topics, such as plants and weather.

Overarching themes of placemaking and social capital development became evident and will be explored in subsequent chapters in relation to social challenges associated with urban living, namely population mobility, social isolation, making safe inclusive green spaces for people to enjoy and increasing the resilience of local neighbourhoods.

Community gardens that are third places simultaneously have at their centre a club-like structure with rules and commitments in order to function safely in a public space. Gardeners experienced a sense of community based on common interests that bring them 
together (Day, 2006; Delanty, 2010). The investigation found that individual community gardens fit on a scale between a club or community organisation (with formal governance, membership obligations, locked access, and common interests), to a third place (as described by the eight characteristics). A model (Figure 4.1) was created for this chapter to illustrate how third place community gardens operate simultaneously as a club or community organisation and a third place. The new model represents the duality which has been related back to Oldenburg's (1999) suggestion that some commercial places such as bars, barber shops and cafés act as third places. This is despite the commercial places having management structure and rules.

The framework of third place characteristics is very useful in determining whether the community gardens are third places. The framework could be applied to research on other public spaces and facilities. However, the framework could be improved by increasing the eight characteristics to nine. The characteristic, "accessible and accommodating", is more useful in the analysis framework if applied as separate characteristics.

Results of analysis using the third place framework show that four of the six community gardens investigated in this research study are third places across all eight characteristics. Community gardens that exhibit every third place characteristic are: open to the public at all hours; based in a walkable location in the neighbourhood it serves (local cycling distance was also included); have regulars with varying levels of commitment, ie. members, staff, volunteers and visitors; and their activities and stories reach beyond the physical boundaries to local people who are not members.

Locking the community garden, although explained, is not considered a feature of third places. However, all six community gardens meet the overall intent of third places. Kookaburra community garden was more like a club or community organisation than a third place in that it was not neutral (the general public are free to come and go without obligations) because the design has locked fences with key entry and the governance is formal membership roles, duties and obligations.

While two of the community gardens did not exhibit every characteristic of third places, the specifics of each case were particular to each community garden. For example, the definition of 'local' could be expanded to the nearest. In the case of Kookaburra, the members are drawn from the local suburb and the garden is the closest to where they live, but not within walking distance. In the case of Bluevale, the garden is interest-based rather 
than place-based, drawing members from further afield, for example to educate about sustainability. This interest-based community garden plays a role of introducing people to the neighbourhood, however, the scale of the neighbourhood is larger i.e. city-wide. This has implications on defining 'local' for the scale of a third place.

Features of design, location and governance that make community gardens particularly effective third places include that they have facilities that encourage social interactions, such as shaded seating areas. The gardens are situated within easy walking distance or local bike ride of all their members, which encourages familiarity through repeated incidental interactions between locals, both regulars and newcomers. They are open to the public at all times. While the openness and accessibility led to some negative aspects of theft and vandalism in the community gardens, the members who were interviewed seemed to cope with that challenge. Membership commitments are not too onerous and non-members feel free to spend time in the garden. In addition, activities are held which activate the third place, encouraging members and the wider neighbourhood to meet up.

It should be noted as a limitation of the study, that the six cases visited in the study may not be representative of all types of community gardens that come in a myriad of places, purposes and designs. The choice of case studies sites intentionally represents different types of garden designs, governance and locations. While unable to be representative of all community gardens in the city in which they are situated, they represent the diversity of situations and designs that exist within the definition of community gardens used in this thesis. However, the 29 case study interviews adequately demonstrate ways in which community gardens can act as third places in that they provide data saturation by including cases which vary in their fit to each characteristic of third place.

This chapter has shown that community gardens vary in the degree to which they are third places, exhibiting all or a majority of third place characteristics and presented a model proposing how they can act simultaneously as a community organisation and a third place. The case study community gardens exhibited inclusivity across age, gender, cultural background, socio-economic status and disability. The common purpose of gardening and factors associated with gardening meant there were enhanced opportunities for authentic conversations and interactions amongst members and visitors. Involvement of 'regulars' aids in the introduction of newcomers to the neighbourhood, which in turn builds a sense of place and sense of community. There was a notable nostalgia for a sense of community 
among some community gardeners, similar to that expressed by Oldenburg in his argument for the valuable role that third places have in communities (1999).

Third places have potential to ameliorate some of the challenges associated with increasing urbanisation and population mobility, such as increased isolation and alienation in cities and demise of sense of community, as they allow locals and newcomers to informally meet. Reducing social isolation and providing healthy spaces improves the wellbeing of urban areas. Features of community gardens that act as third places can inform planners designing or redesigning and activating public spaces in line with the goals of UN Sustainability Goal 11.7 for providing safe and inclusive green spaces. These impacts of community gardens as third places in urban environments, namely: place-making and social capital development through inclusivity and introducing to place will be discussed in Chapters 5 and 6 . 


\section{CHAPTER 5 - PLACEMAKING COMMUNITY GARDENS}

Oldenburg (1989) labelled public places for informal social gatherings as "the great good place" or the "third place". As discussed in the literature review (Chapter 2), Oldenburg's list of third places include commercial spaces such as cafes, or municipal-run places such as parks, piazzas and libraries. Cumbers et al. (2017) describe the citizen-led creation of community gardens as a dynamic act of placemaking. What is unique to community gardens (as defined in this thesis) is that they are designed, created and/or maintained by the members of the public themselves. This is an act of placemaking and it is enhanced in community gardens by facilitating local residents' development of a sense of place through access to each other (community) and to nature (garden). While the garden aspect of community gardens provides the link to the land, the community aspect connects the people to each other. As a third place, it links the members to the people in the neighbourhood.

This chapter explores the placemaking attributes of community gardens that can be considered as third places, including providing a working definition of the concept. This chapter will firstly draw on four of the eight third place characteristics which make a place, namely: home away from home; low profile; playful; and easy to access/accommodating. This chapter will then explore placemaking in relation to UN Sustainable Development Goal 11.7 about providing inclusive green spaces for the community. The chapter will also explore the placemaking role of third place community gardens in relation to social challenges arising from population mobility. It will discuss who is involved in community garden placemaking, and what motivates (and demotivates) them to be involved and what support is available for the community of community gardeners. The qualities of the third places will also be discussed.

\section{Research question and significance}

The research sub-question which this chapter is addressing is: If a community garden is a third place, does it play a role in placemaking?

Figure 5.1 contextualises the research question in relation to the overarching question, 'To what extent are community gardens third places?', which established that all of the case study community gardens exhibit all or most of the eight third place characteristics. 
This chapter deals with the placemaking (left hand) side of the diagram and the next chapter (6) deals with the social capital (right hand) side of the diagram.

Figure 5.1: Situating the placemaking research question

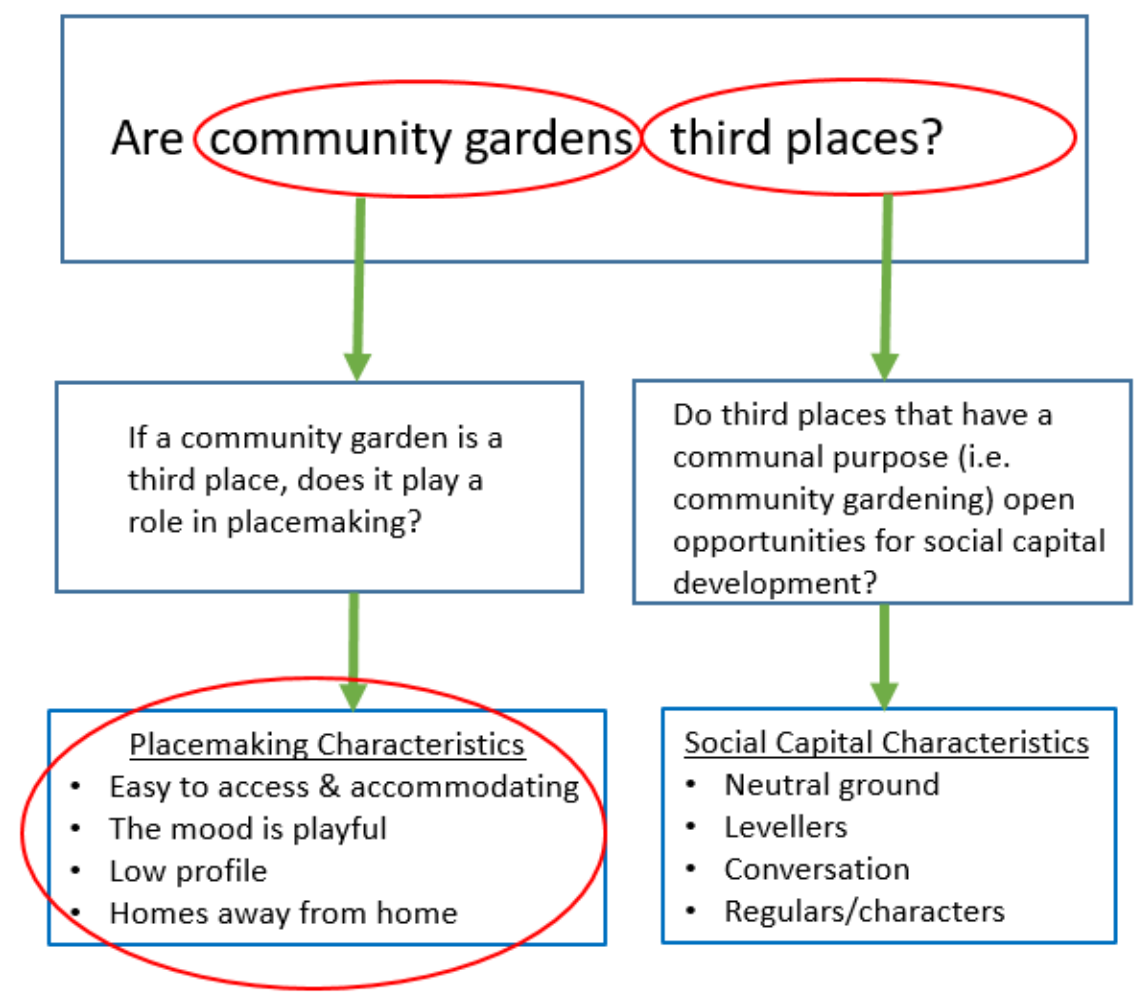

\section{Method}

Thematic analysis of the data in Chapter 4 noted that four of the eight third place characteristics related primarily, though not exclusively, to placemaking qualities of community gardens that are third places. For the purpose of discussion, this chapter will focus on those four characteristics which relate closely to placemaking, namely: easy to access \& accommodating; the mood is playful; low profile; and, home away from home.

This chapter will discuss the data collected at the six case study sites (described in detail in the Methods Chapter 3), in relation to placemaking. The sites cover a range of stages of establishment, therefore inform the act of placemaking from the beginning, through steady state, and on to renewal. Marville in Brisbane was only one year old at the time the interviews were conducted, so the process of establishment was freshly on the minds of the interviewees. Frank Street in Brisbane had previously undergone a period of neglect, but at the time of interviews was in a phase of renewal. Hagenlund Library Garden in Denmark experiences seasons and is dormant in winter, and membership 
changes with each new growing season. The other three community gardens (Kookaburra at the Gold Coast, Pine Park in Sydney and Bluevale in Brisbane) were well established and continuous throughout the year. The participants in this study include a variety of roles and length of membership. This chapter about placemaking will lead to chapter 6 , which focusses on features of third place community gardens that enable them to build social capital in a local neighbourhood.

\section{Significance}

There is a gap in the literature on placemaking aspects of third places which will be addressed by this chapter. As discussed in Chapter 4, the communal purpose of gardening provides opportunities for members to initiate conversations with visitors and passers-by, making community gardens potentially more effective as third places. In addition, by being a third place, the goals or motivations of the community garden and its members, reach out to more people in the community.

The act of placemaking will be explored as one way of addressing the issue of population mobility by providing an opportunity for a mobile population to become part of a place, albeit in some cases temporarily. The alternative is unsettled population with no ties to the local community. Philosophers including Lefebvre are concerned that the constant movement of city dwellers and their increasing connections on a global rather than local scale undermines people's connection to the place where they live (Lefebvre, 2014). Tuan (2014) noted that mobility weakens people's attachment to place. Placemaking addresses a human need to have a sense of belonging somewhere, as features in Maslow's hierarchy of needs which includes love and belonging (Maslow, 1943).

Decreased connection to place can lead to demotivation for citizenship. As de Tocquiville (1899) noticed in the late $1800 \mathrm{~s}$, the government cannot do everything for everyone and the citizens have to organise themselves to achieve some public goals. The argument for active citizenship is still relevant today as reflected by Könst, van Melik and Verheul (2018, p. 592), who say that "public space is increasingly a co-production of state, market and community" rather than a dichotomy between public and private. For a variety of reasons, control of public space is being handed to the local citizens in some cities - be it for lack of funding for municipalities or democratization of public space (de Magalhães \& Freire Trigo, 2017; Könst, van Melik \& Verheul, 2018). In addition, with increasing 
need for citizens to be resilient through rapid environmental and social changes of the Anthropocene, supporting people to be active, engaged and resilient citizens is important.

Community gardens which are third places contribute to achieving the UN Sustainable Development Goal 11.7, to "provide universal access to safe, inclusive and accessible, green and public spaces, in particular for women and children, older persons and persons with disabilities" (UN, 2015). This chapter builds towards a developing a model of third place community garden to contribute to neighbourhood transformation of a public space, into a third place community garden.

\section{Definition of Placemaking}

The term 'placemaking' is being used in this chapter to describe the act of making a space into a place, whereby the resultant 'place' is somewhere that people can identify with and possibly feel some ownership over or connection to. Placemaking theories have been variously referred to as 'place-construction' (Cresswell, 2004) and 'place-shaping' (Carmona, 2014), amongst other names and similar concepts. Definitions of placemaking are discussed more fully in Chapter 2. The definitions all note that placemaking is a human-centred activity and they include words and concepts such as transforming places, 'placecreating', and collaborative process, design and regeneration (Carmona, 2014; Cresswell, 2004; Friedmann, 2010; Placemaking Chicago, 2008; Project for Public Places, 2007; Schneekloth \& Shibley, 1995; Sweeney, Mee, McGuirk \& Ruming 2018). Kirkpatrick, Lefroy and Harwood (2018, p. 112) refer to "place spaces" where people have turned their view of a space into a place with meaning for themselves. Placemaking occurs at or near where people live in scale ranging from a bedroom to global branding of cities (Friedmann, 2010). For the purpose of this thesis, placemaking is investigated on the scale of local public spaces in the neighbourhood. There is no definitive definition of placemaking which best suits this analysis, so through a combination of elements of the definitions discussed above (and in Chapter 2), the following definition of placemaking has been devised:

Placemaking is a dynamic act of people collaboratively transforming public space into public places that increase the social life and sense of belonging to a local area. 
The definition above takes account of the dynamic nature of creating and maintaining community gardens and third places. Placemaking is important because it connects people to the place and creates the conditions for active citizenship (Lefebvre, 2014). As collective neighbourhood activities, creating and maintaining a community garden, has a transformative effect of purpose and design and is ever changing through the seasons and renewing memberships and visitors.

Community gardens are dynamic places, and not just because of the growth of plants. Dynamic interrelations develop that reflect the make-up of the local community. The photos below show Marville community garden at 1 year from establishment and then 1 year and 5 months later. Not only have the plants grown, but the neighbourhood has made it their own with toys for the children to share and a pizza oven (not in shot).

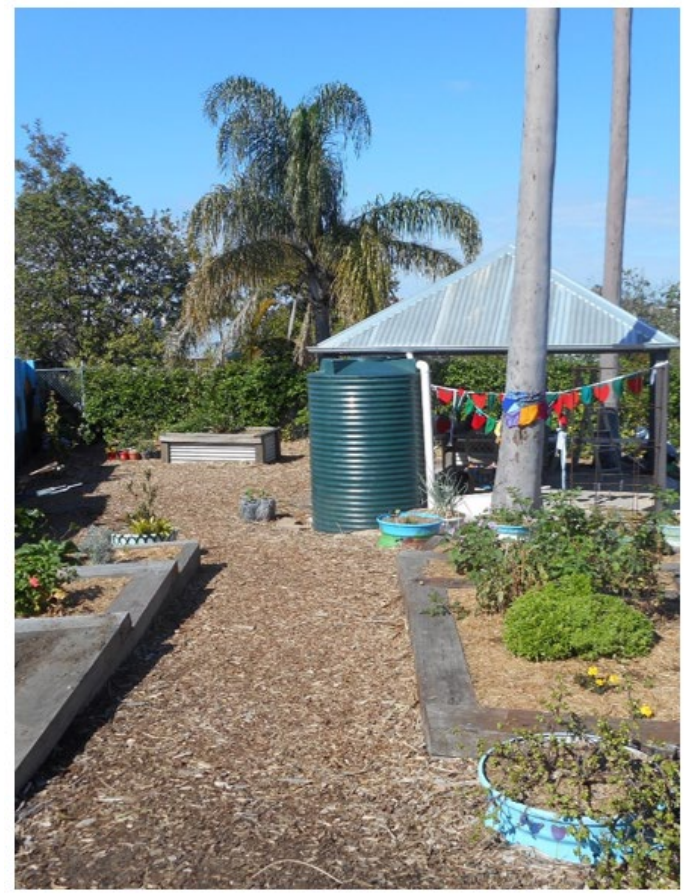

October 2016

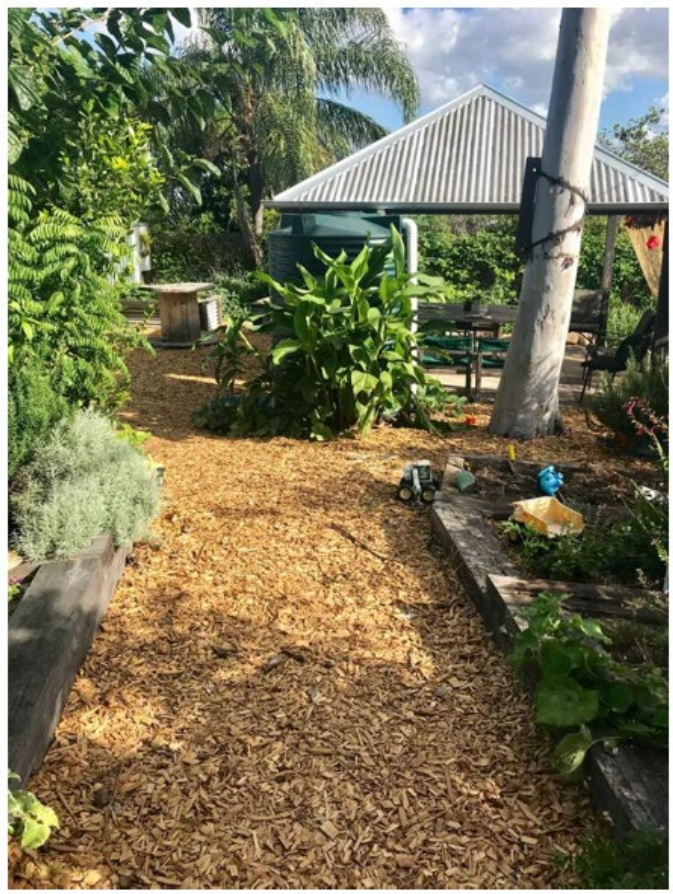

March 2018

Image 5.1: Marville Community Garden - growth from 2016 to 2018. Source: Author.

\section{Placemaking characteristics of third place community gardens}

Oldenburg's third place concept is place-based (1999). Accessible by walking and open at times which suit the visitors, they are places where neighbourhood faces become familiar. Community gardens are citizen initiated and enacted places which connect 
people to nature and to each other in their local neighbourhood. As Matthew at Pine Park describes, each garden is unique to the people who make the place.

Different community gardens have a different collective personality about it. We're still going after 15 years. Not that we are great gardeners but at least we are willing to have a go. The garden is borne of the community and then it's the community that keeps it going. (Matthew, Pine Park)

In contrast to Pine Park, Marville is a relatively newly created community garden. Several participants at the Marville Community Garden talked about their goal to transform empty space into a place for the neighbourhood to use.

What I like best is seeing what was an unused space become something that was nice to spend time in pretty close to home. (Stefan, Marville)

In Marville Community Garden, the gardening is secondary to providing a community space.

There's not much greenspace in the area, so it's a way to get more open space and just have a nice area where people can hang out. (David, Marville)

Stefan and David are indicating that the place they have helped to make is performing in a pleasing way, providing public space that is pleasant to use. Community gardens are sites of placemaking through growing a sense of community and civic pride and through linking people to nature and to each other. Albert at Frank Street considers that helping with the community garden is "community service". Community gardening adds the value of 'communal purpose' to third places, improving their potential to deliver the benefits of third places to urban communities.

The incidental interactions and lively, conversational atmosphere of a third place makes it an enjoyable, relaxed place to be (Oldenburg, 1997). As determined in Chapter 4, Community gardens exhibit most, and in many cases all of the characteristics of third places in that they, to varying extents, have porous boundaries, where many people not involved directly still show an interest and interact with gardeners. Interactions with the community can take place on-site and also outside the garden where the garden is an 
opening topic of conversation. Most importantly the characteristic 'easy to access and accommodating', enables them to turn a space into a place. Unlike the responsibilities which may come with home or work, third places are not serious but should exhibit a playful mood. They are described by Oldenburg as low profile, homely and plain (1999). Third places should be relaxed and sociable - like a home away from home (Oldenburg, 1997). These four third place characteristics combine to provide a relaxed atmosphere of the place. The next section will look at each of these third place characteristics briefly to establish the placemaking role of third place community gardens.

\section{Easy to access and accommodating}

Easy to access relates to the third place being within walking distance of most of its regulars. The urban form affects population health and there are tools for measuring the health and economic impacts of the physical activity of walking and cycling, for example the World Health Organisation (WHO) Health Economic Assessment Tool (HEAT) (Zapata-Diomedi, et al., 2019). However, this thesis looks at the social impacts of providing facilities which are within a walkable (or for this thesis a short bike ride) of the locals.

The Sydney garden is easy to access as all of the gardeners live within walking distance of it and accommodating as it is open 24 hours a day to the public. The garden occasionally receives publicity, which attracts potential members from outside the local area, but members encourage them to find (or start) a community garden closer to their home. This emphasis on walkability is echoed throughout the membership as it promotes the usability of the produce and the neighbourhood composting facility, as Barbara describes.

It is close enough that I can put my compost out. I'd come down and pick a few plants to cook with dinner. I think if it was further than that you just wouldn't visit. (Barbara, Pine Park community garden)

Barbara describes two functions of that public place which are helpful to her goals composting and cooking. The place is incorporated into her daily life. The characteristic 'accommodating' is about the times that the third place is open. It needs to be available to visit in the times between home and work duties. 
Hagenlund Library Garden provides another example of a place which is easy to access and accommodating as involvement in the garden is free and situated within the housing estate that it services. Violet at Marville community garden mentions that the garden was locked when they first began, but since they decided to keep it open, they have people from all over the neighbourhood, including people who work in the area, use the garden for a variety of purposes.

It was locked and now it's unlocked, so-yeah. People seem to eat lunch-I saw some people having - other day - having a jam, I guess. I saw some teenage girls doing their fingernails on the school holidays and stuff. So, I guess people are starting to get used to it. ... Sometimes we have-there's like a community parents group that we have on Wednesday afternoons and sometimes we have that here, just because it's a nice space to be, and I know that not all of them are members. So-yeah-some people walk past and ask about it. They don't tend to come in. Sometimes you see people - I have seen people eating lunch here from workplaces down there [pointing to the business district]. (Violet, Marville)

Violet describes how increasing the access through the decision of the group to unlock the gate at all times has created a vibrant place for the whole neighbourhood. The community garden is acting as a third place.

\section{Playful}

As discussed in the literature, placemaking includes re-making an area. The Hagenlund interviewee discussed how the community garden was able to revivify the previously unattractive area outside the library. The interviewee noted that it has vastly improved what was a "boring" concrete area and that adults now congregate and socialise in the area. The mood at Hagenlund Library Garden is playful and activities such as harvest festivals and regular meetings help to create a social atmosphere.

So we have these small individual meetings and then we have one day when we go and all plant together. So we make a bit of a party and we plant together. (Yvonne, Hagenlund)

Similar to Hagenlund, Marville Community Garden invites community members to enjoy and make use of the garden. 
We've actually commented before at the playgroup how the kids seemed much better entertained here when there's no formal playground compared to when we go to a playground. They get bored easier at the playground than they do here. (Violet, Marville)

Violet noted the enjoyment that the unstructured play in the natural environment brings to the children who attend playgroup. Unstructured play, particularly in nature-based environments, brings many benefits to children in achieving a number of developmental milestones such as problem solving and coping with risk, as well as enjoyment (Houser, Roach, Stone, Turner and Kirk, 2016). Playing in the garden is part of a "continual production of places, place identity, and social memory" as memories are created and recreated in everyday places (Atkinson, 2007, p. 522).

At Pine Park, there is time for relaxation after the meetings and communal working bees.

I bring the cakes as well. It's a very important role. This is the right sort of meeting to have cakes at. People do a lot of work and then they have some cakes - I think that is very important. (Harriet, Pine Park Community Garden)

While Harriet's tone was somewhat joking, bringing the cakes helped transform the meeting from a duty to a social occasion and helped to increase the social aspect of the placemaking activity.

\section{Low profile}

Pine Park community gardeners are not shy in admitting that their garden is low profile. Barbara described her strategy of keeping weeds in her garden plot in order to hide the produce she wants protect from people who steal or vandalise the plants. This and a fairly low key attitude to the community garden's tidiness contributes to the low profile atmosphere of the community garden, which Matthew described as:

... by no means a beautiful community garden. I mean there are others around that are gorgeous things to look at. Ours is a bit more ramshackle than that. (Matthew, Pine Park)

The Hagenlund Library Garden is low profile and not showy with casual seating and outdoor umbrellas provided for locals to enjoy the garden area. The case study community 
gardens, while all actively maintained, were organic works in progress rather than manicured show gardens.

\section{Home away from home}

The community gardens can feel like homes away from home and provide quiet moments for the enjoyment of gardening. As discussed earlier, Fred, who is a retired and very active community gardener at the Gold Coast, jokes that his wife thinks he lives at the garden.

Claire at Pine Park commented on the relaxing nature of attending the community garden. As quoted earlier, Claire visits regularly to do a bit of work on the garden and finds it very relaxing.

Similarly, Jim at Kookaburra Park enjoyed regularly attending the garden to enjoy the atmosphere.

I'd walk it (the dog) every day, and so part of the walk was always stopping by here. Just for ten minutes, to water. It was summer. It'd be five o'clock in the morning, beautiful! You'd see the sun rise. Today there's a lot of people around, but usually you come, there might be a few cars at a time, and it's just very quiet and peaceful - And then you're out in the sun really. (Jim, Kookaburra)

Jim spoke of the regularity of his visits, in part because the summer necessitates regular watering. Community gardens are dynamic places as they require constant attention and choices of plants suitable to the seasons. In Brisbane, a gardener commented that Marville Community Garden provides a place that people can relate to as somehow partly their own.

Whenever I do happen to drive by, I always have a look in, and often as not, I see somebody doing something in here and I don't always recognise them. So I think it is - people feel like they can come in and do what they like. So, I think that's important. That was the goal-was to open up the space because there's no parks in the area. (Brenda, Marville)

Brenda seems to be describing a sense of belonging and comfortable association with the place. There is evidence that Hagenlund Library Garden feels like home away from home, with the librarian noting that locals are enjoying the seating at library closing time and 
are reluctant to give up the cushions which are put inside for the evening. All of the case study gardens have provided examples of members and visitors incorporating these community gardens into their daily lives and relating to them as a place of their own.

\section{UN Sustainability Goal 11}

Community gardens have the potential to contribute to achieving UN Sustainable Development Goal (UNSDG) 11 - "Sustainable Cities and Communities" and in particular, Goal 11.7:

By 2030, provide universal access to safe, inclusive and accessible, green and public spaces, in particular for women and children, older persons and persons with disabilities. (UN, 2015)

The UN Sustainable Development Goals were released internationally in 2015 and adopted by Australia in 2016. Community gardens which are third places have demonstrated that they can be a community space which promotes inclusion. They are a green space which is open to the public and in which the participants are actively involved (Draper \& Freedman 2010; Ohmer et al., 2009). Arfvidsson et al. (2017) discuss the difficulties associated with measuring the progress towards achieving the UNSDG 11, given difficulties in defining "urban" and trying to match the different metrics used across different municipalities. Indicators and performance management tools are useful in order to track progress towards achieving the UNSDGs (Holloway, 2017). This thesis is not quantifying progress towards achieving UNSDG 11.7, but it provides qualitative discussion and examples of the role community gardens can play in relation to UNSDG Goal 11.7 in terms of nature (green public spaces) and people (safe, inclusive and accessible). The integration of the placemaking data and social capital data in Chapter 7 provides a framework which could be applied as an indicator of progress towards reaching the UNSDG Goal 11.7 goal.

Community gardens combine nature with community, hence can contribute to creating inclusive green spaces as described by UNSDG 11.7. Community gardens are sites of placemaking through growing a sense of community and civic pride and through biophillia of linking directly to nature and the earth. Planners already recognise a need for providing access to nature through provision of public green space (Ferris et al., 2001; Yokohari and Amati, 2005). In the case study site, Bluevale City Garden, which is 
situated in a busy inner-city part of Brisbane, the garden provided a welcome natural space.

I always make sure I have time to walk through all the different parts just to see what's happening in the different bits and, yeah it's nice! I mean, when you're in there in the thick of it you're all surrounded by all those trees and there actually are all these busy roads and stuff around you, but you can't see them you feel like you're in a nice sort of sanctuary. Yeah, it's really nice! (Clarissa, Bluevale)

Clarissa had grown up in the country and seemed to appreciate the sanctuary that the community garden provided from the business of the city.

Placemaking through a community garden connects the placemakers (gardeners) to nature in urban environments, which promotes healthier lifestyles and reduced anxiety (Shanahan et al., 2015; Shi et al., 2014; Yokohari \& Amati, 2005). Community gardens are viewed by those involved as "important tools for improving communities, particularly for distressed neighbourhoods that often lack green space" (Ohmer et al., 2009, p. 398). Community gardens are a combination of a social landscape (community) and natural landscape (garden) in an urban landscape. Stefan at Marville community garden talked about his desire to transform unused green space into something for the community.

It's nice to sort of see community being developed near where you live, get to know your neighbours and people who live around you, and also it's a public garden, so it's a nice use of green space... It was an empty lot when we moved in... this was just sort of overgrown green grassy lot and before we found out there were plans to try and take it over and turn the community garden. Mates of mine and I were planning to do guerrilla gardening here, but then we found out pretty quickly that were like larger schemes at play, so we decided to step back. (Stefan, Marville)

Stefan had been willing to do some "guerrilla gardening" 10 in order to transform the space but was happy to join the more formal efforts to develop the site into a green space for the use of the community, once permission to use the space had been achieved.

The gardening motivations theme emerged from comments which illustrated a desire to access public green space for gardening, experiencing nature, or other outdoor purposes.

${ }^{10}$ Guerrilla gardening refers to gardening on land that people do not have permission to cultivate. 
In many cases this amounted to expanding one's own space at home, often limited in an apartment, to include public space as their own/shared place.

I think people are sort of starting to realise it's here and that. It's probably not a community garden in the sense that it's like, a crop rotation and it is like producing masses of fruit to feed the neighbourhood, which is what a lot of community gardens have worked for. It's more of a green space that we can, you know, use as a space to learn about gardening in the back yards and yeah, I mean we do, like I said we had hundreds of passion fruit, so we had boxes kept on the table ... passion fruits and, you know, we've got lots of herbs. (Mandy, Marville)

Living in housing with limited access to space for gardening or play activities motivated a number of gardeners to join their local community garden. The gardening motivation included access to open green space and gardening space and/or access to organic produce. When discussing their community garden, participants noted practices which could be identified as sustainable practices such as composting, recycling, mulching, harvesting rainwater and growing without the use of chemicals. Despite this, environmental action or sustainability as a concept was rarely mentioned and was not included as a primary motivation of any participants. Access to nature was discussed.

Unfortunately kids, you know, in the world we live in today, it's just being lost more and more and then the natural play has been taken out of the curriculum so much. It is so academic focused that I think it's just nice to watch them explore and discover and see stuff and smell different things and they're smelling the different herbs and, the reaction of some of the kids that have obviously, had spices in the home or that have never had anything. The textures of - to make it sort of probably more of a sensory garden longer term would be my ideal. That you can come here and, you do, you get caught up in the different sights and smells and, touches and that would be awesome. (Mandy, Marville)

Upon recounting to an interviewee at Pine Park Community Garden, that I had mistaken the nettle for the (famous) Vietnamese mint and hurt my hand, the participant shared a humorous story which can be categorised as the opportunity for unstructured play. Matthew refers to one of the founders of the community garden, the French Grandmother. 
The nettle. That was the French grandmother and that was (planted) to keep the kids out of the garden you know, they used to chase frogs in there, there used to be little ponds in the middle of each thing. And her idea was to plant nettles and not have any dock or aloe vera, or anything that could take the edge of it. The idea was it would keep the kids out. It was a flawed strategy. What the kids would do was grab some kid, wrestle him to the ground, take his shoes off and throw his shoes into the middle of the nettle. (Matthew, Pine Park)

While not advocating that the design of third places should provide opportunities for children to taunt each other, nor for adults to control behaviour through cruel plant selection, Matthew's recounting this story illustrates the freedom of activity in the community garden. In dense urban environments, there can be a lack of space left for unregulated activity and unstructured play (Houser et al., 2016).

Most community gardens are broadly place-specific to weather, seasons, soil type and choice of plants relating to local diet. Tuan (1977) suggested that the mobile person may find a 'superficial' sense of place rapidly by finding out abstract knowledge about a place, however a deeper sense of place develops through time and experiencing the seasons. Penny at Bluevale grew up in a different climate zone and found the community garden helped her to learn about growing food in Brisbane.

It is not easy to grow food in this area and to know what grows and it has taken me a long time. (Penny, Bluevale)

Community garden members transform space into place by connecting with the soil and putting down roots, as expressed by a Sydney gardener:

I guess just having somewhere for us just dig around and grow stuff. It's just really nice to have like a patch of earth because living in apartments, you never had a patch of earth. You have like pots of earth but, you know, you'd never had a patch of earth. (Tina, Pine Park)

This gardener is making a distinction between a pot of soil and soil connected to the earth. Tina's statement illustrates how gardening is a placemaking act, linking people to place - her "patch of earth". This is another example of UNSDG 11.7's green space connecting people to the place. 


\section{Placemaking - Safe, inclusive and accessible}

Making a place that is safe, inclusive and accessible is discussed more fully in Chapter 6 on third place community gardens and social capital. However, this section will provide a few examples of acts of placemaking which occurred in the case study community gardens, thereby delivering social benefits of third places to urban communities. Effective third places have implications for people's sense of place, their feelings of safety and their happiness and wellbeing. Community gardens are often used to remake neighbourhoods into more sustainable and physically and socially healthy places (Spierings et al., 2018).

Several interviewees indicated that their primary motivation for joining their community garden was to connect to nature by growing food and that the social and community aspect was an unexpected bonus. For example, Jane at Kookaburra was motivated to grow food, but "didn't realise we would help one another so much". The garden has helped Jane to start, "feeling a part of a community, of the Gold Coast".

Community gardens are established and/or maintained by members of the local population for both individual and collective benefits. Mandy at Marville community garden expressed a desire for inclusivity of the people who live in the neighbourhood, which relates to the third place characteristic of leveller.

The initial concept was to do like a herbs of the world idea and be able to have this as a bit multicultural. [There are] a lot of Vietnamese [people] in the neighbourhood and Russians ...to tap into those groups, the Serbians, and get them to show us - how spices and herbs and stuff work in their ideas. And I'm hoping with the pizza oven to get back to that sort of way a bit. (Mandy, Marville)

Mandy has also tried to encourage people of different ages to get involved in the garden to varying success.

An older gentleman, he was probably in his 50s, you know, and he helped me with the rocks when I got them and was unloading the stuff and he saw me, and said, "Do you want to get involved?" He goes, "Oh no, it's full of young people." And I just thought it's not really, but I think it's that sort of, you know, I think, I'm hoping that, you know, eventually that will start to break down, but at the moment 
I think, you know, it probably is a bit like that so. When people come here and walk past and they see me up here with my two children and they go, "Oh it's a children's thing," like <laughs > (Mandy, Marville)

While Mandy noted that she was unsuccessful in convincing the man in his 50s to join the garden, it is notable that the person assisted her in a third place way, offering help as it was needed. David at Marville also noticed that some older passers-by are: "not quite actively involved", but show their involvement in ways outside of formal membership, through chatting or donating plants. While the organisers lament the lack of diversity of membership, they have overlooked the value of the casual interactions with older people in the neighbourhood. Their placemaking activities (arranging rocks and growing plants) have been supplemented by garden visitors who are not members. As per the chapter's placemaking definition, those neighbourhood people are helping to collaboratively transform the public space, formerly an overgrown abandoned piece of land left over from a freeway subdivision, into a public place for the local people. The Marville Community Garden group have plans to make the place attract a more diverse membership and refer to their "whiteness" as a possible cause of lack of diversity.

We're still in early days and I mean most of the work that's been happening has been done by the committee who are all kind of white Australian. We're all pretty much the same. I think eventually, we would like to encourage people to grow what they know, wherever it's from, and teach others about it too. (Brenda, Marville)

While the Marville members notice that there is room for improvement in involving greater diversity of age and ethnicity from the neighbourhood, these kinds of casual involvement are third place interactions which contribute to placemaking.

The Frank Street community garden also noted their homogeneity, in this case that most members were young families: "who all pretty much know each other already", through being neighbours and attending the same local school. The main organiser sought to address their issue with limited diversity by surveying the local neighbourhood. The response was that people wanted individual garden plots rather than the current design of all communal areas. 
I did a survey on SurveyMonkey earlier in the year and that was one of the questions, and there have been inquiries throughout - not tons or anything, but enough to make me think that it's the go and plus, I went to the Jane Street Community Garden ${ }^{11}$ recently and was told that - yeah - they started with everything communal and then went to individual plots. I think it suits the way people are quite into property and stuff, ownership. (April, Frank Street)

While April might seem against the idea of individual plots, as noted in Chapter 4, individual plots encourage regular attendance at the community garden, which taps into Jane Jacobs' themes of 'eyes on the street', and vibrancy of the area (1961). The members chose not to redesign the community garden in that way at that time of the interviews. The complex process of making and using public space, which Carmona (2014) terms 'place-shaping', is an ongoing process, open to revisiting and reviewing.

In a big operation such as Bluevale which faces ongoing challenges of flooding and past challenges such as contaminated land, the placemaking is ongoing. Keeping on top of changes, challenges and improvements requires a motivated team of people. Attracting greater membership was a recurring theme observed at the meetings attended. Similar to Frank Street community garden, Penny at Bluevale felt that the familiarity of existing members may discourage new people from joining. On getting new volunteers involve, Penny said:

I can't put it into words why we don't have so many volunteers now. We've already got an established group which makes it harder for people. So we are not as welcoming as we used to be? I think we really used to go out of our way to welcome people. It was a bit exhausting. And you just know. Why am I doing this? I'm never going to see you again. Goodbye. 'Blah blah blah, Isn't it all beautiful blah blah blah.' Especially since the contamination, we've got some old long term volunteers we've really become established as a group. And that might be a bit prohibitive to new people I'm not sure. (Penny, Bluevale)

Penny's candour about the tiring drain on enthusiasm of these interactions with visitors and potential volunteers from beyond the neighbourhood was not encountered at the other

\footnotetext{
${ }^{11}$ James Street is another Brisbane community garden, mentioned in relation to cooperating with other community gardens.
} 
community gardens. It should be remembered that Bluevale community garden is an interest-based community garden, attracting numerous visitors from beyond the local area and conducting tours, work programs, the nursery and numerous classes and workshops. While other community gardens noted that the enthusiasm of new members may wane with the failure of their attempts to grow food, they were not fatigued by the extent of turnover of members. As Penny is a local, perhaps the fatigue is a clash between the local third place and a large-scale educative and business function of this particular community garden.

In the case of Hagenlund Library Garden, making a community garden on site builds on a well cited third place - libraries (Aabo \& Audunson, 2012). The act of adding a community garden which is free; open to everyone; and is within walking distance, extends the library third place into the community garden. The benefits to the neighbourhood of this free accessible outdoor garden space in what was previously bare concrete are in evidence.

I think in many ways this garden has made at least this part of the neighbourhood more friendly, more inviting, more social. ... It gives you another feeling than going through a grey and empty space. It was very boring, very bland. It was just grey and grey. (Yvonne, Hagenlund)

Library Community garden is an example of placemaking which addresses the UN Sustainable Development Goal 11.7's to provide inclusive nature based spaces to a diverse population.

One of our goals for setting up the garden was to open it up to people who are not living in this neighbourhood to make it a little more attractive and green. It is a neighbourhood with 50\% ethnic minorities. It has been, I'm not sure if it still is, but it has been on the ghetto list, which is a list the politicians in Denmark made and it is comprised of different factors... It is an area that has a bit of a bad reputation but a lot of the people that live here are happy living here. ... So it is also a little bit about branding and about making people come and live more together and have places to hang out and meet each other. (Yvonne, Hagenlund)

This placemaking act by the librarians is supported by the private company which owns the residential development. It has encouraged a broader range of residents to visit the 
library and reportedly improved community mixing by providing a communal purpose for ethnically diverse local residents to spend time together.

\section{Placemaking in relation to population mobility}

Placemaking addresses a human need to have a sense of belonging somewhere, even for the part of the population which is mobile or temporarily in a location. Research on placemaking strategies of the mobile population cover a range of scales, from microplacemaking in a home, to a globalised view of placemaking with largescale movement of populations (Cresswell, 2004). Maslow's Theory of Motivation argues that human beings are motivated by unsatisfied needs (1943). Maslow (1943) developed five levels of the "Hierarchy of Needs", one of which is "Love and Belonging" which features a "sense of connection". Lambert et al. (2013, p. 1425) conducted a psychological study which found that a sense of belonging is associated with, "a belief that one's life is meaningful". The act of placemaking will be explored as a way for a mobile population to become part of a place, developing ties to the local place and community.

Population mobility is defined by the Australian Bureau of Statistics as, "the geographic movement of people where there has been a change in the place of usual residence" (ABS, 2018). The percentage of the estimated resident population of Australian who were born overseas has increased in ten years from 25.1\% (5.2 million persons) in 2007 to $29.0 \%$ (7.1 million persons) in 2017 (ABS, 2019). That is $29 \%$ of people who are making Australia their place. As well as international population movement, Australian residents are mobile within Australia. The latest Australian census estimated internal migration at 376,700 people moved interstate in 2016-17, an increase of $1.3 \%$ from the previous year. In Australia, in the 5 years between 2001 and 2006, approximately 40\% (6.6 million) people over five years old changed their home address. Of those, 86\% (5.7 million) moved within the same state or territory and of those who moved within the same state and territory, 36\% (2.1 million) moved in five years at least once within the same SLA (the smallest spatial unit used by the Australian Bureau of Statistics). This is a relatively localised area when considering, for example, that there are 163 SLAs within the City of Brisbane in Queensland. "The movement of people at smaller geographic levels is an important factor in population change at the local level" (ABS, 2018). Such micro-level population changes can account for population changes such as gentrification, or changing needs of a local area in response to an aging (provision of 
health services) or younger population (provision of schools). Adjustments to a new home setting can be difficult, whether international, interstate or merely across to a new suburb.

There are two aspects to the intersection of community gardens and population mobility, namely the effect of community gardens on a mobile population and the effect of a mobile population on the continuity and longevity of the community garden. Community gardens provide the opportunity for participants and visitors to develop geographical connection to the place where they live. If becoming members, the community garden also offers the opportunity to demonstrate a sense of commitment and influence the social and environmental shape of the neighbourhood. The main organizer of the Frank Street community garden summed up her idea of the goal of the garden:

Because I just think people should. I don't know. I think the community is being eroded by the way we live, the way we drive everywhere. Life is really compartmentalised and we don't actually connect to people or look around us to see what we have and I think community gardens - yeah-because it's a focus on a local space and it's your time and your - it's just -it's your community and I think that people need to invest in their community if they're going to be happy. (April, Frank Street)

Community gardens provide a public venue that improves social interactions between local residents (Ferris, Norman \& Sempik, 2001; Firth, Maye \& Pearson, 2011) and are particularly important where traditional links between neighbours have been weakened by population mobility and isolation (Frumkin, 2003).

Brenda brings in the dimension of being a renter, which in Queensland can bring precarious attachment to place as leases can expire in six months with no justification required by the landlord to change tenants. Brenda describes how that affects one's commitment to placemaking.

I think for this space, it was initially because it was so close and it was so ugly, and I just thought it would be nice to be able to do something positive and make something pretty. I don't know. It just-it's so easy, especially when you're renting and you're moving every couple of years you get just kind of apathetic and you live with ugly things because - whatever, I'll just move next year, and it 
doesn't matter. So I thought this would be something a bit more permanent. We knew we would stay in the area, if not in that house the whole time, so I thought it might be nice to have something to work on for the more than just the time that I'm renting a place. In that respect, it's worked out. It's been nice to see the change over time. (Brenda, Marville)

Brenda talks about being 'apathetic' to contribute to placemaking when tenure is tenuous. However, she describes how she decided to contribute 'for the moment' in order to 'do something positive'. This statement signals a broader issue of the seeming pointlessness of involvement for residents who are unsure of the length of time they will stay in a location. Mandy also at Marville discussed that the numbers of people who come to events at the garden is testament to its success and of people's desire to connect with their local community.

We had about just some 200 people turn up for our opening. So most of them were local and people I hadn't met. So that was really, it was really overwhelming. It was a wonderful turn up ...it was really good to have that many people come to such a small site. To most people we'd be such an insignificant site, but to have there's only 500 houses on the hill - and to have 200 people turn up was pretty overwhelming for me....people are wanting to engage, they're wanting to get to know their neighbours, they're wanting to become involved. They might not physically want to plant plants, or hose, or do whatever but they obviously wantthey crave that social interaction. (Mandy, Marville)

Mandy points out the distinction between locals who want to garden and those who may not have that interest in common but find it a good site to meet people in their neighbourhood.

The other aspect of the intersection of community gardens and population mobility is the effect of mobility on continuity of community garden membership. While placemaking is a dynamic action, and renewed membership feeds into changes which can occur in design and governance of community gardens, providing continuity despite the everchanging membership can present challenges. Several of the gardens' committees had ways of dealing with changing membership.

People join with different levels of enthusiasm and there's, there's sort of that turnover of people that think it's a great idea, but then they realise, or they just 
don't know, they've got a garden full of weeds. And then from a community standpoint it's, it's just hard, it's really. We've lost quite a few members. A lovely couple, English couple, have given up their garden, they've sort of downsized and moved further away. But there's some newies too you know, so there's some younger ones coming. We just set up a dropbox account, because you know, the problem with the turnover of people, ... we'd have a repository of some sort where you know uh, if Janet hands over the role, the password everything is in there (Jim, Kookaburra)

In an urban environment with a self-reported high population mobility, the community garden can act as a place to sustain neighbour involvement. The visit to Kookaburra Community Garden occurred on a working bee day where members were preparing for an upcoming open day to attract new members. A repository of neighbourhood knowledge passed from 'regular characters' to new residents who join the Community Garden or who chat with the regulars.

At Sydney's Pine Park, succession planning is a challenge which has fed into their current non-hierarchical governance structure. Succession planning was noted as an issue at Pine Park and Kookaburra and is a common issue with neighbourhood action groups and voluntary organisations (Rogers, McAuliffe, Piracha and Schatz, 2017). Matthew from Pine Park provides the following cautionary tale that is not based on population mobility as much as population longevity.

Some time ago, well when the garden started, they start with some kind of dominant character in them and some of them, I don't know if they fail, but they all struggle when that dominant character leaves or in our case died. And that's what happens. You know often times they're retired people because they've got the time to put the effort into it and you know you have to drum up that sort of enthusiasm and that's what we had here. ...after she died we had to organize ourselves again because we relied on her a lot. And I think the second go around, rather than have someone take over as the king of the castle, we were very keen that we were much more an egalitarian mob. So what we do, some people take on I suppose particular responsibilities. (Matthew, Pine Park). 
Pine Park members have continued to avoid having one member as the leader. Having observed a monthly meeting at Pine Park, the ideal of consensus decision making was, in practice, somewhat more like a majority rule when discussing their maintenance planning. One member had a different idea of the material to use on the common paths, but was not so committed to his preference as to hold up the decision. These kinds of group meetings to make decisions are part of the placemaking process. This example demonstrates the fluidity of decision making in a community organisation which has decided to not be too rigid in its governance style. Edward, who had adjusted from having "complete control" over his own garden, described the communal decision making process as:

... generally I find it positive. I mean, sometimes <laughs $>$ I once described the decision-making process here like some kind of 1970s encounter group - you know, where there was more therapy than decision making. But I've kind of - it doesn't bother me anymore. (Edward, Pine Park)

Placemaking involves gaining skills and knowledge to create or change a place, so new members can require skill sharing. At Marville, because they were at the founding stages, the participants talked about all "learning together". At Bluevale, Penny talked about her difficulty finding a role which suited her when she first volunteered.

I was helping people garden and they were getting me to weed and that was a bit of a pain because I didn't know what to do because I wasn't well supervised really. (Penny, Bluevale)

Her volunteering picked up when a committee member directed her to another member who sought help with a bush tucker project.

So I wouldn't have lasted really, but I think Martin told me that Jens wanted someone to do the naming of the bush tucker. And that's when I started doing that. Then I could work on my own and I was fine. I taught myself mainly. ... It was fun. (Penny, Bluevale)

Penny taught herself the skills she needed and with the assistance of other members, created a bush tucker project which is very successful. Finding a suitable role in the community group and gaining skills and experience is part of placemaking. As people 
move from one location to a new home neighbourhood for employment, family or other reasons, they take with them a set of transferable placemaking knowledge and skills to their new location.

Martin and I live close by so it is your neighbourhood and you can't leave so you stay. Which is a good thing too that people can go and start other ones up elsewhere. (Penny, Bluevale)

The changing membership allows opportunities to exploit the dynamic nature of placemaking community gardens. Renewed combinations of community gardeners have the opportunity to respond to the dynamics of the neighbourhood - be it, for example, gentrification, revitalising degraded areas, or responding to community goals such as improving accessibility and inclusivity.

Placemaking through community gardens is an important device to break down the social alienation by connecting people to a time and place.

\section{Supporting placemaking}

Lennon and Moore (2019, p. 120) draw attention to Lefebvre's understanding of space as "continually and simultaneously both a product and producer of social dynamics". Placemaking is dynamic and responds to an action where people are guided by the current form of the community garden, but they are also agents in changing the structure and governance of the garden. As at Kookaburra, the group can decide to fence the property and have keyed entrance. In van Holstein's (2019, p. 10) study into the gentrifying effect of community gardens, they note that "networks and strategic alliances shift in response to neighbourhood change and that the effects and social inequalities inherent in gentrification thus seep into a project". While this research is not exploring gentrification, the findings in this study align with van Holstein's findings in that the dynamic combinations of those involved in the community garden governance change the physical and operational manifestation of the garden according to the desires of the community (or the strongest voices in the community) (2019).

At Pine Park the group at the time had experimented with locking the gate but the group agreed it didn't work, so now have other strategies for dealing with vandalism (which by all accounts seemed to be a degree of tolerance and resignation). 
In the manner of a third place, the involvement in placemaking at Marville extends beyond the membership.

(We) get a lot of foot traffic with both the football and the cricket, we get a lot people just walking past and seeing what's going on, but there've been so many people stop off and then say, "Oh I love what you're doing," or "I've been watching it grow", that aren't probably actively involved but, you know, are grateful for the space, but I've seen just up here eating their lunch that obviously go, 'Where can we go?', “Oh we'll just duck up to the garden'. (Mandy, Marville)

Mandy talks about people "watching it grow". This is an example of the dynamism of placemaking, where even a (third place) visitor is involved in the growth of the garden through monitoring its progress. A Marville Community Gardener discussed the mural which was painted to beautify the freeway noise barrier.

I know they organised a grant to get some artist to come and paint it together, so I think - I wasn't involved for that, but I understand there was like a community involvement. And I know a lot of children came along and helped paint a lot of the initial designs and then the actual Main Roads sponsored artist came and finished the pattern. (Mandy, Marville)

Planning and production of the mural was a co-operative placemaking act to improve the atmosphere of the garden.

Frank Street and Marville community gardens have communal growing plots only. This suits Marville as they have limited space and it is working well as a third place. Frank Street is a third place, completely open in design, access and there are no membership obligations, yet it reportedly struggles to attract members or regular visitors. April's survey of her local neighbourhood found that having no individual plots was seen as unattractive to potential members. However, Marville also has no individual plots, which shows that specific characteristics such as the design, governance and placement of a community garden need to suit the preferences of the local community. The Frank Street case study illustrates the importance of involving the local community in decisions about the community garden so that it is the best fit for the particular neighbourhood in which it is situated. 
Local authorities play an important role in community gardens through the issuing of land on which to host a community garden. Some gardeners feel the precarious tenure. Chana et al. $(2015$, p. 633$)$ point out that: "policies that clearly establish tenure are crucial, as the benefits of community gardening are often lost when community garden spaces are lost". Pine Park and Hagenlund are both well supported by the local council or land owner, which means the cost and organisational demands are reduced compared to other unsupported community gardens. The Pine Park gardeners have access to their city council's community garden advisor and can ask for garden maintenance materials such as mulch. Hagenlund is run by the librarians and all gardening costs are covered by the private land owner.

The members at Bluevale City Garden express some tentativeness about their tenure, despite having continuous access since 1994. With a tone of understatement, Martin says, "It's been interesting that whole relationship with council". The participants note various ways in which they are responsive to the council's requirements, including remaining non-political in relation to the changeover of local councillors. Members mentioned the requirements of the council including discouraging homeless people from staying; raising the height of the building in response to repeated flooding; responding to the contaminated land rulings. The participants in this garden also noted the many ways in which the council has been supportive. This is somewhat reminiscent of the Celata and Coletti (2017, p. 17) study of community gardens in Rome which noted that regulating community gardens "is very often caught in a delicate balance of promotion and control, co-optation and 'policing' and risks to exacerbate already existing distinctions between collaborative and confrontational initiatives". In the case of Bluevale, when the council determined that the land was contaminated, they provided some material support to rectify the situation. Martin felt this was a political move to fit with the then council's 'green' image.

“They didn't really want to shut us down. That would've just been a loss to the community at large. So, once they realised that, they - strange stuff, but I think it was mostly political. They're also about saving their own image as well as ours". (Martin, Bluevale) 
There is an element of precariousness about community gardens, including this one which had been established for 25 years at the time of interview. How does the precariousness combine with a mobile population and the dynamic nature of gardening to produce a sense of place? Perhaps perpetuity is not of central concern to the third place, where interactions between people, creating relationships and memories are the way to attach to place.

A member of Pine Park was positive about the support they had received in the past, but was fairly negative about being currently allocated an advisor to the community garden.

These days they've got a community garden coordinator and it seems certainly to me that she has to justify her position to the administration council so she's very keen to ... what's she want us to do? At some point she wanted us to measure all the stuff that comes out of the gardens to measure what sort of crops we get out of it and we said no. We are a little bit belligerent like that. A lot of it is pilfered. We have trouble with pests. Some kids will come a long and knock all the fruit off the plumtree with a stick. It's a struggle. Everything we get out of there is like a little treasure. There are other people in the community come along and take a little bit themselves. We don't know how much comes out of it. ... She says well I sort of have to tell council what's going on. Well the value of a community garden is not just how many tomatoes you can grow. So we've been sort of resistant to all her designs on how things should work, so we have less and less to do with her. Which suits us. (Matthew Pine Park)

The Bluevale and Pine Park examples illustrate the balance that authorities face between being supportive and allowing the people autonomy over the land use or being restrictive and prescriptive. As with van Holstein's study of community gardens in Sydney, the gardeners express resistance to assistance (or interference) from the local council. In van Holstien's (2019, p. 11) study the respondents reportedly thought that the council would like more control over the look and operation of the community garden and that they, "resisted efforts by government to enact discursive ownership over the space".

Local governments have a role to play in supporting citizen-led third places such as community gardens. In the case of Kookaburra community garden, the local council changed the definition of a community garden from a community group to agriculture, which dramatically increased the cost of water. Although their local councillor was helpful in trying to lobby for a reversal of the water rate change, at the time of interview 
they had not been successful. The garden president describes his surprise at the council's unsupportive decision:

Strangely, there's classifications within Council in terms of how you're charged for the various rates and water and so forth and "community" means you get it for nothing virtually. Now, for whatever reason all the gardens on The (Gold) Coast are classified as agricultural. And we've fought, via [name of local council member], he's lobbied on our behalf, but we've lost it, so, we thought we could have a win, but we haven't. I mean, we're not for profit. ... Why would you? Look at this [pointing to the garden]. I mean, why wouldn't you support something that pretty much runs itself? All we're asking for is a break. (Jim, Kookaburra)

Jim went on to explain that they have had to implement time-consuming fund raising activities. The additional fund raising responsibility adds to the time commitment involved in running the gardening, particularly in a hot summer with regular watering, plus committee functions and their charity work, is a substantial commitment for many members.

All but one of the community gardens was maintained and funded in the majority by the members themselves. By contrast, the Hagenlund Library Garden was well resourced. For example, there was the opportunity for the organisers to ask the building corporation for resources, such as the fully grown and fruiting apple trees. However, the coordinator said it would benefit from having a paid gardener who could advise and assist with the community garden, as the librarians note that they 'have a library to run'. These demotivating factors and the actions taken or hoped for in response, are examples of the dynamic nature of placemaking in community gardens which are third places. While in one sense providing community gardens which are less onerous for community members to maintain may erode the agency of the members, it may increase accessibility and participation in community gardens.

\section{Motivations for creating a place}

The motivation, effort and resources required to initiate and build a community garden are substantial. Interviews at the newest of the case study sites illustrated one way in which a community garden is initiated: 
We were at some community group meeting just up the street and she'd raised the issue of maybe it's time for a garden here and after the meeting, I went and I said, "Actually I had that same idea and I'd really like to help," and she was just like, "Oh, great, yeah, let's do it together". And [we] got a committee involved rounded up a committee and it's been really good. (Brenda, Marville)

By being a third place, the goals or motivations of the community garden and its members, reach out to more people in the community. Those goals may include, as with Kookaburra community garden, providing food to impoverished residents and personal access to fresh organic food. In the case of Bluevale City Farm, their sustainability workshops are educational opportunities and their employment (WEX) program teaches work skills. In Celata and Coletti's (2017) study of Rome, approximately 170 community gardens cover varying purposes including producing healthy food, providing a public group space, thereby promoting social inclusivity. Marrickville community gardeners in inner Sydney overwhelmingly attract young and relatively well-off professionals who are seeking sustainability to the point of citizen action - creating community gardens without permission in the midst of gentrifying their patch (Sharman, 2010).

At the case study site or Bluevale City Garden, a former committee member discussed the motivations of their members.

When I was volunteer co-ordinator I did a little survey ... we were asking people questions along the line of, what do you want to get out of being here? And it was basically two things, it was social time, like, having a sort of a social scene and belonging; And learning skills. That was pretty much, the only two answers we got! (Clarissa, Bluevale)

One of the goals at Bluevale City Garden was to include Indigenous food plants in their gardens. "Jens does the bush tucker workshop on Saturdays. They are all fairly well attended" (Penny, Bluevale). Bluevale members formed a First Nations Advisory Group and implemented a number of initiatives (discussed further in Chapter 6) such as the first nation story telling in their children's program. It would be interesting to follow up in future research on the placemaking role of linking people to the original people and food of the land on which they live.

The skill of growing food was one of two motivations of most members, but in association with the social aspect of learning and socialising. Across the six case study sites, not all 
respondents could pin down their community garden motivation to just one factor, so remained as mixed motivations featured frequently, in particular the combination of "community" and "gardening", for example at Frank Street community garden:

I was hoping I would just learn a bit more about gardening. And also I'm just yeah I like to hang out with local community members. So it is social as well. (Emma, Frank Street)

Kat, at the same garden, had a different mix of motivations, which was about the kids, the community and growing fresh produce nearby. Many of the participants noted that they had sufficient gardening space at home, but they wanted to garden with other community members.

It seems like a lot of the people who are involved have some part of backyard anyway. So in terms of production for eating or things like that, it seems like there's kind of enough for that around and maybe-yeah - people are involved for another reason like neighbourhood kind of stuff. I don't know. That's the impression that I get in these early stages <laughs $>$. ...We like gardening. We like public space, kind of being - having somewhere that we can go when - see other people in our neighbourhood. (Violet, Marville)

The combined motivations of "community" and "gardening" reflect a desire to garden with other people. This was evident at Marville Community Garden where a lot of the people involved had enough space to grow food at their own house. Similarly, Albert at Frank Street community garden grows his own food at home, but visits the community garden several times a week for the purpose of "just keeping the area nice, really" and views the neighbourhood efforts as a form of "community service”.

\section{De-motivating factors}

Community gardens are not a bed of roses. Most interviewees mentioned factors such as theft and/or vandalism. It is worth considering demotivating factors, as these erode the motivational enthusiasm of participants and may impact the longevity of the community gardens. For example, the 24/7 accessibility to the unlocked Bluevale community garden came at a cost. Problems of vandalism and theft arose for most of the gardeners interviewed. The current members expressed that the acts had discouraged the gardeners, but their talk demonstrated a level of tolerance for such negative events and some 
strategies for minimizing losses. Barbara at Pine Park explained that she keeps some weeds in her plot in order to hide her plants from theft and vandals.

When they take whole plants or someone rips up your whole plot... I purposely don't pull out the weeds so people think it is weeds. Easy and not so disappointing. (Barbara, Pine Park)

Therefore not all incidental interactions with the people of the neighbourhood are heartwarming third place interactions and some enthusiastic gardeners were demotivated by vandalism. Similarly, Frank Street community garden, which had no individual plots, had to contend with what might be described as systematic theft of produce which would be shared with members and neighbours.

Part of the problem is that we do have people who come in here and take stuff that they are not supposed to. I was here on Thursday afternoon and that tree was full of paw paws and a couple of these trees had lemons and limes and there was a bunch of bananas there and between Thursday and today (Saturday), all gone. So I don't know what is going on. Every now and then we'll get something. We'll be able to get some tomatoes and stuff, but nah, nothing significant. It is almost like a sweep. Like the cumquats, probably like half a dozen (trees) they just come in and do A sweep. ... There is nothing you can do really. (Albert, Frank Street)

Albert's response - nothing you can do - denotes an element of tolerance and resignation to the problem. Similarly, Edward at Pine Park explains that the vandalism is something they tolerate.

There was an idea about a big, tall fence around it and that died. Look, it's just the nature of moving in an area that's - very huge amounts of people here, pretty well at the bottom of the ladder, socially. Big drug use problems here, people are very poor. It's a kind of intergenerational. (Edward, Pine Park)

Edward has expressed his understanding of the problems which may cause the vandalism. Barbara at Pine Park explains that locking the gate would take away from the community aspect of the community garden, because a locked garden would be, "a lot more exclusive. Not so community minded."

Turner's (2011 p516) research found that the gardeners felt sad and "violated" when their gardens are vandalised or produce is stolen by intruders. An alternative response to 
vandalism is evident at Kookaburra with their fencing the public out of their garden. Referring back to the dynamic nature of placemaking, the Kookaburra members are empowered to make design decisions like this. While the fences may reduce the garden's third place aspect, members have had the agency to involve the wider community in other ways. As described by Jim, the president of the committee, "As a committee, we've made quite a lot of difference, really I suppose embracing community". In addition to the garden's involvement with the local special school and volunteers from the local private high school, the members contribute to a local homeless charity by growing food in a specific plot for them.

\section{Qualities of the places made}

As discussed in Chapter 2, Oldenburg's list of third places are mainly commercial and municipal venues. Community gardens may provide an authentic sense of community which may previously have occurred in more settled suburbs through community groups such as churches and sports teams, or through extended family, and ties to place (Putnam, 2000). Perhaps the fact that the people make the community garden makes it more authentic. Gaynor (2006, p. 167) discusses the "postmaterialist" values which became prominent in the 1980s when: "Ecological lifestyles represented an attempt to reclaim an authenticity of experience seen as lacking in modern consumer society, in which people were alienated from nature, and from each other". Sharon Zukin (2010, p. 197) refers to community gardens as bringing "authenticity" to urban environments, ranging over time through social movements, ethnic identities, middle-class "locavores", gentrification, and embodying strategies for sustainability. Many philosophers argue that humans are programmed to strive and such striving over difficulties and obstacles provides an "authenticity" missing from a world of ease (Foley, 2010, p. 63). Numerous interviewees at some point mentioned the work involved in organising maintenance of the gardens or their own plot. As at the relatively new Marville community garden, members appreciated the sense of satisfaction from working together cooperatively.

It's nice to get out with your neighbours and work together for - towards a common goal and it's nice to see a transformation take place. (Stefan, Marville)

Working together cooperatively to create a place strengthens the ties between people and provides skills which help with the adaptive capacity and subsequent neighbourhood 
resilience of the garden participants. Adaptive capacity and social capital development will be discussed further in the next chapter.

The gardens themselves provide an opportunity for authenticity. The librarians at Hagenlund Library Garden had expected that the participants might like to cultivate plants from their own cultures. If this was the case it may follow similar findings as SaldivarTanaka and Krasny (2004), who determined that the Latino gardens in New York City, "provide a connection between immigrants and their cultural heritage". The Hagenlund library gardeners included immigrants from Turkey and Pakistan, but they grew the same plants as the Danish resident gardeners.

We were expecting that people would introduce plants that we weren't familiar with but that hasn't really been the case. (Yvonne, Hagenlund)

Perhaps pragmatically, because the seeds and plants are provided for free, all members grow the same food plants.

Community gardens are made by the people, for the people, so no two designs are the same. This uniqueness makes places authentic compared to the "exhibitionism" and "phoneyness" of some master planned street designs (Jane Jacobs, 1961, p. 228). People's actions are shaped by their environment and they in turn shape their environment by their actions. A community garden is often an untidy place in a world of straight lines and hard surfaces. An unruly connection to space in the city. Community gardens are a place where the people can have a sense of control over place to respond to a particular group's needs.

Design features, which encourage locals to interact, improve the effectiveness of third places. The inclusion of seats, cushions and sheltered meeting spaces contribute to the sociability of the community gardens for visitors and members. The garden design can contribute to inclusivity goals through being accessible to people with disabilities through the addition of raised garden beds as at Kookaburra Community Garden. Placement of the gardens is important for third places, as walkability is essential to encourage familiarity through repeated incidental interactions between local residents. Further research could be conducted on optimum design and placement of community gardens to best facilitate third place interactions.

Community gardens which are not third places still have valuable roles to play in supporting the community. The factors which facilitate community gardens to be third 
places can be applied to the design of other social spaces to enhance their placemaking qualities. The third place with a "communal purpose" framework may prove useful for investigating the community aspects of other public infrastructure.

Placemaking is enhanced in community gardens through connecting people to nature in their local neighbourhood. Where many interviewees joined a community garden to grow food, they grew to appreciate the sense of community they developed with fellow gardeners and local residents. Pine Park and Hagenlund offer personal growing plots, which assists with enthusiasm and regular attendance to tend to plots. In addition, both gardens have formal and informal connections with the wider community. Community gardens at all case study sites enhanced the placemaking connections to the garden and the community.

Community gardens act as a third place with a communal purpose, attracting a broad range of residents motivated by a broad range of motivations around community, gardening and food growing. Removing barriers to gardening in time poor and agency poor neighbourhoods would increase the accessibility and effectiveness of the 'community' aspect of community gardens. To be an effective third place, the governance and participant commitment should not be inhibitive. The Pine Park garden has a nonhierarchical management style, where informality of membership poses no burdensome obligation. Members have roles such as the overseeing compost or the membership contact. Collecting the low annual membership fees is the method for checking membership annually and the funds are kept in a tin at someone's house. They changed their governance structure from a hierarchical structure, to non-hierarchical as they feel it suits their current membership. The ability to change their governance structure shows their organisational flexibility to respond to the current membership preferences. Such flexibility is part of their adaptive capacity, which feeds into the resilience of the group and the neighbourhood.

The factors which make community gardens effective third places, ie purposeful interactions, can be applied to the design of social spaces. Community gardens, in general, act as a third place with a communal purpose and that this makes them effective for placemaking and improving social capital. This research may help inform city planners to plan for and support community gardeners and may prove useful for investigating the 
community aspects of other public infrastructure including men's sheds, dog parks and skate bowls.

"Urban design represents an on-going journey through which places are continuously shaped and re-shaped - physically, socially and economically - through periodic planned intervention, day-to-day occupation and the long-term guardianship of place" (Carmona , 2014, p. 34). This means that the local people can be responsive to the needs of locals and have the power to change their community garden to become more (or less) third place-like. The placemaking re-shaping was in evidence as the library community garden:

We are in a constant evaluation of how we think it works and how we can improve it. We would really, really love to have a gardener who could come like just once a week and also teach people a little bit about what to do and how to take care of the plants because some of them haven't gardened before. (Yvonne, Hagenlund)

In the case of Frank Street garden, their own survey showed that in order to attract more regular visitors and members, they should introduce individual plots. Whereas at Kookaburra, members favoured security over free-wandering visitors and by erecting six foot high fences with barbed wire on top, they decreased the third-place aspect of the community garden.

\section{Conclusion}

The community gardens are inclusive third places, which encourage placemaking through connecting people with each other and with the land. Community gardens at all case study sites enhanced the placemaking connections to the garden (land and nature) and enhanced the placemaking connections to the community (people). Many interviewees grew to appreciate the sense of community they developed with fellow gardeners and local residents. This chapter described the ways in which community gardeners were inadvertently enacting UN Sustainable Development Goal 11.7 by providing inclusive green spaces for the community. Third place community gardens implement the global UN Sustainable Development Goal at the local level.

This chapter also discussed how the act of placemaking to create third place community gardens encouraged inclusivity, as people worked together to create and maintain their community garden, or watch the garden's progress with interest. Inclusivity was apparent 
in the examples given and will be discussed more fully in the following chapter (6) on social capital.

The factors that facilitate community gardens to be third places can be applied to the design of other social spaces to enhance their placemaking qualities. The research shows that community gardens go some way towards improving quality of life in urban environments, through providing enjoyable intergenerational social interactions in a nature-based environment. Community gardens are not a system-level change and in and of themselves are unlikely to be a universal panacea for urban problems, but lessons learned here could be incorporated into the wellbeing of a city. By creating a third place where people can connect to the land and the locals where they live, community gardeners are sparking an interest in the local environment and engaging the neighbourhood in citizen action. Given that community gardens that are third places exhibit qualities which help improve wellbeing in urban communities, cities would benefit from planning to reduce barriers to community garden participation. 


\section{CHAPTER 6 - GROWING SOCIAL CAPITAL}

Social capital is a measure of the social connections which produce positive benefits for not just the individual, but the collective (Putnam, 2000). This is important in addressing issues of social isolation and alienation and issues associated with population mobility and neighbourhood resilience. Data from the case studies is used to investigate if community garden participation leads to increased social capital, through building social ties within and beyond the garden setting. The hypothesis in this chapter is that community gardens, which act as third places, improve social capital for individuals and the neighbourhood in two ways. Firstly, community gardens that act as third places promote the creation of weak ties leading to bridging capital between members, neighbours, and visitors in the local neighbourhood. Secondly, for some members they also act somewhat like clubs, offering the opportunity to strengthen weak ties into strong ties of friendship leading to bonding capital.

Two themes emerged from the data which relate to creating and strengthening social capital. The first is that some community gardens exhibit inclusivity, thereby potentially build inclusive social capital. This relates to the third place characteristics, 'neutral' and 'leveller'. The neutral characteristic means that everyone is free to enter and spend time there and leveller is a descriptor that shows how nobody is excluded by any personal factors such as health, gender, cultural background, age and economic status. Secondly, the other important theme which emerged from the interview data was that the community gardens play a role in introducing people in the neighbourhood (new and established) to each other. This relates to the third place characteristics, 'conversation' and 'regulars'. 'Conversation' is the main activity in third places and allows people to interact with each other. As Oldenburg (1997) explained, third places which include an activity which can be shared by the group enhance the opportunity for conversations. 'Regulars' are the people who play a role in introducing newcomers and bringing everyone together.

This chapter is responding to the research question:

Do third places that have a communal purpose (i.e. community gardening) open opportunities for social capital development?

Figure 6.1 (below) situates the research question in relation to the overarching question, 'To what extent are community gardens third places?', which established that all of the 
case study community gardens exhibit all or most of the eight third place characteristics. Analysis of the data in Chapter 4 noted that four of the eight third place characteristics related dominantly, though not exclusively, to social capital making qualities of community gardens which are third places. For the purpose of discussion, this chapter will focus on the four third place characteristics: Neutral ground, Levellers, Regulars and Conversation. The characteristics Neutral ground and Levellers are grouped in discussion about the inclusivity of community gardens which are third places. Conversation and Regulars are grouped in discussion about community gardens which are third places acting in a role of introducing people to the place.

Figure 6.1: Situating the social capital research question

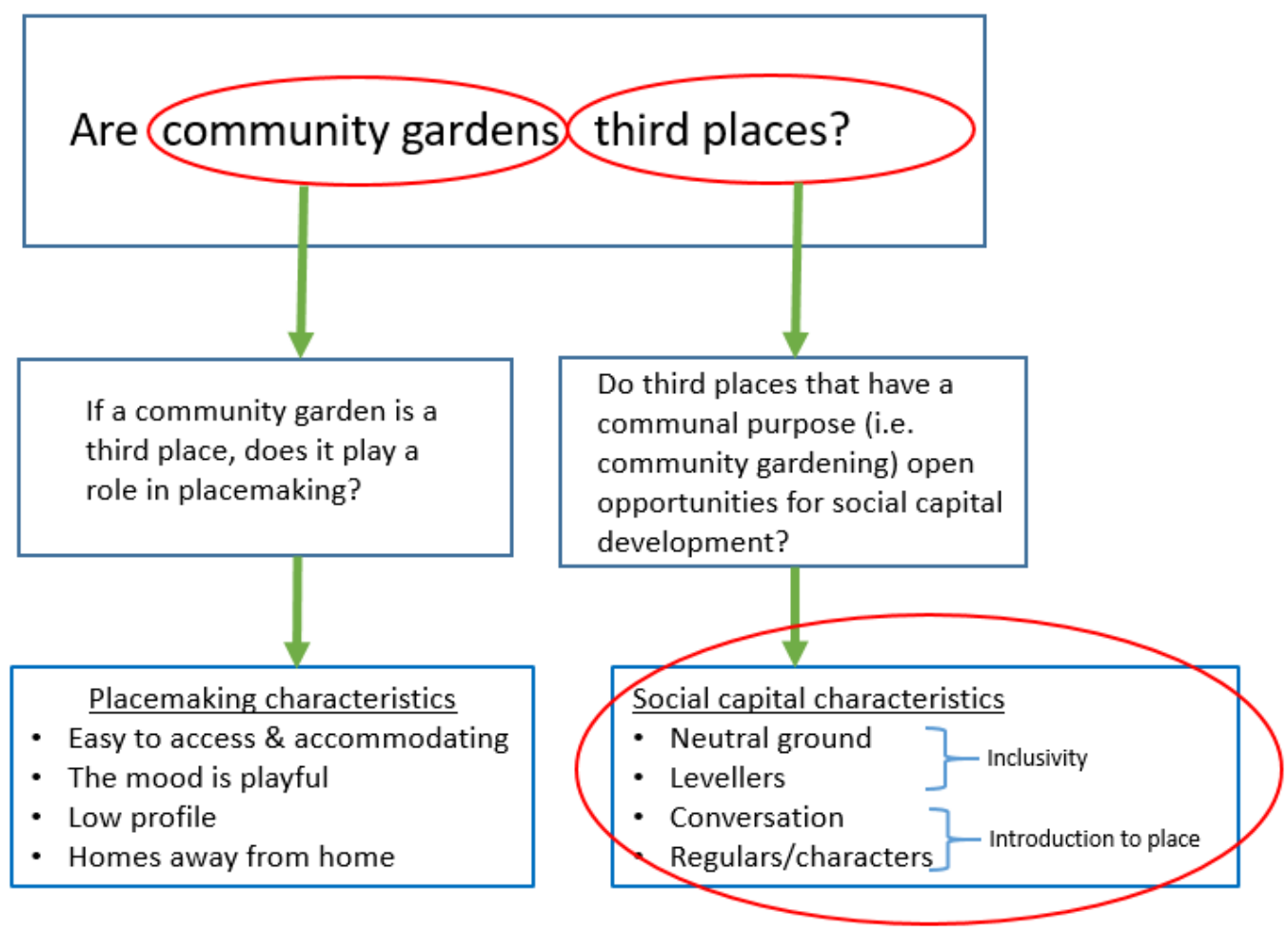

This chapter will discuss the data collected at the six case study sites firstly to explore inclusivity, then introduction to place. The chapter will relate both these concepts and the four third place characteristics to social capital. The community garden case study sites: one at the Gold Coast (Kookaburra), one in Sydney (Pine Park), three in Brisbane (Marville, Frank Street and Bluevale) and one in Denmark (Hagenlund); are described in 
detail in the Methods Chapter (3). They cover a range of types of community gardens. The community garden participants in the study include long term members, founding members, committee members, new members, paid staff, and regulars who are volunteers but not members. Chapter 4 determined that community gardens are third places when they exhibit all or most of the third place characteristics and this was demonstrated in community gardens which are: open to the public at all hours; based in a walkable location in the neighbourhood it serves; have regulars - both members and visitors; and their activities and stories reach beyond the physical boundaries to local people who are not members. Chapter 5 explored the placemaking qualities of community gardens which are third places. This chapter builds on the previous chapters to determine features of third place community gardens that enable them to build social capital in a local neighbourhood.

\section{Social Capital}

Social capital theory has been developed from a range of research and used for varying purposes by numerous theorists including Pierre Bourdieu, Robert Coleman and Robert Putnam as discussed in the literature review (Chapter 2). In addition, discussion of Jane Jacobs and Mark Granovetter's works on the value of social networks have also been discussed. As previously noted, Putnam's (2000, p. 19) definition of social capital will be applied in this chapter:

\section{"Social capital refers to connections among individuals - social networks and the norms of reciprocity and trustworthiness that arise from them."}

Putnam's definition can be applied effectively to qualitative data, as explained in the methods chapter (3). Putnam applies the concept as social connections which produce positive benefits for not just the individual, but the collective (Putnam, 2000). It was acknowledged in the Literature Review (Chapter 2) that Putnam recognises that social capital can be enacted in ways which produce negative results for the broader community, for example criminal gangs. However, for the purpose of a collective neighbourhood activity, such as creating and maintaining a community garden, the community based social capital definition of Putnam is more applicable than a more individualistic definition of Bourdieu (Jenkins, 2002). Putnam's definition is similar to Australian 
Bureau of Statistics (ABS) and OECD social capital definition which informs numerous policies and planning for community wellbeing (ABS, 2004).

This chapter will refer to some of Coleman's work on applying social capital theory, as described in the literature review (Chapter 2). Coleman (1988) identifies social capital as a resource which individuals can utilise in order to achieve their own interests and advancement. While this is true that individuals may benefit by their interaction with the community garden community, this thesis is looking more generally at the values of social capital between networks of people and in creating a sense of community, particularly qualities of "norms of reciprocity" and "trustworthiness" rather than measuring any particular personal benefits (Coleman, 1988; Putnam, 2000, p. 19).

Clubs and societies have membership criteria, rules and obligations. They can generate strong ties of social capital, or bonding capital (Putnam, 2000). Bonding capital is a form of ties between people with a strong group identity who are somewhat alike in identity and/or interests. By comparison, the incidental social interactions linking people in third places are more likely to generate weak ties of association (Granovetter, 1983; Oldenburg, 1999). The weak ties are a form of bridging capital all of which contribute to building local social capital and forming of a sense of community (Granovetter, 1983; Putnam, 2000). Bridging capital links people across groups and connects people to others who have different backgrounds and interests. Edwards (2004, p. 103) argued that "social cohesion in part depends on a balance of bonding, bridging, and linking ties". The theory of social capital is useful for investigating how community gardens function to enable people to increase social ties between neighbours (Firth, Maye \& Pearson, 2011). For the purpose of a collective neighbourhood activity, such as creating and maintaining a community garden, Putnam's community-based social capital definition is useful.

\section{Significance}

This chapter is significant in that it investigates how community gardens which are third places can play a role in producing and distributing social capital, thereby reducing the impacts of population mobility and social isolation and increasing the resilience of a neighbourhood. Draper and Freedman (2010) suggested that as community gardens are a collective activity, they promote social interactions between members. Putnam (2000) associated the demise of sense of community to the decline of group participation in 
public recreational activities and corresponding isolation of individuals within neighbourhoods. Putnam linked the decline of recreational participation to declining civil engagement in broader society including trade unions, and churches. Coleman (1988, p. 100) cites a lack of community of trust in, "most metropolitan areas of the United States", saying the normative structures are absent. Klinenberg (2001, p. 501) gives an example that the "degradation and fortification of urban public space" in Chicago is the result of, and perpetuates social isolation and fear of crime which creates conditions of low trust and low social capital, reducing the resilience of neighbourhoods. Interactions with the local neighbourhood can provide 'receptivity' or tolerance of strangers and feelings of belonging and safety in an increasingly globalised society (Easthorpe \& McNamara, 2013; Montgomery, 1998).

This chapter is addressing a gap in the literature about how community gardens which are third places can affect the social capital of individuals and the community in the local neighbourhood. Chapter 3 found that community gardens are on the whole, third places. Chapter 4 determined that by being a third place, the goals and motivations of community gardens, reach out to more people in the community, often overtaking the initial motivation of growing food (Pascoe \& Howes, 2017). Chapter 4 also determined that the placemaking attributes of community gardens contribute to the aims of UN Sustainability Goal 11.7, to provide safe and inclusive green and public spaces for the local community (UN, 2015). In addition, increased social capital of a neighbourhood has also been found to lead to greater resilience to disaster, which in the case of community gardens, is enhanced by their potential for improving food security (Aldrich, 2012; Chana, et al., 2015; Nursey-Bray et al., 2014; Turner, 2011).

The development of resilience through improved social capital will be explored in this chapter in relation to third place community gardens. Developing social capital in a neighbourhood is impactful given potential for climate related and other potential impacts which can be thrust upon a community. Norris et al. (2008, p. 127) describe social capital as one of the "adaptive capacities" of a community which enables them to be resilient and recover from adversity. "Resilience" is a term originally derived from ecological studies and essentially measures a system's ability to "bounce back" to its original state after some kind of change is imposed upon it (Davidson et al., 2016). Davidson et al. drew on 
a range of research on resilience in order to find a coherent and practical way to define it for use in the social sciences:

"Fostering development of those elements that will enable social-ecological systems to absorb and/or adapt to unforeseen change and deal with uncertainties - learning to live with change, maintaining diversity (natural, cultural, social, economic, and institutional) to increase options, combining different types of knowledge for learning, and providing opportunities for self-organization." (Davidson et al., 2016, p. 27)

They define different three levels of resilience, two of which will be referred to in this chapter, namely: Type 1 is "basic resilience" and Type 2 is "adaptive resilience" (Davidson et al., 2016, p. 26 \& 27). Basic resilience has, "four core elements comprising persistence or resistance, absorption of disturbance, recovery or bouncing back to a previous stable state, and retention of system identity" (Davidson et al., 2016, p. 26). "Adaptive resilience," which will be discussed later in relation to Bluevale City Garden which suffers regular flooding, involves "self-organization and adaptability" (Davidson et al., 2016, p. 27). These forms of resilience can relate to disturbances not just of climate, ecology or other natural forces, but also economic, political and social events which impact the particular community (Davidson et al., 2016). An economic disturbance affecting Kookaburra community garden will be discussed in this chapter. This thesis refers to neighbourhood resilience, where the neighbourhood is place-based and includes everyone in the area rather than a cohesive community of people. However, Black and Hughes definition of a resilient community is apt for this thesis:

"A resilient community is one that is able to respond effectively and bounce back in the face of adverse circumstances, whether these be economic, environmental or social" (Black \& Hughes 2001, p. 16).

Third places act as a port of entry for newcomers as they help introduce people to each other and to their neighbourhood (Oldenburg, 1999). As discussed in the previous chapters, population mobility, which is in evidence in all case study sites, affects the wellbeing of the individuals and community (Coleman, 1988). Community gardens which are third places have potential to be a source of social capital for new residents. 
The rise in numbers of community gardens (enumerated in Chapter 2) is evidence of a growth in new forms of civic engagement public cooperation.

Numerous community gardeners in this study indicated that the social aspect of the garden was not the primary reason for joining a community garden, however, it was seen as a benefit, or an unexpected bonus. Humans are motivated by unsatisfied needs and one of those needs is, "Love and Belonging" (Maslow, 1943). This can be seen in reference to a desire for a sense of "community" and in seeking out friendship and belonging to a group. Community gardeners are motivated to get to know people in the neighbourhood; share resources and produce; learn together; feel a part of a community; and/or combat loneliness (Pascoe \& Howes, 2017).

Apart from their role as an informal public meeting place, most of the case study sites have arrangements and activities with other groups. Pine Park members help out with the local school garden; Bluevale reach out to the community through education, markets, children's playgroup and employment programs; and Marville is a site where many activities such as workshops and playgroup take place.

\section{Inclusivity}

Two of the third place characteristics contributed to their inclusivity, namely 'neutral' ground and 'leveller' (Oldenburg, 1999). The data shows that community gardens which were determined to be third places across all eight characteristics were inclusive across age, socio-economic status, cultural background, disability and gender.

\section{Neutral}

Neutral ground in third places means everyone is free to come and go without obligations (Oldenburg, 1999). The neutral characteristic is present when the community garden is open at all times to anyone and committee membership obligations and fees area not prohibitive or onerous. The literature indicates that community gardens are generally inclusive and informal, based around a broad range of motivations and goals attracting people of a range of ages and demographics (Gaynor, 2006; Guilart et al., 2012; Lyons et al., 2013; Ohmer et al., 2009; Pascoe \& Howes, 2017; Turner, 2011). The benefits of third 
place community gardens being neutral locations is the opportunity for locals across a wide range of backgrounds being able to mix and form weak ties of association and/or strong ties of friendship and reciprocity with regulars in their neighbourhood, regardless of varying commitment to the facility. This section of the chapter looks broadly at how the characteristics of neutral and leveller influence the findings on inclusivity of a third place community garden.

Being open, the Pine Park community garden acts as neutral ground where people of the neighbourhood join in. Some found out about the garden through neighbours while most came across it while walking through the neighbourhood. They have a notice board which welcomes potential members and explains the membership requirements and when the meetings are scheduled. Pine Park community garden acts as a third place to the wider community. As Matthew explains, 'There are local people who take an interest in the garden without being actively involved in it'. Some members try to encourage those visitors to join.

We do get a fair few (passers-by) stop and chat. Some people stop and pick stuff, so we make a point of saying, "Hi, do you know how the garden works? If you want to pick, how about you contribute?" - Just join the garden rather than just picking. Or some people think that "community garden" means they can pick what they want. It is not necessarily a bad intention. They just don't know, whereas some people do know and they come when they think no-one is watching (laughs). (Barbara, Pine Park)

Barbara turns a potential negative interaction with a member of the neighbourhood into a positive opportunity to educate about how the garden works and encourage involvement. This is an act of making connections and building social capital in the form of bridging from the bonded interest group across to others outside of the group membership. People from outside the garden take an interest in the Pine Park garden as a topic of conversation at the local pub, or coffee shop. For example, the local coffee supplier took an interest in the garden's coffee trees and showed the members how to care for the trees and helped them to harvest and roast the coffee beans. One member noted there is a local pride in the garden even amongst non-members. As determined in Chapter 3, community gardens exhibit most, and in many cases all of the characteristics of third places in that they, to varying extents, have porous boundaries, where many people who are not involved in community gardens still show an interest and interact with gardeners. The interview data 
shows that community gardens can be inclusive third places, mixing members with local non-members. This addresses a planning problem that even in spaces designed for social mixing, often little effort is made to plan for interaction between participants of differing backgrounds (Parizeau, 2017).

The library community garden in Hagenlund Library Garden acts as a neutral ground, started in order to 'engage' with the adults who live in the area by providing an attractive green place where they can get to know the library staff and each other. As noted previously, Yvonne at Hagenlund, the idea behind the library garden was "about making people come and live more together and have places to hang out and meet each other".

As with the other case study community gardens, the openness of the garden 24 hours a day leaves it vulnerable to theft and vandalism. As previously mentioned, this was in evidence at Hagenlund on a sign posted on the garden beds asking that no one steal the children's vegetables which were for the upcoming children's harvest party.

Discouraging and negative interactions between the community garden and the neighbourhood were explored in more detail in the 'placemaking' chapter. For example, Edward at Pine Park explained that the vandalism is: "part of the nature of moving in an area that's very huge amounts of people here, pretty well at the bottom of the ladder, socially". His acceptance of the difficulties that some people in the area face was evidence of tolerance for people who were struggling with life in some way.

Similarly at Kookaburra Community Garden, which generally prefers a more organised way of being charitable with their plots for donating food to the homeless charity, the president of the committee was fairly philosophical about one particular regular visitor:

We've had some issues with just this particular lady who, um, I haven't been here when she's been here, but apparently she'll wander in and just, do a bit of 'shopping' and disappear, cause she says 'it's a community garden' so...(Jim, Kookaburra)

Some of the challenges of community gardens being accessible in a neutral location include dealing with theft, vandalism and homelessness, as discussed in other sections of this thesis. This level of tolerance is in stark contrast to the tensions observed in Egerer and Fairbairn's (2018) research observations of tensions caused by locals picking the produce in Californian gated community gardens. In some cases, the urban commons became exclusionary spaces where tensions amongst members and against the 
neighbourhood play out (Egerer \& Fairbairn, 2018). The way the members of this research study's case study sites choose to react to negative interactions with the public is evidence of their adaptive capacity to absorb the impacts, namely: ignore the loss of a bit of produce at Kookaburra; invite the plant pickers to join the garden at Pine Park; or make changes to minimise the impacts with signage on the children's gardens. This relates back to the definition of resilience building mentioned earlier where the social group self-organise to take advantage of opportunities and adapt to change. This is in evidence at Marville with saving the chickens from floods:

Every 2 years we have a flood. Lately (every) one year. We have major floods so the chooks come to our place, people come to our place, and then sometimes we are down here in the middle of the night rescuing chooks. Our life has been built around floods a lot. Probably how we got quite valued here because I became famous for a chook rescue on the front page of every newspaper in the country. $<$ Laughs $>$ in my red wheelbarrow. (Penny, Bluevale)

The photo referred to the major flood which submerged large areas of Brisbane in 2011. The garden members have found ways to respond to and minimise the impact of the increasingly frequent flooding events. As with the definition of resilience, the Bluevale members are "learning to live with change ... combining different types of knowledge for learning, and providing opportunities for self-organization" (Davidson et al., 2016, p. 27). The networks of social capital built up through the garden can bear fruit when the community garden is confronted with change. In van Holstein's $(2019$, p. 10) community garden study they note that, "strategic networks do not only emerge when a garden is under threat" and adds that the networks change in response to the composition of the neighbourhood and changing priorities.

Marville community garden showed the use of social capital when trying to gain access to the small patch of unused land described by Stefan as "overgrown" and by Brenda as "ugly" which now is the neighbourhood's third place community garden. Interested individuals in the neighbourhood worked together to lobby for the land and showed resilience as they faced knock backs. 
At Kookaburra community garden, as noted earlier, they were faced with an economic disturbance/impact when the city council decided to reclassify community gardens as agriculture rather than a community facility, which increased the cost of their water. The garden president described their efforts to fight the decision and to enlist the support of their local counsellor. They were not successful in having the decision overturned, so through group fundraising activities they have found another way to bounce back.

Water's our biggest enemy. We've expanded with more and more tanks. We had one tank, then two tanks, then three tanks. (Jim, Kookaburra)

The community demonstrated adaptive capacity in two ways. Firstly, though not successful to date, they enlisted assistance from their local councillor to try to lobby for a reversal of the political decision which affects their running costs. The Kookaburra community have built social capital with their local councillors by keeping in touch and inviting them to their AGMs, "We had the councillors here at our AGM we have a bit of a lunch" and the group make the meetings into a "social occasion". Through the "linking social capital" they build with their local councillor, they were able to call on him for support. "Linking social capital involves relationships with those in authority and positions of power and is useful for garnering resources" (Edwards, 2004, p. 103). The garden president said of their local councillor that, "he lobbied hard for us".

Jim notes his confusion that the council decision is seemingly not supporting a community organisation which is by and large self-supporting. The second way the group demonstrate resilience is to rally together to raise money through fund raising activities. Jim notes that he is able to: "source the sausages and the catering at very good prices", through his work (human capital) therefore they make a good profit for the garden. It is a team effort to do the fund raising, as Leanne's comment below describes.

I always put my hand up to do barbecues and that because I like people, I like talking to people, and it's a good conversation piece. When people see it at Bunnings or Masters, 'community garden', you know, it generates discussion. (Leanne, Kookaburra)

Not only does this group activity raise funds to pay for the cost of water and keep down the membership fees, but Leanne uses the opportunity to talk to the wider community 
about the garden. Again, as a third place, the community garden reaches out to people beyond the garden boundary.

\section{Leveller}

Community gardens can act as a leveller where the diversity of people's backgrounds and abilities are irrelevant to visiting or participation. Third places act as levellers when they bring together people of different ages, classes, cultural background and skill levels. Oldenburg (1999, p. 45) described third places as welcoming "people from many different walks of life". Community gardens create a mix of people interacting. This section will illustrate examples of inclusivity across the case study sites by findings on the characteristic - 'leveller'.

\section{Ages:}

Oldenburg argues that: "Third places can bring youth and adults into association with one another" (1997, p.7). Third places have implications for the challenges of planning urban spaces for different ages for active aging and child friendly cities (Alidoust \& Bosman, 2015; Gleeson \& Sipe, 2006; Mansvelt, 2008). Mixed ages was evident in all case study sites, for example the Pine Park site, where Edward described some of the ages of members:

It's made up of ... some in their 20s, 30s. I'm probably the oldest person in the group. But there is another set, there's about maybe four or five of us who are 60 plus. And then there's some people in their 50s, and then there's the rest of them. (Edward, Pine Park)

There are also children actively involved in all of the case study gardens. Parents indicated that their children liked the gardening experience. One Kookaburra Community Garden participant said of his seven year old:

Yeah he gets in there. Definitely. He loves to see things grow. Helps us decide what to grow. Takes a bit of ownership of it. This one (baby) actually had his very first fruit from here two weeks ago... a strawberry. (Samuel, Kookaburra) 
Similar to Sam at Kookaburra, Emma at Frank Street appreciated that the community garden is a good place for children, saying:

"A big part of it is probably the kids actually, for me. They just get to be around people gardening and nature and gets them out of the house”. (Emma, Frank Street)

In all sites there was a positive response about involvement of children in the community gardens. This is reminiscent of McGlone's (2016) study of pop-up parks, which found that children feel safer and freer to interact with community members when they are in a protected public space in sight of trusted adults. Children interacting with adults was in evidence at Pine Park, where Tina explained:

I think probably the whole, sort of, participating in the community thing because when I grew up, it wasn't really like that where I lived, although maybe because my family wasn't particularly involved. We weren't that type of family and I think that I want the children to have a little bit of that, you know? And also going to talk to different people and, as you can see, that one keeps calling out and is extremely interactive and he will just talk and talk and talk and talk. And, fortunately, most people there really like talking to him $<$ laughs $>$ So it's sort of good for that -for them just to be exposed to different people and the food thing as well. (Tina, Pine Park)

Tina had expected the adults at the garden to find her children a little annoying, but instead she found several members who enjoy talking with the children:

They're really good with the kids like they give them heaps of time. At the Sunday meetings, they don't mind them running around. There's one lady in particular who just chats and chats and chats and chats to him and shows him stuff and spiders and insects. She's really, really lovely. And there's - one of the guys who volunteers down at the school, who was sort of explaining how a native beehive works and all this kind of stuff. (Tina, Pine Park)

A number of participants particularly liked that the children learned where food comes from.

Before I had the kids I just thought it would be nice to just grow a few things and just actually learn about it because I don't really know anything about gardening. And since the kids, I just thought it would be nice for them and also for the same 
reasons, so they can learn that it doesn't just come from the store. Like, the first time my son saw an orange on a tree like he just didn't get it, you know? (Tina, Pine Park)

The welcome participation of children was noted at all gardens. At Marville, a parent appreciated that the children got to spend time free roaming in nature.

We have the community playgroup here, which is I think is making the kids feel really comfortable in this space at a time when there's not a working bee, so then when there is a working bee, often there's a lot of kids running around the dirt pile. (Violet, Marville)

Oldenburg (1997) and Jane Jacobs (1961) point out the need for safe public places for teenagers to hang out away from home and school. There were no teens involved at Pine Park at the time of interviewing. Notably, Matthew said one enthusiastic child gardener lost interest when he became a teen: "He kind of lost interest at 16. He spent about 10 years as a kid gardener".

At Kookaburra Jim noted that there was involvement of teens from the local private boys high school as their nominated community service day. Jim said: The boys (were) here last week. They actually tidied up the little herb garden there.

However, in a more naturalistic manner along the lines of Jacobs' and Oldenburg's ideas of a teen hang out, at the Marville Community Garden, local teens used the garden as a third place.

We leave it open... I saw some teenage girls doing their fingernails on the school holidays...(Violet, Marville)

Third places, particularly those which combine social interaction with physical activity, have beneficial health and wellbeing outcomes for the community (Frumkin, 2003). Community gardens provide an opportunity for older local residents to become involved or to interact with neighbours. Alidoust and Bosman (2015) found that for older people in their study, the third places such as shopping centres, churches and the public library provided older people with valued opportunities for seeing familiar people. Third places reduce social isolation of older residents and community gardens have the bonus of providing fresh food and promoting active living. Fred who was nearly 80 years old at the time of the interview had a number of roles at Kookaburra Community garden, including: 
I'm on the committee, I look after their lawns and do their whippersnipping for them and I plant the garden here, the community garden, look after that. (Fred, Kookaburra)

Fred refers to the "community garden" meaning the communal garden bed in which they grow the food to donate to charities. Fred also has his own personal garden plot.

It's giving me an outlet for something to do. Yeah, if my wife's away all day, what am I going to do, I can't sit there and look at myself, but it's an outlet for me to come. (Fred, Kookaburra)

On the day of the interview, Fred was observed energetically mowing the communal lawn areas. Fred's physical and social activity are an example of the beneficial role the garden can play in the wellbeing of older people. Kim et al. (2017, p. 1039) conducted a longitudinal study of a representative sample of U.S. people over 50 years of age and found that sense of purpose in life "may play an important role in maintaining physical function among older adults", which is important given the social and economic impact of an aging population.

David and Mandy, members of the Marville, noted that it was difficult to get older locals to join their community garden, however, the interactions with older people occurred in a third place manner by chatting and exchanging information and plants. This is an example of making the connections from the group (bonding capital) to others in the neighbourhood (bridging capital). The older locals may not want to be involved for reasons proffered such as their perception that it is a place for young people or children:

When people come here and walk past and they see me up here with my two children and they go, "Oh it's a children's thing, "<laughs>" (Mandy, Marville)

However, the older neighbours interact with locals in a third place manner, for example by offering plants and advice, without the commitment of becoming members. This acts as a way of creating weak ties with the members and familiarity with people in the neighbourhood. Similarly, the teenagers at Marville found a way to use the community garden as a third place - away from home, yet safe and free. It can be seen that by being third places, community gardens can be used by a wide mix of people in different age groups. As the individuals from the different age groups find their own ways to interact with the community garden members, more people in the neighbourhood become 
recognisable to each other and provide the eyes on the street mentioned in the Placemaking chapter (Jacobs, 1961). These ingredients for social capital development build the resilience of the neighbourhood by connecting a diverse group of people, increasing social connectedness, which is readily drawn upon in times of crisis (Aldrich, 2012).

\section{Gender:}

Oldenburg's (1999) third place examples feature arguably single-gender and masculinedominated sites, perhaps harking back to a more gender-segregated post-war era. As discussed in the literature review, a bar might not be a third place where a female feels comfortable initiating a conversation with a stranger. In his original book, Oldenburg (1999) described third places are a face-to-face place only, though he did note some role for the telephone in the case of isolated housewives. While this idea of stay at home wives may seem outdated, the question of effectiveness of some third places for informal neighbourhood building across genders is still relevant today. Planning for genderinclusive public spaces has potential to improve the social capital of women, which has implications for improving overall community wellbeing (Son et al., 2010). Gender inclusivity is a goal of UNSDG 11.7 (UN, 2015).

The case study community gardens provided opportunities for gender inclusiveness. Equivalent numbers of males and females were observed at all case study sites. As previously discussed, Brenda at the Marville Garden, took on roles which supported the community garden but were suitable to being pregnant or with a young baby.

Similarly at the Kookaburra Community Garden, one gardener commented on the benefits of community garden involvement for his wife with their new baby, commenting that:

My wife definitely does (garden). It's one of the great things about being here. The new bug [baby] it gets her out of the house and gives her a project. At the moment she's probably in charge [of the garden plot]. (Samuel, Kookaburra)

A Pine Park gardener spoke of the benefits of participation perceived by a single parent who joined and attended with her child: 
.... she didn't really know anybody and she said, 'The garden was a great place to go where I could talk to other adults and everybody would play with the young bloke', so she was a big fan. (Matthew, Pine Park)

The community garden acts as a third place where specific gender is neither an advantage nor a barrier and opportunities arise for initiating purposeful conversations in an active outdoor site. Gender inclusivity was also taken into consideration by the fact of providing safety measures, as described by Jim, the President of the committee overseeing Kookaburra Community Garden. The garden is situated below the road level on one side and backing onto a suburban warehouse site on the other (see Image 6.1). There are very few reasons for passers-by to see into the community garden. While this makes it peaceful and secluded, it is not such a good placement in terms of eyes on the street providing safety.

We've started asking people to lock the gate, when they come in. Lock themselves in. Yeah we've got female members too and I mean I've said to them look, I hate to say it but, you're on your own, if you're here own your own. ... In fact it was in the last (committee) minutes where we said look, for your own safety, because basically you're on your own here, so if someone came down... (Jim, Kookaburra)

While locking the garden and having keyed entry may seem like an exclusive practice, reducing the third place characteristic, 'accessible', the justification provided by the garden president seems inclusive, as the additional safety measure provides reassurance and safety for the female members. This kind of consideration fits with the UN sustainable development goal 11.7 about providing safe and green public places for women and children. The other five gardens are not locked, however they are all other gardens are more visible to passers-by. Increasing the visibility and connectivity of the garden would be a preferable solution to locking oneself in, but this would be a difficult design challenge given the Kookaburra's site at the end of a quiet street below road level (Holden, 2019). Personal safety was mentioned by one other participant, in this case at Bluevale City Garden:

You know I'd always been told, 'Oh don't talk to those people' and, 'Got to be so careful' and you did kind of have to be careful. Like on the days that I was cleaning, I'd be there on my own and people would be drinking by the creek and 
hanging around. But I think we got to know them. There was a guy called Mark, and another guy. I forget his name, but they slept there pretty much every day and they were like the caretakers, after hours caretakers of the farm. Yeah everyone got to know them and it was a good sort of working relationship. (Clarissa, Bluevale)

The issue of safety for Clarissa arose when she was alone at the garden. This issue was partly addressed by caution and partly by the group building a 'working relationship' with the regular homeless men who lived nearby - building trust. When choosing locations for community gardens and their design, feelings of safety should be taken into consideration if the garden is to provide a safe and green public place for women and children.

\section{Cultural background:}

In Australia in mid-2016, 28.5\% of Australia's resident population was born overseas, increasing to $29.0 \%$ (7.1 million persons) in 2017 (ABS, 2017; ABS, 2019). If Australian third places are to be considered culturally inclusive, cultural diversity should correspondingly be represented there. Cultural diversity was noted by members at the Kookaburra Community Garden.

We had the councillors here at our AGM. We have a bit of a lunch and it might be a Thai [member] like might put on some Thai food, or we had some Bosnian members that put on a lamb, except it was Ramadan, which was cruel because they couldn't eat it. (Jim, Kookaburra)

While the Kookaburra Community Garden did have examples of ethnic diversity amongst members, Marville Community Garden members lament that the cultural diversity of their neighbourhood is not yet represented in their membership and referred to the committee as, "all kind of white Australian. We're all pretty much the same".

Marville Community Garden members indicated that they would like to encourage diversity of cultural background through strategies of encouraging people to grow the food they know and sharing that knowledge with the other gardeners. Vincent et al. (2016) discuss a middle class yearning to experience cultural difference and exercise their egalitarian principles, yet found that ad hoc encounters did not result in lasting cultural inclusivity. While third place encounters are unscheduled, community gardens as third 
places provide opportunities for depth of interaction and conversation when people cooperate together on the garden.

The Hagenlund Library Garden organisers encourage participation of anyone who wants to join in and therefore acts as a leveller across the diversity of languages and ethnicity in the local housing area which the library serves.

We have a group of women from Pakistan and we have some women from Turkey and we have an older Danish lady and a Danish family and we have one family from Somalia and we have a woman from Thailand, so it is actually representing this neighbourhood quite well. It is an opportunity to make people meet across age and cultures and languages. (Yvonne, Hagenlund)

Yvonne gives examples of cooperation and members minding each other's garden plots, mentioned later in the chapter. Gardening also potentially extends the idea of 'conversation' to cooperative activities which can include non-spoken interacting across language barriers.

Some community gardens try to include Indigenous food plants, as in evidence at Bluevale City Garden.

I was doing the bush tucker and I had my own garden and the nursery was there and the nursery helped me. I did a lot of research myself. I went to the library at Mt Cootha (botanic gardens). You can get lots of books. (Penny, Bluevale)

As previously noted, one of the long-time members runs popular bush tucker workshops. Unfortunately, it is not clear from the interview data if part of the purpose of including an informative bush tucker garden may be to make the garden more inclusive to existing or potential Indigenous members, nor is it possible to tell if local Indigenous people were involved in providing information about local bush tucker. In 2016 the organisation formed a Decolonisation Action Group and in 2018, the garden formed a First Nations Advisory Group ${ }^{12}$. Bluevale have implemented a number of initiatives including an Education Discounts policy for First Nations people to attend courses; cultural awareness workshops for staff and volunteers; and introduced first nation story telling into the children's program. The above mentioned efforts to include Indigenous ideals, knowledge

\footnotetext{
${ }^{12}$ Information about the community garden group's Indigenous policies and programs was retrieved from reports on their webpage. They cannot be referenced without contradicting the researcher's ethics permissions which require providing pseudonyms.
} 
and plants in Bluevale are attempts to be inclusive. Indigenous involvement in community gardens, which are not ostensibly for the purpose of being Indigenous community gardens, is a significant topic for future investigation, particularly in relation to reconciliation and building social capital with the original inhabitants of Australia.

\section{Disability:}

Pine Park and Frank Street community gardens have provision for older gardeners or participants with physical considerations with access to the high rise garden beds. Similarly, the Kookaburra Community Garden is inclusive of physical disability amongst members through provision of highset gardens for those who cannot bend over to garden and social membership for those unable to garden (See Image 6.1). For example, Janet at Kookaburra has been able to maintain her gardening activity after a workplace incident:

I've got a high rise garden because I've got a dodgy back so-yeah. This beautiful garden - sometimes you think you'll come down for about half an hour. It's just so beautiful that you're here for two hours it's a really lovely environment. (Janet, Kookaburra)

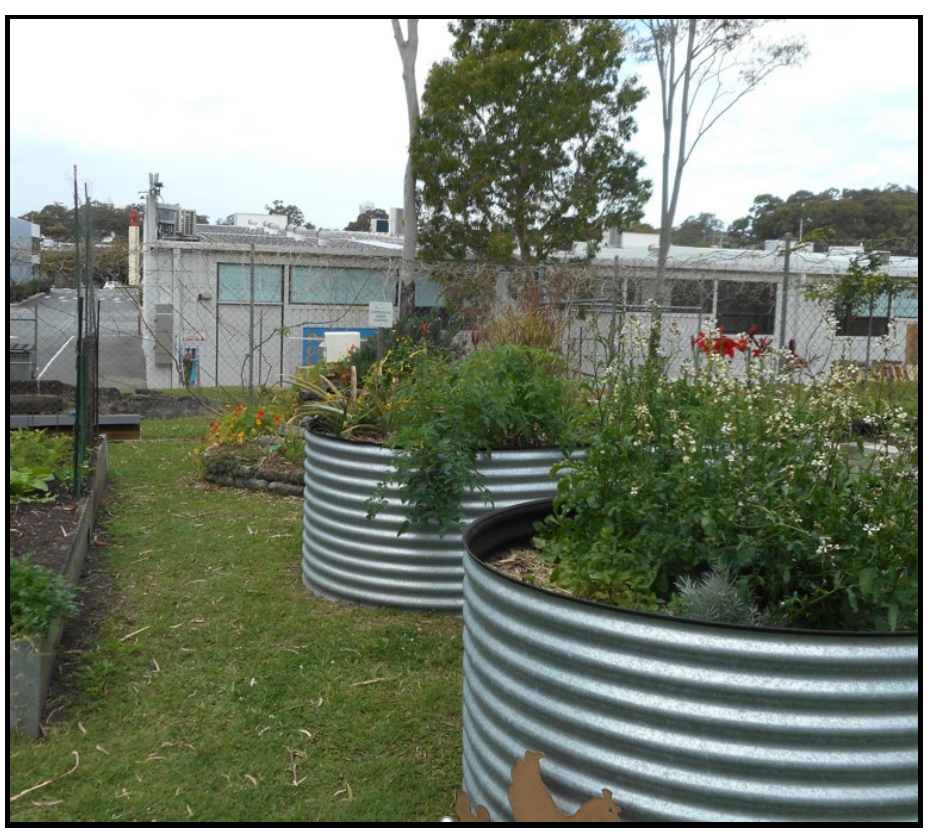

Image 6.1: Highrise garden plots at Kookaburra Community Garden at the Gold Coast. Source - Author, September, 2015.

As the president of Kookaburra community garden expressed, the committee members feel that their work has helped to bring the community together. 
As a committee, we've made quite a lot of difference, really I suppose embracing community and I mean we have the Special School are you aware of their involvement? So they approached us and we, or the principal did, approached me and I said 'absolutely' so, that's their plot, but I guess what they do is come here under supervision and within their ability do bits and pieces around the garden but, you know, doesn't amount to much, but they love it. (Jim, Kookaburra Park)

The Kookaburra Community Garden also incorporated an intellectual disability charity into their communal area design.

This high rise with the chooks, it is run by ... an organization that deals with multiple handicaps and so they bring their members down. (Daisy, Kookaburra)

Kookaburra was able to provide older gardeners who were no longer able to garden and those who were on a waiting list for an individual plot, with social membership which provided access to the garden shed and the pleasant surrounds.

She's given up her plot some time ago, but she still has got [social membership] we have some social members for people that used to perhaps be part of the garden and they've given up their plot because they haven't been able to keep up, but they still like the idea that they can come here and enjoy the garden and we're happy if they want to help do some weeding on the community plot so they've still got an association. They still have a key. (Janet, Kookaburra)

Janet has described how people of varying ability can maintain their association with the community garden. This flexibility in design and membership of Kookaburra is helping to reduce the social isolation that many older people can feel when they are stuck indoors unable to participate and mingle with their neighbours and community. Community gardens which can incorporate a variety of gardening situations in their design are able to cater to greater inclusivity, which enables them to be third places and to build the social capital for local residents.

\section{Occupation/ socioeconomic status:}

Third places are inclusive across socioeconomic status (Oldenburg, 1997). In the Pine Park community garden, members who were interviewed covered a variety of 
occupations including retirees, professionals, a university student and her small children and an unemployed person. One member of the Pine Park community garden suggested theirs, "has become sort of a middle class play thing in the middle of the housing commission area", however, their membership included "three or four members" from the local social housing.

You pay an annual fee, $\$ 20$ if you're not working and $\$ 40$ if you are working. (Tina, Pine Park)

The Kookaburra Community Garden included members who were unemployed or on age pensions, plus donated produce grown in the charity plots to local charities. This is similar to the findings in Glasgow of Crossan et al. (2016), where community gardens are sites which demonstrate equality of participation in creating a sense of community. The Kookaburra Community Garden and Pine Park community gardens demonstrated their attention to financial inclusivity by offering reduced membership fees for those on pensions or welfare.

Membership was optional in the Marville Community Garden, as with Frank Street. Pine Park, situated in the middle of social housing, actively encourages interactions with the broader neighbourhood. For example, several members help out with the neighbouring primary school garden. Members recounted use the garden by locals for such things as reading the paper, collecting grass for a pet rabbit, and regularly walking through it. One the slightly defensive interchange was noted in the observations between a local and two of the community gardeners, one of whom asked me, "Are you getting this?" (on the recording). It was an exchange where the local explained that she pulls out some of the grass on the paths to feed her rabbit. The gardener said in a joking manner that she was welcome to pull out all the grass (meaning that it is a weed). The neighbour became a bit defensive, misunderstanding the light tone of the passing remark. The gardeners tried to be reassuring, but the impression remained that some of the over the fence exchanges may be challenging. In what way this one-off exchange was of benefit to the community is difficult to determine, however, without the community garden, these opportunities for informal interactions between different people in the neighbourhood may not occur at all.

Pine Park Community Garden has on occasion also been a place for homeless locals.

I remember at one of our gardening meetings there were these two young kids that were sort of standing just near where we were and someone said, "You guys 
alright? You looking for something?" The kid said, "No, I live here”. They don't live there very long. There are a lot of rough sleepers (here). (Matthew, Pine Park)

Pine Park experiences a number of homeless people sleeping in the garden. Members from three of the community gardens discussed their interactions with homeless locals. Emin at Bluevale noted:

Yeah, someone is sleeping over there. It's a bit of a shock when you come early in the morning and someone is sleeping here and I guess it's a shock to them as well. It's an interesting place. (Emin, Bluevale)

Emin advised that the City Council no longer allows the organisation to let people sleep there and they have to be moved on.

It's a bit of a conundrum because it's illegal to camp on council land but it's also obviously not illegal to be homeless, so where do people go if they don't have housing? So it's a societal issue, for sure. We definitely have dealt with a fair share of homeless people over last year. ...Even though I really feel for people that are in the situation, we're just not equipped to deal with homelessness. We're just not a facility to deal with that. So it's just a balance of compassion and also just saying, "Look, you can't stay here. These are the services you can hit up," but I guess the council - it's on our lease that we're actually not allowed to camp here, not saying that we give permission to homeless people camp here but it just happens because it's so open. (Emin, Bluevale)

Emin and Matthew demonstrate empathy and are inclusive in their interactions with the homeless people, but as Emin points out, they are unable to provide a solution. Before the implementation of the council rule, Clarissa at Bluevale had noted that the garden staff had "a good sort of working relationship" with a few regular homeless people who were seen in some ways to play an unofficial role, 'they were like the caretakers, after hours caretakers of the farm'. The trust and reciprocity was lost in the implementation of council rule. The interaction of a public open space and homelessness causes concern for the wellbeing of the homeless people and for the safety of the garden members. Kookaburra community garden contributes to homeless people by growing food for a charity which supports them. This is a form of bridging capital where members from one organisation interact and support members of another community organisation. Kookaburra contributes 
to the resilience of the neighbourhood by helping to feed those in need. This is an example of the potential role of community gardens in the provision of food for the homeless and as such, it is a topic which merits future investigation.

Emin at Bluevale City Garden is a paid employee of the garden and part of his role is to oversee the training and work of the unemployed people who are undertaking the government compulsory Work Experience Program (WEX). Those partaking in the scheme work alongside members and volunteers, increasing their social capital and number of weak ties.

A few of the WEX participants have definitely stayed on as volunteers or have signed up to become volunteers but some of the more keen ones are also. This is a huge generalisation, but some of the more interested WEX participants tend to get jobs, and so they're intrinsically motivated. So I feel like that also translates to them being able to get a job outside of the farm. Some of them they come back but later on, they drift off and then find full-time employment which is good. So the really good WEX participants, we lose fairly quickly because they find employment. We had some really, really good ones and really skilled ones in construction. (Emin, Bluevale)

Bluevale City Garden could be said to improve more forms of capital because as well as building social capital through meeting new people, Emin is teaching various skills to the employment program participants, therefore he is helping to build their human capital ${ }^{13}$ as well. Martin at Bluevale City Garden noted, however, that some of the unemployed participants find their place at the garden.

Normally they're on for three months or so. Some of them have been around for years, mind you. They keep coming back. They've found themselves a niche there and they've been on WEX at Northey Street for three or four years because they just like it. 'This is my life'. And they're getting enough money as far as they're concerned. They're not too worried about not getting a job or they've got some issues where they can't get a job, and they just find this suits them well. Some of those guys come out seven o'clock in the morning and they'll stay right through

\footnotetext{
${ }^{13}$ Human capital refers to "tools and training that enhance individual productivity" (Putnam, p.18, 2000).
} 
until 5:00 in the afternoon. They're not obliged to at all, so that in a sense, they're serious volunteers in the place, as well as being on the WEX program. (Martin, Bluevale)

The WEX program participants mix with the other participants at the Bluevale City Garden, therefore increase the diversity of garden participants and gain themselves human and social capital. Clarissa at Bluevale summed up inclusivity through the diversity of participants at Bluevale City garden:

I think much of the farm crew saw themselves as a collective of misfits, rejects, and counter culture types and found some comfort in finding a place for themselves. Bluevale grows people far more than it grows food. And it often grows the people that find it hard to grow in most other places - people in remission, people long-term unemployed, struggling with mental health or social isolation, or just strong personalities etc. I consider this to be its greatest asset. (Clarissa, Bluevale)

Clarissa has described how Bluevale provided the inclusive space which allowed connections grow amongst a diverse collection of people. However, Clarissa warned against a different kind of exclusion:

But, I think also that 'corporate-looking' people or people that looked more mainstream (i.e. 'the people walking through on their way to work or other places') would not have been as likely to have been invited to be involved in activities at the farm, especially if they don't have a background in horticulture or permaculture. We had an admin worker there for a while that was really pushing us to make more of a habit of seeing the more well-dressed 'off-to-a-normal-joblooking-people' as potential human resources for the farm. She saw that we had the potential to have biases against these people, and she might have had a point. (Clarissa, Bluevale)

The pragmatic view of the administration staff member was to value the human and social capital of 'mainstream' people. As discussed later in this chapter, it is possible that the so called mainstream people are involved as the allotment holders.

Third place community gardens are generally 'levellers', inclusive across ages, gender, cultures, socioeconomic status and disability. The leveller quality of the case study community gardens echo the UN Sustainability Goal 11.7 to contribute public spaces 
which are inclusive for "women and children, older persons and persons with disabilities" which was discussed more fully in the Placemaking chapter (UN, 2015). The case study community gardens have demonstrated their inclusivity or attempts at inclusivity. The case study sites also are neutral, as everyone is free to be there. The data has illustrated that third place community gardens help introduce people to each other and to their neighbourhood, regardless of their membership status, as visitors and volunteers and in some cases staff and unemployed participants were free to be there. The neutrality and the inclusivity of the garden set the scene for improving the social capital of the neighbourhood.

The social capital generated was enacted as resilience in several examples including response to flooding (Bluevale), response to homeless people (Bluevale, Pine Park and Kookaburra); responding to financial pressures (Kookaburra); and bouncing back from incidents of vandalism and theft (all of the sites). Levelers and neutral are the characteristics which set the conditions for introducing local people to each other in third places. Two other third place characteristics play a role in building social capital in community gardens, namely 'conversation' and 'regulars'.

\section{Ports of entry}

"As public life is populated with strangers more than ever before; as strangers frighten us more than ever before; and as communities nonetheless depend upon the successful integration of strangers...” (Oldenburg, 1999, p. xvi).

Oldenburg refers to third places as 'ports of entry' for newcomers into the life of the neighbourhood by helping newcomers to meet and learn about people in their community (Oldenburg, 1999, p. xviii). 'Conversation' and 'regulars' emerged in the thematic analysis pointing to the role of community gardens in facilitating the introductions of local people to the community garden and to each other.

Every case study site illustrated the characteristic of introduction and integration of individuals who were new to the area into their local community. Community gardens which were determined to exhibit all third place characteristics showed qualities of introducing newcomers to the place in which they live, whether they were new residents or had been in the location for some time. This section will illustrate examples across the 
case study sites of how locals are introduced to place, therefore increasing the social capital of the neighbourhood.

Clarissa, a former committee member at Bluevale City Garden, had moved from the country and found the garden by accident. Clarissa found it was a very good way to meet people in her new city; "I met heaps of people, yeah. It was good. Heaps and heaps of people, yup." She was initially motivated to be involved to learn skills and later picked up paid work at the garden, but she valued the friendships she made there as well. Her main motivation for joining was:

Learning how to grow food, but I don't think that's why I stayed there, I think I stayed there because it was really interesting like the dynamics of the place, and the personalities and the people. You do make friends. (Clarissa, Bluevale)

As with Clarissa, all of the case study community gardens exhibit the characteristic of introduction and integration of individuals who were new to the area into their local community, with the mobility of residents particularly noted at the Kookaburra Community Garden.

There's been quite a few long-term tenants here. I don't know. There's always going to be turnover and the Gold Coast is a high turnover place. People come and go, but-yeah. ... there's lots of good about the place and I'm happy to be a part of it. (Harry, Kookaburra)

Harry discusses the high turnover in relation to the population of the town, however Jim, the President notes several additional reasons for losing members including: some older members who went into care; some members are not good at gardening and lose interest; and he and his wife had an international job transfer coming up. There is insufficient data in this study to show that the community garden was able to persuade anyone to stay at the Gold Coast, however, several participants noted that the garden helped them to meet people and, like Harry, feel more a "part of" the community. Fred, at the same garden, echoed Harry's sentiment by relating to the "community spirit" engendered at the garden.

We all get along fine, it's a, it's a community garden and it's a community spirit and it's a community. (Fred, Kookaburra Community Garden) 
Fred invokes the idea of building social connections as people learn to 'get along'. The Pine Park community garden also helped members develop a sense of belonging to the local area.

The way we first met people when we first moved here was through the garden. One of the girls got married and we went to the wedding. One plays in a band and we go and see. We go bushwalking. (Matthew, Pine Park)

Not only did Matthew and his wife meet local people through the community garden, but those weak ties developed into strong ties of friendship demonstrated by their involvement in social activities and invitation to a family event such as a wedding. The bonding ties of friendship exhibit trust and reciprocity. The third place characteristics of 'conversation' and 'regulars' in particular emerged in the thematic analysis contributing to the role of community gardens in introducing people to place. In addition, social engagement and participation occurs in new ways and places such as the internet (Sennett, 2012). Emma mentioned how social media can assist people to find out about the garden and for those already involved, it can keep them up to date with events.

People can find out [about the garden] if they want to. They can look it up. There's a Facebook page. We're talking about it, but there's always more you could do to make it accessible, I guess. ... It's a way to know when stuff is happening because depending on weather - it's been just really hot, then really rainy, and it hasn't been on. So it's just to keep up-to-date when it's on. It's pretty important. (Emma, Frank Street)

The Facebook page offers the opportunity to create connections with those in the area looking to join a community garden by providing information and the contact details. Similarly, Mandy at Marville noted how useful Facebook was:

As it sort of evolved, we set up a Facebook page... it's amazing how many people are constantly hitting that page. (Mandy, Marville)

Sweeney et al. (2018) note the value of Facebook posts in spreading information and achievements of a community garden to the wider public. 


\section{Conversation}

The mechanism allowing third places to assist in integrating new residents into a local community is the third place characteristic, 'conversation'. Oldenburg (1999) assumes that strangers will easily strike up a conversation in a third place, though he notes that a shared activity enhances the opportunity for conversation. This research demonstrates that third places with a communal purpose, such as community gardens, give people reasons to initiate a conversation. As discussed in Chapter 4, Violet compared striking up a conversation at a party compared to at a community garden.

It's always awkward meeting new people, but at least here there's something to do. Like you're not just standing around. Sometimes in a party, it's more awkward 'cause you're put in a space to socialise, whereas here, you've kind of got something to do and then you end up talking anyway. (Violet, Marville)

Violet talks about how "awkward" it can be to strike up conversations with unknown people. Initiating conversation is a by-product of the shared interest and activity of gardening, which makes creating social connections easier. Similarly, in Hagenlund Library Garden, Conversation is more authentic in the community garden because there is a purpose for initiating a conversation.

So these cultural meetings where you try to make people meet because then you have made a cultural meeting - it's uphill. This is better. People can see why they should participate. (Yvonne, Hagenlund)

Violet's (Marville) and Yvonne's (Hagenlund) comments, from two distinctively different types of community gardens, illustrate that having an activity to participate together on makes initiating conversation with strangers easier. Alvesson and Sandberg (2013, p.58) draw attention to "implicit assumptions" which researchers sometimes make in research. In the case of third place research, Oldenburg (1999) makes an assumption that people (strangers) will strike up a conversation in a third place. The examples above from Violet and Yvonne illustrate how third places which provide a purpose to interactions, for example, a community garden, are able to provide a more authentic reason to interact with unfamiliar people in the neighbourhood. This makes community gardens more inclusive and effective third places. 
Community gardens are third places 'with a communal purpose', namely a broad common interest (gardening) in a public place. This is particularly relevant in community gardens, as the regulars and show newcomers the ropes and chat about the organisation or more generally about the garden. The regulars in community gardens need not be members, as demonstrated at several of the gardens, as they can include organisers, plot holders, visitors and neighbours. All of the case study community gardens provide examples of helping new residents to be introduced into the neighbourhood through conversations and common activity in a relaxing environment. Gardening provides a common reason to initiate a conversation as people share information, cooperate on activities or chat with non-members about the garden.

Almost everyone interviewed at the case study community gardens noted conversations with other members, in exchanging knowledge and garden produce, sharing tools, noting the weather, or general non-gardening topics. The sharing of knowledge extends to the network of people who follow the garden on social media. This echoes Draper and Freedman's (2010) findings that the collective nature of community gardens lead to meaningful social interactions. Meaningful social interactions on a regular basis lead to the development of social capital through creation of weak ties of association and strong ties of friendship or team bonding. Community gardens promote conversation beyond the garden, including with locals who are not involved with it, therefore this reinforces the conclusion that community gardens can act as third places. A Leanne at Kookaburra Community Garden member noted how the members "share knowledge" and that the garden "generates a lot of discussion in the wider community."

Conversation is a main activity at the Pine Park community garden, both between members, with visitors and outside the garden, where the garden can be a topic of conversation. As discussed earlier, Claire at Pine Park talked about the people who walk through the garden and ask her about it. Not all of them join the membership, but they like talking about the garden.

Community gardens provide an authentic purpose for initiating conversations on broad topics including weather, plants and local activities. The communal purpose of community gardening opens opportunities for social capital development. Gardening in a community setting acts as a third place and adds value to the third place notion, as the 
garden and the act of gardening provides a common reason to initiate a conversation, facilitated by regulars.

\section{Regulars/characters}

The third place characteristic of 'regulars' describe the locals who play a role of bringing together new residents and locals. Jane Jacobs (1961, p. 8) referred to neighbourhood regulars as 'public characters'. The regulars play a role in helping newcomers to feel part of the neighbourhood by introducing them to the place and the people. At each garden, most members would note a particular person or people who fit the role of the 'regular'. For example at Kookaburra Community Garden, Jane says that Daisy is a member who, "holds everybody together".

There is a core group of influential regulars in the Pine Park community garden who help to organize activities which introduce new or potential members to each other and bring members together.

We met people down here, but we tend not to meet them except here and we've had some social activities over the period. ... There have been activities over time in a rather random and organic way. (Claire, Pine Park)

In Hagenlund Library Garden, the librarians act as the core group of influential regulars. Yvonne said that the children from the school and kindergarten are also regulars, who through their association, introduce the adults to the library where they have the opportunity to find out about the library community garden. The combination of the library and community garden seems powerful in creating an engaging third place.

The garden - one family can have 2 boxes. The youth club has a handful of boxes, the local school has some boxes and the kindergarten has some boxes as well. The library pays for the seeds and seedlings. ...Also the cg here is a way to reach out and engage a little bit more with the adults who live in this area and be more attractive to them. (Yvonne, Hagenlund)

Similarly at Marville, participation is broadened through inclusion of community groups such as the parents group which meets every Wednesday and includes members and nonmembers. Coleman (1988) gives examples of how voluntary organisations increase the social capital of the area to which it serves, not just to the members. He notes that where 
people are linked through more than one form of social capital, the available social capital increases.

The regulars or characters in third places play a vital role in introducing newcomers to a place (Oldenburg, 1999). Kat, at Frank Street garden, cautioned that as a close group of friends, this may make it seem difficult for new people to join in, as:

"Probably not as easy, probably because anytime you go in when people know each other, it might be a little bit awkward" (Kat, Frank Street)

However, this kind of seemingly socially closed grouping of friends is not necessarily a barrier to introducing new people. At the same garden, while interviewing participants in the community gardens, observations were made of interactions where people were introduced to each other (which are only reproducible where ethics permission covered both participants incidentally caught on the recording). For example, the brief introduction on a working bee day at Frank Street Community Garden while interviewing Emma, who pauses to greet a newcomer:

Emma: $\quad H i$.

New person: Hi. I'm Cathy.

Emma: $\quad$ Oh, Hi, Cathy. Emma.

New person: Hi, Emma. Nice to meet you.

Emma: $\quad H a v e$ you been here before, or you know April?

New person: No. But I know April. Yeah.

April: $\quad$ Nice to see you, Cathy.

This is an example of an exchange between a member (Emma) welcoming a new person to the group. The new person had been invited by the committee member, April. It is an unremarkable exchange with implications for the research question: Do third places that have a communal purpose (i.e. community gardening) open opportunities for social capital development? This is an example of forming connections among individuals in the neighbourhood - a process of creating social capital. As Emma noted:

When I started ...I only knew one and not the others and then I gradually got to know other people. (Emma, Frank Street) 
Therefore, Emma had only known one person when she started and the new member also only knew one person, so April acted as the regular who brought in Cathy.

Similarly, at Frank Street Community Garden, Albert was another volunteer, who was meeting members for the first time.

(Work at the garden) average two or three times a week. Because I live nearby...quite often this is the time that I have got something on, but today I've got nothing on so this is the first time that I've met most of the people here. (The members) seem friendly. (Albert, Frank Street)

Emma and Albert illustrate the social network of people expanding at Frank Street Community Garden. Without the community garden, they may not have got to know any of the people they met that day in their local community garden. The people they met will now be familiar faces in the neighbourhood, as described by Oldenburg (1999). Weak ties of association form and the garden gives them an opportunity for these ties to strengthen through cooperative work and social interactions. These small exchanges are capturing the first stage of creating social capital, which will be discussed further in the 'weak ties' section.

Emin at Bluevale City Garden discussed his role in relation to being a paid employee, therefore a regular at the garden. Emin oversees the farm management including bringing together, members, volunteers and the Work Experience Program (WEX) participants.

A lot of volunteers might be here to socialise with other people and that's a really big motivation, whereas us employees, even though we want to be socialised as much as we can, so that's building rapport and building relationship. The reality is we are paid to do a certain job and that's not to socialise all the time. (Emin, Bluevale)

Emin's time socialising in the garden is limited by his duties, but he includes 'building rapport' between participants as part of his role as a paid employee of the garden. As noted in Chapter 3, Bluevale is an interest-based community garden which attracts members from great distances, even beyond the city edges. When asked about the allotment holders at Bluevale City Garden, Martin, a local and regular volunteer, indicated that many allotment holders are not local and that although he spends a good deal of time at the garden, yet he rarely meets them. 
I occasionally meet people there and say hello to them. I don't normally-they're busy. They're there to look after their plot and I have chatted to a couple of them but haven't got to know them well enough to even know their names. So, they come and go. Some days they might be there. They might come to the market and go to the plot. (Martin, Bluevale)

Emin also noted that he rarely sees the allotment holders as they are arriving as he leaves. This fits with Oldenburg's assertion that third places are situated within walking distance of the people's homes. Despite making seven research visits to the garden at different times of day, none of these times coincided with any allotment holders, so it is not possible to comment on their social capital opportunities, however, much about the Bluevale garden was third place-like and the purpose of gardening to grow food brought a diverse group of people together, forging the opportunity for creating and strengthening social capital. The data has shown that inclusivity across age, socio-economic status, cultural background, disability and gender featured in the case study community gardens. Introduction to place is taken into consideration in the next section.

\section{Growing social capital in community gardens}

Having established that the case study community gardens, on the whole, are inclusive third places which generate social capital across a diverse population, this section will discuss the social capital definition as applied to the case studies, namely connections, social networks and norms of reciprocity and trustworthiness. It will also refer back to the distinction between creating and strengthening social capital.

Community gardens which are third places offer opportunities for conversations within and outside the garden membership thereby assisting in introducing new people to the neighbourhood. Using Granovetter's (1983) theory of weak ties, the case study community gardens exhibit instances of the loose ties between acquaintances and people who socialise together occasionally. Community gardens can act as third places, open to the public and situated in a walkable location within a neighbourhood, offering opportunities to increase the number of weak ties of association throughout the neighbourhood. Their advantage of being a third place is that community gardens provide an authentic purpose for people to interact and initiate conversations on broad topics of 
local common interest (weather, plants and activities). The plants and activities in them are points of interest and conversation starters - an important characteristic of third places.

For example, at the Marville community garden, it seemed like gardeners underestimated their impact on the neighbourhood elderly, who did not join the garden, but they interacted meaningfully through sharing the produce; having over the fence chats; and offering plants and cuttings. The mere act of a wave of neighbours and gardeners can increase social interaction and sense of community. Planners and architects can design public places which promote third place interactions, however, the strength of community gardens is that the community itself usually designs, creates and maintains them.

As demonstrated in the 'regulars' section, certain community garden members act as regulars who introduce new people to the garden and to each other. Both Emma and Cathy had only known one person when they joined, the garden organiser, April. However, in the exchange, Emma played the role as a regular and introduced herself to Cathy, thereby increasing the size of the social network. As described by Grant at Frank Street, developing those social connections strengthens the community.

I think it's continuing and developing their connection with the other people in community is my reading of it. I think that's mostly what it's about - strengthening community connections and people who are interested in knowing other people in the community. (Grant, Frank Street)

Gardening in a community setting provides a purpose to initiate a conversation, which in turn is the mechanism for creating a sense of community for new and existing residents. They can act to strengthen the social capital of the community. Social capital is about relationships that facilitate trust, and the case study sites show examples of trusting relationships are being created and developed. Community garden interactions in some cases develop the weak ties of association to strong ties of friendship. As described by Jane at Kookaburra:

It's interesting when you come to a new place, it takes a little while, but you come do something with like-minded people and suddenly you have friends. (Jane, Kookaburra) 
Jane's statement illustrates how the garden connects people with a similar mindset and the act of doing something with them facilitates a strong connection of friendship. Community gardening adds the 'communal purpose' to third places, making them effective at delivering social benefits such as friendship to local urban communities. Effective third places have implications for people's sense of place, their feelings of safety and their happiness and wellbeing. As Chitov (2006, p. 454) noted, "bridging social capital is reinforced by the regulars and characters" in community gardens. The Kookaburra Community Garden members exhibited some bonding capital aspects of club rather bridging capital or weak ties than third place-like, with gardeners experiencing a sense of community based on common interests which bring them together (Day, 2006; Delanty, 2010). This element of club-like similarity of interest between members was also in evidence at Frank Street community garden.

I think they're all friendly, community-minded, environmental, family oriented and-yeah-positive. Yeah. Like the outdoors, nature-loving. (Emma, Frank Street)

Community gardens offer an opportunity for the neighbourhood to work together in formal and informal (third place) manner. The Frank Street community garden also noted that most members were young families who also knew each other through their children going to the same school, which creates bridging ties which link people across groups and connects people to others who have different backgrounds and interests (Edwards, 2004). The social network is strengthened among many of the Frank Street members where they know each other from the community garden and the local primary school. Emma describes how she introduced many of her neighbours/friends to the community garden, hence socialises with them, but the multiple connections bring more interactions.

They're my good friends, they're our neighbours, and I invited them here, so does that make sense? So I do [activities], but not because of the garden.... I do more things with [April], but then we would anyway through school, so multiple connections. (Emma, Frank Street)

This is the case with several members at Frank Street who mention that they spend social time together beyond the garden or school. Where people are linked through more than one source of social capital, the available social capital increases. 
Social media extends the network of the community beyond physical confines of the community garden. Williams and Kim (2019) discuss ways that the internet can provide third places, where the physical community is augmented by the virtual world. This is in evidence at Marville where Brenda talks about the use of Facebook to generate interest in the garden.

There's been a post, there's comments and likes and stuff, which is really good. We put up a-that poster over there that has the Facebook thing on it, and as soon as that went up, the likes and stuff on Facebook just spiked, so I think people definitely want to interact and Facebook is definitely a good way of doing that. (Brenda, Marville)

Through Facebook, people can engage with the community garden community and Brenda detects that people beyond the known membership also 'want to interact'. It is difficult to determine the social capital value of the 'likes' on the garden's Facebook page, but it shows a level of engagement with the wider community and interest in the garden's progress. The Facebook pages inform members and the public about events at the community garden and connections to events run by other community groups. Social media can act as a resource building the resilience of the neighbourhood in times of crisis by connecting diverse groups of people and increasing social connectedness (Aldrich, 2012).

Cooperation in the community garden can build trust in the relationships between community members and this strengthens the social capital of the group. This is in evidence at Marville Community Garden, where local people who didn't know each before the garden idea took off, talked about how they had to work together to get access to the land, to design the garden and then to learn how to garden and get grants. Violet at Marville describes how they were all "learning together" about how to garden and get grants. She said: “...we're all just figuring it out together”.

Coleman (1988) found that trustworthiness is an underlying strength of social capital ties. Social capital is not a tangible entity, "for it exists in the relations among persons" (Coleman, 1988, p. 101). Community gardens can facilitate stronger bridging ties. 
I think that sense of community. Yeah. We've got a very nice strong community. We like to hang out together. (Kat, Frank Street)

Spierings et al. (2018) describe how the act of gardening and creating the community garden created social inclusion between different groups of users, with a temptation to exclude non-gardeners or those who did not hold a plot. This example is not reminiscent of a third place and exclusionary practices are not in evidence at the case study gardens. Kookaburra, with its high fences for security, may at face value be interpreted as exclusionary rather than third place-like, however, as noted earlier, the fences provided assurance of safety to their female gardeners when attending alone. At Kookaburra no personal characteristic excluded anyone from joining this garden, even if they did not want to garden.

The regular interactions between community gardeners and the local visitors creates opportunities for trust to develop beyond the garden boundaries. Harriet talks about the need to develop trust between the gardeners and the community.

It is an open garden. We don't lock it. We have to trust the community to respect our space. We have to work too to make that respect too. We don't get a lot of produce. $<$ laughs $>$ (Harriet, Pine Park)

Harriet views trust as a two-way interaction and jokes that they 'don't get a lot of produce, indicating that the trust is perhaps a little one-sided at that point in time. However, strong trust developed between some of the gardeners. There is evidence that the weak ties of association which formed in the Pine Park community garden built to strong ties for some garden members. A member discovered the Pine Park community garden by walking past it nine years ago and didn't know anyone when she joined. When asked if she had developed friendships through the garden she noted:

Yes I do now. Sally teaches a yoga class. I go to that. Me, Matthew and another gardener, we volunteer at the local school and help them get their garden going and the pre-school. Sometimes some of us get together for a meal. Francine, an older lady, we've been to each other's houses for a cuppa or a meal or to check up on each other. Yeah sometimes we'll all have a meal together and we just look out for each other. Francine is getting a bit frail lately, so there is a sense of caring for each other. (Barbara, Pine Park) 
Barbara demonstrates that the bonds developed between members at the garden can continue past their involvement where they will continue to 'check up on each other'. Similarly at Bluevale, Emin talked about strong ties which developed with a couple of members.

A couple of people. I mean one of my colleagues I actually live with and actually we're going to be living in a granny flat that's owned by one of the founders of this place as well. (Emin, Bluevale)

Third places allow locals and newcomers to informally meet people in their neighbourhood, for example, at the Kookaburra Community Garden:

There are a lot of people in units and flats around here and they just enjoy being part of a community where they can meet people and so on. (Janet, Kookaburra)

The community gardens show evidence of weak and strong ties of association amongst members and weak ties developing beyond the boundaries into the broader neighbourhood. At Hagenlund Library Garden, the garden box holders have opportunities to develop weak ties and for those ties to grow into stronger ties as the gardeners get to know each other. The gardeners start to help each other with acts of reciprocity.

Then they get to know each other. Then they help each other a little bit - 'I'm going on holidays these weeks can you water my boxes for me?' (Yvonne, Hagenlund)

These small acts of starting to help each other are potential social capital resources which contribute to neighbourhood resilience. In this linguistically diverse community, the act of cooperative gardening potentially broadens the third place characteristic of conversation to interacting beyond language barriers.

At Hagenlund community garden there was talk of the difference between doing something for yourself or your own people and doing something to benefit the community. When asked about the difference between being involved in a Danish allotment $^{14}$ and a community garden, Yvonne explained:

\footnotetext{
${ }^{14}$ Danish garden allotment associations (kolonihaveforeninger in Danish) are organisations that rent out plots of land, typically near cities and with cabins that can be inhabited during the summer months.
} 
The community can come in so many different shapes and forms and is more about the community. I think that is the focus and the main reason why you engage in the community garden, whereas having an allotment garden like we do is more for our own benefit. Like that's where we relax and invite our friends and family. But here it is not yours. You are together doing this. (Yvonne, Hagenlund)

The design of the garden and the regularity of members attending the garden effect their third place-ness. Unlike a club, third place community gardens are a space in which locals are free to enter and browse. They also reach out into the neighbourhood, as noted in the Pine Park garden, where people not involved with gardening have pride in the knowledge of it and talk to the gardeners. Third place community gardens connect individuals in a neighbourhood and build social networks. Small interactions centred in or about the community garden lead to people starting to recognise each other and feel a part of the neighbourhood, as per Putnam's (2000, p.19) definition of social capital, about the "connections among individuals - social networks". Opportunities to work together cooperatively strengthen the weak ties into strong ties.

Mandy is kind of getting on some grants, and we're getting some training and all of that sort of stuff. So, I feel like it's a really nice learning together, whereas maybe if there had been experts already within the group - and maybe there are, but they're just not kind of making themselves super felt yet, but-yeah. Ifeel like if there had been experts already, then maybe their voices would've got to the top, whereas seems a little bit more like we're all just figuring it out together. (Violet, Marville)

Cooperative work and learning together such as described by Violet has the potential to build bridging capital into bonding capital. The team working skills are a useful resource for improving neighbourhood resilience.

\section{Third place model and social capital generation}

In Chapter 4, Figure 4.1 modelled how a community garden could be simultaneously a club/community organisation and a third place, with differing roles and levels of commitment for members, volunteers, visitors and locals. Figure 6.2 below, takes this idea further to illustrate the types of social capital likely to be formed depending on level of involvement in the community garden. A community organisation or club has 
organisational requirements and necessitates a number of members attending regularly. This regular attendance and opportunities to work cooperatively together can lead to the development of bonding capital or strong ties between members. As the community garden is not exclusive in its membership, it can still act as a third place for members. The third place interactions are in the middle ring on Figure 6.2 and can include less formal incidental interactions with people in the neighbourhood, leading to bridging capital. Social capital is created in the community garden at the interaction zone of the formal aspects of the community organisation and the third place and is strengthened in the core of activities of the garden. The community engagement is made more impactful through linking capital, which is formed by combining with other community groups and facilities such as the youth group and kindergarten, drawing wide participation across age groups.

Figure 6.2 Community garden third place model - Situating social capital

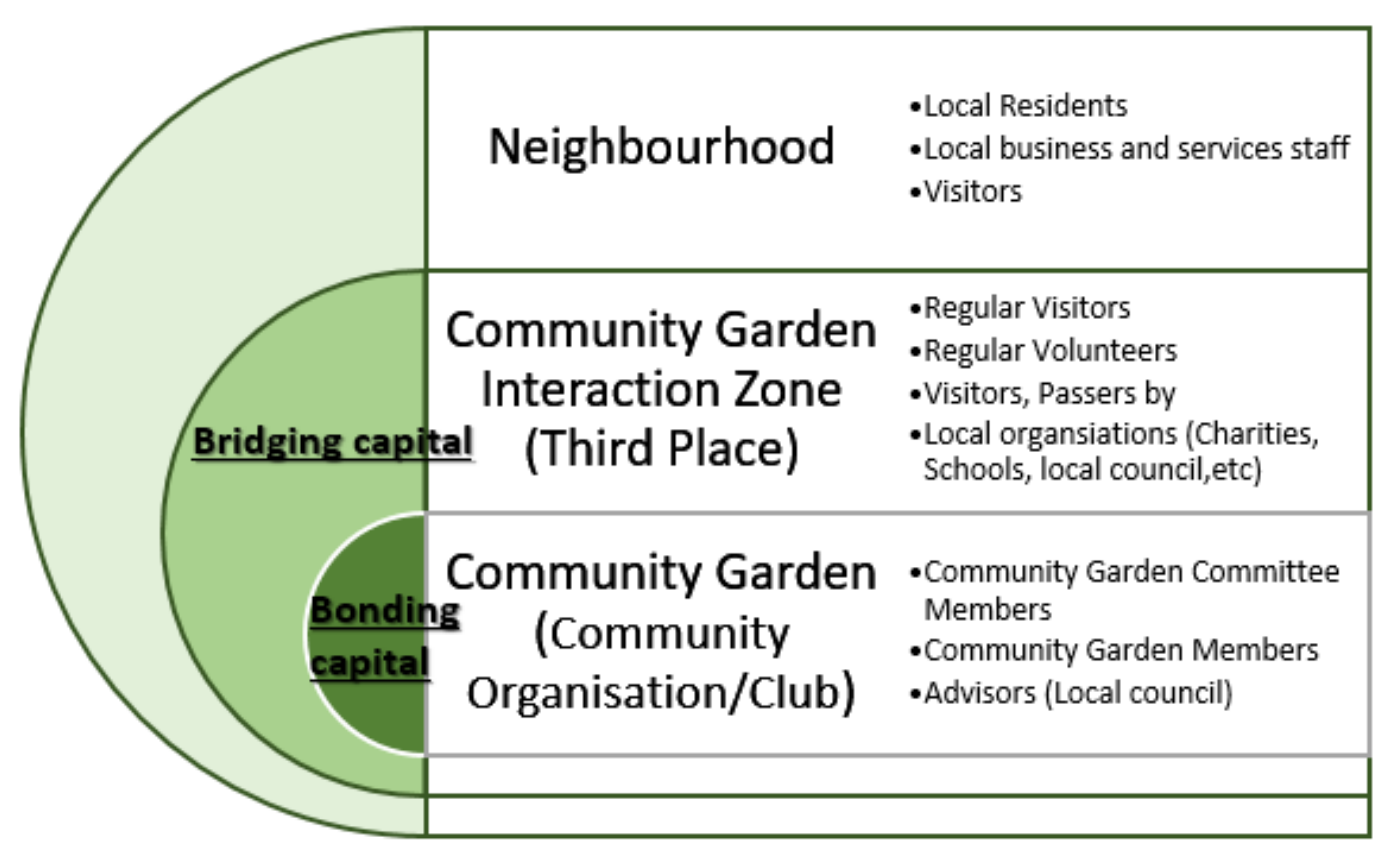

The case study community gardens are all inclusive across age groups, ethnicity, disability and socio-economic status. While some of the gardens hope to attract greater diversity, there is no current obvious barriers to participation. Each member in each garden may sit in a different place on the diagram. Level of involvement in a community garden can vary from person to person and over time as interest or time commitments fluctuate. One could be a regular who is highly involved as a member or without 
necessarily being a member of a community garden. This was the case with some of the Frank Street and Marville regulars as neither garden had individual plots, of which membership was a criteria for access to in the other gardens. At Bluevale it was possible to be a member (criteria for having an allotment) but not very involved or regular at attending.

As Putnam (2000) was concerned about USA citizens privatising their leisure spending more time at home and less time in public together, Klinenburg points out, with internet $\mathrm{TV}$, even within the home, the family may be in separate rooms watching their own preferred entertainment. "The social and physical environment shapes our behaviour" and can alter the way people behave without us recognising the impact (Klinenburg, 2018, p. 13). Demise of public places such as libraries and bookstores, is reducing the number of third places where a diversity of people can interact. Where public space is available, community gardens may prove to be relatively inexpensive citizen initiated facilities for public participation that benefits the neighbourhood.

\section{Conclusion}

The third place characteristics form a useful framework for investigating community gardens and how they contribute to community by building social capital through creating and strengthening the social connections between people involved in, visiting, or neighbouring the community gardens. The rise in numbers of community gardens (enumerated in Chapter 2) is evidence of a growth in new forms of civic engagement public cooperation. In particular this chapter has described the four third place characteristics of neutral, leveller, regular and conversation, which contribute to creating and strengthening social capital in community gardens. The research illustrates the benefits of third place community gardens. Third place community gardens facilitate the creation of social capital through welcoming newcomers including international immigrants to the community; reducing loneliness; and breaking down the self-selecting social interactions. Community gardens can act as third places improving neighbourhood social capital in two ways. Firstly, community gardens promote creation of weak ties (bridging capital). The third place community gardens are visited by passers-by who stop to chat, or in the case of the Pine Park garden, are a point of conversation at other venues such as the local coffee shop and pub. Secondly, for members, they also act somewhat like clubs, where strong ties of friendship are built (bonding capital). 
Resilience is demonstrated through community garden members pulling together to face challenges such as floods, council charges and access to the land. The community garden becomes a hub of resilience, drawing in other local people to help rescue chickens (Bluevale); or in discussion at fund raising sausage sizzles (Kookaburra); or through being lobbied to change council rules (Kookaburra); or provide access to unused land (Marville).

Third places and community gardens share many of the same characteristics. Effective third places strengthen the social capital of the community by increasing the number of weak ties and offering opportunities for those weak ties to develop, via socialising and cooperative work, into stronger ties of friendship. Community garden designers and advisors would benefit by incorporating the characteristics of third places into the design and placement of community gardens. Likewise, given the health and wellbeing benefits of community gardens through access to fresh food, physical activity and social interactions, it would make sense for local authorities to support community gardens and their members. 


\section{CHAPTER 7 - DISCUSSION AND CONCLUSION}

This thesis developed and applied a framework of the eight characteristics of 'third place' to data collected in six case study community gardens in Australia (the Gold Coast, Sydney and Brisbane) and Denmark. It concluded that these case studies exhibited all or most of these characteristics. The concept of third place has proven to be ideal in its application to community gardens because of its ability to link research on place to research on social connections. There are numerous potential benefits from the resulting placemaking and social capital development including: reducing social isolation, increasing social and cultural inclusivity; building neighbourhood resilience; and addressing the UN Goal 11.7.

This thesis provides compelling arguments for the benefits of community gardens which act as third places. Community gardens compete with other interests for limited public space and in some cases there are concerns that community gardens can be sites of gentrification by the middle classes moving into neighbourhoods (van Holstein, 2019). The research findings of this thesis help to inform these types of debates, particularly where community gardens are situated on contested land.

This thesis has shown that community gardens can be informal public places that act as a third place where people can gather, socialise and interact with others in their neighbourhood. Until now, this assertion had not been critically investigated. The findings provide a breadth of understanding on how community gardens can function as third places which are inclusive and which present opportunities for the residents of a neighbourhood to experience purposeful interactions both within and beyond the garden boundaries.

The goal of this concluding chapter is to draw together the literature and the findings from the thesis chapters in order to answer the research questions posed and discuss the implications of their placemaking role and the social capital development of third place community gardens. The chapter is structured around the three research questions to critically reflect on the third place concept and summarise the contribution to the community garden, placemaking and social capital research. It concludes with suggestions for future research. 


\section{Findings Summary}

\section{Question 1: To what extent are community gardens third places?}

One of the aims of this research was to address a gap in the third place and the community garden research by providing a definitive response to the question: To what extent are community gardens third places? While six case study sites may not be generalizable to every community garden, it is possible to answer this question. Community gardens which are open to the public and situated in the local community that they serve, can exhibit most, if not all the qualities and characteristics of third places. All of the case study sites were third places to varying degrees according to the systematic analysis of their key characteristics. Pine Park (Sydney), Marville (inner Brisbane), Frank Street (suburban Brisbane) and Hagenlund (Denmark) exhibit all of the third place characteristics in the local neighbourhood. Their openness and close proximity to the users (gardeners and non-gardeners) resulted in vitality and a variety of uses of the gardens. Although Marville does not have individual growing plots, the garden functions as a communal food growing site which is park-like, thereby responding to the needs of the local community which otherwise lacks open public space. Frank Street also exhibited all of the third place characteristics. Members report that they struggle to attract new members or diversity of participation. They have not yet responded to the community's preference for individual growing plots as indicated by the group's survey of neighbours. However, it may be the garden's proximity affecting its third place qualities as it competes with ample park space and, other than a bike path, it is not well connected to the surrounding suburb.

As Jane Jacob (1961) points out, a vibrant place is one which is woven into the fabric of the urban environment, not one which is placed out of the way. Hagenlund Library garden (Denmark) is a third place during the growing season and links well with another known third place - the library. It is a good example of a garden that is supported by the landowner and facilitated by the librarians and is an excellent example of third place inclusivity across participants' cultural and language backgrounds. Bluevale City Garden (Brisbane) is a third place across all characteristics to those who live close by. Being a larger community garden it acts as a resource of training, ideas and knowledge exchange for other community gardens, while simultaneously being a third place to the locals (who live within walking distance). The disadvantage of the larger site is that there is only fleeting interaction with many of the visitors. This fatigues some regulars, one of whom 
made the interactions sound like being a tour operator repeating the same facts to people who may not stay and become involved in the community garden.

This thesis has made a number of discoveries in relation to the concept of third place and its application. On a practical matter, the characteristic of 'accessible and accommodating' needs to be separated as stand-alone characteristics. "Accessible" is about location and "accommodating" is about timing. Accessible refers to the ease of access so that nothing hinders locals from a casual attendance. For this thesis, Oldenburg's ideal of a walkable location was extended to include a local bike ride. For example, at Frank Street community garden some members rode bikes with their children to the gardens as it was situated in a large park with a bike path. This is an example of how third place characteristics can be adapted to suit the particular site, while retaining the original intent (which in this case is ease of access). There were a number of instances where accessibility was limited. For example, Kookaburra was the closest community garden to their homes, but was accessed by car for some members. The dominant car culture at the Gold Coast was a factor. Kookaburra was limited in the third place characteristic of neutral by having key entry, but it was inclusive by letting anyone apply for a key. Kookaburra was also inaccessible to the retirement village residents next door due to a steep incline between the two neighbouring properties. This example of the effect of the terrain illustrates that assessing a place for its third place qualities is site-specific. What may appear accessible on a map may be quite challenging in reality. Bluevale City Garden was not accessible by walking for numerous members as its popularity drew members, students and staff from further afield. This led to questioning the definition of local. When people are increasingly interconnected globally therefore may perceive citywide to be local.

In order to function according to local authority requirements, community gardens have at their centre a club-like structure with rules and commitments. This structure affects the 'neutral' characteristic of third place. However, the need for organisational structure has been compared in this thesis to Oldenburg's suggestion that commercial spaces, such as pubs and barber shops, can act as third places (1999). Despite governance through committees or in the case of Hagenlund, the librarians, community gardens can simultaneously act as a community organisation and a third place to the participants and to the broader community. Community gardens that are not third places still have important roles to play in supporting the community through formal training, 
sustainability initiatives, exercise, food production for hungry people, organic food, and food security amongst other benefits.

\section{UN Sustainability Goal 11.7}

Community gardens which are third places can contribute to achieving UN Sustainable Development Goal 11.7 to: "provide universal access to safe, inclusive and accessible, green and public spaces, in particular for women and children, older persons and persons with disabilities" (UN, 2015). The case studies were inclusive, accessible, nature-based public places embedded in the local community. They mirror the ideas of Jane Jacobs (1961) about people spending time in nature with each other in their neighbourhood. Children feature at all of the case study sites and retired people at most sites, whether as members or visitors. Provision at all of the gardens was made for people who may have some physical limitations. Similar numbers of males and females were observed at all of the sites, which was an advance on some of the gender segregated or problematic third places which Oldenburg suggested in the 1980s. Ways in which community gardens could be improved in order to achieve UNSDG 11.7 would be to provide enough space and shelter for non-members to enjoy informal relaxation in the garden, for example, the lady who reads the newspaper at Pine Park, or the teens who paint their nails at Marville. It is the combination of community garden and third place which makes them particularly inclusive for women and children, older persons and persons with disabilities.

There is a place and a time for third places and this relates to the characteristics of accessibility and accommodating. There is often scant choice as to where to situate a community garden as there is limited available green space and this is often contested space - competing to be a cricket pitch, a football field, new housing, etc. The locals generally work with what they are allowed to have and what is left post-objections. Marville was an example of an unused piece of land left over from a freeway subdivision. Everyone interviewed at Marville had their eye on this patch of abandoned, overgrown land and a plan for turning it into a garden of some sort. Residents lobbied for two years to gain permission to use it for a community garden. Another example of creative use of 'left over' land is the Bluevale City Garden located on City Council land which is frequently subject to flooding. 


\section{Resilience and adaptive capacity}

Developing social capital in a neighbourhood has an impact when a critical mass of residents know how to work together to access resources and solve problems. This benefits the neighbourhood when they are called to respond to sudden or gradual changes in local environmental, economic or social conditions. Working together and socialising in a community garden, has the effect of strengthening the social capital of the group through repeated interaction and cooperation. People who have worked together on a citizen-initiated local project, such as a community garden, are in all likelihood people who know how to organise themselves and therefore they have the skills and social capital to be more resilient in the face of an adverse impact in their neighbourhood. They have potential to be able to help themselves at times when help might not be on its way. As Black and Hughes (2001) observe, a resilient community is effective at responding to adverse disturbances. For example, Kookaburra Park members were able to coordinate to secure resources through fund raising when their water fees increased. The case studies presented examples of their adaptive capacities which enable them to recover from negative impacts (Norris et al., 2008). The definition of resilience may be to bounce back to its former state, but a neighbourhood may not want to bounce back to exactly what they had before. They may prefer to transform. For example, Bluevale City Garden raised their administration building in response to repeated flooding and raised the chickens off the ground in response to contaminated land. Rigidity can leave a group vulnerable to repeated changes. By being third places, the number of local people who have informal ties with the community gardeners is increased, as are the connections between different community groups.

\section{Reduced social isolation}

When community gardens act as third places in the neighbourhood, they help to reduce social isolation by connecting people and creating a sense of community. Several participants liked the community feel which they and their children experienced in their local community garden, where members worked alongside one another, shared the work and the produce, and the occasional self-congratulatory celebration. They added photos to the website and Facebook page. Many participants expressed a sense of nostalgia for real (or imagined) sense of community of the past and felt that the community garden was a place to regain this community connection. Such nostalgia is similar to that expressed 
by Oldenburg (1999) in his argument for the valuable role of third places in communities. As Putnam (2000) and others argue, modern urban society may be isolating as people's leisure has been increasingly privatised within the home. Urban designers can skilfully create public spaces which appear authentic, however public places need to be activated and frequented by the people if they are to work as vibrant and successful third places. The case studies presented in this thesis illustrates authentic people-led places which have potential to improve a sense of community and sense of place in a local neighbourhood.

Question 2: If a community garden is a third place, does it play a role in placemaking?

Community gardens are the result of a collaborative act of making a public space into a public place that the participants can identify with and feel connected to and that the wider neighbourhood can feel some local pride and interest in. Placemaking is enhanced in community gardens through connecting people to nature in their local neighbourhood. All six case studies enhanced the placemaking connections for local residents to both the community (people) and the garden (place). Four of the eight third place characteristics related primarily, though not exclusively, to placemaking, namely: easy to access and accommodating; the mood is playful; low profile; and homes away from home.

The definition of placemaking was developed in this thesis to suit discussion on community gardens which are third places. It draws from the definitions discussed in the placemaking chapter (5) (Caromona, 2014; Cresswell, 2004; Friedmann, 2010; Placemaking Chicago, 2008; Project for Public Places, 2007; Schneekloth \& Shibley, 1995; Soja, 1996). The placemaking definition used for this thesis is:

\section{Placemaking is a dynamic act of people collaboratively transforming public space into public places that increase the social life and sense of belonging to a local area.}

This definition accounts for the dynamic nature of creating and maintaining community gardens as third places. The placemaking aspect is that they are citizen-initiated and as such, are dynamic places which have potential to be responsive to the specific needs and physical and social preferences of the neighbourhood over time. Community gardens are dynamic places in part by their nature of being associated with seasons and in part by being flexible to redevelopment as directed by the current governance to suit the people 
and the site. Infrastructure may stay the same, but the composition of the neighbourhood changes with population mobility, gentrification and redevelopment amongst other changes. Changeable environmental and economic conditions also require resilience on the part of the neighbourhood.

In discussing place, it is difficult to ignore the role of virtual space. In his original book, Oldenburg (1999) insisted that third places are face-to-face only, though he did note some role for the telephone in the case of isolated housewives. The role of relatively new forms of social media cannot be discounted in the activeness and reach of third places. All of the Australian case study community gardens had Facebook pages that: served to inform potential members of how to join and who to contact; inform members of upcoming gatherings; and share news of harvests and events. Such resources also provide a connection to that particular place and people for those who may have had to move away from the garden. Social media can act as an anchor to a place for people who move out of a neighbourhood.

Community gardens can cater for differing levels of participation and are able to act as a third place by drawing in a larger number of community members and offering the opportunity for placemaking. For example, at the low involvement end of the scale, there are locals who visit the community garden but do not want to join, such as the Sydney social housing local who collected grass for her rabbit, or the Brisbane elderly local who offered plants to the local community garden. Such simple acts are placemaking as they connect people to the place. For many participants, the garden was about giving their children experiences such as unstructured time in the outdoors, teaching them about the origins of food, and connecting to people in the neighbourhood. For some it was about connecting to the land, particularly for those people who resided in high-rise apartments or townhouses without access to land. Numerous participants had come from elsewhere, be that overseas, interstate, or migrating from the country to the city. The act of growing food connected them to the place through experiencing the weather and seasons and meeting the people who live there.

Question 3: Do third places which have a communal purpose (i.e. community gardening) open opportunities for social capital development?

One major contribution of this research is to show how the characteristics of third place can be applied as a framework to assess, create and improve the inclusivity and social 
capital building opportunities of public spaces. This thesis illustrated how the goals or motivations of third place community gardens reach out beyond the garden membership to people in the neighbourhood because the garden is interconnected to the local community. The third place aspect occurs onsite, over the fence, or offsite through charity work, fund raisers, networking events and by being a topic of conversation outside the garden.

In using the idea of third place with a communal purpose, it is acknowledged that Oldenburg envisaged third places to be without purpose. They differed from a club which may be exclusively about one goal or activity. However Oldenburg also described that third places which have a joint activity such as a game which can be shared, are more effective at getting the conversations going and providing a lively atmosphere. The community garden can act as a third place with a communal purpose in that the members have a purpose of growing food plants, but neighbourhood visitors do not need to be involved in order to benefit from the garden surroundings. The garden provides conversation starters for both active and passive involvement in the place. There were numerous personal motivations for being community gardeners, but in common was an enjoyment of the social aspect. Examples have been provided of the ways in which social interaction is strengthened to helping each other, looking out for each other, sharing and friendship.

While many respondents indicated that they initially joined a community garden to grow food, they noted that they grew to appreciate the social aspects. For many it led to a sense of community that they developed with fellow gardeners and local residents. The third place aspect of the community gardens cropped up in sometimes unexpected ways, such as: the interchange with a neighbour about feeding grass to the pet rabbit; the plot of Vietnamese mint leading to a night out for all; or the garden being a topic of conversation in the local pub.

Four of the eight third place characteristics relate dominantly, though not exclusively, to social capital building. The third place characteristics, "neutral ground" and "levellers" are grouped in discussion about inclusivity. The characteristics "conversation" and "regulars" are grouped in discussion about relating to people and place.

As already stated, Putnam's (2000, p. 19) definition of social capital applied in this thesis is: 


\section{"Social capital refers to connections among individuals - social networks and the norms of reciprocity and trustworthiness that arise from them."}

Social capital is an important indicator of the social wellbeing of individuals and the community (ABS, 2015). Community gardeners and people who visit the gardens as a third place may be fulfilling a desire for a sense of "community", as was discussed by many of the participants and several sought the opportunity for their children to learn a sense of community as well. "Love and belonging" is a human need which can be met in part in one's own neighbourhood (Maslow, 1943). In seeking out friendship and belonging to a group, community gardeners get to: know people in the neighbourhood; share resources and produce; learn together; feel a part of a community; and/or combat loneliness (Pascoe \& Howes, 2017). Linking groups of people increases social capital and access to resources.

Commenting on Oldenburg's (1999) belief that strangers will strike up a conversation in a third place, it was demonstrated that some of the research participants normally did not like striking up conversations with strangers. However, they found the purpose of gardening was an excellent conversation starter. While Oldenburg says an activity is helpful, this thesis argues that having a communal purpose which leads to shared activities substantially enhances the effectiveness of introductions in third places. In addition, unlike Oldenburg's idea of meeting new people in local bars, the purpose of gardening negated any confusion of intention in relation to striking up conversations with strangers. Gardening provides a common reason or purpose to initiate a conversation where people share information and participate in activities together or chat with non-members about the garden. Gardening in a community setting adds value to the third place notion, as gardening provides a purpose to initiate a conversation, which in turn is the mechanism for introducing new people and creating a sense of community for new and existing residents.

\section{Inclusivity of community gardens}

The case study community gardens when acting as a third place were found to be inclusive, particularly across ages and genders and socio-economic groups and users abilities. However, it should be noted that not all sites were equally successful in 
attracting people of different ethnic backgrounds. Reference to being "white middle class Australian" was made at two gardens (Marville and Pine Park), however in Pine Park a diversity of accents was observed. This point illustrates how important it is to triangulate multiple sources of data in order to differentiate facts from participant perception. As Marville had not been established for long, the lack of involvement from across the diversity of the entire neighbourhood may have come with time and the groups planned initiatives. It is important to note the context of the site when relaying findings, in this case that the community garden was still being established. There were success stories for ethnic inclusivity as well such as the example of the library community garden which brought together participants across a number of language groups, achieving the previously unachievable goal of the library to bring together immigrants and native residents across a number of language groups to meet in a meaningful way.

\section{Introducing people to the place}

The regulars play a role in creating social capital by introducing people to the place and to the other people and this is usually done through the medium of conversation. The activity of gardening enhances the community garden's third place characteristic of 'conversation'. Involvement of 'regulars' aid in the introduction of newcomers to the neighbourhood, which in turn builds a sense of place and sense of community. The third place strength of the Hagenlund library community garden was its ability to give a communal purpose to bringing together people of different backgrounds in the neighbourhood. Bridging capital was evident, for example, through people arranging to look after another's garden box if they went away. The third place characteristics form a useful framework for investigating community gardens and how they contribute to community by building social capital.

\section{Integrating placemaking, social capital in the third place framework}

Table 7.1 (below) integrates placemaking and social capital with each of the third place characteristics and applies this to provide an idea of how this would be made manifest in a community garden. The integrated placemaking and social capital column could be adapted to assess other public spaces. The integrated framework has potential to be adapted by local authorities as an indicator for tracking progress towards reaching UNSDG 11.7. 
Table 7.1 Integrating placemaking, social capital in the third place framework: The case of community gardens

\begin{tabular}{|c|c|c|c|}
\hline $\begin{array}{l}\text { Third Place Characteristic } \\
\text { (Defined by Oldenburg 1999) }\end{array}$ & Placemaking & Social Capital & $\begin{array}{l}\text { Integrated placemaking and social capital in a } \\
\text { community garden. }\end{array}$ \\
\hline $\begin{array}{l}\text { Accessible } \\
\text { (Location - easy to access) }\end{array}$ & $\begin{array}{l}\text { Located in walking distance or an easy } \\
\text { bicycle ride. Considered close to home. } \\
\text { Preferably located as integrated into the } \\
\text { neighbourhood - on the way from one } \\
\text { place to another. }\end{array}$ & $\begin{array}{l}\text { Bump into familiar faces due to easy access in the } \\
\text { neighbourhood, which provides opportunities for } \\
\text { developing weak ties (bridging capital). }\end{array}$ & $\begin{array}{l}\text { Vacant public land is often contested space, therefore may be small } \\
\text { or on marginal land including: pocket garden; a section of a park; } \\
\text { vacant block converted; co-located at an existing public venue } \\
\text { (library, school, church). Social capital and resilience may be put } \\
\text { into practice if the ownership is contested or if the site is subject to } \\
\text { flooding, etc. Community facilities useful to non-members also - } \\
\text { shaded seating, community composting, giveaway boxes of } \\
\text { produce, etc. }\end{array}$ \\
\hline $\begin{array}{l}\text { Accommodating } \\
\text { (Time - available outside of } 1^{\text {st }} \\
\text { and } 2^{\text {nd }} \text { place duties) }\end{array}$ & $\begin{array}{l}\text { Open to the public at a wide range of } \\
\text { times. Opportunities for placemaking and } \\
\text { involvement can occur at times which suit } \\
\text { busy people. The mix of people and } \\
\text { activities is dynamic. }\end{array}$ & $\begin{array}{l}\text { Opportunity for employed/unemployed/home } \\
\text { duties/retired people to mingle and meet people from } \\
\text { all walks of life. Introduces new people or isolated } \\
\text { people to the place. } \\
\text { Events/times which facilitate a greater number of } \\
\text { people getting together. }\end{array}$ & $\begin{array}{l}\text { Open 24/7. Members, volunteers, visitors can drop in at any time } \\
\text { of day. Limitations include that most activity occurs in daylight } \\
\text { hours. In countries with substantial seasonal variation, the activity } \\
\text { may be dormant during winter. [Visits may occur in the evenings } \\
\text { through informal use by homeless people and unwanted attention } \\
\text { from vandals] Events occur which bring people in contact with } \\
\text { each other - meetings, working bees, open days, workshops, social } \\
\text { events. }\end{array}$ \\
\hline $\begin{array}{l}\text { Playful mood } \\
\text { (Enjoyable. Entertainment by the } \\
\text { participants themselves) }\end{array}$ & $\begin{array}{l}\text { Activities are relaxing and enjoyable. } \\
\text { Activities are cooperative, constructive } \\
\text { and dynamic and result in a sense of } \\
\text { achievement. Participants build a sense of } \\
\text { belonging to the place - sense of place. } \\
\text { Conversations facilitate the activities. }\end{array}$ & $\begin{array}{l}\text { Cooperation between members and volunteers and } \\
\text { visitors builds social capital and potential resilience. } \\
\text { Participants build a sense of community with the } \\
\text { people in the area. Enjoyable conversations facilitate } \\
\text { the activities and interactions. }\end{array}$ & $\begin{array}{l}\text { Different experiences occur depending on the level of } \\
\text { involvement. Range of experiences from enjoying the natural } \\
\text { surroundings to the satisfaction of working to grow food. Planning } \\
\text { and working together (eg. lobbying for land, fund raising, working } \\
\text { bees) is followed by social activities and a sense of camaraderie. } \\
\text { Gardening provides topics of conversation as conversation starters. }\end{array}$ \\
\hline $\begin{array}{l}\text { Low profile } \\
\text { (Homely and comfortable) }\end{array}$ & $\begin{array}{l}\text { The place is informal and the atmosphere } \\
\text { is relaxed. It is made to look welcoming } \\
\text { but effort is not expended on fine } \\
\text { surroundings. The informality 'invites' } \\
\text { people to not worry about being precious. }\end{array}$ & $\begin{array}{l}\text { The informality of the place presents no barriers to } \\
\text { participation, broadening the range of people who can } \\
\text { mingle. }\end{array}$ & $\begin{array}{l}\text { Community gardens are natural places and the functions and } \\
\text { amenities are low key. Many items are made on site or donated. } \\
\text { Inclusivity is factored into design. }\end{array}$ \\
\hline $\begin{array}{l}\text { Home away from home } \\
\text { (Well integrated into daily life) }\end{array}$ & $\begin{array}{l}\text { People feel at home contributing to this } \\
\text { place and being a part of it. There is an } \\
\text { informal sense of ownership of this place. }\end{array}$ & $\begin{array}{l}\text { The people of this place become familiar to each } \\
\text { other. They develop a sense of belonging. }\end{array}$ & $\begin{array}{l}\text { People choose to visit or be involved with this community garden } \\
\text { for a range of personal reasons. Facilities are provided/ procured } \\
\text { which allow people to linger and socialise such as shade, shelter, }\end{array}$ \\
\hline
\end{tabular}




\begin{tabular}{|c|c|c|c|}
\hline & & & $\begin{array}{l}\text { seats, bathrooms, barbeques, water, etc. Thought is put into } \\
\text { inclusive provision for children, elderly and disabled visitors. }\end{array}$ \\
\hline $\begin{array}{l}\text { Neutral } \\
\text { (Everyone free to come and go) }\end{array}$ & $\begin{array}{l}\text { Unlocked and welcoming-Clear signals } \\
\text { that it is OK to come in. }\end{array}$ & $\begin{array}{l}\text { The people are welcoming and the regulars introduce } \\
\text { people to each other. }\end{array}$ & $\begin{array}{l}\text { Variety of activities. Unlocked, accessible, safe. Signage } \\
\text { encourages visitors and information on how to join is clear. }\end{array}$ \\
\hline $\begin{array}{l}\text { Levellers } \\
\text { (No importance on an } \\
\text { individual's status in a society) }\end{array}$ & $\begin{array}{l}\text { Everyone can have a role here and } \\
\text { everyone is welcome regardless of their } \\
\text { background, ages, socio-economic status, } \\
\text { interests, disability, education, etc. The } \\
\text { placemaking activities provide a purpose } \\
\text { to interactions between a diverse groups of } \\
\text { people. A variety of activities are available } \\
\text { to cater for a diverse neighbourhood. } \\
\text { Develop civic action - people power. } \\
\text { Responsive to the current needs of the } \\
\text { local residents. }\end{array}$ & $\begin{array}{l}\text { People from all walks of life are welcome. } \\
\text { Development of weak ties (bridging capital) here. } \\
\text { Development of human capital where skills (work, } \\
\text { committee, grant writing, etc.) are present. Where } \\
\text { other organisations can be involved, this increases the } \\
\text { opportunity for social capital as there are bridges } \\
\text { between groups which have their own social capital. } \\
\text { The networks have a multiplier effect and come to the } \\
\text { fore when resilience is called upon. }\end{array}$ & $\begin{array}{l}\text { Design is inclusive eg. high rise gardens for those who cannot bend } \\
\text { over. Social membership (or no requirement for membership) is } \\
\text { available for anyone who doesn't want to or cannot garden. } \\
\text { Involvement of people of different ages. Providing an activity } \\
\text { which helps people to get over their differences. Involve charities, } \\
\text { schools, other organisations. }\end{array}$ \\
\hline $\begin{array}{l}\text { Regulars } \\
\text { ('Characters' play a role in } \\
\text { integrating new visitors) }\end{array}$ & $\begin{array}{l}\text { Regulars play a role in the organisation of } \\
\text { placemaking activities. Depending on the } \\
\text { chosen arrangements and governance. The } \\
\text { placemaking roles should not be too } \\
\text { burdensome on individuals for the sake of } \\
\text { the longevity of the organisation. }\end{array}$ & $\begin{array}{l}\text { The regulars play the role of introducing people to } \\
\text { each other and are the connectors between groups. }\end{array}$ & $\begin{array}{l}\text { Regulars understand what grows, how the community garden } \\
\text { works and some are part of the organisation which keeps the } \\
\text { garden growing. Visitors and volunteers can also be regulars. }\end{array}$ \\
\hline $\begin{array}{l}\text { Conversation } \\
\text { (The main activity) }\end{array}$ & $\begin{array}{l}\text { Conversations are the way in which } \\
\text { decisions are made and cooperative work } \\
\text { is undertaken. It also provides a feedback } \\
\text { loop which aids in responsiveness to the } \\
\text { needs of the community. }\end{array}$ & $\begin{array}{l}\text { Conversations are the medium by which connections } \\
\text { between people are made and subsequent social } \\
\text { capital is formed. }\end{array}$ & $\begin{array}{l}\text { Community gardens provide a communal purpose to initiate } \\
\text { conversations. Opportunities for conversations are enhanced due to } \\
\text { gardening in a communal way. The garden provides a myriad of } \\
\text { topics of conversation for members and visitors (plants, weather, } \\
\text { non-garden topics taking place in a nice outdoor location) and are a } \\
\text { topic of conversation beyond the boundaries at local places. }\end{array}$ \\
\hline
\end{tabular}




\section{Accessible}

Accessible and accommodating are joined as one third place characteristic in (Oldenburg, 1999). However, this research suggests that they should be applied as separate characteristics. Accessible relates to location and means the place is easy to access. While Oldenburg classified accessible as walkable, for the purpose of this thesis, an easy bicycle ride has been included as accessible because the assumption behind walkability relates to the distance not being a barrier to participation. This is placemaking in that the venue is considered close to home and preferably is integrated into the local neighbourhood, situated on the way from one place to another. As such it provides improved or increased opportunity to develop the social capital of participants, visitors and locals through increasing the number of chance encounters with familiar faces due to easy access in the neighbourhood. These chance interactions provide opportunities for developing weak ties (bridging capital).

The community garden should be situated in a place where people are likely to be passing. Crucial to this type of community garden is the walkable locality for ease of visiting. The advantage of a walkable, accessible location available at a wide range of times is that it increases the chances of the locals bumping into each other frequently enough to come to recognise each other. This familiarity creates opportunities for potential weak or strong ties to grow. However, even places that are located within walking distance can be inaccessible because it is perceived as isolated or is at the end of a road where no one walks by. Locating community gardens in a thoroughfare, for example Pine Park in Sydney, is conducive to third place interactions. Jacobs (1961, p. 129) talks about using: "parks and squares and public buildings as part of this street fabric; use them to intensify and knit together the fabric's complexity and multiple user". Pine Park is ideally situated in a shady place near a playground, tennis and basketball courts, surrounded by public housing, next door to a school, community compost, on the way between the private housing on the hill to the coffee shops and pubs below. It may be more like third places to have a number of small community gardens which are easily accessible than a larger one which requires transport to get there. The third place aspect is the interaction between the gardeners and the passers-by who stop to chat. 
Examples of accessible third place community gardens include: pocket gardens; a section of a public park; a converted vacant block; or co-location at an existing public venue (eg. library, school, church). Vacant public land is often contested space or may be small or on marginal land. Social capital may be put to use in the form of adaptive capacity or resilience if the ownership is contested or the site is subject to flooding, or other social, environmental or economic impacts.

\section{Accommodating}

A third place should be accommodating in that it fits between the duties of home and work/school (in the broadest sense of home and work duties) and: "stand ready to serve people's needs for sociability and relaxation in the intervals before, between, and after their mandatory appearances elsewhere" (Oldenburg, 1999, p. 32). Accommodating relates to the times that the venue is open, preferably times available outside of first and second place duties. This is placemaking in that it is open to the public at a wide range of times, so involvement can occur at times which suit busy people, retired people, unemployed people, parents/caregivers, volunteers and children. The mix of people is dynamic as it changes over times and days. As such it provides the opportunity to improve or increase the social capital of participants, visitors, locals by providing opportunities for people from all walks of life to mingle. Opportunities which facilitate a greater number of people getting together occur through such activities as working bees and social events. By being places which are open at a variety of times, opportunities increase for introducing new people or isolated people to the place.

Community gardens are somewhat restrictive in the category of accommodating because they are visited during daylight hours, though as noted at most case study sites, they do have visitors after dark. It should be noted that many of Oldenburg's examples of third places also have restricted opening hours, such as a barber shop or corner store. Case study examples of accommodating are: watering on the way to school; dropping off the compost; picking a few herbs to go in the dinner; stopping by between work and picking up the children; spending the day there while the wife is at work; and, an activity to do with the new baby. There are exceptions and adjustments according to the context, for example Hagenlund community garden is only accommodating during daylight hours in summer as there is no growing season in winter, yet during the growing season, this garden acts well as a third place. 
A third place community garden is open 24/7. Members, volunteers, visitors can drop in at any time of day. Limitations include that most activity occurs in daylight hours. In countries with substantial seasonal variation, the activity may be dormant during winter. Visits may occur in the evenings through informal use by homeless people or unwanted attention from vandals. Events such as meetings, working bees, open days, and workshops, which encourage people to visit, activate the third place.

\section{Playful mood}

The playful mood characteristic is that the third place is enjoyable and entertainment is provided by the participants themselves. This is placemaking because participants relax and enjoy their time at the venue. Good times and memories of place are created. Activities are cooperative, constructive and dynamic and result in a sense of achievement, and sense of place. Conversations facilitate the activities and as such provide the opportunity to improve or increase the social capital of participants, visitors, locals. Cooperation between members and volunteers and visitors builds social capital and potential resilience. Participants build a sense of belonging to the place and the people in the area. Enjoyable conversations facilitate the activities and interactions.

In a third place community garden, experiences of the playful mood differ depending on the level of involvement. From enjoying the natural surroundings to working to grow food. Planning, working together (lobbying for land, fund raising, working bees) followed by social activities create a sense of camaraderie. Gardening acts as a conversation starter by providing topics of common interest and shared activities. Community gardens as an enjoyable third place where leisure time is spent (i.e. not work or home time), which adds weight to Hemmingway's (1999) assertions about the role of leisure activities in the formation of social capital through building connections and trust between participants.

\section{Low profile}

Low profile is a characteristic which can be described as homely and comfortable. This is placemaking in that the place is informal and the atmosphere is relaxed and people feel like it is their 'home away from home'. It is made to look welcoming but effort is not expended on fine surroundings. The informality invites people to not worry about being overly cautious with their surroundings as one might in a first or second place. As such it 
provides the opportunity to improve or increase the social capital of participants, visitors and locals, as it presents no barriers to participation. With no barriers to participation, the range of people who can mingle is broad. Third place community gardens are natural places and the functions and amenities are low key. Many items are made on site or donated.

\section{Home away from home}

The home away from home characteristic describes how the facility is well integrated into daily life and there is an informal sense of ownership of this place. This is placemaking in that people feel at home contributing to this place and being a part of it. As such it provides the opportunity to improve or increase the social capital of participants, visitors, locals by the people of this place becoming familiar with each other and developing a sense of belonging.

A homely third place community garden provides facilities which allow people to linger and socialise such as shade, shelter, seats, bathrooms, barbeques and water. Thought should be put into provision for children, elderly and disabled visitors. The community garden may include community facilities which are also useful to non-members, such as shaded seating, community composting and giveaway boxes of produce.

\section{Neutral}

The neutral characteristic manifests itself as everyone is free to come and go. This is placemaking in that the unlocked place signals that visitors are welcome to come in. As such it provides the opportunity to improve or increase the social capital of participants, visitors and locals by the regulars introducing people to each other. In a third place community garden this neutrality can be achieved by providing a variety of activities and by being unlocked, accessible, and safe through active participation and eyes on the garden.

\section{Levellers}

The Levellers characteristic in a third place means that no importance is placed on an individual's status in a society. This is placemaking in that everyone can have a role and 
everyone is welcome at the place regardless of their background, age, socio-economic status, interests, disability, education, etc. The placemaking activities provide a purpose to interactions between a diversity of people. The place is people powered and is responsive to the current needs of the local residents. As such it provides the opportunity to improve or increase the social capital of participants, visitors and locals because people from all walks of life are welcome. Weak ties (bridging capital) develop here and human capital is present in the form of gardening skills, committee roles, grant writing, etc. Where other organisations can be involved, this increases the opportunity for social capital as there are bridges between groups which have their own social capital. The networks have a multiplier effect and come to the fore when resilience is called upon.

Third place community gardens are levellers when they make provision for diversity, such as including high rise gardens for those who cannot bend over. Social membership (or no requirement for membership) for anyone who doesn't want to or cannot garden. Providing an activity which helps people to get over their differences and involve charities, schools and other organisations.

\section{Regulars}

Regulars are the characters who play a role in integrating new visitors and play a role in creating and running the organisation. Regulars provide the opportunity to improve or increase the social capital of participants, visitors and locals by introducing people to each other and as the connectors between groups. In a third place community gardens, regulars understand what grows, how the community garden works and some are part of the organisation which keeps the garden growing. Visitors and volunteers can also be regulars if they frequent the community garden for activities such as enjoying nature or enjoying the open space.

\section{Conversation}

Oldenburg (1999) described conversation as the main activity of third places. This is placemaking in that Conversations are the way in which decisions are made and provides the feedback loop which aids in responsiveness to the needs of the community. Conversations provide the opportunity to improve or increase the social capital of participants, visitors, locals by being the medium which connects people. In third place 
community gardens, opportunities for conversations are enhanced due to gardening in a communal way. The garden provides a myriad of topics of conversation for members and visitors (plants, weather, non-garden topics taking place in a nice outdoor location) and are a topic of conversation beyond the boundaries at local places.

\section{'Ideal' third place community garden}

All of the community gardens are supported in some way by the local authority and/or commercial sponsors, though all but Hagenlund also spend time fund raising and/or applying for grants in order to maintain their facility. Fundraising activities can have some beneficial effects by increasing community awareness and building social capital, but a heavy reliance on fundraising may be a burden in terms of time and effort for community gardeners. Community gardens which struggle to meet costs and conform to council regulations require enormous effort and can fall into a trap of relying heavily on few individuals to keep the organisation going. People are busy. The members and volunteers run a public space which benefits more people than just the members. The Gold Coast, Sydney and Brisbane councils have community garden policies and various councillors provide support for one-off events or ongoing support. Additional ways to be helpful include providing assurance of land tenure, providing land which is not so marginal (subject to flooding), not introducing new fees, and being considerate of the activities going on (e.g. don't accidently poison the bees). Making it easier for a wide range of people to be involved, the mix of people opens opportunites for social capital development and those weak ties of association and strong ties of friendship.

The way to maintain the involvement is through the lively friendly conversations and homely enjoyable atmosphere provided by community gardens. The people with high involvement (usually members or committee members), act as the third place 'regulars' who become familiar faces and introduce people to each other. It is important that the regulars are not overburdened with the organisational task of running the garden and in particular not overburdened by unnecessary local authority rules and costs. Grant applications, committee functions and charity work can build the social capital and adaptive capacity of members, but can result in substantial commitment for many members. Support for the gardens should not unnecessarily add to the administrative burden, for example the community garden officer who requested that Pine Park gardeners record their produce output (and her request was duly noted). Resources 
provided to the community gardens should aim to support the longevity of the enterprise. Responses need to fit the specifics of each community garden's local community.

Unlike many of Oldenburg's third place examples, community gardens are organised and maintained by the people themselves. This gives people some sense of agency over the operation and responsiveness to changing local conditions. Different governance styles were in evidence across the case study sites ranging from formal (including paid personnel at Bluevale) to informal ("consensus" decision making and membership money kept in a tin somewhere at Pine Park). The non-hierarchical, low membership barriers, quasi-consensus decision making seemed to work. Keeping it light and being cooperative. Pine Park had learnt from the past that being too reliant on one strong character is not conducive to longevity. The Kookaburra community garden was a larger community garden with good facilities and perhaps this is a result of its active and highly structured committee. The president worried about who would take over on their departure due to an impending work transfer. Similarly, one of the members expressed concern that he would be pressured to join the committee, which is not a role he looked forward to. In the case of Hagenlund, the organisational work and costs were borne by the library and the land owner. Most important to the concept of third place is gaining a balance or perhaps an attitude, on divergent opinions in the governance of community gardens if they are to be fun lively places to visit.

Community gardens are fruitful gardening and positive community activity - yet being in publicly accessible space, they interact with the surrounding community in somewhat unpredictable serendipitous and/or occasionally problematic, unfortunate or unexpected ways. Though many incidental interactions with the non-gardening community in community gardens are positive, reported negative interactions with the community occur generally when the gardeners are not in attendance and are evidenced by vandalism, theft and use by the homeless. Most community gardeners in this study are tolerant of limited theft of produce they have grown, however, vandalism or theft of entire crops, is viewed variously as "frustrating" and "discouraging". The negative impact of vandalism and has reportedly taken its toll on membership of community gardens at times. The use of community gardens by homeless people is tolerated to some extent, though reportedly one particular case site was told by the council that they must ensure that the people move on, despite their having built some rapport with a few of the regulars. This thesis hopes 
to initiate discussion on enhancing the beneficial community aspects of community gardening in public spaces, while exploring ways to ameliorate negative interactions.

Although there could be variations which would be specific to the site and the local community, a third place community garden would exhibit many of the features described in Table 7.2 (below): 
Table 7.2: Suggested Third Place Community Garden Features

\begin{tabular}{|c|c|}
\hline $\begin{array}{l}\text { Community } \\
\text { Garden } \\
\text { Characteristic }\end{array}$ & Third place community garden features \\
\hline $\begin{array}{l}\text { Design } \\
\text { Location }\end{array}$ & $\begin{array}{l}\text { - Walkable distance from its main membership and placed on a frequented path for the } \\
\text { - } \quad \text { Beaut residents. } \\
\text { - } \quad \text { Raised garden beds and accessible paths for the disabled members/visitors. } \\
\text { - Involve the local citizens in designing the garden to be responsive to the current } \\
\text { neighbourhood needs and preferences - individual garden beds or communal or a mix; } \\
\text { features for the children; park-like gathering areas, etc. } \\
\text { - Individual plots to encourage regular visits and investment of time. } \\
\text { - } \quad \text { Pleasant communal areas - shade, shelter, facilities which encourage lingering. } \\
\text { - Through signage and practice, make it obvious to local residents that they are welcome } \\
\text { - } \quad \text { to spend time in the site. } \\
\text { - Provign for reduced theft and vandalism incidents where possible (lighting, busy area). } \\
\text { - Include communication devices such as a blackboard and/or social media which can } \\
\text { connect and inform potential members/visitors. } \\
\text { Include social membership. }\end{array}$ \\
\hline $\begin{array}{l}\text { Activities \& } \\
\text { Membership }\end{array}$ & $\begin{array}{l}\text { - Common purpose or range of purposes and motivations. } \\
\text { - Open and over the fence interactions - embedded in the community, impact reaches } \\
\text { beyond the fence boundaries. } \\
\text { - } \quad \text { Networked to other community groups. } \\
\text { - Inclusive, diverse membership and design and conditions which support diversity. } \\
\text { - Opportunities to build weak ties through public events, community activities and give } \\
\text { - } \text { Opay produce. } \\
\text { Opportunities to develop weak ties into strong ties through social activities and } \\
\text { cooperative work, including regular working bees, workshops or meetings (with a } \\
\text { social aspect). } \\
\text { Different roles, levels of opportunity (casual volunteering, membership, allotments, } \\
\text { passers-by, events). Include roles which suit people's physical or time constraints, } \\
\text { social membership, charity work. } \\
\text { Develop resilience to negative interactions with the public (eg. vandalism). }\end{array}$ \\
\hline $\begin{array}{l}\text { Governance, } \\
\text { Support \& } \\
\text { Tenure }\end{array}$ & $\begin{array}{l}\text { - Citizen initiated, governed and maintained but supported by private enterprise or local } \\
\text { authority through advice and funding. } \\
\text { - Alternatively - the work is largely done by authorities but local people can gather and } \\
\text { have conversation stimulated by the garden - accessible to the community. } \\
\text { - Provide security of tenure. } \\
\text { - } \quad \text { Provide land which is not marginal (eg. affected by regular flooding). } \\
\text { other busy places. }\end{array}$ \\
\hline
\end{tabular}

These key features could serve to inform the planning and design of third place community gardens, where community building is a goal. It is possible to single out one of the case study sites to illustrate how the third place characteristics are enhanced by the community gardening activity and how the community gardening is enhanced by being a third place. This is not to say it is better than the others, nor that it is perfect in every way, 
nor to discount the third place aspects of the other five community gardens in this study, but Pine Park Community Garden in Sydney is an excellent example which meets every third place characteristic.

Pine Park community garden is resilient in that is has survived an arson attack, shifting location, encounters with vandals, and problematic interactions with homeless people. It is interconnected being on route between the housing and schools and businesses. It is colocated with a number of facilities in a park including tennis and basketball courts and a children's play area. It is an efficient use of the limited public space to create a functional green space. It has communal facilities. Membership has very low barriers and people are welcome to use the garden in their own ways. It has individual plots which encourages regular visits (creates "regulars") and has communal growing which is shared (for example the community roasting the coffee beans). Members actively try to encourage people who regularly visit to join, but not people who live some distance away. The garden serves to introduce people to the place. Communication with each other and the neighbourhood is carried out through a number of mediums - meetings, face to face chatting, blackboard, signs and the Facebook page - plus they sometimes make the news. The City of Sydney council supports it and has a framework for supporting community gardens. The council provides an advisor and materials, but is not officious or demanding. It is networked with commercial and state organisations, the local coffee brewer, the restaurant and the primary school garden. It is a conversation starter in places outside the garden such as the local pub. It caters for people who do not have enough space to grow their own food. It caters to people who want to have a sense of community. The group have made a conscious decision to share the organisational load. Their governance is nonhierarchical and all are encouraged to have some role to help with longevity. Decision making is consensus though by observation, for expediency it seemed that decisions were by the majority. Their meetings include a social element. Weak ties are made connections between social housing residents and local residents who live in wealthier houses nearby. Strong ties of friendship have developed and it has led to people keeping an eye out for each other.

\section{Further Research}

In drawing together a number of concepts and theories, using case studies which present a wide variety of locations and individuals, numerous ideas for further inquiry arose. 
The findings of this thesis suggest that further research on community gardens as third places could include an additional participant category of local voices from outside the community garden membership in order to learn more about their reach as third places.

Indigenous involvement and recognition in third place community gardens could be another important area of investigation. One case study had included an educative bush tucker garden, however, this had been developed by non-Indigenous community garden members. There are numerous community gardening projects run by or in conjunction with Indigenous Australians ranging from school gardens, to community gardens to commercial market gardens and their success is dependent on planning and involvement that is very site and context specific (Fawcett, 2013). The potential for Indigenous involvement in designing community gardens which act as third places to the local community would be an important and interesting topic for future investigation.

The factors which facilitate community gardens to be third places, i.e. purposeful interactions, can be applied to the design of social spaces to enhance their placemaking qualities and improving social capital. The third place with a communal purpose framework may prove useful for investigating the community aspects of other public infrastructure such as privatised public space, men's sheds, dog parks and skate bowls.

The impact of climate change and adaption to unpredictable and extreme weather could be an area of further investigation. Growing food and enjoying outdoor third place interactions in the Anthropocene may present design challenges for community gardeners. Numerous participants mentioned the heat, watering in summer, contaminated soil and increased frequency of flooding. The impact of the hot weather reduces the accommodating third place characteristic, as people, particularly at the Gold Coast, mentioned gardening very early in the morning to avoid the heat. Designing gardens which are responsive to increased numbers of extreme events was in evidence at Bluevale City garden with the lifting of their administration building above flood levels and chicken rescue plans. There may be need to adapt outdoor sites to provide places which are productive and pleasant to visit and resilient to extreme events. Another related research idea builds on the example at Bluevale where local people rally to rescue the chickens in extreme rainfall. Are people who have established networks through a community garden more likely to help each other out during an extreme weather event? 
This question would investigate if building social capital increases the resilience of the local neighbourhood to the impacts of climate change.

Research which could follow on from this thesis includes using third place community gardens as a site to investigate how communities respond to the dynamics of neighbourhood change caused by densification, population mobility and changes in economic circumstances. For example, a gentrifying community garden may switch focus from growing food to supplement the householders' groceries, to a focus on growing organic herbs for recipes and sustainably composting their food scraps. If the community garden fails, new residents could take it over or repurpose the space, as happened at Frank Street. Community gardens are somewhat flexible, unlike demolishing a failed infrastructure, for example a multistorey carpark. If they have to move they can rebuild, such as Pine Park which was forced to move location but were compensated with better facilities such as raised garden beds. The images of Marville community garden one year on from their beginnings shows how possible it is to create a community garden from scratch. Bluevale respond to floods and contamination. Investigating how they face challenges, but respond with flexibility and resilience coupled with social capital could provide important insights into how citizens collectively respond to a changing environment.

\section{Conclusion}

This thesis concludes that community gardens can meet all eight third place characteristics, act as a third place with a communal purpose, and attract a diversity of residents with a broad range of motivations around community, gardening and food growing. This research shows how third place community gardens support the community to address challenges of social isolation and the effects of population mobility by contributing to providing safe and inclusive green spaces for a diverse urban population. Community gardens that act as third places ameliorate some of the challenges associated with increasing urban challenges, such as increased isolation and alienation in cities and demise of sense of community, as they allow locals and newcomers to informally meet. This thesis is the first time the connection between community gardens and third place an informal neighbourhood meeting place outside of home (first place) or work (second place) - has been systematically investigated. This qualitative case study applied a third place framework to six case study community gardens (five in Australia, one in Denmark) and related the findings to social challenges associated with increased urbanisation and 
population mobility. Third places are important in drawing together people in a neighbourhood, relieving social isolation by helping them feel a part of the place where they live, particularly for residents who are new to an area. The placemaking role of community gardening strengthens the connection to place and the social capital of the participants and locals.

This thesis used the concept of third place to engage with theories of placemaking and social capital, which produced findings on neighbourhood resilience and implications for UN Sustainable Development Goal 11.7 in providing safe and inclusive green spaces. It identified a number of recommendations that may inform the design of third place community gardens and may work as indicators for UN Sustainable Development Goal 11.7. Community gardens offer opportunities for conversations within and outside the garden membership thereby assisting in introducing new people to the neighbourhood, and increasing local social capital, which along with improved local food security improve local neighbourhood resilience. The weak ties of association can be developed into strong ties through frequent interactions, social activities and cooperative placemaking activities. Community gardens are placemaking, facilitating local residents' development of a sense of place through access to nature and to each other - community.

Community gardens which are open to the public and walkable distance from members' homes and include an activities or individual plots which encourage regular visits are likely to act as third places, even if by organisational necessity, they need to have some club-like characteristics. Third place community gardens have a purpose - gardening which provides many topics for conversation starters between regulars (the gardeners, volunteers and frequent visitors) and the local residents. This thesis produced a model showing how community gardens can operate both as a club and a third place, therefore encourage the formation of both weak ties of association and strong ties of bonding capital. Given that community gardens which are third places exhibit qualities which help improve wellbeing in urban communities, cities would benefit from reducing barriers to community garden participation and increasing access to space and resources for such community gardens.

Community gardens and third places are two public sites of civic engagement. Combining the two into community gardens which are third places creates an inclusive public place which enhances the benefits of both. Community gardens which are third places reach out and benefit more people in the neighbourhood, embedding the garden into the 
community. If a third place, the various goals of community gardeners, such as sustainability action and education, reaches more people in the neighbourhood. Also, by being of interest to more people in the neighbourhood, this potentially increases local support for the use of the public land as a community garden. Third places are more effective at their role in being an informal public places where locals get to know each other, because there is a purpose to the interactions or a conversation starter with the regulars.

This research could be used to inform city planners in increasing accessibility and participation in community gardens. Removing barriers to gardening in time poor and agency poor neighbourhoods would increase the accessibility and effectiveness of the 'community' aspect of community gardens. To improve the informal quality of third place, the community garden governance and participant commitment should not be too onerous. There may be a balance to strike between planning authorities providing community gardens which are less onerous for community members to maintain and the agency of the members.

Oldenburg (1999, p. 14) described a number of elements of third place to achieve a "thriving informal public life" including that a third place should be welcoming, obligation-free, bring people of different ages and backgrounds together and be places which people visit in order to enjoy themselves. Each community garden may not exhibit every one of the third places characteristics perfectly, but the important elements of third places contribute to achieving relaxed informal local public places which increase people's familiarity with each other in the neighbourhood. Effective third places strengthen the social capital of the community build people's sense of place, and improve their happiness and wellbeing. Placemaking is a dynamic process and this is no more evident than in a community garden where the purpose, design, seasons and participants change over time. The research critically engaged with the third place concept and provided insights into designing, building and supporting meaningful third places and in supporting the citizens who design, create and maintain community gardens which are third places.

At the time of completing this thesis, the concept of third place is 30 years old, yet the problem of its absence in both contemporary suburban housing developments and densifying city residential areas is still applicable today. This thesis has uniquely 
demonstrated a method for applying the concept to a particular type of place in order to assess its qualities as an informal public place which brings together people of a neighbourhood. For this reason, the method has practical implications for urban design and renewal. In applying the third place concept, the researcher updated it to: expand the eight characteristics to nine characteristics by separating accessible and accommodating; in the characteristic 'leveller' to specifically include consideration of inclusivity across age, gender, ethnicity and disability; and critique the idea of 'local' with regards to a highly mobile population and the role of social media in virtual communities. The thesis drew out the important implications for the role of third places in reducing social isolation, improving neighbourhood wellbeing and building and community resilience, particularly in combination with these and other social benefits of community gardens. In presenting the work through publications and presentations and media, it has become apparent that third place is a concept which academics, professionals and the broader general population readily relate to, value and can apply to their own lives.

This thesis has provided significant insights into some of the pressing challenges in urban society brought about through an increasingly urban and mobile population, such as a sense of disconnect from place; social isolation; fear of strangers; and how to work together to respond to a crisis. Given the positive aspects of community gardens and third places, the combination provides a non-prescriptive, authentic citizen driven way to address some of the social challenges of urban societies. The effect of community gardens which are third places in an increasingly urbanised world dominated by social isolation, lack of inclusive, safe and accessible public places, is that they foster both active and passive engagement, leading to improved neighbourhood resilience for individuals and local communities. 
Appendices

Appendix 1 Published conference paper - co-authored (confidential due to copyright) 


\title{
A GROWING MOVEMENT: MOTIVATIONS FOR JOINING COMMUNITY GARDENS
}

\author{
JOANNE PASCOE \& MICHAEL HOWES \\ Cities Research Institute, Griffith University, Australia
}

\begin{abstract}
Community gardens play an important role in building urban resilience through improving food security and by increasing neighbourhood social capital. As community gardens become more popular in many countries, understanding what motivates people to join them and stay involved is, therefore, worth researching. This paper explores the key motivations of community gardeners using data from interviews conducted with people involved in a range of community gardens on the east coast of Australia (including Brisbane, the Gold Coast and Sydney) as well as two locations in Denmark (Copenhagen and Odense). Our analysis synthesised three main categories of motivation which are broadly described as "individual", "community" and "gardening". Individual motivations included: a retirement activity; educating one's own children about growing and eating good food; access to organic produce; alternative to supermarket food; and personal learning, enjoyment and satisfaction. Community motivations included: civic action; a way to meet people when new to the neighbourhood; growing food for charities; teaching children to interact with the community; and community-based social activity. Gardening motivations included: being outdoors; enjoying nature; access to earth; and growing food plants. While community gardening is often cited as a sustainable activity, the environment only emerged once as a key focus in relation to organic food production. Interestingly, there was still evidence of sustainable practices such as community composting and pesticide-free growing across all sites. The range of motivations show that the gardens go some way towards improving the quality of life in urban environments through providing intergenerational social interactions which are enjoyable, increasing local social capital and inadvertently improving local food security and sustainability.

Keywords: community gardens, motivations, sustainability, social capital, community.
\end{abstract}

\section{INTRODUCTION}

Community gardens play an important role in improving sustainability of urban environments by providing social, economic and environmental benefits. They can reduce alienation, build social capital, and improve food security, thereby leading to increased urban resilience to disasters [1]. Finding out what motivates people to join and stay involved in community gardens is therefore important. This paper analyses and synthesizes categories of key motivations using data from interviews conducted with participants involved in community gardens on the east coast of Australia (including Brisbane, the Gold Coast and Sydney) and in Denmark (Copenhagen and Odense).

The next section gives a brief summary of the literature as a background to our analysis. The methods, results, analysis and discussion are then provided. Overall a wide range of motivations are identified, but while sustainability is practiced, it surprisingly does not feature as a stated primary motivation amongst the participants.

\section{BACKGROUND}

Community gardens are established and/or maintained by members of the local population for both individual and collective benefits. They provide a public venue that improves social interactions between local residents [2], [3] and are particularly important where traditional links between neighbours have been weakened by population mobility and isolation [4], [5]. 
This research is timely because community gardening is a growing trend in many countries. The total number of community gardens registered with Australian Community Gardens Network grew by $250 \%$ between 2010 and 2016 to 600 [6]. Community gardens emerged in Singapore in 2005 and by 2008 there were 240 [7]. In 2007, the American Community Garden Association estimated that there were 18,000 to 20,000 community gardens in the USA and Canada combined [8].

There is a great deal of literature on the benefits which individuals and society receive from community gardens, which include: providing food to impoverished residents; crime prevention; beautifying an area; enacting 'Local Agenda 21' (LA21); exercise; civic engagement; enjoyment; access to fresh organic food; increased social capital; improved nutrition and wellbeing; educational opportunities (nutrition, work skills); and community building [2], [3], [5], [9], [10]. The literature generally shows that community gardens bring positive outcomes for individuals and their community. For example, in Singapore, elderly members benefitted from the connection with nature and the nostalgic aspect of the gardens reminding them of their farming days in pre-urbanised Singapore [7]. In Melbourne, Australia, community gardening reduced social isolation by providing an opportunity for neighbours to meet each other [11]. In West Hollywood, USA, community garden participants increased their physical activity by $6 \%$ and increased their fruit and vegetable consumption by $10 \%$ [12]. Ohmer et al. [13] found that community gardens improve access to green space in densely urbanised neighbourhoods. Galdini [5] noted that community gardens improve social cohesion and vitality in Berlin. Several studies show community gardens are an avenue for providing an alternative to modern food production and distribution [14]-[16]. School gardens draw in the community by encouraging parents, relatives and neighbours to be involved as volunteers [2], [17].

Some of the motivations identified in the literature include: a desire to grow organic, locally grown, seasonally appropriate food [3], [12], [18]; a need for cheap food, or to find an alternative to modern food production and distribution [14], [15]; the desire to connect with nature [19]; the motive to promote and enact environmental sustainability [2]; and the desire to be part of a community, sharing produce and working cooperatively [15]. The motivations are varied and in the main indicate a desire to address individual, social, and environmental issues that arise within contemporary urban society.

\section{METHODS}

The research question being explored by this study is: What motivates people to join and take part in community gardening? We address this question by interviewing participants from a variety of different types of community gardens in different locations [20], [21]. Semi-structured interviews with key stakeholders sought to identify the broad range of motivations of community garden participants. Key stakeholders included: members, volunteers, visitors, and authorities who provide advice/support. They cover a broad range of people and urban environments. Answers have been analysed by coding the data into themes using NVIVO.

The data collection stage is not complete. To date, 24 interviews have been conducted. The case study sites include 4 community gardens in Australia (1 Sydney, 2 Brisbane, 1 Gold Coast) and 2 in Denmark (1 Copenhagen, 1 Odense). All six gardens employed sustainable practices as evidenced by organic growing, mulching, harvesting rainwater, seed-saving, composting and two also included native bee keeping. 


\section{FINDINGS}

Our research generated three main categories of motivations:

- Individual;

- Community; and

- Gardening.

In addition, it should be noted that numerous participants included multiple motivations in their initial response. Each of the three themes is described and then example (deidentified) participant quotes are provided.

\subsection{Individual}

The "Individual" motivations theme emerged from comments which illustrated personal satisfaction, individual benefits and enjoyment as motivations for joining a community garden.

Growing and eating organic produce and access to an alternative to supermarket food were primary motivations for a number of interviewees:

I enjoy that you know where it's come from, that it's organic. You can grow what you want. (Australia 4)

I was just getting things from the shops that were seasonal, but I really didn't know what I was getting. And I've learnt, you know, in the time I've been here my children - my teenagers - will eat more vegetables. I think it's the taste factor. And you know that it's organic - it's something you've grown yourself. (Australia 4)

The personal enjoyment and satisfaction of growing food and being in a garden environment were motivators for some gardeners:

I get a huge amount of satisfaction out of having things I've grown that I can eat. I mean, in financial terms, it's nonsense. (Australia 1)

It's just nice being outside and doing stuff. (Australia 2)

Some participants were motivated by a desire to gain new skills and learn about gardening, while others were keen to educate their children:

I just thought it would be nice to just grow a few things and just actually learn about it because I don't really know anything about gardening. (Australia 1)

...since the kids, I just thought it (gardening) would be nice for them and ... so they can learn that it doesn't just come from the store. Like, the first time my son saw an orange on a tree like he just didn't get it, you know? It was just like at a friend's house at Marrickville or something he just - cause he'd only ever see stuff to come from a supermarket and then it was just like "What!" (Australia 1)

Several gardeners were motivated to find an activity to spend their time on which would also provide opportunities for the company that community gardening provides. Amongst this motivation group were retired gardeners and an under-employed local resident:

I know what times they're there, so if I feel like some company, I come down in the morning. Tam will be here or Fred will be here and I'll just be able to chat. (Australia 4) 
One gardener was spoken of as motivated by publicity for their business.

A chef - who opened a restaurant and went around to schools and various organisations and asked us if we could set aside part of one of our plots so she could grow some Vietnamese mint, right? And we said yes, and she did, and then at the end of the year she invited us all up to come and have a meal at the restaurant. But it was very interesting because this story, there's a whole lot of media coverage about all of this, you know. And for the life of me, I don't think she ever came and harvested any of the mint. We've got this huge stand of Vietnamese mint there. (Australia 1)

Individual motivations included a desire to meet and spend time with people; to learn new skills and teach their own children about gardening; and personal satisfaction and enjoyment. Respondents in this category primarily spoke of benefits to themselves as the primary motivation for joining a community garden.

\subsection{Community}

The "Community" motivations theme emerged from comments which illustrated motivations to be more involved with the community; to improve the community through civic action; teaching the children to interact with the community; and neighbourhood social activity.

Several gardeners were motivated to join their community garden so they and/or their children could experience community involvement, as it was seen as a safe place to teach children how to interact with the community:

I think probably the whole, participating in the community thing because when I grew up, it wasn't really like that where I lived, although maybe because my family wasn't particularly involved. We weren't that type of family and I think that I want the children to have a little bit of that, you know? And also going to talk to different people and, as you can see, one that keeps calling out is extremely like interactive and he will just talk and talk and talk and talk. And, fortunately, most people there really like talking to him <laughs> So it's sort of good for that. (Australia 1)

Some of the key stakeholders who had roles as organisers of their local community garden were motivated to enact a sense of civic duty to improve the resources or integration of the community:

I think community gardens - yeah - because it's a focus on a local space and it's your time and - it's your community and I think that people need to invest in their community if they're going to be happy. (Australia 2)

Some gardeners at one inner city garden were motivated to start a community garden to help provide their local community with much needed public greenspace:

There's not much green space in the area, so it's a way to get more open space and just have a nice area where people can hang out and like the actual gardening part of it - it's nice. We have a garden at home, as well. The actual gardening part is secondary, I think. <laughs> (Australia 3)

The main motivation that the library staff had to start a community garden in a residential development's public courtyard outside their library was to help improve community cohesion: 
It is an opportunity to make people meet across age and cultures and languages.... Making people meet just because they are different is not really working. What makes people come together is if they share a common interest. It is not like, 'OK I can just go and meet people from Pakistan and Turkey, but what is the point? But if we can go and garden together, I would like to do that.' (Denmark 1)

Other interviewees were motivated in a community sense as they sought a way to meet people when new to the neighbourhood and others were motivated by growing food for local charities. "Community" motivated participants focused on the social aspect of the group activity and/or the beneficial community outcomes.

\subsection{Gardening}

The "Gardening" motivations theme emerged from comments which illustrated a desire to access public green space for gardening, experiencing nature, or other outdoor purposes.

Living in housing with limited access to space for gardening or play activities motivated a number of gardeners to join their local community garden:

We live in a duplex, so we haven't got a lot of room to grow our own veggies and so forth.... We've got things in pots, but it's just nice to have that little bit of extra bit of dirt to play in. (Australia 4)

Yeah I love bringing dogs around/a lot of people bring dogs to run around here. I like to bring the dog to run around. Border collie. It has a little play out the front here. Yeah it is great. (Australia 4)

Although no children were interviewed, adults mentioned that the activity of gardening was very popular amongst the children:

It's nice to do something, especially with the kids outside. They really like it. It's just nice doing something outside. (Australia 2)

The children are very proud of their gardens. (Denmark 2)

Connection with the earth and biophilia (connection with nature) were motivators for some participants:

It's nice to - so, just a lovely thing to do, get your hands in the dirt <laughs $>$. Watch things grow $<$ laughs $>$. (Australia 4)

Oh, I love gardening. I love being outside.... I find it relaxing. (Australia 3)

The gardening motivation included access to open green space and gardening space and/or access to organic produce. When discussing their community garden, participants noted practices which could be identified as sustainable practices such as composting, recycling, mulching, harvesting rainwater and growing without the use of chemicals. Environmental action or sustainability as a concept was not mentioned and was not included as a primary motivation of any participants.

\subsection{Mixed motivations}

Mixed motivations featured frequently, in particular the combination of "community" and "gardening", for example: 
I was hoping I would just learn a bit more about gardening. And also I'm just yeah I like to hang out with local community members. So it is social as well. (Australia 2)

It's good for the kids. It's a nice community activity as well, and also the idea of there being fresh produce growing nearby, that's good. (Australia 2)

The combined motivations of "community" and "gardening" reflect a desire to garden with other people. Many of the participants noted that they had sufficient gardening space at home, but they wanted to garden with other community members.

\subsection{Demotivation}

It is also worth considering demotivating factors, as these erode the motivational enthusiasm of participants and may impact the longevity of the community gardens. For example, some enthusiastic gardeners were demotivated by vandalism:

Our garden is not locked, so anybody can walk into it and because of that, it suffers a fair bit of pilfering, it suffers a fair bit of vandalism, ... some people are shooting up drugs in there so it can be a pretty frustrating place to try and grow veges... All of us have been discouraged by that and you know at times I think everybody I know that has been down there has said I am going to give this up, it is just too hard. But we still keep batting on thinking let's not let 'em beat us. (Australia 1)

Several community garden organisers noted that some local residents who joined the community garden were less motivated than they initially thought:

People join with different levels of enthusiasm and there's sort of that turnover of people that think it's a great idea, but then they realise, or they just don't know, they've got a garden full of weeds. (Australia 4)

None of the community gardens investigated so far had difficulty in maintaining enough members to keep their garden going. Active members noted that competing priorities or moving neighbourhoods rather than lost motivation were the main causes of former members withdrawing from their community garden.

\section{DISCUSSION}

Our analysis generated three main categories of motivation which are broadly described as: "individual", "community" and "gardening". Mixed motivations featured prominently, and, as might be expected of community gardeners, the most frequent combination was of "community" and "gardening".

The three emerging themes of Individual, Community and Gardening mirror three of the five "Hierarchy of Needs" from Maslow's Theory of Motivation. The theory argues that human beings are motivated by unsatisfied needs. The three motivations in the case of these community gardens are physiological needs; love and belonging; and self-actualisation [22].

Physiological needs are evidenced by "gardening" and include growing food and access to green space. Some community gardeners were motivated to gain control over the production and distribution of one of our most basic needs - food - through by-passing the supermarket; providing medicinal or ethnic foods not available in the market place; and/or growing local organic food.

Love and belonging can be seen in reference to a desire for a sense of "community" and in seeking out friendship and belonging to a group. The social aspect is evidenced in those 
community gardeners motivated to get to know people in the neighbourhood; share resources and produce; learn together; feel a part of a community; and/or combat loneliness.

Self-actualisation mirrors the "Individual" category, where community gardeners are motivated by a desire to be a good parent, a good citizen; self-improvement through learning new skills and knowledge; and/or to feel a sense of accomplishment.

The point at which the three broad motivations for joining a community garden intersect may have one (or more) factor in common. City residents are seeking more control of their immediate environment as an antidote to alienation by growing local "community".

Sustainability, although not stated as a motivation, is enacted direct action, contributing to a larger environmental movement. Sustainability is embedded in the choice of community gardening as an activity but is not always explicitly recognised by the participants. The literature pointed to environmental motivations of many community gardens in the forms of sustainability action and environmental education [2], [17], [19], [23]. While the environment is often cited as a community garden motivation, in our study the environment only emerged once as a key focus for one respondent in relation to organic food production. Interestingly, there was evidence of sustainable practices, such as community composting and pesticidefree growing, across all sites (Australia and Denmark) and native bee keeping in two Australian sites. So surprisingly the improvements in sustainability appear to be a by-product of other motivations.

People's actions are shaped by their environment and they in turn shape their environment by their actions. A community garden is often an untidy place in a world of straight lines and hard surfaces. Community Gardens are a place where the people make the rules. Wright-Mills [24] wrote of the sociological imagination that: "By the fact of his (sic) living, he contributes, however minutely, to the shaping of this society and to the course of its history, even as he is made by society and by its historical push and shove". The community gardeners, by gardening in an urban public space, contribute to the shaping of his/her city and society, to the course of its history and direction of its future.

\section{CONCLUSIONS}

The range of motivations revealed by our research show that community gardens go some way towards improving quality of life in urban environments, through providing enjoyable intergenerational social interactions in a nature-based environment. The individual motivations revealed by community gardeners varied, however overall indicate that they seek involvement with their community in an outdoor environment by growing organic food together. The community gardeners increase local social capital and inadvertently improve local food security and sustainability skills. Investigating these motivations is important because they can help to shape more effective strategies for addressing problems associated with modern urban life. This may in turn inform debates about wellbeing in cities and feed into planning policy. Community gardens are not a system level change and in themselves are unlikely to be a universal panacea for urban problems, but lessons learned here could be incorporated into the wellbeing of a city. The research may help inform on a role for city authorities to assist, facilitate or to plan for and support community gardeners. From an academic standpoint, this research may be important by uniquely drawing together a range of social theories on social capital, motivations, wellbeing, sustainability, civic engagement, environmental education, social inclusion and place-making. It is hoped that this research will be of value to community gardeners, urban planners, environmentalists, alternative food networks and academics who research such topics. 


\section{REFERENCES}

[1] Aldrich, D., Building Resilience: Social Capital in Post-Disaster Recovery, University of Chicago Press: Chicago, 2012.

[2] Ferris, J., Norman, C. \& Sempik, J., People, land and sustainability: Community gardens and the social dimension of sustainable development. Social Policy and Administration, 35(5), pp. 559-568, 2001.

[3] Firth, C., Maye, D. \& Pearson, D., Developing "community" in community gardens. Local Environment: The International Journal of Justice and Sustainability, 16(6), pp. 555-568, 2011.

[4] Frumpkin, H., Healthy places: Exploring the evidence. American Journal of Health, 93(9), pp. 1451-1456, 2003.

[5] Galdini, R., Placemaking as an approach for innovative urban renewal practices: Community gardens in Berlin. International Review of Sociology, 16(1), pp. 1-21, 2016.

[6] The Network, Australian Community Gardens Network Web Site, Australia, http://communitygarden.org.au/acfcgn/. Accessed on: 6 Feb. 2017.

[7] Tan, L. \& Neo, H., "Community in Bloom": Local participation of community gardens in urban Singapore. Local Environment, 14(6), pp. 529-539, 2009.

[8] Birky, J. \& Strom, E., Urban perennials: How diversification has created a sustainable community garden movement in the United States. Urban Geography, 34(8), pp. 1193-1216, 2013.

[9] Guitart, D., Pickering, C. \& Byrne, J., Past results and future directions in urban community gardens research. Urban Forestry \& Urban Greening, 11(4), pp. 364-373, 2012.

[10] Draper, C. \& Freedman, D., Review and analysis of the benefits, purposes, and motivations associated with community gardening in the United States. Journal of Community Practice, 18(4), pp. 458-492, 2010.

[11] Kingsley, J.Y. \& Townsend, M., 'Dig in' to social capital: Community gardens as mechanisms for growing social connectedness. Urban Policy and Research: An Australian and New Zealand Guide to Urban Affairs, 24(4), pp. 525-537, 2006.

[12] Twiss, J., Dickinson, J., Duma, S., Kleinman, T., Paulsen, H. \& Rilveria, L., Community gardens: Lessons learned from California healthy cities and communities. American Journal of Public Health, 93(9), pp. 1435-1438, 2003.

[13] Ohmer, M., Meadowcroft, P., Freed, K. \& Lewis, E., Community gardening and community development: Individual, social and community benefits of a community conservation program. Journal of Community Practice, 17(4), pp. 377-399, 2009.

[14] Hogan, L. \& Thorpe, S., Issues in Food Miles and Carbon Labelling, Australian Bureau of Agricultural and Resource Economics (ABARE): Canberra, 2009.

[15] Gaynor, A., Harvest of the Suburbs: An Environmental History of Growing Food in Australian Cities, UWA Publishing: Perth, 2006.

[16] Walter, P., Theorising community gardens as pedagogical sites in the food movement. Environmental Education Research, 19(4), pp. 521-539, 2013.

[17] Pascoe, J. \& Wyatt-Smith, C., Curriculum literacies and the school garden. Literacy Learning: The Middle Years, 21(1), pp. 34-47, 2013.

[18] Cox, R. et al., Common ground? Motivations for participation in a communitysupported agriculture scheme. Local Environment, 13(3), pp. 203-218, 2008.

[19] Turner, B., Embodied connections: Sustainability, food systems and community gardens. Local Environment: The International Journal of Justice and Sustainability, 16(6), pp. 509-522, 2011. 
[20] Silverman, D., Validity and Reliability, Interpreting Qualitative Data: Methods for Analysing Talk, Text and Interaction, SAGE Publications: London, pp. 144-170, 1993.

[21] Yin, R., Case Study Research. Design and Methods, 4th ed., SAGE Publications: London, 2009.

[22] Maslow, A.H., A theory of human motivation. Psychological Review, 50(4), pp. 370396, 1943.

[23] Sharman, L., The future of urban community gardens: Issues, barriers and solutions for councils and community. Proceedings of the Promoting Sustainability, Health and Inclusion in the City Conference, University of Canberra, pp. 41-51, 2010.

[24] Wright-Mills, C., The Sociological Imagination, Oxford University Press: New York, p. $12,1959$. 
Appendix 2 In print book chapter (confidential due to copyright) 
Appendix 3 In print book chapter - co-authored (confidential due to copyright) 


\title{
1. Rethinking third places and community building
}

\author{
Caryl Bosman and Joanne Dolley
}

\section{INTRODUCTION}

Ideals of community as produced by many planning discourses - in Australia, the UK and America - in the 2000s are not dissimilar to their historical forbears. Most remain associated with aspirations to 'the good life', a more caring, sharing, connected and united world (Freie 1998). An imagined gemeinschaft village life is still a popular image of 'community': small scaled, place-based, face-to-face relationships, self-contained, self-governing and self-referential. However, the unquestioned belief that physical planning can create ideals of community and provide the necessary ingredients for 'the good life' is no longer axiomatic. The often simplistic interpretation of 'community' has meant social and cultural difference has not always been recognised and everyday life patterns have been largely regulated by the 'master' plan. We argue that the values attributed to ideals of community have been re-invented, re-produced and re-inscribed, over the course of the twentieth century as universal and unquestionable 'truths'. This chapter maps some of the planning techniques and rationalities that underpin these 'truths'; 'truths' that ultimately affect the planning and development practices that comprise many contemporary city landscapes and in particular in the case of this book, third places.

This first chapter introduces the concept of third place and establishes a critical platform for understanding the relations between place and community. The chapter concludes with an outline of the book structure. The chapters in this book highlight the importance of third places and how they can be incorporated into urban design to offer places of interaction - promoting togetherness in an urbanised world of mobility and rapid change; frequently cited causes for the demise of community and the decline in social health and well-being. The book chapters analyze a diverse array of spaces identified as third places, authored by scholars from different disciplines and from different countries around the world. 


\section{RETHINKING THIRD PLACE}

In 1989 the sociologist, Professor Ray Oldenburg, released the influential book The Great Good Place: Cafes, Coffee Shops, Community Centers, Beauty Parlors, General Stores, Bars, Hangouts, and How They Get You Through the Day, in which he described his concept of third place. Third place is a concept which identifies places which are not home (first place) or work (second place), but are 'informal public gathering places' (Oldenburg 1997 p. 6). They are neutral places which provide opportunities for people to meet and interact and to develop a sense of belonging to place (Oldenburg 1999). Oldenburg (1989) attributes eight distinguishing characteristics in defining or identifying third places:

1. Neutral ground or a common meeting place.

2. Levelers or places that encourage, and are inclusive of, social and cultural diversity.

3. Places that are easy to access and accommodate various sedentary and active activities.

4. Place champions or regular patrons.

5. Low profile and informal places.

6. Places which foster a playful atmosphere.

7. A home away from home.

8. A place where conversation is the primary activity.

Third Places are as relevant at the end of the second decade of the twentyfirst century as they were 30 years ago. Urbanisation and its associated problems and solutions, and in particular the effect on community relations, remain 'hot topics'. Loss of community and sense of place is often identified as a problem by social researchers. Oldenburg (1997 p. 7) wrote: 'Life without community has produced, for many, a life style consisting mainly of a home-to-work-and-back-again shuttle. Social well-being and psychological health depend upon community'. One conceptual place where community building occurs is the third place. In a time of rapid urbanisation, with a UN projection that 75 per cent of the population will be living in cities by 2050 , there is a critical need to revisit third place as a possible contribution to easing increasing levels of anxiety and loneliness and thereby contributing to the health and well-being of individuals and communities (Hollis 2013; Jacobs 1996; Firth et al. 2011; Putnam 2000).

There has been a great deal of interest the concept of third place. A 2018 Google Scholar search on Oldenburg's 1989 book found it cited in 2634 articles. Oldenburg published his second third place book Celebrating The Third Place: Inspiring Stories about the 'Great Good Places' at the 
Heart of Our Communities (2001) at the turn of the century. The book is a collection of 19 essays which tell stories by proprietors and patrons about successful businesses in the USA which have purposely incorporated third place in their physical planning and urban design schemes. These include a shopping centre, tavern, restaurant, coffeehouse, garden shop and a bookstore. Both of Oldenburg's books continue to inspire research across a broad range of locations and in a variety of theoretical frameworks. For example, authors have incorporated the third place concept into the design of aged care facilities; many have explored new types of third places such as libraries, parks and other non-commercial public places; and others have investigated cyberspace and social media in terms of third places. For example, Mele et al. (2015) found that wet markets in Singapore are a good example of third places, facilitating casual and regular social interactions between local residents across ethnicities, gender and socio-economic status. Jones et al. (2015), discovered that fast food outlets act as effective third places bringing together ethnically diverse customers, facilitated by their predictability and ubiquity. There are ever new places which can be added to the list of third places, including the camaraderie which is evident in smoking zones in the countries with limited public spaces for smoking; or the height of popularity of the game of Pokemon Go, where everyone from school children to adults with child-like wonder traipsed through churchyards, building foyers, parklands using their mobile devices searching for place-based electronic creatures.

Third places are important because they act as 'mediation between the individual and the larger society' and increase neighbourhood sense of belonging and community (Oldenburg 1999 p.xxix). Numerous social researchers suggest that everyday incidental interactions of third places improve relationships between neighbours; decrease loneliness and isolation; improve the perception of safety; build social capital and create a sense of place (Oldenburg 1999; Thompson and Maggin 2012; Galdini 2016; Vincent et al. 2016).

\section{PLANNING FOR COMMUNITY: HISTORICAL LEGITIMISATIONS}

This section highlights particular sites in which ideals of community were/ are employed as planning techniques, with the intention to produce specific outcomes and achieve particular economic ends - disciplined, docile subjects and collectives. We draw attention to Ebenezer Howard's Garden City; Frank Lloyd Wright, Raymond Unwin and Charles Reade's versions of the same; New Urbanist interventions and Eco-Village promulgations 
primarily to suggest some of the historical precedencies that many urban planning discourses re-produced as more-or-less 'truthful', 'normal' and 'good'. In addition, by including references to some of the 'heroic' patriarchal planning histories - Howard, Wright, Unwin and Reade - it is not our intention to re-inscribe, what Leonie Sandercock refers to as totalising modernist narratives. Rather, following Sandercock the revisiting of these histories is to 'recover, to make visible, these stories that have been rendered invisible' (Sandercock 1998 p. 5). It is pertinent to consider the planning context and historical ideals of community as the context for third places. As Oldenburg explained, 'American planners and developers have shown a great disdain for those earlier arrangements in which there was life beyond home and work' (Oldenburg 1989 p. 18). This leads to Oldenburg's description of third places as 'those gathering places where community is most alive and people are most themselves' (Oldenburg 1989 p. 40).

\section{Garden City Emergences}

One of the most enduring and influential planning treatises that sought to construct the site of 'community' as civil, moral and good was Ebenezer Howard's Garden City model. Howard (1850-1928) drew from a wide range of literature and ideas of the late nineteenth century to address issues arising from the mass migration of rural dwellers to city centres. Through planning and design of self-contained and self-governing Garden Cities, linked by rapid transport routes, Howard sought to provide the accessibility and sociability of the city together with the healthiness of country life. In his book To-morrow: A Peaceful Path to Real Reform the Garden City is given as being aligned with nature, offering social opportunities, ample recreation areas that are readily and easily accessible to all residents, a healthy inexpensive lifestyle, clean air and water, well paid employment opportunities, sound investment potential, and the freedom of individuality within the context of 'community' co-operation (Hall and Ward 1998). It was thus fully inclusive. Howard's aim, according to Jane Jacobs, 'was the creation of self-sufficient small towns, really very nice towns if you were docile and had no plans of your own and did not mind spending your life among others with no plans of their own' (Jacobs 1972 p. 27). The Garden City is given as the epitome of 'the good life'; an ideal rather than a lived experience. In this model all residents are disciplined, docile and obedient subjects and there is no dirt, poverty, illness, or disease. Notwithstanding, Howard did acknowledge the existence of individuals who required specialised care. He notionally allowed for a lunatic asylum sited within the greenbelt bounding the Garden City. 
Howard's Garden City 'community' included a range of people from industrial capitalists to low paid labourers and the political structure of the Garden City was based upon equality, mutual consensus, sharing and fairness. The boundaries of the Garden City are restricted and fixed by the feasibility of all members to participate in a mutual communicative process, so limiting the number of people who can live within the city. Also, membership of the collective is only ascribed to those who actively and physically participate. Those who choose not to participate or are unable to, are alienated or deemed to be deviant. The Garden City model, thus delineates the included 'us' from the excluded 'them' and determines what is 'ours' and what is 'theirs'.

At the same time that Howard was experimenting with his Garden City model, the American architect Frank Lloyd Wright (1867-1959) was arguing for a city planning approach that reflected and embodied democracy and the modern world. Wright's utopian vision for 'Broadacre City', as with Howard's Garden City, emerged at a time of social dis-ease, with the 'ills' of capitalism and overcrowding being the primary impetus for city planning practices of the day. Wright's planned city, as with some of his contemporaries - in particular the Swiss/French architect, Le Corbusier was largely premised on the belief that physical planning practices could produce the greatest happiness for the greatest number. Thomas Osborne and Nikolas Rose (1999 p. 747) argue that Wright's model city - as with Corbusier's versions - was a governmental space: 'in the sense that the construction of this organic social city and the normal citizen who will inhabit it functions as the regulative ideal of a range of programmes and initiatives within which the normal citizen is the social citizen of what [has been called] "healthy social communities".

As did Howard, Wright too sought to create an urban environment that would facilitate healthy and happy subjects, achieved through planning techniques that deployed ideals of community. Wright's Broadacre City, as the title implies, was a merging of city life and country values. Wright sought to establish 'community' through the provision of extensive farm and recreational areas, pollution free factories, local schools, a range of houses to cater for a cross-section of the population, and an inclusive local government structure. Wright argued for an organic architecture that responded to local topographies, climates, and functions. Like Howard, Wright recognised the importance of modern technology rather than harking back to the Middle Ages for his imagery, as some of his English contemporaries - Raymond Unwin in particular - were advocating. Wright's model city boldly embraced modern ideology, the car and manufactured standardised components. By the 1960s, however, these Modernist town planning techniques and practices were being criticised 
for producing a 'low grade, uniform environment from which escape was impossible' (Mumford 1991 p. 553). This criticism was reiterated in the 1990s by the New Urbanists - as argued below - who blamed Modernist planning practices for the demise of 'community' and all that pertains to 'the good life'. Oldenburg (1989 p. 180) describes the effects as: 'The planners and developers continue to add to the rows of regimented loneliness in neighborhoods so sterile as to cry out for something as modest as a central mail drop or a little coffee counter at which those in the area might discover one another.'

In Britain, Modernist town planning techniques and practices were mostly portrayed in the post World War Two re-workings of Howard's Garden City model, renamed 'New Town'. The early New Towns were government incentives with a focus on public housing and employment opportunities, although not always within walking distance as with Howard's model. This new version of the Garden City sought to address issues arising from the post war period: affordable housing for returning war veterans, the growing use of the motor vehicle, and the fashionable shopping mall. Oldenburg (1989 p. 282) noted the post World War Two period as a turning point for an 'informal public life' as people retreated to their homes and corner stores and cafés have 'fallen to urban renewal', replaced by freeways and modern infrastructure.

Although New Town planning techniques were influenced by and reflected contemporary (late 1940s-1950s) trends and technologies, at the same time they largely drew upon and re-produced Howard's early 1900s city-in-the-country model. New Towns were sited in rural areas and as such were promoted for their country lifestyle; a 'more balanced and complete community life' (Freestone 1989 p. 227). Many New Town planners looked to a past romanticised ideal of village life to create an essentially urban 'community'. In these instances ideals of community were invoked to depict nostalgia for the 'good old days'. The historically imagined, gemeinschaft ideals of community that the planners were promoting, however, seemed no longer applicable or possible. The changes in lifestyles and trends in the late 1950s and 1960s suggested many people did not have the same connection to place that traditional village life relied upon. Increased mobility during this time, higher wage opportunities, and changes in gender roles and technology - and therefore labour requirements - often meant fundamental changes to many urban living patterns. Oldenburg (1989 p. 285) noted, 'Segregation, isolation, compartmentalization and sterilization seem to be the guiding principles of urban growth and renewal.'

As with Howard and Wright's city planning models, New Town ideals of community were to be achieved primarily through the provision for 
a range of houses to cater for a range of people. Unlike some of the nineteenth-century social mix planning techniques - that co-located working and middle class housing - the planning of New Towns relied on the social and physical segregation and ranking of blue and white collar workers. B.J. Heraud (1968 p. 35) argues that there was a supposition held by many New Town planners that, exposure to a 'mixed environment' would 'enlarge people's horizons and so benefit society as a whole'. In addition, Mark Peel (1992 p. 25) suggests that there was a general belief among many planners, at the time, that New Towns if planned properly, could still produce valued social outcomes-social mix, neighbourhood community, and village-like social relationships'. This achievement was flawed from the outset given the differences between the spontaneous and irregular characteristics of village layouts and the planned and controlled New Town landscapes. As N. Dennis (1968) points out, village life revolved around an overlapping and complex web of everyday relationships with people who were generally known and named. New Town planning, however, involved a group of new residents who did not necessarily know each other or have anything in common. It could be argued that this set of circumstances cries out for informal meeting places. Oldenburg (1989 p.286) discusses the challenges of 'trying to enjoy life amid a badly designed environment' and suggests that 'grass roots efforts are the best hope for creating enjoyable urban habitats'. Several chapters in this book discuss grass roots efforts to create a sense of community, in particular, Chapter 7 which looks at music archives and Chapter 8 on community gardens.

By the 1980s, the commitment of the Australian government (and the British government) to New Town programmes was dwindling. This was partly the result of increased migration, demographic and lifestyle shifts and changes in modes of government. The withdrawal of the government from direct involvement in the planning and development of new residential areas opened opportunities for private enterprise intervention.

\section{Village Idyll}

Although Howard did not fully realise his Garden City dream, his work was the impetus for others who believed they could instigate social reform through planning for ideals of community. Raymond Unwin (1863-1940), having resigned as Howard's Garden City architect, remoulded Howard's model in line with his own ideology. Unwin focused more on middle class residential commuter suburbs. He drew heavily on the Arts and Crafts Movement of John Ruskin and William Morris and turned to the Middle Ages for his imagery and ideals. This bias was encapsulated in his book 
Town Planning in Practice first published in 1909. In effect, through specific town planning practices Unwin sought to regulate everyday life of the individual, in accordance with particular ideals of community, an argument which is taken up a little later.

For Unwin, village life encapsulated 'the good life' and ideals of community. The village was a site of both social and aesthetic value; social in terms of bringing together a group of like-minded people, with similar values and interests, and aesthetic in the sense of place creation. Unwin believed that through the use of local building materials and practices, residents would establish an identity and a sense of belonging to place. This common identity he argued established 'community', as people shared common ties and memories. Unwin's concept of 'community' is thus closely aligned with gemeinschaft relationships. Here, 'community' is consigned to being rural as opposed to urban. It is associated with belonging rather than alienation, communality rather than individualism and the traditional rather than the modern. The urban versus rural dialectic is played out in a direct and blatant fashion. Howard sought to sift the qualities associated with 'the good life' from both poles in his Garden City model, while Unwin drew almost exclusively from the rural pole. In Unwin's argument for a 'new form of community that would rise up out of the land, clear, clean, honest and alive' (Unwin 1994 p.xxi), place-based relationships and imagined, 'golden age' values are re-inscribed.

Unwin sought to rationalise, re-organise and rank the largely incremental and spontaneous planning practices that informed village life in pre-industrial England. He stated that (Unwin 1901 p. 93):

It is the crystallisation of the elements of the village in accordance with a definitely organised life of mutual relations, respect or service, which gives the appearance of being an organised whole, the home of a community, to what would otherwise be a mere conglomeration of buildings.

This attempt by Unwin, to create a 'new form of community' by developing low density residential 'villages' for like-minded people, has been criticised for propagating suburban sprawl and reinforcing social polarisation. As we will demonstrate, many current planners and developers also promulgated village planning techniques and practices as a means to produce ideals of community.

Unwin's village model emerged in the antipodes and found its way to South Australia through Charles Reade (1880-1933). Reade was commissioned by the South Australian government to design a garden suburb as a model example of latest planning practice. The new fully planned village, now known as Colonel Light Gardens, contrasted with existing suburban development which was largely haphazard and subject to opportunists 
and laissez-faire practices. Australian suburban development had emerged in opposition to the slums; the 'dense, dirty, unnatural, disorderly and disease ridden, vs [the] open, clean, natural and healthy'(Davison 1993 p. 3). Reade traded heavily on this imagery in his argument for the village model. Reade's model was underpinned by and realised through the implementation of planning techniques pertaining to ideals of community.

Like Howard and Unwin, Reade attempted to plan a residential setting that would be manifest through largely utopian images of docile and happy 'community' subjects. Reade's village model represented a healthy environment, an enclave for white nuclear families, a moral and upright 'community', stability, conformity and a sound financial investment (Freestone 1989 pp. 84-85). The Australian suburbs have historically been socially exclusive places, home only for those who could afford to move from the dense and overcrowded cities to embrace the country lifestyle which suburbia promised.

\section{Urban Villages ${ }^{1}$}

Much of the recent (1990s-2000s) planning rhetoric about the re-creation of villages and re-establishing of 'communities' is essentially about a lifestyle that is walkable. In these discourses a walkable lifestyle is promoted as being one that fulfils and sustains everyday needs within the locality, so reducing the need to use non-renewable resources. In these new villages, the government of everyday life is through practices of social interaction, through physical mobility (walking or cycling) and local travel. The Modernist planning techniques regulated behaviour through motorised travel and many Modernist planners argued that this mode of travel liberated the individual. Liberation and 'freedom' are now construed in relation to physical mobility. Through planning practices that emphasise pedestrian propinquity, individuals are 'liberated' from the car and from the negative impacts of suburban landscapes. Howard's Garden City model too, allegedly, offered residents 'freedom' to walk to places of employment and places of recreation. This focus is reiterated in the New Urbanists discourses: passive social contact, proximity and appropriateness of space.

The New Urbanist Movement was established in the early 1990s by a group of American architects and its proponents believe it is poised to become the dominant real estate and planning trend of ... [this] century' (Steuteville 2000). The New Urbanist Movement (largely operated

\footnotetext{
1 The term 'urban village' was popularised by HRH The Prince of Wales in the 1980s.
} 
through private enterprise practices) has had a significant impact on some of the planning policies, legislation and projects set up by the American Federal Department of Housing and Urban Development (HUD). The movement is described as a reworking of traditional neighbourhood ideology for the social environment of the 1990s (Fulton 1996). Heidi Landecker (1996) likens the movement to a new religion with prophets (founders Peter Calthorpe, Elizabeth Plater-Zyberk and Andres Duany), a Bible (The New Urbanism: Toward an Architecture of Community ed. Peter Katz) and thirteen commandments given to regulate planning and development practices. New Urbanist development practices have been primarily taken from Unwin's Town Planning in Practice first published in 1909 and Clarence Perry's 'Neighbourhood Unit' of 1929.

New Urbanist discourses claim to address the 'ills' of Modernism and the 'evils' of conventional suburban planning of the 1930s and 1940s. Modernist architects, such as Le Corbusier and Frank Lloyd Wright, are blamed for the demise of 'vital communities' by privileging private over public spaces, focusing on the motor vehicle and instigating segregation policies (Calthorpe 1994 p.xv). The Modernists, Vincent Scully (1994) laments, killed the traditional city and everything that pertained to 'the good life': 'community', 'correctness' and 'humanness'. Many New Urbanists consider American suburbia to be a landscape that largely inhibits experiences of 'the good life' - ideals of community and gemeinschaft relationships. Suburbia is depicted as being lonely and isolated, without public spaces to gather informally; a place where children grow up unbalanced, without any understanding of traditional (gemeinschaft?) values, morals or social responsibilities (Audirac 1999). As Oldenburg (1989 p. 282) described, 'Adolecents spend more time in shopping malls than they do in any place beyond home and school. The duel degree is in consumership and passivity'. In response to the view of suburbia, many New Urbanists argue for a return to a cherished national icon, 'that of a compact, close-knit community' (Katz 1994 p.ix) achieved through comprehensive, historically founded, more-or-less 'truthful' planning techniques.

As such, the New Urbanist ideology remains within a Modernist agenda. The Modernists too believed that by the design of physical infrastructure particular social patterns could be created or influenced. For them it was through the dominance of car travel and the development of tower blocks. The New Urbanists seek to achieve the same end through a return to traditional village life. Both argue for the creation of 'community' (however defined) achieved through planning and built form as the means to cure the contemporary 'ills' of society. While the Modernists sought to achieve their end through the celebration of new technology and affirming 
their belief in the future, the New Urbanists look to a romanticised past (a pre-capitalist, pre-industrial, pre-motorised era) for their realisation of 'community' (Audirac and Shermyen 1994).

For the New Urbanists, it is the fundamental qualities of small country towns or villages that they wish to emulate, rather than city urbanity. Peter Calthorpe gives the key New Urbanists planning determinates as being 'pedestrian scale, an identifiable centre and edge, integrated diversity of use and population and defined public space' (Calthorpe 1994 p. 122). These 'post-suburban' developments are proposed to include the urban advantages of employment, civic, commercial and retail opportunities coupled with the rural advantages of clean air, healthy lifestyles and open public spaces. These qualities the New Urbanists state - as did Howard - are essential for 'restoring functional, sustainable communities' (Steuteville 2000).

In keeping with Howard's Garden City model and the subsequent derivatives, the New Urbanists claim for 'community' also includes a variety of house types and styles for a range of life stages and incomes. The New Urbanist Charter (Congress for the New Urbanism 1998) states 'Within neighborhoods, a broad range of housing types and price levels can bring people of diverse ages, races, and incomes into daily interaction, strengthening the personal and civic bonds essential to an authentic community.' The difference between the earlier city/town/village planning models and the New Urbanists models rest in private enterprise interests. Ideals of community become a commodity only for those who can afford them.

The rationalities of government underpinning these new 'fully planned communities' are no longer fuelled by aspirations of social reform for the poor. Rather, they are influenced by market forces, where ideals of community are commercialised and sold as a commodity for profit. Any remnant of social reform embedded in these rationalities applies only to those who can afford it. Andres Duany and Elizabeth Plater-Zyberk suggest that middle-class home owners reduce the number of cars per family, in order to set back the higher costs of living in a New Urbanist development. They state 'No other action of the designer can achieve an improvement in the availability of housing for the middle class comparable to the sensible organization of a good neighborhood plan' (Duany and Plater-Zyberk 1994 p.xix).

In arguing for a new (or not so new) pattern of urban development the New Urbanists assume that the majority of Americans are inherently unhappy and dissatisfied with suburban life: a large allotment, detached house, back yard, privacy and car reliance. Some research suggests however, that suburbia fosters positive relationship networks because 
residents tend to be of similar life stages; for example, young families, families with teenagers or retirees.

The use of ideals of community as planning techniques - be they espoused by New Urbanists or others - has ethical implications in that planners become implicated in regulating and moulding behaviour patterns to certain ends: collective cohesion, interaction, sharing, supportive networks, membership and personal investment. Ideals of community utilised as planning techniques also assumes that individuals have a predisposition for neighbourly interaction, irrespective of personal histories, incomes and beliefs. In addition, they assume that residents will be happy to reduce or moderate their use of the car in an environment that is not always conducive to the economic journey. Oldenburg (1989 p. 286) refers to informal public life of the past as the "triumph of the space user over the space planner - we simply took over establishments and spaces created for other purposes. What is revolutionary about our new environment is its unprecedented resistance to user modification.'

\section{'Sustainable' Villages}

More recently a new village product has entered the housing market. This fully planned product, or Eco Village, is designed in accordance with accepted sustainability principles; most commonly: recycling, solar power and rain water retention infrastructures. Many Eco Village discourses re-inscribe New Urbanist planning techniques in a bid to create ideals of community. Hugh Barton (2000 p. 11) defines an Eco-Village as 'an attractive, convivial and healthy place that balances privacy with community and local provision with city access'. As do the New Urbanists, EcoVillage discourses also argue for ideals of community as produced through an assemblage of urban and rural lifestyle rhetorics. Similar to Unwin and Wright's theorisations, identity with place is to be achieved through practices of planning and architecture, which are to respond to the local climate, topography and landscape. The model for these contemporary villages suggests they are located in country areas and include a range of employment opportunities to cater for all skill levels. Eco-Village proponents also argue for residential diversity - a range of house sizes and styles and diversity of people, from across the full spectrum of the population - as a planning technique essential for the production of 'sustainable communities'. It is through the practices of planning and architecture that, Alison Gilchrist (2000 p. 150) suggests, ideals of community become 'inextricably linked to sustainability'.

Eco-Villages are also resource inclusive developments with a focus on pedestrian propinquity; in that schools, retail, commercial and civic 
amenities are provided for, in conjunction with residential accommodation. Like the New Urbanists, the assumption underpinning Eco-Village planning techniques is that the provision of local amenities and an emphasis on pedestrian propinquity will produce friendly verbal interaction and local networks will be established. Importantly, this 'sustainable' village model is based upon efficient networks of activities and travel within and between villages, so eliminating the need for a privately owned motor vehicle, and traditional village values apply: gemeinschaft relationships and 'the good life'.

Eco-Villages, as with previous schemes, have been criticised for ignoring the existing pattern of contemporary life. Taylor (2000 p. 28) suggests that a 'new' model of development is not what is required to achieve the desired and much debated ecologically sustainable - and we would add 'community' formation - goals. Rather, planners, architects and other urban theorists need to work within the given fabric of modern urban life if any significant change is to be realised. Goals need to be realistic rather than based on utopian ideals of social mix and ideals of community. Peter Hall and Colin Ward (1998 p. 121) suggest this involves, among other things, equally top-down State regulations and bottom-up local approaches. In our positioning of third place, this book acknowledges both these governmental modes of producing place and community networks. This historical background provides the rationale for the variety of planning and design contexts within which third places exist (or don't exist) and in which grass roots actions of the residents can create third places.

\section{STRUCTURE OF THE BOOK}

The book explores the virtual and geographical understanding of place and community through the lens of third places. The first six chapters focus on theoretical and broad concepts of third place for example: rethinking third place and community (this chapter); feminist perspectives; life stage perspectives: older age and child friendly; and urban design and safety considerations: green planning and eyes on the street. The final five chapters focus on specific examples of third places: community museums; community gardens; cyber space; public transport and sidewalks.

In Chapter 2, 'Feminist Perspectives on Third Places' Simone Fullagar, Wendy O'Brien and Kathy Lloyd apply a feminist perspective to third place, concluding that women require third places that are both physically and socially transparent, that is, safe spaces. This chapter questions normative urban design assumptions often associated with white middle class male views. The feminist perspective was not included in Oldenburg's 
early work largely because the prevailing assumption of the time was that feminine space related to the home (first place). Fullagar et al. identify how third places facilitate or constrain women's right to the city. The focus on feminism in this chapters also highlights links between third place and transgender and non-binary identities. It also points to ways of thinking about gendered experiences relating to class, sexuality, culture, age and ability. Building upon Oldenburg's conception of third places as places where people interact, the authors discuss third places as more than human, places where people also interact with plants, animals and urban infrastructure. The chapter concludes with an acknowledgement that third places are essentially good and they call for more work to be done to create places that are inclusive for everyone and which allow all people to exercise their right to the place.

Chapter 3 builds on concerns of gender and third places to focus on the latter stages of a life. Sara Alidoust and Caryl Bosman analyse third places in terms of the contributions they can make to promoting social health for many people over the age of 65 . Ageing populations are world-wide phenomena and there is general acknowledgement that urban design and planning principles, including the provision of third places, need to recognise and support active and healthy ageing agendas. Accessibility of amenities is critical in achieving these agendas. The chapter concludes by arguing for the planning of transport and third place interventions in sprawling suburban landscapes, to allow older people more opportunities to be socially connected.

The other end of the lifecycle continuum is taken up in Chapter 4 by Geoff Woolcock in his chapter on child-friendly third places. Geoff investigates third places in relation to how child friendly they are, using South Bank Parklands in Brisbane, Australia as a case study. He unpacks the significance of built and natural third places in the health and well-being of children and young people. Woolcock paints a disturbing picture of childhood obesity, inactivity and social disconnectedness and argues for the importance of well designed third places that, "not only welcome children but also establish social and psychological connections that stimulate learning and ultimately, active civic participation'. The chapter provides the traits of an effective child-friendly third places including opportunities for unstructured, challenging, adventurous (but safe) play.

Elizelle Juaneé Cilliers' chapter, Chapter 5, seeks to demonstrate the value and role of planning in creating and recreating public spaces which are third places; neutral places which provide opportunities for people to meet and interact and to develop a sense of being a part of a place. To do this she identifies a number of design elements to support the provision and reclaiming of third places in contemporary urban contexts. Through 
different approaches to planning (place-making, green planning and lively planning) she establishes an evidenced-based framework using five international, best-practice case studies to develop third places. The chapter concludes with a global challenge 'to change life, we must first change spaces into third places'.

In keeping with the urban planning/design theme, in Chapter 6 Gordon Holden draws on Jane Jacobs' 'Eyes on the Street' to examine the role of third place in improving perceived safety. Holden focuses on the multidimensional and interconnected aspects of perceived and actual safety within the context of third places in neighbourhoods. He discusses the complexities surrounding the concept of neighbourhoods and the positive arguments for 'eyes on the street' in urban environments as means to create perceived and actual zones of safety. Holden proposes that third places contribute to 'eyes on the street' and therefore safety because these places act as nodes, attracting public participation and interaction. Through the use of four case studies on the Gold Coast, Australia he explores the presence or absence of third places within the context of recorded crime in those places. He concludes that third place may well contribute significantly to both the perception of and actual safety of a place and lower crime rates.

The remaining chapters in the book looks at particular sites as third places. The concept of third place also includes places that foster hobbies and collective networks as in the theme of Chapter 7: 'Understanding Popular Music Heritage Practice Through the Lens of "Third Place". Lauren Istvandity, Sarah Baker, Jez Collins, Simone Driessen, and Catherine Strong draw from different case studies ranging from do-ityourself archiving, digital archives, walking tours, and pop music reunion tours to build a convincing augment for the value and currency of alternative third places in urban areas. Baker, in particular, points to the value of community archives and museums as third places which foster social health and can prevent an increase in social isolation among older single adults. In the same chapter Collins posits third places in the virtual online space. This new variety of third place, she argues, allows 'individuals come together online, forming communities dedicated to creating, populating, sustaining and celebrating alternative popular music histories'. The final section of this chapter focuses on tours as third places. Strong's thesis is built around 'how the physical space of urban environments plays a role in how popular music is remembered'. She argues that walking tours are inherently third places. Driessen considers how 'the reunion concert tour of heritage music acts as a site where aspects of third place are enacted'. In this understanding of third place, the reunion concert venue becomes a temporary third place. 
Chapter 8, by Joanne Dolley is entitled Third Places and Social Capital: Case Study Community Gardens'. This chapter explores the literature on community gardens and the author's recent research which investigated community gardens against third place characteristics in a range of locations in Australia and Denmark. All of the case study community gardens exhibited most or all of the eight third-place characteristics and some were particularly effective third places. The theoretical framework used for this research project is social capital and more specifically, Gravonetter's 'weak ties'. The chapter gives examples of ways in which community gardens can act as third places. The findings provide insights for better design of third places and the design of community gardens, where building social capital and sense of community is a goal.

Dmitri Williams and Do Own Kim's chapter, 'Third Places in the Ether Around Us: Layers on the Real World', focuses on the third places which exist beyond the 'physical realm' to non-physical spaces made possible through technology. They approach the topic through theories utilised in the study of computer-mediated communication, in particular the concept of 'layering' of multiple online and offline environments. Williams and Kim outline the strengths and weaknesses of virtual places over real-world places. They identify aspects of virtual space which enhance third place interactions by cutting through barriers of socio-economic status and physical attributes. However, the authors caution on the use of filter bubbles, which feed us interactions with like-minded people, isolating our social connections somewhat like a gated community - possibly Oldenburg's 'worst nightmare'. Williams and Kim also draw attention to new technology blurring the edges between first, second and third places, for example, as social media interrupts work, work emails edge into home life, and third place virtual games take place at home. The chapter concludes that as we move into an 'ever-more technologically mediated future', technology has potential to provide third places to anyone anywhere, but just as physical architecture influences human behaviour, it is important to consider the design of the social 'architecture' of online spaces.

Chapter 10 focuses on public transport as a third place. Daniel O'Hare 'considers whether the public transport commute, historically a linear experience between the workplace and home, can be a third place rather than a soulless shuttle to be bracketed with "work" as the opposite to "home". O'Hare examines the changing nature and form of work and he links this to the design of cities and the experience of commuters' journeys. He posits that many young adults today (2018) are choosing not to drive and consequently the use of public transport, active modes of travel and third places are flourishing. Public transport is continually shaping and 
reshaping the level of passenger interaction, with in-vehicle design and waiting areas (station/stop) designs either facilitating or limiting certain types of interactions. The use of mobile technology means many public transport users can connect to virtual communities and so transform the travel journey into a third place. The chapter ends with a call for a greater recognition of public transport as a third place to be 'enjoyed rather than endured' and that well-designed and managed public transport contributes to people-centred cities.

The final chapter, Chapter 11, by Leila Mahmoudi Farahani and David Beynon, focuses on streets as sites of third place activity. By analysing the unobtrusive video footage of interactions which occur along several commercial streets in the City of Greater Geelong, Victoria, it was determined that sidewalk cafés and restaurants, shops and interaction zones such street crossings act, in varying degrees, as third places. Their methodology of video analysis of the use of space and their depiction of findings through diagrams provides a unique level of detail of third place interactions. Using their data and referring theoretically to Lefebvre's ideas on meanings in space, they are able to comment on what makes a vital, active streetscape and propose design features which can enhance the design of third places.

\section{CONCLUDING THOUGHTS}

Third places are neutral, open places which act as levelers to bring together local residents of different ethnicities, ages, genders, socio-economic status, education levels and interests. Third places are sites of diversity where everyone is welcome, free to come and go and feel comfortable. Third places can play an important role in improving social interactions in neighbourhoods. Ray Oldenburg, the creator of the concept, listed many examples of third places, such as parks, cafés and piazzas, where people could meet informally. This chapter provides the historical and current urban planning context in which third places reside. This book is a timely exploration of the role of third place in building relations of community in a modern highly urbanised mobile society.

\section{REFERENCES}

Audirac, I. (1999) 'Stated preference for pedestrian proximity: An assessment of new urbanist sense of community', Journal of Planning Education and Research, 19(1): 53-66. 
Audirac, I. and Shermyen, A.H. (1994) 'An evaluation of neotraditional design's social prescription: Postmodern placebo or remedy for suburban malaise?' Journal Of Planning Education and Research, 13(3): 161-173.

Barton, H. (2000) 'Conflicting perceptions of neighbourhood'. In Barton, H. (ed.) Sustainable Communities. London: Earthscan, pp. 3-17.

Calthorpe, P. (1994) 'The region'. In Katz, P. (ed.) The New Urbanism: Toward an Architecture of Community. New York: McGraw-Hill, pp. xi-xvi.

Congress for the New Urbanism (1998) 'Charter of the new urbanism'. Available: www.cnu.org (accessed 3 December 2018).

Davison, G. (1993) 'The past and the future of the Australian suburb'. In Coles, R.C. (ed.) Urban Research Program. Canberra: Research School of Social Sciences, Australian National University, pp. 1-26.

Dennis, N. (1968) 'The popularity of the neighbourhood community idea'. In Pahl, R.E. (ed.) Readings in Urban Sociology. London: Pergamon, pp. 74-92.

Duany, A. and Plater-Zyberk, E. (1994) 'The neighborhood, the district and the corridor'. In Katz, P. (ed.) The New Urbanism: Toward an Architecture of Community. New York: McGraw-Hill, pp.xvii-xx.

Firth, C., Maye, D. and Pearson, D. (2011) 'Developing "community" in community gardens', Local Environment: The International Journal of Justice and Sustainability, 16(6): 555-568.

Freestone, R. (1989) Model Communities: The Garden City Movement in Australia. Melbourne: Thomas Nelson Australia.

Freie, J.F. (1998) Counterfeit Community: The Exploitation of Our Longings for Connectedness. Maryland: Rowman \& Littlefield.

Fulton, W. (1996) 'The new urbanism challenges conventional planning', Land Lines, September 8(5).

Galdini, R. (2016) 'Placemaking as an approach for innovative urban renewal practices: Community gardens in Berlin', International Review of Sociology, 2016: $1-21$.

Gilchrist, A. (2000) 'Designing for living: The challenge of sustainable communities'. In Barton, H. (ed.) Sustainable Communities. London, Earthscan, pp. $147-159$.

Hall, P. and Ward, C. (1998) Sociable Cities: The Legacy of Ebenezer Howard. London: John Wiley \& Sons.

Heraud, B.J. (1968) 'Social class and the new towns', Urban Studies, 5: 33-58.

Hollis, L. (2013) Cities Are Good for You: The Genius of the Metropolis. London: Bloomsbury Publishing.

Howard, E. (1898) To-morrow: A Peaceful Path to Real Reform. London: Swan Sonnenschein \& Co.

Jacobs, J. (1972) The Death and Life Of Great American Cities. London: Penguin.

Jacobs, M. (1996) The Politics of the Real World. Meeting the New Century. London: Earthscan Publications.

Jones, H., Neal, S., Mohan, G., Connell, K., Cochrane, A. and Bennett, K. (2015) 'Urban multiculture and everyday encounters in semi-public, franchised café spaces'. The Sociological Review, 63(3): 644-661.

Katz, P. (1994) 'Preface'. In Katz, P. (ed.) The New Urbanism: Toward an Architecture of Community. New York: McGraw-Hill, pp. ix-x.

Landecker, H. (1996) 'Is new urbanism good for America?' Architecture AIA Journal, 85(4): 68-77.

Mele, C., Ng, M. and Chim, M. (2015) 'Urban markets as a "corrective” to advanced 
urbanism: The social space of wet markets in contemporary Singapore'. Urban Studies, 52(1): 103-120.

Mumford, L. (1991) The City In History: Its Origins, its Transformations and its Prospects. London: Penguin Books.

Oldenburg, R. (1989) The Great Good Place: Cafes, Coffee Shops, Community Centers, Beauty Parlors, General Stores, Bars, Hangouts, and How They Get You Through the Day. New York: Paragon House.

Oldenburg, R. (1997) 'Our vanishing third places'. Planning Commissioners Journal, 25: 6-11.

Oldenburg, R. (1999) The Great Good Place: Cafes, Coffee Shops, Bookstores, Bars, Hair Salons, and Other Hangouts at the Heart of a Community. New York: Marlow \& Company.

Oldenburg, R. (2001) Celebrating the Third Place: Inspiring Stories about the 'Great Good Places' at the Heart of Our Communities. Boston: Da Capo Press.

Osborne, T. and Rose, N. (1999) 'Governing cities: Notes on the spatialisation of virtue', Environment and Planning D: Society and Space, 17(6): 737-760.

Peel, M. (1992) 'Planning the good city in Australia: Elizabeth as a new town'. In Coles, R.C. (ed.) Urban Research Program, Working Paper No. 30, pp. 1-60. Canberra: Research School of Social Sciences, Australian National University.

Perry, C. (1929) 'The Neighborhood Unit', Monograph One. Vol. 7, Regional Survey of New York and its Environs, Neighborhood and Community Planning. New York: New York Regional Plan, 1929.

Putnam, D. (2000) Bowling Alone. New York: Simon \& Schuster.

Sandercock, Leonie (1998) Towards Cosmopolis. London: John Wiley \& Sons.

Scully, V. (1994) 'The architecture of community'. In Katz, P. (ed.) The New Urbanism: Toward an Architecture of Community. New York: McGraw-Hill, pp. 221-230.

Steuteville, R. (2000) 'The new urbanism: An alternative to modern automobileorientated planning development', New Urban News, 28 June 2000. Available: www.newurbannews.com (accessed 20 December 2018).

Taylor, N. (2000) 'Eco-villages: Dreams and reality'. In Barton, H. (ed.) Sustainable Communities. London: Earthscan, pp. 19-28.

Thompson, S. and Maggin, P. (2012) Planning Australia: An Overview of Urban and Regional Planning. Cambridge: Cambridge University Press.

Unwin, R. (1901) 'Building and natural beauty'. In The Art Of Building A Home. London: Longmans Green, p. 93. Quoted in Creese, Walter (1986) The Search For Environment: The Garden City: Before and After. New Haven: Yale University Press.

Unwin, R. (1994) [1909]) Town Planning In Practice. New York: Princeton Architectural Press.

Vincent, C., Neal, S. and Iqbal, H. (2016) 'Encounters with diversity: Children's friendships and parental responses'. Urban Studies, 54(8): 1974-1989. 
Appendix 4 The Conversation Article - co-authored 


\section{Facts matter. Make a tax deductible donation today.}

Donate now

\section{THE CONVERSATION}

Academic rigour, journalistic flair

\section{Many people feel lonely in the city, but perhaps 'third places' can help with that}

March 22, 2018 6.33am AEDT

Third places are most effective when, like Waverley Community Garden in Sydney, they appeal to people of all ages and backgrounds. d-olwendee/flickr, CC BY

\section{Many people feel lonely in the city, but perhaps 'third places' can help with that}

March 22, 2018 6.33am AEDT

Loneliness is a hidden but serious problem in cities worldwide. Urban loneliness is

\section{Authors}

connected to population mobility, declining community participation and a growth in single-occupant households. This threatens the viability of our cities because it damages the social networks they rely on.

One response to these trends involves "third places". These are public or commercial spaces that provide informal opportunities for local people to mix socially on neutral ground.

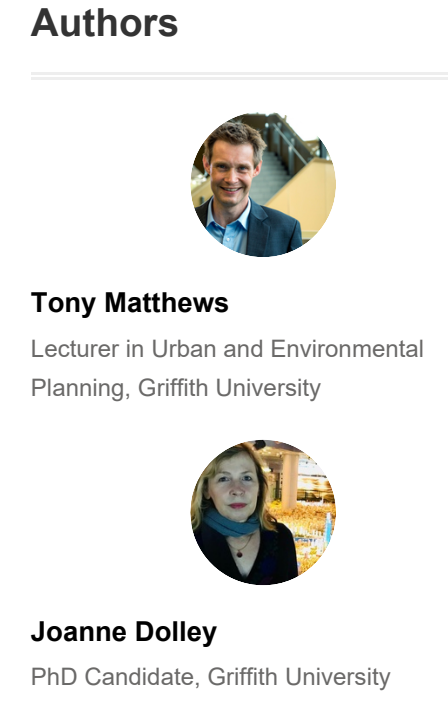




\section{Read more: We are living alone together in today's cities - and that calls for smart and 'bolshie' moves}

The concept of third place, developed by Ray Oldenburg, is distinct from first and second places. A first place is the private space of home. Second places are where people spend significant time, often formally. These include schools, universities and workplaces.

Common examples of third places in cities include community gardens, libraries, public swimming pools, cafes, men's sheds, farmers' markets and dog parks.

Researchers at the Cities Research Institute are investigating whether these "third places" can reduce urban loneliness. Here, we report and discuss some insights from that work.

\section{How can third places reduce loneliness?}

There is growing understanding of the negative outcomes and costs associated with loneliness. These include fractured communities, declining trust, stress, depression and disease. Clearly this is neither desirable nor sustainable.

\section{Read more: Loneliness is bad for your health}

More than a century ago the sociologist George Simmel observed how mobility disrupts social connection and creates isolation. The urban migrant leaves behind their own social ties and often struggles to connect to their new community. This challenges both the migrant and their new neighbours.

Third places can help by creating or enhancing a sense of community on a smaller, more human scale - a relief from the overwhelming sensory experience of a large and unfamiliar city. The village-like feeling of third places can reduce people's anxieties and make them more comfortable with trying a new social experience.

\section{Read more: Neighbourhood living rooms - we can learn a lot from European town squares}

Third-place interactions encourage conversation in a homely atmosphere. Regulars who are local to the area often help with this.

In third places, people are free to come and go without obligation. The status and backgrounds of users are largely irrelevant. These places are generally designed to be accessible, accommodating and inviting for all ages, low-profile, comfortable and conversational. 


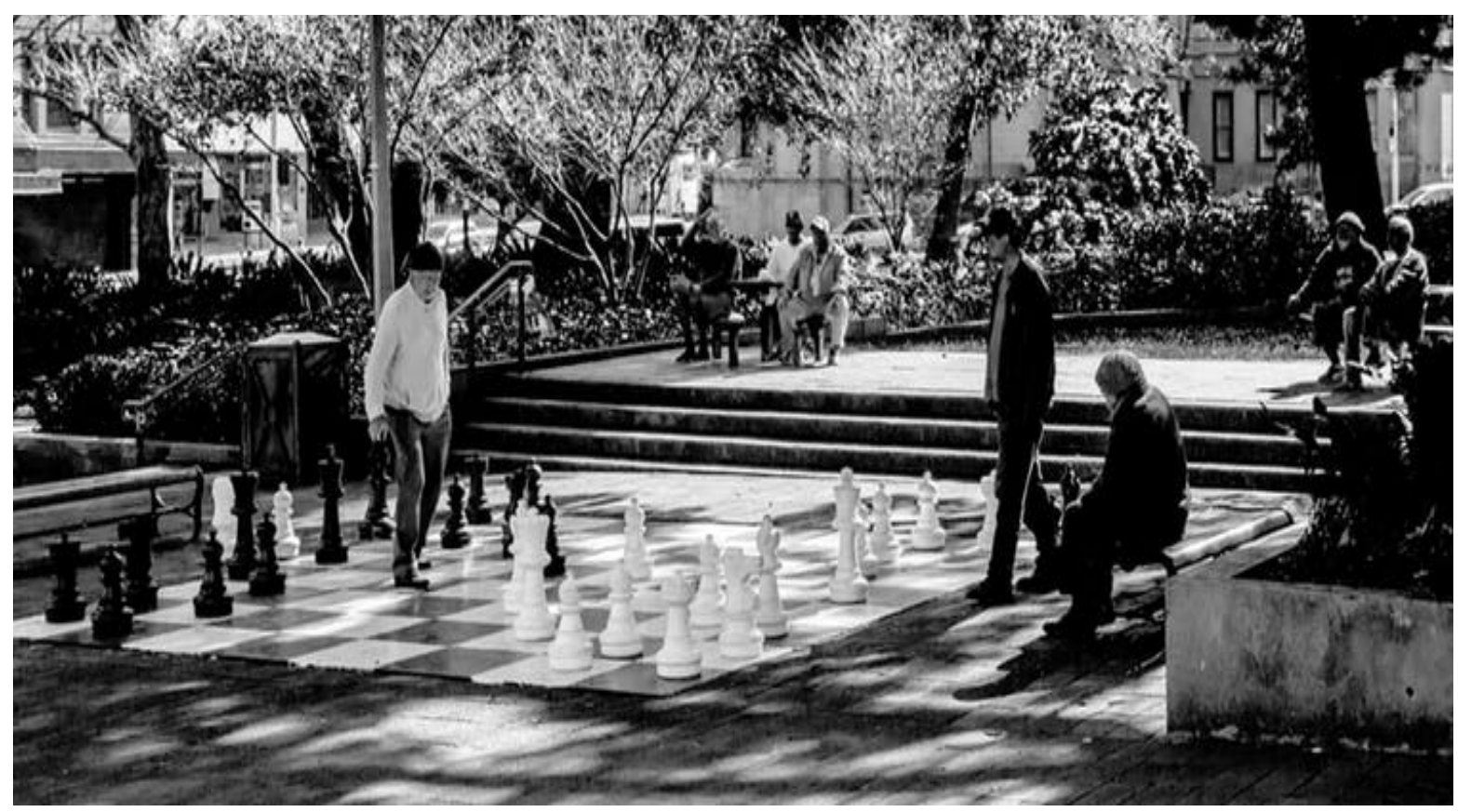

Third places that offer opportunities for shared activities, such as a game of outdoor chess, provide reasons to strike up a conversation. alexmerwin13, CC BY-NC-ND

Third places bring people together based on shared spaces, which become more important than individual histories. This can reduce wariness of strangers and create social connections. Third places can lead to more resilient and better-connected communities, building up social capital, while reducing loneliness.

\section{Providing quality third places}

There are steps that can be taken to design and safeguard third places. Local councils and urban planners have important roles, given their central place in directing land uses.

Perhaps the most important thing is to understand the valuable social capital that successful third places offer. Once planners understand the value of third places, they can actively work to support them.

Walkability is an important factor. Third places encourage familiarity through repeated incidental interactions between locals, both regulars and newcomers. Ideally, people connect within their local neighbourhoods. Being able to visit without needing a car can encourage more people to use a place.

Space for third places can be designed into neighbourhoods and urban areas. Sections of parkland can be given over to public facilities such as outdoor gym equipment, dog parks or skate parks. Dedicated trading areas can be provided for farmers' markets.

Third places are most effective when they encourage interactions between locals. Providing facilities and activities creates a purpose to interactions and reasons to start chatting.

Local councils can support citizen-led activities such as community gardens and men's sheds. They can also provide activities such as Tai Chi classes. 


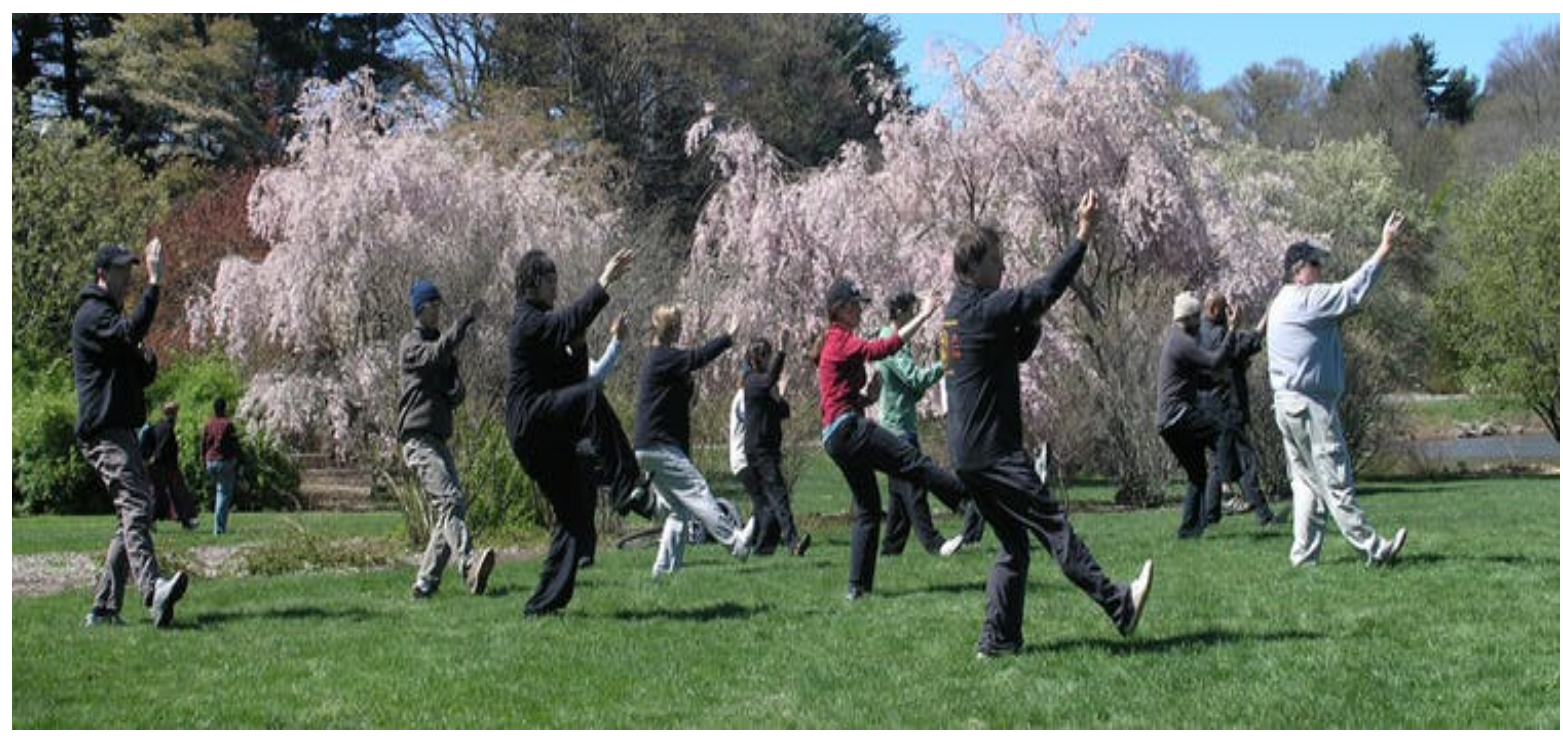

Outdoor Tai Chi classes turn green spaces into third places. Brian Robinson/Flickr

Protecting existing third places is as important as providing new ones. For example, a local council may be tempted to allow housing to take over the site of a community garden. While there may some be reasons to support that idea, it should be carefully considered against the loss of social capital and the risk of entrenching social isolation.

\section{Valuing and promoting third places}

We live in an age of urban mobility with no historical comparison. Many of us have been strangers in a new city. Loneliness is an unwelcome and growing feature of this urban mobility. Third places offer a useful and tested model for reducing loneliness by improving community.

Yet many city dwellers see these spaces but don't use them. In this sense, perhaps the biggest barrier is our willingness to make the time to seek out and participate in third places. For those people who do, banishing loneliness could be one of the greatest benefits.

\section{Read more: Planners know depressingly little about a city's impacts on our mental health}

Cities Loneliness Community Public space Urban community Cities \& Policy Social ties

Neighbourhood cohesion

Before

\section{you go...}

The Conversation serves society by making knowledge accessible to everyone, not just a select few. Our only agenda is a better informed public. If you care about what we do please make a donation now and help secure our future. 
Appendix 5 Interview schedule 


\section{Semi-Structured Interview Questions}

\section{Introduction}

1. How would you describe your role in this community garden? (eg. member, volunteer, regular visitor)

2. How long have you been a member/visitor?

3. How often do you visit this community garden?

4. How did you find out about the garden?

\section{Motivation}

5. Why did you want to join/visit a community garden?

6. Why do you want to grow food?

7. How much space do you have at home to grow plants? Do you grow food at home?

\section{Leveller}

8. What do you think motivated other members to join this garden?

9. How would you describe the people who come here?

10. How welcome did you feel when you joined? Do you think everyone feels welcome? Is it easy for new people to join in?

\section{Accessibility and accommodation}

11. Is there a community garden closer to your home? How do you get here?

12. Why did you choose this community garden?

\section{Conversation/ Playful mood}

13. What sort of activities do you participate in when you visit here?

14. What do you like most about being a member of a community garden?

15. How is the food grown at the community garden distributed when harvested?

16. What are some of the enjoyable aspects of being part of this community garden?

17. Is there something about what you grow that others are interested in?

\section{$\underline{\text { Regulars }}$}

18. Did you already know people here?

19. Can you describe how many regular attendees are here?

20. Do you join in activities outside the garden with any of the members - if so what kind?

\section{Neutral ground}

21. Are children/teens welcome to visit the community garden?

22. Do many casual visitors come here? Are they welcomed? How?

\section{Home away from home/ Low profile}

23. Is it a relaxing place to be?

24. Would you prefer to be here than other places? 


\section{Social media}

25. How important is the internet to your group?

26. What type of social media does your group use? Facebook? Website? Email? If so, how is it used? (ie post photos, email each other, newsletters, keep in touch with each other.) 27. Is this group networked to other groups?

\section{Social capital / weak ties}

28. Do you and/or other members of the community garden participate in other community activities? If so, what sort of activities?

29. Is participation in the community garden different from what you expected? How?

30. What has been the main benefit of joining this community garden?

Demographics(You may choose not to answer these)

1. male/female

2. What age group are you in? $16-25 ; 25-50 ; 50-65 ; 65+$

3. Approximately how many hours of daylight uncommitted leisure time do you have per week? / What is your main occupation?

4. What is your first language/language spoken at home?

\section{Other Comments}

Do you have any other comments about community gardens in general?

\section{Research Findings}

Thank you for your time participating in this research. As a token of my appreciation, please accept this small gift of heirloom vegetable seeds. A summary of the research findings will be given to organisers at your Community Garden. If you would like to be sent a copy personally, please provide your contact details.

\section{Third place checklist}

\begin{tabular}{|l|}
\hline Neutral ground \\
\hline Acveller \\
\hline Conversibility and accommodation \\
\hline Regulars \\
\hline Low profile \\
\hline Playful mood \\
\hline Home away from home \\
\hline
\end{tabular}


Appendix $6 \quad$ Ethics clearance 


\section{GRIFFITH UNIVERSITY HUMAN RESEARCH ETHICS COMMITTEE}

\section{5-Jul-2014}

Dear Ms Pascoe

I write further to the additional information provided in relation to the provisional approval granted to your application for ethical clearance for your project "NR: Motivations for Joining a Community Garden" (GU Ref No: ENV/26/14/HREC).

The additional information was considered by Office for Research.

This is to confirm that this response has largely addressed the comments and concerns of the HREC. This decision is subject to:

Only one condition remains:

Please provide written confirmation that participating organisations (e.g. community garden NGO, local government agencies, etc.), as they become available.

However, you are authorised to immediately commence this research on the strict understanding that these matters are addressed and that you provide details of how they were addressed.

Please note that failure to provide a timely response to these matters may result in this authorisation being suspended or withdrawn. The standard conditions of approval attached to our previous correspondence about this protocol continue to apply.

It would be appreciated if you could give your urgent attention to the issues raised by the Committee so that we can finalise the ethical clearance for your protocol promptly.

Regards

Rick Williams 
Manager, Research Ethics

Office for Research

Bray Centre, N54 Room 0.15 Nathan Campus

Griffith University

ph: 0737354375

fax: 0737357994

email: rick.williams@griffith.edu.au

Researchers are reminded that the Griffith University Code for the Responsible Conduct of Research provides guidance to researchers in areas such as conflict of interest, authorship, storage of data, \& the training of research students.

You can find further information, resources and a link to the University's Code by visiting http://policies.griffith.edu.au/pdf/Code\%20for\%20the\%20Responsible\%20Conduct\%20of\%20Resear ch.pdf

PRIVILEGED, PRIVATE AND CONFIDENTIAL

This email and any files transmitted with it are intended solely for the use of the addressee(s) and may contain information which is confidential or privileged. If you receive this email and you are not the addressee(s) [or responsible for delivery of the email to the addressee(s)], please disregard the contents of the email, delete the email and notify the author immediately 


\section{Reference List}

Aabø, S., \& Audunson, R. (2012). Use of library space and the library as place. Library \& Information Science Research, 34(2), 138-149. doi: 10.1016/j.lisr.2011.06.002

Abrahamson, M. (1983). Social research methods. Englewood Cliffs., N.J.: Prentice-Hall.

Alaimo, K., Reischl, T., \& Allen, J. (2010). Community gardening, neighborhood meetings, and social capital. Journal Of Community Psychology, 38(4), 497-514. doi:

10.1002/jcop. 20378

Aldrich, D. (2012). Building resilience. Chicago: University of Chicago Press.

Alidoust, S., Holden, G., \& Bosman, C. (2014). Urban Environment and Social Health of the Elderly: A Critical Discussion on Physical, Social and Policy Environments. ATHENS JOURNAL OF HEALTH, 1(3), 169-180. doi: 10.30958/ajh.1-3-1

Alidoust, S., \& Bosman, C. (2015). Planning for an ageing population: links between social health, neighbourhood environment and the elderly. Australian Planner, 52(3), 177-186. doi: $10.1080 / 07293682.2015 .1034145$

Alvesson, M., \& Sandberg, J. (2013). Constructing Research Questions. Doing Interesting Research. London: Sage.

Arfvidsson, H., Simon, D., Oloko, M., \& Moodley, N. (2016). Engaging with and measuring informality in the proposed Urban Sustainable Development Goal. African Geographical Review, 36(1), 100-114. doi: 10.1080/19376812.2015.1130636

Atkinson, D. (2007). Kitsch Geographies and the Everyday Spaces of Social

Memory. Environment And Planning A: Economy And Space, 39(3), 521-540. doi: $10.1068 / \mathrm{a} 3866$

Auge, M. (1995). Non-Places. An Introduction to Supermodernity. London: Verso.

Australian Bureau of Statistics (2017). 2071.0 - Census of Population and Housing: Reflecting Australia - Stories from the Census, 2016. (2019). Retrieved from http://www.abs.gov.au/ausstats/abs@.nsf/Lookup/by\%20Subject/2071.0 2016 Main\%2 0Features $\sim$ Snapshot\%20of\%20Australia,\%202016 2 accessed 5/3/19

Australian Bureau of Statistics (2018). 2071.0 - Census of Population and Housing: Reflecting Australia - Stories from the Census", 2016 Retrieved from http://www.abs.gov.au/ausstats/abs@.nsf/mf/2071.0

Australian Bureau of Statistics (2019). 3412.0 - Migration, Australia, 2017-18. (2019).

Retrieved from

http://www.abs.gov.au/ausstats/abs@.nsf/Latestproducts/3412.0Main\%20Features2201718? opendocument\&tabname $=$ Summary $\&$ prodno $=3412.0 \&$ issue $=2017$ -

$18 \&$ num $=\&$ view $=$

Australian Bureau of Statistics (2017). 3412.0 - Migration, Australia, 2015-16. Retrieved from http://www.abs.gov.au/ausstats/abs@.nsf/mf/3412.0

Australian Bureau of Statistics (2015). Housing Mobility. Retrieved from http://www.abs.gov.au/ausstats/abs@.nsf/Lookup/by\%20Subject/4130.0 2013-

14 Main\%20Features Housing\%20Mobility 10003 (accessed 12 September 2017).

Australian Bureau of Statistics. (2004). Information Paper - Measuring Social Capital. An Australian Framework and Indicators. Commonwealth of Australia: Commonwealth of Australia.

Australian Community Gardens Network (2014). Retrieved from http://communitygarden.org.au/acfcgn/

Bende, C., \& Nagy, G. (2016). Effects of community gardens on local society. Belvedere Meridionale, 28(3), 89-105. doi: 10.14232/belv.2016.3.7 
Berkes, F., \& Ross, H. (2013). Community Resilience: Toward an Integrated Approach. Society \& Natural Resources, 26(1), 5-20. doi: 10.1080/08941920.2012.736605

Birky, J. and Strom, E. (2013). Urban Perennials: How Diversification has Created a Sustainable Community Garden Movement in The United States. Urban Geography, 34(8), pp.1193-1216.

Black, A., \& P. Hughes. (2001). The identification and analysis of indicators of community strength and outcomes. Department of Family and Community Services, Government of Australia, Canberra.

Bloor, M., \& Wood, F. (2006). Keywords in Qualitative Methods, Sage Research Methods Retrieved from http://srmo.sagepub.com/view/keywords-in-qualitative-methods/n32.xml

Bonow, M., \& Normark, M. (2018). Community gardening in Stockholm: participation, driving forces and the role of the municipality. Renewable Agriculture And Food Systems, 33(6), 503-517. doi: 10.1017/s1742170517000734

Brisbane City Council. (2019). Brisbane community garden guide BCC, Retrieved from https://www.brisbane.qld.gov.au/sites/default/files/community_garden_guide_aug_2013. pdf

Brisbane Population. (10190. Retrieved from http://www.population.net.au/brisbanepopulation/

Bryman, A. (2012) Social Research Methods $4^{\text {th }}$ Ed. Oxford University press, Oxford

Calderon, R., Blackstock, M., Lea, R., \& Fels, S. (2014). Supporting Conversation and Community Interaction With a Table-Top Community Garden Application. Paper presented at the Pervasive Displays, Copenhagen, Denmark.

Cameron, J., \& Wright, S. (2014). Researching diverse food initiatives: from backyard and community gardens to international markets. Local Environment, 19(1), 1-9. doi: $10.1080 / 13549839.2013 .835096$

Carmona, M. (2013). The Place-shaping Continuum: A Theory of Urban Design Process. Journal Of Urban Design, 19(1), 2-36. doi: 10.1080/13574809.2013.854695

Carmona, M., Tiesdell, S., Heath, T., \& Oc, T. (2010). Public Places Urban Spaces : The Dimensions of Urban Design (2nd Ed.). Saint Louis, MO, USA: Routledge.

Celata, F. and Coletti, R. (2018). The policing of community gardening in Rome. Environmental Innovation and Societal Transitions, 29, pp.17-24.

Chakravarti, A., \& Tiwari, R. (1990). A Basic Research Paradigm in Geography. Journal Of Geography, 89(2), 53-57. doi: 10.1080/00221349008979595

Chan, J., DuBois, B. and Tidball, K. (2015). Refuges of local resilience: Community gardens in post-Sandy New York City. Urban Forestry \& Urban Greening, 14(3), pp.625-635.

Chitov, D. (2006). Cultivating Social Capital on Urban Plots: Community Gardens in New York City. Humanity \& Society, 30(4), pp.437-462.

Cilliers, E.J. (2019). Planning for third places through evidence-based urban development. In J. Dolley \& C. Bosman (Ed.), Rethinking Third Places: Informal public spaces and community building. (pp. 73-94 ). UK: Edward Elgar Publishers.

Coleman, J. S. (1988). Social Capital in the Creation of Human Capital American Journal of Sociology, Vol. 94, Supplement: Organizations and Institutions: Sociological and Economic Approaches to the Analysis of Social Structure (), pp. S95-S120

Communities in Bloom. (2019). Retrieved from https://www.nparks.gov.sg/gardening/community-in-bloom-initiative

Cox, R., Holloway, L., Venn, L., Dowler, L., Hein, J., Kneafsey, M., \& Tuomainen, H. (2008). Common ground? Motivations for participation in a community-supported agriculture scheme. Local Environment, 13(3), 203-218. doi: 10.1080/13549830701669153

Crabtree, L. (1999). Sustainability as seen from a vegetable garden. Retrieved from http://thirdangel.com/sustainability/honours/Crabtree\%20honours\%20thesis.pdf 
Cresswell, T. (2004). Place. A Short Introduction. UK: Wiley-Blackwell.

Crick, A. (2011). Rethinking Oldenburg: Third Places and Generation Y in a Developing Country Context. Paper presented at the International CHRIE Conference, University of the West Indies.

Crossan, J., Cumbers, A., McMaster, R., \& Shaw, D. (2016). Contesting Neoliberal Urbanism in Glasgow's Community Gardens: The Practice of DIY Citizenship. Antipode, 48(4), 937-955. doi: 10.1111/anti.12220

Crowley, K., \& Nakamura, A. (2017). Defining Regional Climate Leadership: Learning from Comparative Analysis in the Asia Pacific. Journal Of Comparative Policy Analysis: Research And Practice, 20(4), 387-403. doi: 10.1080/13876988.2017.1390844

Cumbers, A., Shaw, D., Crossan, J., \& McMaster, R. (2017). The Work of Community Gardens: Reclaiming Place for Community in the City. Work, Employment And Society, 32(1), 133-149. doi: 10.1177/0950017017695042

Davidson, J., Jacobson, C., Lyth, A., Dedekorkut-Howes, A., Baldwin, C., \& Ellison, J. et al. (2016). Interrogating resilience: toward a typology to improve its operationalization. Ecology and Society, 21(2). doi: 10.5751/es-08450-210227

Day, G. (2006). Community and Everyday Life. U.K.: Routledge

De Magalhães, C., \& Freire Trigo, S. (2017). Contracting out publicness: The private management of the urban public realm and its implications. Progress In Planning, 115, 128. doi: 10.1016/j.progress.2016.01.001

Delanty, G. (2010). Community. London: Routledge.

Denscombe, M. (2010). The Good Research Guide for small scale social research projects (4th Ed.). England: Open University Press.

Dietz, R. (2002). The estimation of neighborhood effects in the social sciences: An interdisciplinary approach. Social Science Research, 31(4), 539-575. doi: 10.1016/s0049$089 x(02) 00005-4$

Dodson, Jago (2014) Interrogating the Public City, 27-41 in The Public City, Gleeson, B \& Beza B. Melbourne University Press, Melbourne.

Dolley, J. (2019). Third places and social capital: Case study community gardens. In J. Dolley \& C. Bosman (Eds.), Rethinking Third Places: Informal public spaces and community building. (pp. 136-157). UK: Edward Elgar Publishers.

Draper, C., \& Freedman, D. (2010). Review and Analysis of the Benefits, Purposes, and Motivations Associated with Community Gardening in the United States. Journal Of Community Practice, 18(4), 458-492. doi: 10.1080/10705422.2010.519682

Drucker, S., \& Gumpert, G. (1997). Voices in the street. Cresskill, N.J: Hampton Press.

Eagleton T. (2008). The Meaning of Life. A very short introduction. Oxford: Oxford University Press.

Easley, D., \& Kleinberg, J. (2010). Strong and Weak Ties. In D. Easley \& J. Kleinberg (Eds.), Networks, Crowds, and Markets: Reasoning about a Highly Connected World (pp. 4784): Cambridge University Press.

Easthorpe, H., \& McNamara, N. (2013). Measuring Social Interaction and Social Cohesion in a high Density urban Renewal Area: The Case of Green Square. Paper presented at the State of Australian Cities Sydney, Australia. http://www.soacconference.com.au/wpcontent/uploads/2013/12/Easthope-Social.pdf

Edwards, R.W. (2004). Information Paper Measuring Social Capital An Australian Framework and Indicators. Canberra: Australian Bureau of Statistics.

Egerer, M., \& Fairbairn, M. (2018). Gated gardens: Effects of urbanization on community formation and commons management in community gardens. Geoforum, 96, 61-69. doi: 10.1016/j.geoforum.2018.07.014 
ETRA. (1998). Environment, Transport and Regional Affairs - Fifth Report. Retrieved from House of Commons (U.K.): http://www.parliament.the-stationeryoffice.co.uk/pa/cm199798/cmselect/cmenvtra/560/56002.htm

Fawcett, A. (2013). Food and other gardens in and about remote communities. A guideplanning considerations and project opportunities. Balmain, NSW: Remote Indigenous Gardens Network.

Ferris, J., Norman, C., \& Sempik, J. (2001). People, Land and Sustainability: Community Gardens and the Social Dimension of Sustainable Development. Social Policy \&Amp; Administration, 35(5), 559-568. doi: 10.1111/1467-9515.t01-1-00253

Firth, C., Maye, D., \& Pearson, D. (2011). Developing "community" in community gardens. Local Environment, 16(6), 555-568. doi: 10.1080/13549839.2011.586025

Fiss, P. (2009). Case Studies and the Configurationally Analysis of Organizational Phenomena. In Byrne, D. \& Ragin, C. (Eds.), The Sage Handbook of Case-based Methods (pp. 424439). London, UK: Sage Publications.

Flanagan, W. (1993). Contemporary Urban Sociology. Cambridge: Cambridge University Press.

Foley, M. (2010). The age of absurdity. Why modern life makes it hard to be happy. New York: Simon \& Schuster.

Forrest, R., \& Kearns, A. (2001). Social Cohesion, Social Capital and the Neighbourhood. Urban Studies, 38(12), 2125-2143. doi: 10.1080/00420980120087081

Friedmann, J. (2010). Place and Place-Making in Cities: A Global Perspective. Planning Theory \& Practice, 11(2), 149-165. doi: 10.1080/14649351003759573

Frumkin, H. (2003). Healthy Places: Exploring the Evidence. American Journal Of Public Health, 93(9), 1451-1456. doi: 10.2105/ajph.93.9.1451

Fullagar, S, O'Brien,W. and Lloyd, K. (2019). Feminist perspectives on third places; Planning for third places through evidence-based urban development. In J. Dolley \& C. Bosman (Eds.), Rethinking Third Places: Informal public spaces and community building. (pp. 20-37). UK: Edward Elgar Publishers.

Gans, H. (2017). Urban Sociology in Trump's America and Beyond. City \& Community, 16(2), 127-130. doi: 10.1111/cico.12231

Gaynor, A. (2006). Harvest of the Suburbs: An Environmental History of Growing Food in Australian Cities. Perth: UWA (Unversity of Western Australia).

Gehl, J. (2010). Cities for people. London: Island Press.

Gleeson, B., \& Sipe, N. (2006). Creating Child Friendly Cities: Reinstating kids in the City. London: Routledge.

Glover, T. (2004). Social Capital in the Lived Experiences of Community Gardeners. Leisure Sciences, 26(2), 143-162. doi: 10.1080/01490400490432064

Glover, T. (2003). The Story of the Queen Anne Memorial Garden: Resisting a Dominant Cultural Narrative. Journal Of Leisure Research, 35(2), 190-212. doi: 10.1080/00222216.2003.11949990

Gold Coast City Council. (2019). Gold Coast City Transport Strategy 2031. Retrieved from http://www.goldcoast.qld.gov.au/gold-coast-city-transport-strategy-8579.html

Gómez, E., Baur, J., \& Malega, R. (2017). Dog park users: An examination of perceived social capital and perceived neighborhood social cohesion. Journal Of Urban Affairs, 40(3), 349-369. doi: 10.1080/07352166.2017.1343634

Granovetter, M. (1983). The Strength of Weak Ties: A Network Theory Revisited. Sociological Theory, 1, 201. doi: 10.2307/202051

Grant, B., \& Giddings, L. (2002). Making sense of methodologies: A paradigm framework for the novice researcher. Contemporary Nurse, 13(1), 10-28. doi: 10.5172/conu.13.1.10

Guest, G., Bunce, A., \& Johnson, L. (2006). How Many Interviews Are Enough?. Field Methods, 18(1), 59-82. doi: 10.1177/1525822x05279903 
Guitart, D., Pickering, C., \& Byrne, J. (2012). Past results and future directions in urban community gardens research. Urban Forestry \& Urban Greening, 11(4), 364-373. doi: 10.1016/j.ufug.2012.06.007

Gumpert, G. \& Drucker, S.J. (1997). Voices in the street: explorations in gender, media, and public space. Cresskill, N.J.: Hampton Press.

Halfpenny, P. (1982). Positivism and Sociology: Explaining Social Life, in Controversies in Sociology. (13th Ed.) Sydney: Allen \& Unwin.

Hall, P. (2002). Cites of Tomorrow. An Intellectual History of Urban Planning and Design in the Twentieth Century. Oxford, UK: Blackwell Publishing.

Hall, N., Ross, H., Richards, R., Barrington, D., Dean, A., Head, B., Jagals, P., Reid, S. and Hill, P. (2018). Implementing the United Nations' sustainable development goals for water and beyond in Australia: A proposed systems approach. Australasian Journal of Water Resources, 22(1), pp.29-38.

Hartley, J. (2005). Case Study Research. In C. S. Cassell, G. (Ed.), Essential Guide to Qualitative Methods in Organizational Research (pp. 323-333). London UK: Sage Publications.

Hemingway, J. (1999). Leisure, Social Capital, and Democratic Citizenship. Journal of Leisure Research, 31(2), pp.150-165.

Hensley, N. (2015). Cultivating Biophilia: Utilizing Direct Experience to Promote Environmental Sustainability. Journal of Sustainability Education, March, 2015.

Hjort, M., Martin, W., Stewart, T. and Troelsen, J. (2018). Design of Urban Public Spaces: Intent vs. Reality. International Journal of Environmental Research and Public Health, 15(4), p.816.

Hogan, L., \& Thorpe, S. (2009). Issues in food miles and carbon labelling. Retrieved from Canberra: http://data.daff.gov.au/data/warehouse/pe_abarebrs99001677/foodmiles.pdf

Holden,G. (2019). Eyes on the street: the role of 'third places' in improving perceived neighbourhood safety. In J. Dolley \& C. Bosman (Ed.), Rethinking Third Places: Informal public spaces and community building. (pp. 95-115). UK: Edward Elgar Publishers.

Holland, L. (2004). Diversity and connections in community gardens: a contribution to local sustainability. Local Environment, 9(3), pp.285-305.

Hollis, L. (2013). Cities are good for you: The Genius of the Metropolis. UK: Bloomsbury Publishing.

Holloway, A. (2017). Localising Global Goals in Australia's Global City: Sydney. Transactions on Ecology and the Environment (Vol 226). UK: WIT Press.

Hondagneu-Sotelo, P. (2010). Cultivating Questions for a Sociology of Gardens. Journal of Contemporary Ethnography 2010 originally published online, 39(5), 16.

Hou, J. (2018). Governing urban gardens for resilient cities: Examining the 'Garden City Initiative' in Taipei. Urban Studies, 004209801877867. doi: 10.1177/0042098018778671

Houghton, K., Foth, M. and Miller, E. (2013). The continuing relevance of the library as a third place for users and non-users of IT: the case of Canada Bay. The Australian Library Journal, 62(1), pp.27-39.

Houser, N., Roach, L., Stone, M., Turner, J. \& Kirk, S. (2016). Let the Children Play: Scoping Review on the Implementation and Use of Loose Parts for Promoting Physical Activity Participation. AIMS Public Health, 3(4), pp.781-799.

Houston, D., McCallum, D., Steele, W. and Byrne, J. (2016). Climate Cosmopolitics and the Possibilities for Urban Planning. Nature and Culture, 11(3).

Huron, A. (2017). Theorising the urban commons: New thoughts, tensions and paths forward. Urban Studies, 54(4), 1062-1069. doi: 10.1177/0042098016685528

Jacobs, M. (1996). The Politics of the Real World. Meeting the New Century. London: Earthscan Publications. 
Jacobs, J. (1961). The Life and Death of Great American Cities. New York: Random House.

Jaeger, W. (2005). Environmental Economics for Tree Huggers and Other Skeptics. New York: Island Press.

James, P. \& Magee, L. (2016). Domains of sustainability. In Global Encyclopedia of Public Administration, Public Policy, and Governance. New York: Springer.

Jenkins, R. (2002). Pierre Bourdieu revised edition. London: Routledge.

Jive'n, G., \& Larkham, P. J. (2003). Sense of Place, Authenticity and Character: A Commentary. Journal of Urban Design, 8(1), 14. doi:10.1080/1357480032000064773

Jones, H., Neal, S., Mohan, G., Connell, K., Cochrane, A., \& Bennett, K. (2015). Urban Multiculture and Everyday Encounters in Semi-Public, Franchised Cafe Spaces. The Sociological Review, 63(3), 644-661. doi: 10.1111/1467-954x.12311

Kavanaugh, A., Reese, D., Carroll, J., \& Rosson, B. P. i., Kluwer, B.V. Deventer, The Netherlands, The Netherlands, ISBN:1-4020-1611-5. (2005). Weak Ties in Networked Communities. The Information Society: An International Journal, 21(2), 12. doi:10.1080/01972240590925320

Kim, E., Kawachi, I., Chen, Y., \& Kubzansky, L. (2017). Association Between Purpose in Life and Objective Measures of Physical Function in Older Adults. JAMA Psychiatry, 74(10), 1039. doi: 10.1001/jamapsychiatry.2017.2145

Kingsley, J. Y., \& Townsend, M. (2006). 'Dig In' to Social Capital: Community Gardens as Mechanisms for Growing Social Connectedness. 24, 4, 12. doi:10.1080/08111140601035200

Kirkpatrick, J., Lefroy, T., \& Harwood, A. (2018). Turning place into space - Place motivations and place spaces in Tasmania. Landscape And Urban Planning, 178, 112121. doi: 10.1016/j.landurbplan.2018.05.027

Klinenberg, E. (2001). Dying Alone. Ethnography, 2(4), 501-531. doi: $10.1177 / 14661380122231019$

Klinenberg, E. (2018). Palaces for the People. New York: Crown Publishing Group.

Knox, P. L. (2005). Creating Ordinary Places: Slow Cities in a Fast World. Journal of Urban Design, 10(1), 1-11. doi: 10.1080/13574800500062221

Könst, A., R., van Melik, R. \& Verheul, W.J. (2018) Civic-led public space: Favorable conditions for the management of community gardens. Town Planning Review, 89 (6), 575-595.

Kuhn, T.S. (1970). The Structure of Scientific Revolutions. In International Encyclopaedia of Unified Science (Vol. 2.Number 2). Chicago: The University of Chicago Press.

Lambert, N., Stillman,M., Tyler, F., Hicks, J. \& More, A. (2013). To belong is to Matter: Sense of Belonging Enhances Meaning in Life. Personality and Social Psychology Bulletin, 39(11), 1418-1427.

Lefebvre, H. (2014). Dissolving City, Planetary Metamorphosis. Environment and Planning D: Society and Space, 32(2), 203-205. https://doi.org/10.1068/d3202tra

Lennon, M., \& Moore, D. (2018). Planning, 'politics' and the production of space: the formulation and application of a framework for examining the micropolitics of community place-making. Journal Of Environmental Policy \& Planning, 21(2), 117-133. doi: 10.1080/1523908x.2018.1508336

Lewis, L., Galloway-Gilliam, L., Flynn, G., Nomachi, J., Keener, L., \& Sloane, D. (2011). Transforming the Urban Food Desert From the Grassroots Up. Family \& Community Health, 34, S92-S101. doi: 10.1097/fch.0b013e318202a87f

Lockie, S. (2016). Beyond resilience and systems theory: reclaiming justice in sustainability discourse. Environmental Sociology, 2(2), 115-117. doi:

10.1080/23251042.2016.1182308 
Lyons, K., Richards, C., DesFours, L., \& Amati, M. (2013). Food in the City: Urban Food Movements and the (Re)-Imagining of Urban Spaces. Australian Planner, 50(2), 157163.

Maller, C., \& Farahani, L. (2018). Snakes in the city: understanding urban residents' responses to greening interventions for biodiversity. Paper presented at: State of Australian Cities National Conference, 28-30 November 2017, Adelaide, South Australia.

Mansvelt, J. (2008). Urban spaces - ageing places? Insights from interviews and focus groups into the spatiality of later life. In Maginn, P.J., Susan M. Thompson,S.M. \& Tonts, M. (Eds.) Qualitative Urban Analysis: An International Perspective (Vol. 9) (pp. 197211). Melbourne: Emerald Group Publishing Ltd.

Maslow, A. H. (1943). A theory of human motivation. Psychological Review, 50(4), pp. 370396.

McClintock, N. (2013). Radical, reformist, and garden-variety neoliberal: coming to terms with urban agriculture's contradictions. Local Environment, 19(2), pp.147-171.

McGlone, N. (2016 ). Pop-Up kids: exploring children's experience of temporary public space. Australian Planner, 53(2).

Mele, C., Ng, M. and Chim, M. (2014). Urban markets as a 'corrective' to advanced urbanism: The social space of wet markets in contemporary Singapore. Urban Studies, 52(1), pp.103-120.

Miller, W. (2015). UK allotments and urban food initiatives: (limited?) potential for reducing inequalities. Local Environment, 20(10), pp.1194-1214.

Mintz, G., \& Mcmanus, P. (2014). Seeds for Change? Attaining the benefits of community gardens through council policies in Sydney, Australia. Australian Geographer,45(4), 541558. doi:10.1080/00049182.2014.953721

Montgomery, J. (1998). Making a city: Urbanity, vitality and urban design. Journal of Urban Design,3(1), 93-116. doi:10.1080/13574809808724418

Morgan, K. (2009). Feeding the City: The Challenge of Urban Food Planning. International Planning Studies, 14(4), 341-348. doi:10.1080/13563471003642852

Noaks, L., \& Wincup, E. (2004). Interviews. In Introducing Qualitative Methods: Criminological research (pp. 74-89). London: SAGE Publications Ltd

Norris, F. H., Stevens, S., Pfefferbaum,B., Wyche,K. \& Pfefferbaum, R. L. (2008). Community resilience as a metaphor, theory, set of capacities, and strategy for disaster readiness. American Journal of Community Psychology 41(1-2),127-150.

NSW Planning and Environment. (2018). A Plan for Growing Sydney. Retrieved from https://www.planning.nsw.gov.au/Plans-for-your-area/A-Metropolis-of-Three-Cities/AMetropolis-of-Three-Cities/Highlights

Nursey-Bray, M., Parnell, E., Ankeny, R. A., Bray, H., \& Rudd, D. (2014). Community gardens as pathways to community resilience? Reflections on a pilot study in Adelaide, South Australia. South Australian Geographical Journal,113, pp. 13-28. doi:10.21307/sagj-2016-004

O'Hare, D. (2019). Third places in transit: public transport as a third place of mobility. In J. Dolley \& C. Bosman (Ed.), Rethinking Third Places: Informal public spaces and community building. (pp. 174-195). UK: Edward Elgar Publishers.

Ohmer, M., Meadowcroft, P., Freed, K., \& Lewis, E. (2009). Community gardening and Community Development: Individual, Social and Community Benefits of a Community conservation Program. Journal of Community Practice, 17, 22.

Oldenburg, R. \& Brissett D. (1982). The Third Place. Qualitative Sociology 5(4), pp. 265-284).

Oldenburg, R. (1991). The Great Good Place. New York: Paragon House.

Oldenburg, R. (1997). Our Vanishing Third Places. Planning Commissioners Journal, 25, 8 10 . 
Oldenburg, R. (1989). The Great Good Place. Cafes, Coffee Shops, Community Centers, General Stores, Bars, Hangouts, and How They Get You through the Day. New York: Paragon House.

Oldenburg, R. (1999). The great good place: Cafes, coffee shops, bookstores, bars, hair salons, and other hangouts at the heart of a community. New York: Marlow \& Company.

Pacho, T.O. (2015). Exploring Participants' Experiences Using Case Study. International Journal of Humanities and Social Science, 5(4), pp.44-53.

Parizeau, K. (2016). Witnessing urban change: Insights from informal recyclers in Vancouver, BC. Urban Studies,54(8), 1921-1937. doi:10.1177/0042098016639010

Pascoe, J. \& Wyatt-Smith, C. (2013). Curriculum literacies and the school garden. Literacy Learning: The Middle Years, 21(1), pp. 34-47.

Pascoe, J. \& Howes, M. (2017). A growing movement: motivations for joining community gardens. In: Brebbia, C. and Longhurst, J. (eds) Sustainable Development and Planning IX, WIT Transactions on Ecology and the Environment, Vol. 226: UK: WitPress, pp.381-389. Retrieved from https://www.witpress.com/Secure/elibrary/papers/SDP17/SDP17033FU1.pdf

Patel, R. (2006). Working the Night Shift: Gender and the Global Economy. ACME: An International E-Journal for Critical Geographies, 5(1), pp. 9-27.

Patton, M. (2002). Qualitative research and evaluation methods. 3rd ed. Thousand Oaks, CA: Sage.

Pini, B., Mayes, R., \& Mcdonald, P. (2010). The emotional geography of a mine closure: A study of the Ravensthorpe nickel mine in Western Australia. Social \& Cultural Geography,11(6), 559-574. doi:10.1080/14649365.2010.497850

Placemaking Chicago (2008). Placemaking Chicago. Retrieved from http://www.placemakingchicago.com/about/ placemaking Chicago

Population Australia (2019). Brisbane population 2019. Retrieved from http://www.population.net.au/brisbane-population/

Project for Public Spaces (2007). What Is Placemaking? Retrieved from https://www.pps.org/article/what-is-placemaking

Putnam, D. (2000). Bowling Alone. New York: Simon \& Schuster.

Ragusa, A.T. (2010). Seeking trees or escaping traffic? Socio-cultural factors and 'tree change' migration in Australia. In Luck, G., Black, R. \& Race, D. (Eds.). Demographic change in rural landscapes: what does it mean for society and the environment? (pp.71-100). Netherlands: Springer.

Rickards, L., Mulligan, M. \& Steele, W. (2018). The Resonance and Possibilities of Community Resilience. In J. Bohland, S. Davoudi \& J.L. Lawrence (Eds.) The Resilience Machine. (Ch.6). Routledge: New York.

Rogers, D., McAuliffe, C., Piracha, A. \& Schatz, L. (2017). Resident Involvement in Urban Development in Sydney: The New Politics of the City. Report 14HT11 Blue Sky Report; University of Sydney. Retrieved from http://usyd.nikashsingh.com/hht/2017_ROGERS_ResidentInvolvement_lowres.pdf

Rogge, N. \& Theesfeld, I. (2018). Categorizing urban commons: Community gardens in the Rhine-Ruhr agglomeration, Germany. International Journal of the Commons, 12(2), 251274.

Saldivar-Tanaka, L., \& Krasny, M. E. (2004). Culturing community development, neighborhood open space, and civic agriculture: The case of Latino community gardens in New York City. Agriculture and Human Values,21(4), 399-412. doi:10.1023/b:ahum.0000047207.57128.a5

Saunders, M., Lewis, P., \& Thornhill, A. (2009). Research methods for business students. Essex, UK: Pearson Education Limited. 
Schneekloth, L. H. Shibley, R.G. (1995). Placemaking: The Art and Practice of Building Communities. New York: Wiley.

Sennett, R. (2012). Together: The Rituals, Pleasures and Politics of Cooperation. USA: Yale University Press.

Shanahan, D. F., Lin, B. B., Bush, R., Gaston, K. J., Dean, J. H., Barber, E., \& Fuller, R. A. (2015). Toward Improved Public Health Outcomes From Urban Nature. American Journal of Public Health,105(3), 470-477. doi:10.2105/ajph.2014.302324

Sharman, L. (2010). The future of urban community gardens: issues, barriers and solutions for councils and community. Proceedings of the Promoting sustainability, health and inclusion in the city conference. pp. 41-51. Canberra: University of Canberra.

Shi, S., Gou, Z., \& Chen, L. H. (2014). How does enclosure influence environmental preferences? A cognitive study on urban public open spaces in Hong Kong. Sustainable Cities and Society,13, 148-156. doi:10.1016/j.scs.2014.04.011

Silverman, D. (1993). Validity and Reliability, Interpreting Qualitative Data: Methods for Analysing Talk, Text and Interaction (pp. 144-170). London: SAGE Publications.

Silverman, D. (2006). Interpreting Qualitative Data: Methods for Analyzing Talk, Text and Interaction (3rd Ed.). London: Sage.

Singh-Peterson, L., \& Lawrence, G. (2015). Insights into community vulnerability and resilience following natural disasters: perspectives with food retailers in Northern NSW, Australia. Local Environment, 20(7), 782-795. doi: 10.1080/13549839.2013.873396

Slaughter, R. (2010). The Biggest Wake Up Call in History. Brisbane: Foresight International.

Soja, E.W. (1996). Thirdspace. Journeys to Los Angeles and other real-and-imagined places. Cambridge, USA: Blackwell Publishers.

Son, J., Yarnal, C., \& Kerstetter, D. (2010). Engendering social capital through a leisure club for middle-aged and older women: implications for individual and community health and well-being. Leisure Studies, 29(1), 67-83. doi: 10.1080/02614360903242578

Spierings, B., Van Liempt, I. \& Maliepaard, E. (2018). Ownership and membership: Practices and experiences of neighbourhood residents in the Wijsgeren Community garden in Amsterdam. Journal of Economic and Social Geography. 109(5) Retrieved from https://onlinelibrary.wiley.com/doi/full/10.1111/tesg. 12337

Steinkuehler, C., \& Williams, D. (2006). Where Everybody Knows Your (Screen) Name: Online Games as "Third Places". Journal Of Computer-Mediated Communication, 11(4), 885-909. doi: 10.1111/j.1083-6101.2006.00300.x

Stevenson, F., \& Petrescu, D. (2016). Co-producing neighbourhood resilience. Building Research \& Information, 44(7), 695-702. doi: 10.1080/09613218.2016.1213865

Sweeney, J., Mee, K., McGuirk, P., \& Ruming, K. (2018). Assembling placemaking: making and remaking place in a regenerating city. Cultural Geographies, 25(4), 571-587. doi: $10.1177 / 1474474018778560$

Taleb, N.N. (2007). The Black Swan. The impact of the highly improbable. London, UK: Penguin Books.

Talen, E. (2008). Design for Diversity : Exploring Socially Mixed Neighborhoods. Burlington, MA, USA: Architectural Press.

Tan, L., \& Neo, H. (2009). "Community in Bloom": local participation of community gardens in urban Singapore. Local Environment, 14(6), 529-539. doi: $10.1080 / 13549830902904060$

Thompson, S., \& Maggin, P. (2012). Planning Australia: An Overview of Urban \& Regional Planning. U.K.: Cambridge University Press.

Thornton, A., Lyons, K. \& Sharpe, S. (2018). Carving out space for community gardens in Australia: exploring the potential of community gardens as social movements for urban change in Sydney and Canberra. In L.Shevellar \& P.Westoby. (Eds.), The Routledge 
Handbook of Community Development Research (1st Ed). (pp. 223-235). London: Routledge.

Tocqueville, Alexis de. (1899). Democracy in America, Volume 1 Chapter 3 Chapter III: Social Conditions of the Anglo-Americans Translator: Reeve, H. New York: Colonial Press. Retrieved from https://web.archive.org/web/20081201215034/http://etext.lib.virginia.edu/toc/modeng/pu blic/TocDem1.html

Tuan, Y. (1977). Space and place: The perspective of experience. USA: University of Minnesota Press.

Tuan, Y. (2014). Space, Place, and Nature: The Farewell Lecture. Retrieved from http://www.yifutuan.org/dear_colleague.htm

Turner, B. (2011). Embodied connections: Sustainability, food systems and community gardens. Local Environment,16(6), 509-522. doi:10.1080/13549839.2011.569537

Twiss, J., Dickinson, J., Duma, S., Kleinman, T., Paulsen, H., \& Rilveria, L. (2003). Community Gardens: Lessons Learned From California Healthy Cities and Communities. American Journal of Public Health,93(9), 1435-1438. doi:10.2105/ajph.93.9.1435

United Nations. (2015). Goal 11: Make cities inclusive, safe, resilient and sustainable. Retrieved from https://www.un.org/sustainabledevelopment/cities/ Cities - United Nations Sustainable Development Action 2015. (n.d.). Retrieved from https://www.un.org/sustainabledevelopment/cities/

UNSC. (2015). Technical report by the Bureau of the United Nations Statistical Commission (UNSC) on the process of the development of an indicator framework for the goals and targets of the post-2015 development agenda. Retrieved from https://sustainabledevelopment.un.org/content/ documents/6754Technical\%20report\%20of\%20the\%20UNSC $\% 20$ Bureau $\% 20$ (final).pdf

Van Holstein, E. (2019). Strategies of self-organising communities in a gentrifying city. Urban Studies, 004209801983246. doi:10.1177/0042098019832468

Veen, E. J., Derkzen, P., \& Visser, A. J. (2014). Shopping Versus Growing: Food Acquisition Habits of Dutch Urban Gardeners. Food and Foodways,22(4), 268-299. doi:10.1080/07409710.2014.964604

Veitch, J., Wang, W., Salmon, J., Carver, A., Giles-Corti, B., \& Timperio, A. (2017). Who Goes to Metropolitan Parks? A Latent Class Analysis Approach to Understanding Park Visitation. Leisure Sciences, 40(5), 343-355. doi: 10.1080/01490400.2017.1325798

Vic Health. (2011), Perceptions of Safety; Community Indicators Victoria. Victoria Health.

Vincent, C., Neal, S., \& Iqbal, H. (2016). Encounters with diversity: Children's friendships and parental responses. Urban Studies, 54(8), 1974-1989. doi: 10.1177/0042098016634610

Wachsmuth, D., \& Brenner, N. (2014). Introduction to Henri Lefebvre's "Dissolving City, Planetary Metamorphosis”. Environment And Planning D: Society And Space, 32(2), 199-202. doi: 10.1068/d3202int

Walker, S. (2015). Urban agriculture and the sustainability fix in Vancouver and Detroit. Urban Geography,37(2), 163-182. doi:10.1080/02723638.2015.1056606

Walter, P. (2013). Theorising community gardens as pedagogical sites in the food movement. Environmental Education Research, 19(4), 521-539. doi: $10.1080 / 13504622.2012 .709824$

Williams, D. \& Kim, D.O. (2019). Third places in the ether around us: layers on the real world. In J. Dolley \& C. Bosman (Ed.), Rethinking Third Places: Informal public spaces and community building. (pp. 158-173). UK: Edward Elgar Publishers.

Wilson, R., Gosling, S., \& Graham, L. (2012). A Review of Facebook Research in the Social Sciences. Perspectives On Psychological Science, 7(3), 203-220. doi: $10.1177 / 1745691612442904$ 
Woods, M., Paulus, T., Atkins, D., \& Macklin, R. (2016). Advancing Qualitative Research Using Qualitative Data Analysis Software (QDAS)? Reviewing Potential Versus Practice in Published Studies using ATLAS.ti and NVivo, 1994-2013. Social Science Computer Review, 34(5), 597-617. doi: 10.1177/0894439315596311

Wright-Mills, C. (1959). The Sociological Imagination. New York: Oxford University Press. Yin, R. (2009). Case Study Research.Design and Methods. London, UK: Sage Publications. Yin, R. (1993). Applications of case study research. Applied social research methods series (Vol. 34). London: Sage publications.

Yokohari, M., \& Amati, M. (2005). Nature in the city, city in the nature: case studies of the restoration of urban nature in Tokyo, Japan and Toronto, Canada. Landscape And Ecological Engineering, 1(1), 53-59. doi: 10.1007/s11355-005-0012-2

Zapata-Diomedi, B., Boulangé, C., Giles-Corti, B., Phelan, K., Washington, S., Veerman, J., \& Gunn, L. (2019). Physical activity-related health and economic benefits of building walkable neighbourhoods: a modelled comparison between brownfield and greenfield developments. International Journal Of Behavioral Nutrition And Physical Activity, 16(1). doi: 10.1186/s12966-019-0775-8

Zoellner, J., Zanko, A., Price, B., Bonner, J., \& Hill, J. (2012). Exploring Community Gardens in a Health Disparate Population: Findings from a Mixed Methods Pilot Study. Progress In Community Health Partnerships: Research, Education, And Action, 6(2), 117-118. doi: $10.1353 / \mathrm{cpr} .2012 .0018$

Zukin, S. (2010). Naked City. The Death and Life of Authentic Urban Places. New York: Oxford University Press. 